Cochrane Database of Systematic Reviews

\title{
Risperidone versus placebo for schizophrenia (Review)
}

Rattehalli RD, Zhao S, Li BG, Jayaram MB, Xia J, Sampson S

Rattehalli RD, Zhao S, Li BG, Jayaram MB, Xia J, Sampson S.

Risperidone versus placebo for schizophrenia.

Cochrane Database of Systematic Reviews 2016, Issue 12. Art. No.: CD006918.

DOI: 10.1002/14651858.CD006918.pub3.

www.cochranelibrary.com 
TABLE OF CONTENTS

HEADER

ABSTRACT

PLAIN LANGUAGE SUMMARY

SUMMARY OF FINDINGS

2

BACKGROUND

Figure 1.

OBJECTIVES

METHODS

RESULTS

Figure 2.

Figure 3.

Figure 4.

DISCUSSION

AUTHORS' CONCLUSIONS

ACKNOWLEDGEMENTS

REFERENCES

CHARACTERISTICS OF STUDIES

DATA AND ANALYSES

Analysis 1.1. Comparison 1 RISPERIDONE vs PLACEBO, Outcome 1 Mental state: no clinically significant response in psychotic symptoms (defined by various scale total score change) - short term (up to 12 weeks).

Analysis 1.2. Comparison 1 RISPERIDONE vs PLACEBO, Outcome 2 Leaving the study early - short term (up to 12 weeks). ....... Analysis 1.3. Comparison 1 RISPERIDONE vs PLACEBO, Outcome $3 \mathrm{Global}$ state: 1 . average endpoint scores of CGI severity scale (high=poor) - short term (up to 12 weeks).

Analysis 1.4. Comparison 1 RISPERIDONE vs PLACEBO, Outcome 4 Global state: 2 . no significant clinical improvement CGI short term (up to 12 weeks).

Analysis 1.5. Comparison 1 RISPERIDONE vs PLACEBO, Outcome 5 Global state: 3. needing additional medication - short term (up to 12 weeks).

Analysis 1.6. Comparison 1 RISPERIDONE vs PLACEBO, Outcome 6 Mental state: 1 . average endpoint scores on various scales on psychotic symptoms (high=poor) - short term (up to 12 weeks).

Analysis 1.7. Comparison 1 RISPERIDONE vs PLACEBO, Outcome 7 Mental state: 2 . skewed data - short term (up to 12 weeks). .

Analysis 1.8. Comparison 1 RISPERIDONE vs PLACEBO, Outcome 8 Adverse effects: 1a. extrapyramidal - various effects - short term (up to 12 weeks).

Analysis 1.9. Comparison 1 RISPERIDONE vs PLACEBO, Outcome 9 Adverse effects: 1b. extrapyramidal - AIMS average endpoint score - short term (up to 12 weeks).

Analysis 1.10. Comparison 1 RISPERIDONE vs PLACEBO, Outcome 10 Adverse effects: 1c. extrapyramidal - skewed data (various scales) - short term (up to 12 weeks).

Analysis 1.11. Comparison 1 RISPERIDONE vs PLACEBO, Outcome 11 Adverse effects: 2 . any adverse event - short term (up to 12 weeks).

Analysis 1.12. Comparison 1 RISPERIDONE vs PLACEBO, Outcome 12 Adverse effects: 3. cardiovascular - short term (up to 12 weeks).

Analysis 1.13. Comparison 1 RISPERIDONE vs PLACEBO, Outcome 13 Adverse effects: 4. central nervous system - short term (up to 12 weeks).

Analysis 1.14. Comparison 1 RISPERIDONE vs PLACEBO, Outcome 14 Adverse effects: 5 . endocrine - serum prolactin increase above reference range ( $23 \mathrm{ng} / \mathrm{ml}$ ) - short term (up to 12 weeks).

Analysis 1.15. Comparison 1 RISPERIDONE vs PLACEBO, Outcome 15 Adverse effects: 6 . gastrointestinal system - short term (up to 12 weeks).

Analysis 1.16. Comparison 1 RISPERIDONE vs PLACEBO, Outcome 16 Adverse effects: 7 a. metabolic - weight gain - short term (up to 12 weeks).

Analysis 1.17. Comparison 1 RISPERIDONE vs PLACEBO, Outcome 17 Adverse effects: 7b. metabolic - skewed data - average change value on lipid profile - short term (up to 12 weeks).

Analysis 1.18. Comparison 1 RISPERIDONE vs PLACEBO, Outcome 18 Adverse effects: 8. musculoskeletal system - short term (up to 12 weeks).

Analysis 1.19. Comparison 1 RISPERIDONE vs PLACEBO, Outcome 19 Adverse effects: 9 . physiology - short term (up to 12 weeks). 
Analysis 1.20. Comparison 1 RISPERIDONE vs PLACEBO, Outcome 20 Adverse effects: 10. respiratory system - short term (up to 12 weeks).

Analysis 2.1. Comparison 2 RISPERIDONE + CLOZAPINE vs PLACEBO + CLOZAPINE, Outcome 1 Mental state: no clinically significant response in psychotic symptoms (defined by PANSS/BPRS $<20 \%$ decline) - short term (up to 12 weeks).

Analysis 2.2. Comparison 2 RISPERIDONE + CLOZAPINE vs PLACEBO + CLOZAPINE, Outcome 2 Leaving the study early - short term (up to 12 weeks).

Analysis 2.3. Comparison 2 RISPERIDONE + CLOZAPINE vs PLACEBO + CLOZAPINE, Outcome 3 Global state: 1. average endpoint scores of CGI severity scale (high=poor) - short term (up to 12 weeks).

Analysis 2.4. Comparison 2 RISPERIDONE + CLOZAPINE vs PLACEBO + CLOZAPINE, Outcome 4 Global state: 2 . no significant clinical improvement CGI - short term (up to 12 weeks).

Analysis 2.5. Comparison 2 RISPERIDONE + CLOZAPINE vs PLACEBO + CLOZAPINE, Outcome 5 Global state: 3. general functioning - average endpoint GAF score (high=good) - short term (up to 12 weeks).

Analysis 2.6. Comparison 2 RISPERIDONE + CLOZAPINE vs PLACEBO + CLOZAPINE, Outcome 6 Mental state: 1. average endpoint scores on various scales on psychotic symptoms (high=poor) - short term (up to 12 weeks).

Analysis 2.7. Comparison 2 RISPERIDONE + CLOZAPINE vs PLACEBO + CLOZAPINE, Outcome 7 Mental state: 2. average endpoint scores on various scales on psychotic symptoms (high=poor) - medium term (up to 26 weeks).

Analysis 2.8. Comparison 2 RISPERIDONE + CLOZAPINE vs PLACEBO + CLOZAPINE, Outcome 8 Mental state: 3 . skewed data short term (up to 12 weeks).

Analysis 2.9. Comparison 2 RISPERIDONE + CLOZAPINE vs PLACEBO + CLOZAPINE, Outcome 9 Adverse effects: 1a. extrapyramidal - average endpoint SAS score - short term (up to 12 weeks).

Analysis 2.10. Comparison 2 RISPERIDONE + CLOZAPINE vs PLACEBO + CLOZAPINE, Outcome 10 Adverse effects: $1 \mathrm{~b}$. extrapyramidal - skewed data (various scales) - short term (up to 12 weeks).

Analysis 2.11. Comparison 2 RISPERIDONE + CLOZAPINE vs PLACEBO + CLOZAPINE, Outcome 11 Adverse effects: $1 c$. extrapyramidal - skewed data (various scales) - medium term (up to 26 weeks).

Analysis 2.12. Comparison 2 RISPERIDONE + CLOZAPINE vs PLACEBO + CLOZAPINE, Outcome 12 Adverse effects: 2 . any adverse event - short term (up to 12 weeks).

Analysis 2.13. Comparison 2 RISPERIDONE + CLOZAPINE vs PLACEBO + CLOZAPINE, Outcome 13 Adverse effects: $3 a$. cardiovascular - short term (up to 12 weeks).

Analysis 2.14. Comparison 2 RISPERIDONE + CLOZAPINE vs PLACEBO + CLOZAPINE, Outcome 14 Adverse effects: $3 b$. cardiovascular - QTc interval - short term (up to 12 weeks).

Analysis 2.15. Comparison 2 RISPERIDONE + CLOZAPINE vs PLACEBO + CLOZAPINE, Outcome 15 Adverse effects: 4. central nervous system - short term (up to 12 weeks).

Analysis 2.16. Comparison 2 RISPERIDONE + CLOZAPINE vs PLACEBO + CLOZAPINE, Outcome 16 Adverse effects: 5. gastrointestinal system - short term (up to 12 weeks).

Analysis 2.17. Comparison 2 RISPERIDONE + CLOZAPINE vs PLACEBO + CLOZAPINE, Outcome 17 Adverse effects: 6a. haematological - short term (up to 12 weeks).

Analysis 2.18. Comparison 2 RISPERIDONE + CLOZAPINE vs PLACEBO + CLOZAPINE, Outcome 18 Adverse effects: 6b. haematological - medium term (up to 26 weeks).

Analysis 2.19. Comparison 2 RISPERIDONE + CLOZAPINE vs PLACEBO + CLOZAPINE, Outcome 19 Adverse effects: 7a. metabolic - weight gain - short term (up to 12 weeks).

Analysis 2.20. Comparison 2 RISPERIDONE + CLOZAPINE vs PLACEBO + CLOZAPINE, Outcome 20 Adverse effects: 7a. metabolic - weight gain - medium term (up to 26 weeks).

Analysis 2.21. Comparison 2 RISPERIDONE + CLOZAPINE vs PLACEBO + CLOZAPINE, Outcome 21 Adverse effects: $7 \mathrm{~b}$. metabolic - average endpoint value on lipid profile - short term (up to 12 weeks).

Analysis 2.22. Comparison 2 RISPERIDONE + CLOZAPINE vs PLACEBO + CLOZAPINE, Outcome 22 Adverse effects: 7c. metabolic - average endpoint value - short term (up to 12 weeks).

Analysis 2.23. Comparison 2 RISPERIDONE + CLOZAPINE vs PLACEBO + CLOZAPINE, Outcome 23 Adverse effects: 8. sleep skewed data - average change score (UKU) - short term (up to 12 weeks).

Analysis 2.24. Comparison 2 RISPERIDONE + CLOZAPINE vS PLACEBO + CLOZAPINE, Outcome 24 Quality of life: average endpoint score (QLS, high=good) - short term (up to 12 weeks).

Analysis 3.1. Comparison 3 SENSITIVITY ANALYSIS: RISPERIDONE vS PLACEBO (based on attrition), Outcome 1 Mental state: 1. no clinically significant response (defined by PANSS/BPRS) - short term (up to 12 weeks).

ADDITIONAL TABLES

APPENDICES

FEEDBACK

WHAT'S NEW 
[Intervention Review]

\section{Risperidone versus placebo for schizophrenia}

Ranganath D Rattehalli¹, Sai Zhao², Bao Guo Li³, Mahesh B Jayaram4, Jun Xia5, Stephanie Sampson 6

1General Psychiatry, Logan Hospital, Brisbane, Australia. ${ }^{2}$ Systematic Review Solutions Ltd, Tianjin, China. ${ }^{3}$ Interventional therapy department, Tianjin Medical University Cancer Institute and Hospital, Tianjin, China. ${ }^{4}$ Department of Psychiatry, Melbourne Neuropsychiatry Centre, Melbourne, Australia. ${ }^{5}$ Cochrane Schizophrenia Group, The University of Nottingham, Nottingham, UK. ${ }^{6}$ The University of Nottingham, Nottingham, UK

Contact address: Ranganath D Rattehalli, General Psychiatry, Logan Hospital, Meadowbrook, Brisbane, QLD 4131, Australia. rdrattehalli@hotmail.com.

Editorial group: Cochrane Schizophrenia Group.

Publication status and date: New search for studies and content updated (no change to conclusions), comment added to review, published in Issue 12, 2016.

Citation: Rattehalli RD, Zhao S, Li BG, Jayaram MB, Xia J, Sampson S. Risperidone versus placebo for schizophrenia. Cochrane Database of Systematic Reviews 2016, Issue 12. Art. No.: CD006918. DOI: 10.1002/14651858.CD006918.pub3.

Copyright @ 2016 The Cochrane Collaboration. Published by John Wiley \& Sons, Ltd.

\section{A B S T R A C T}

\section{Background}

Risperidone is the first new-generation antipsychotic drug made available in the market in its generic form.

\section{Objectives}

To determine the clinical effects, safety and cost-effectiveness of risperidone compared with placebo for treating schizophrenia.

\section{Search methods}

On 19th October 2015, we searched the Cochrane Schizophrenia Group Trials Register, which is based on regular searches of CINAHL, BIOSIS, AMED, EMBASE, PubMed, MEDLINE, PsycINFO, and registries of clinical trials. We checked the references of all included studies and contacted industry and authors of included studies for relevant studies and data.

\section{Selection criteria}

Randomised clinical trials (RCTs) comparing oral risperidone with placebo treatments for people with schizophrenia and/or schizophrenialike psychoses.

\section{Data collection and analysis}

Two review authors independently screened studies, assessed the risk of bias of included studies and extracted data. For dichotomous data, we calculated the risk ratio (RR), and the 95\% confidence interval (CI) on an intention-to-treat basis. For continuous data, we calculated mean differences (MD) and the $95 \% \mathrm{Cl}$. We created a 'Summary of findings table' using GRADE (Grading of Recommendations Assessment, Development and Evaluation).

\section{Main results}

The review includes 15 studies $(\mathrm{N}=2428)$. Risk of selection bias is unclear in most of the studies, especially concerning allocation concealment. Other areas of risk such as missing data and selective reporting also caused some concern, although not affected on the direction of effect of our primary outcome, as demonstrated by sensitivity analysis. Many of the included trials have industry sponsorship of involvement. Nonetheless, generally people in the risperidone group are more likely to achieve a significant clinical improvement in mental state ( $6 \mathrm{RCTs}, \mathrm{N}=864$, RR $0.64, \mathrm{Cl} 0.52$ to 0.78 , very low-quality evidence). The effect withstood, even when three studies with $>50 \%$ attrition rate were removed from the analysis ( $3 \mathrm{RCTs}, \mathrm{N}=589$, RR $0.77, \mathrm{Cl} 0.67$ to 0.88 ). Participants receiving placebo were less likely to have a clinically significant improvement on Clinical Global Impression scale (CGI) than those receiving risperidone $(4 \mathrm{RCTs}, \mathrm{N}=594, \mathrm{RR}$ 
$0.69, \mathrm{Cl} 0.57$ to 0.83 , very low-quality evidence). Overall, the risperidone group was $31 \%$ less likely to leave early compared to placebo group (12 RCTs, $\mathrm{N}=2261$, RR $0.69,95 \% \mathrm{Cl} 0.62$ to 0.78 , low-quality evidence), but Incidence of significant extrapyramidal side effect was more likely to occur in the risperidone group ( $7 \mathrm{RCTs}, \mathrm{N}=1511$, RR 1.56, $95 \% \mathrm{Cl} 1.13$ to 2.15 , very low-quality evidence).

When risperidone and placebo were augmented with clozapine, there is no significant differences between groups for clinical response as defined by a less than $20 \%$ reduction in PANSS/BPRS scores ( $2 \mathrm{RCTs}, \mathrm{N}=98, \mathrm{RR} 1.15,95 \% \mathrm{Cl} 0.93$ to 1.42, low-quality evidence) and attrition (leaving the study early for any reason) (3 RCTs, $\mathrm{N}=167$, RR $1.13,95 \% \mathrm{Cl} 0.53$ to 2.42 , low quality evidence). One study measured clinically significant responses using the CGI, no effect was evident ( $1 \mathrm{RCT}, \mathrm{N}=68, \mathrm{RR} 1.1295 \% \mathrm{Cl} 0.87$ to 1.44 , low quality evidence). No data were available for extrapyramidal adverse effects.

\section{Authors' conclusions}

Based on low quality evidence, risperidone appears to be benefitial in improving mental state compared with placebo, but it also causes more adverse events. Eight out of the 15 included trials were funded by pharmaceutical companies. The currently available evidence isvery low to low quality.

\section{PLAIN LANGUAGE SUMMARY}

\section{Risperidone versus placebo for schizophrenia}

\section{Review question}

Is risperidone (tablet form) more effective than placebo in treating the symptoms of schizophrenia or schizophrenia-like illnesses?

\section{Background}

People with schizophrenia often hear voices and see things (hallucinations) and have strange beliefs (delusions). These are called 'positive symptoms'. Mental illness also causes tiredness, apathy, emotional numbness, and withdrawal. These are called 'negative symptoms'. The main treatment for the symptoms of schizophrenia are antipsychotic drugs. Antipsychotic drugs can be classified into typical (older) and atypical (newer) drugs. Typical antipsychotics such as chlorpromazine and haloperidol have been the mainstay of treatment for decades, and have been effective in reducing the positive symptoms of schizophrenia. Negative symptoms, however, have been fairly resistant to treatment. In addition, drug treatments are associated with unpleasant side effects that cause people to stop taking medication, which may lead to relapse. It is thought that newer atypical antipsychotics, such as risperidone, are more effective than the older antipsychotics as they reduce the positive symptoms but cause fewer side effects.

\section{Study characteristics}

Searches for high-quality randomised trials were carried out in 2008, 2013 and 2015. The review now includes 15 studies with 2428 participants. The studies randomised participants (in- and outpatients) with schizophrenia or schizophrenia-like illnesses into treatment groups that received oral risperidone or placebo.

\section{Key results}

Results from limited data suggest that risperidone is more effective than placebo for reducing the overall symptoms of schizophrenia, and participants receiving risperidone were more likely to comply with treatment. However, like the older typical antipsychotics, risperidone was also associated with serious side effects, such as parkinsonism.

\section{Quality of the evidence}

The evidence available was very low quality. Information and data were limited, poorly reported, and probably biased in favour of risperidone. Nearly half of the included trials were funded by drug companies. Firm conclusions are difficult to make based on the results of this review. Better conduct and reporting of trials could increase confidence in the results.

Ben Gray, Senior Peer Researcher, McPin Foundation. http://mcpin.org/ 
SUMMARY OF FINDINGS

Summary of findings for the main comparison. RISPERIDONE compared to PLACEBO for schizophrenia

RISPERIDONE compared to PLACEBO for schizophrenia

Patient or population: patients with schizophrenia

Settings: inpatient and outpatient

Intervention: RISPERIDONE

Comparison: PLACEBO

\begin{tabular}{|c|c|c|c|c|c|c|}
\hline \multirow[t]{3}{*}{ Outcomes } & \multicolumn{2}{|c|}{ Illustrative comparative risks* $(95 \% \mathrm{CI})$} & \multirow{3}{*}{$\begin{array}{l}\text { Relative effect } \\
(95 \% \mathrm{Cl})\end{array}$} & \multirow{3}{*}{$\begin{array}{l}\text { No of Partici- } \\
\text { pants } \\
\text { (studies) }\end{array}$} & \multirow{3}{*}{$\begin{array}{l}\text { Quality of the } \\
\text { evidence } \\
\text { (GRADE) }\end{array}$} & \multirow[t]{3}{*}{ Comments } \\
\hline & Assumed risk & Corresponding risk & & & & \\
\hline & PLACEBO & RISPERIDONE & & & & \\
\hline \multirow{4}{*}{$\begin{array}{l}\text { Mental state: no clinically significant re- } \\
\text { sponse in psychotic symptoms (defined } \\
\text { by various scale total score change) - } \\
\text { short term (up to } 12 \text { weeks) - defined by } \\
\text { PANSS/BPRS }<20 \% \text { decline } \\
\text { Follow-up: } 12 \text { weeks }\end{array}$} & \multicolumn{2}{|c|}{ Study population } & \multirow{4}{*}{$\begin{array}{l}\mathbf{R R} \mathbf{0 . 6 4} \\
(0.52 \text { to } 0.78)\end{array}$} & \multirow{4}{*}{$\begin{array}{l}864 \\
\text { (6 studies) }\end{array}$} & \multirow{4}{*}{$\begin{array}{l}\oplus \ominus \odot \odot \\
\text { Very Low } 1,2,3\end{array}$} & \\
\hline & 692 per 1000 & $\begin{array}{l}\mathbf{4 4 3} \text { per } 1000 \\
\text { (360 to } 540)\end{array}$ & & & & \\
\hline & \multicolumn{2}{|l|}{ Moderate } & & & & \\
\hline & 733 per 1000 & $\begin{array}{l}469 \text { per } 1000 \\
\text { (381 to } 572 \text { ) }\end{array}$ & & & & \\
\hline \multirow{4}{*}{$\begin{array}{l}\text { Leaving the study early - short term (up } \\
\text { to } 12 \text { weeks) - any reason } \\
\text { Follow-up: } 12 \text { weeks }\end{array}$} & \multicolumn{2}{|c|}{ Study population } & \multirow{4}{*}{$\begin{array}{l}\text { RR } \mathbf{0 . 6 9} \\
(0.62 \text { to } 0.78)\end{array}$} & \multirow{4}{*}{$\begin{array}{l}2261 \\
\text { (12 studies) }\end{array}$} & \multirow{4}{*}{$\begin{array}{l}\oplus \oplus \odot \ominus \\
\text { Low } 1,3\end{array}$} & \\
\hline & 495 per 1000 & $\begin{array}{l}342 \text { per } 1000 \\
\text { (307 to } 386)\end{array}$ & & & & \\
\hline & \multicolumn{2}{|l|}{ Moderate } & & & & \\
\hline & 486 per 1000 & $\begin{array}{l}335 \text { per } 1000 \\
(301 \text { to } 379)\end{array}$ & & & & \\
\hline \multirow{3}{*}{$\begin{array}{l}\text { Global state: } 2 \text {. no significant clinical im- } \\
\text { provement - CGI, short term (up to } 12 \\
\text { weeks) } \\
\text { Follow-up: } 12 \text { weeks }\end{array}$} & \multicolumn{2}{|c|}{ Study population } & \multirow{3}{*}{$\begin{array}{l}\text { RR } \mathbf{0 . 6 9} \\
(0.57 \text { to } 0.83)\end{array}$} & \multirow{3}{*}{$\begin{array}{l}594 \\
\text { (4 studies) }\end{array}$} & \multirow{3}{*}{$\begin{array}{l}\oplus \ominus \ominus \ominus \\
\text { very low } 1,2,3\end{array}$} & \\
\hline & 744 per 1000 & $\begin{array}{l}\mathbf{5 1 3} \text { per } \mathbf{1 0 0 0} \\
(424 \text { to } 618)\end{array}$ & & & & \\
\hline & Moderate & & & & & \\
\hline
\end{tabular}




\begin{tabular}{|c|c|c|c|c|c|}
\hline & 732 per 1000 & $\begin{array}{l}\mathbf{5 0 5} \text { per } \mathbf{1 0 0 0} \\
\text { (417 to } 608)\end{array}$ & & & \\
\hline \multirow{4}{*}{$\begin{array}{l}\text { Adverse effects: } 1 \text { a. extrapyramidal - var- } \\
\text { ious effects - short term (up to } 12 \text { weeks) } \\
\text { - general - any significant EPS } \\
\text { Follow-up: } 12 \text { weeks }\end{array}$} & \multicolumn{2}{|c|}{ Study population } & \multirow{4}{*}{$\begin{array}{l}\text { RR } 1.56 \\
\text { (1.13 to } 2.15)\end{array}$} & \multirow{4}{*}{$\begin{array}{l}1511 \\
\text { (7 studies) }\end{array}$} & \multirow{4}{*}{$\begin{array}{l}\oplus \oplus \ominus \ominus \\
\text { Low } 1,3\end{array}$} \\
\hline & 73 per 1000 & $\begin{array}{l}\mathbf{1 1 3} \text { per } \mathbf{1 0 0 0} \\
\text { (82 to } 156)\end{array}$ & & & \\
\hline & \multicolumn{2}{|l|}{ Moderate } & & & \\
\hline & 106 per 1000 & $\begin{array}{l}\mathbf{1 6 5} \text { per } \mathbf{1 0 0 0} \\
\text { (120 to } 228)\end{array}$ & & & \\
\hline
\end{tabular}

${ }^{*}$ The basis for the assumed risk (e.g. the median control group risk across studies) is provided in footnotes. The corresponding risk (and its $95 \%$ confidence interval) is based on the assumed risk in the comparison group and the relative effect of the intervention (and its 95\% $\mathrm{Cl}$ ).

Cl: Confidence interval; RR: Risk ratio;

GRADE Working Group grades of evidence

High quality: Further research is very unlikely to change our confidence in the estimate of effect.

Moderate quality: Further research is likely to have an important impact on our confidence in the estimate of effect and may change the estimate.

Low quality: Further research is very likely to have an important impact on our confidence in the estimate of effect and is likely to change the estimate.

Very low quality: We are very uncertain about the estimate.

1 Downgraded one level due to risk of bias: studies contributing data to this body of evidence have unclear or high risk of bias in one or more domains, some were also sponsored by pharmaceutical companies.

2 Downgraded one level due to inconsistency: some concerns of heterogeneity were identified.

3 Downgraded one level due to publication bias: 'strongly suspected' - most studies were sponsored by pharmaceutical companies.

Summary of findings 2. RISPERIDONE + CLOZAPINE compared to PLACEBO + CLOZAPINE for schizophrenia

\section{RISPERIDONE + CLOZAPINE compared to PLACEBO + CLOZAPINE for schizophrenia}

Patient or population: people with schizophrenia

Settings: inpatient and outpatient

Intervention: RISPERIDONE + CLOZAPINE

Comparison: PLACEBO + CLOZAPINE

\begin{tabular}{|c|c|c|c|c|c|c|}
\hline \multirow[t]{2}{*}{ Outcomes } & Illustrative co & arative risks ${ }^{\star}(95 \% \mathrm{CI})$ & \multirow{2}{*}{$\begin{array}{l}\text { Relative effect } \\
(95 \% \mathrm{CI})\end{array}$} & \multirow{2}{*}{$\begin{array}{l}\text { No of Partici- } \\
\text { pants } \\
\text { (studies) }\end{array}$} & \multirow{2}{*}{$\begin{array}{l}\text { Quality of the } \\
\text { evidence } \\
\text { (GRADE) }\end{array}$} & \multirow[t]{2}{*}{ Comments } \\
\hline & Assumed risk & Corresponding risk & & & & \\
\hline
\end{tabular}




\begin{tabular}{|c|c|c|c|c|c|c|}
\hline & $\begin{array}{l}\text { PLACEBO + } \\
\text { CLOZAPINE }\end{array}$ & $\begin{array}{l}\text { RISPERIDONE + } \\
\text { CLOZAPINE }\end{array}$ & & & & \\
\hline \multirow{2}{*}{$\begin{array}{l}\text { Mental state: no clinically significant response } \\
\text { in psychotic symptoms - short term } \\
\text { PANSS/BPRS }<20 \% \text { decline } \\
\text { Follow-up: } 6-8 \text { weeks }\end{array}$} & \multicolumn{2}{|l|}{ Moderate ${ }^{1}$} & \multirow{2}{*}{$\begin{array}{l}\text { RR } \mathbf{1 . 1 5} \\
\text { (0.93 to } 1.42)\end{array}$} & \multirow{2}{*}{$\begin{array}{l}98 \\
\text { (2 studies) }\end{array}$} & \multirow{2}{*}{$\begin{array}{l}\oplus \oplus \ominus \ominus \\
\text { low } 1,2\end{array}$} & \\
\hline & 725 per 1000 & $\begin{array}{l}\mathbf{8 3 4} \text { per } \mathbf{1 0 0 0} \\
\text { (674 to } 1000)\end{array}$ & & & & \\
\hline $\begin{array}{l}\text { Leaving the study early due to any reason - } \\
\text { short term }\end{array}$ & 119 per 1000 & $\begin{array}{l}135 \text { per } 1000 \\
\text { (63 to } 288)\end{array}$ & $\begin{array}{l}\text { RR1.13 } \\
\text { (0.53 to } 2.42)\end{array}$ & $\begin{array}{l}167 \\
\text { (3 studies) }\end{array}$ & $\begin{array}{l}\oplus \ominus \Theta \odot \\
\text { very low 1,2,3 }\end{array}$ & \\
\hline $\begin{array}{l}\text { Global state: no significant clinical improve- } \\
\text { ment - CGI short term } \\
\text { Follow-up: } 8 \text { weeks }\end{array}$ & 735 per $1000^{3}$ & $\begin{array}{l}\mathbf{8 2 4} \text { per } \mathbf{1 0 0 0} \\
(640 \text { to } 1000)\end{array}$ & $\begin{array}{l}\text { RR } \mathbf{1 . 1 2} \\
\text { (0.87 to } 1.44 \text { ) }\end{array}$ & $\begin{array}{l}68 \\
\text { (1 study) }\end{array}$ & $\begin{array}{l}\oplus \oplus \ominus \ominus \\
\text { low } 1,2\end{array}$ & \\
\hline $\begin{array}{l}\text { Adverse effects: extrapyramidal - short term } \\
\text { Follow-up: } 12 \text { weeks }\end{array}$ & See comment & See comment & Not estimable & - & See comment & $\begin{array}{l}\text { No study re- } \\
\text { ported this out- } \\
\text { come }\end{array}$ \\
\hline \multicolumn{7}{|c|}{$\begin{array}{l}\text { *The basis for the assumed risk (e.g. the median control group risk across studies) is provided in footnotes. The corresponding risk (and its } 95 \% \text { confidence interval) is } \\
\text { based on the assumed risk in the comparison group and the relative effect of the intervention (and its } 95 \% \mathrm{CI} \text { ). } \\
\text { Cl: Confidence interval; RR: Risk ratio }\end{array}$} \\
\hline \multicolumn{7}{|c|}{$\begin{array}{l}\text { GRADE Working Group grades of evidence } \\
\text { High quality: Further research is very unlikely to change our confidence in the estimate of effect. } \\
\text { Moderate quality: Further research is likely to have an important impact on our confidence in the estimate of effect and may change the estimate. } \\
\text { Low quality: Further research is very likely to have an important impact on our confidence in the estimate of effect and is likely to change the estimate. } \\
\text { Very low quality: We are very uncertain about the estimate. }\end{array}$} \\
\hline
\end{tabular}

1 Downgraded one level due to risk of bias: studies contributing data to this body of evidence have unclear risk of bias in one or more domains.

2 Downgraded one level due to imprecision: wide confidence interval including no effect and appreciable harm, and less than optimal information size.

3 Downgraded one level due to publication bias: 'strongly suspected' - most studies were sponsored by pharmaceutical companies. 


\section{B A C K G R O U N D}

Risperidone (Figure 1) is the first new-generation antipsychotic drug made available in the market in its generic form. It has been used in the treatment of schizophrenia and related psychotic disorders for over a decade.

\section{Figure 1. Risperidone}

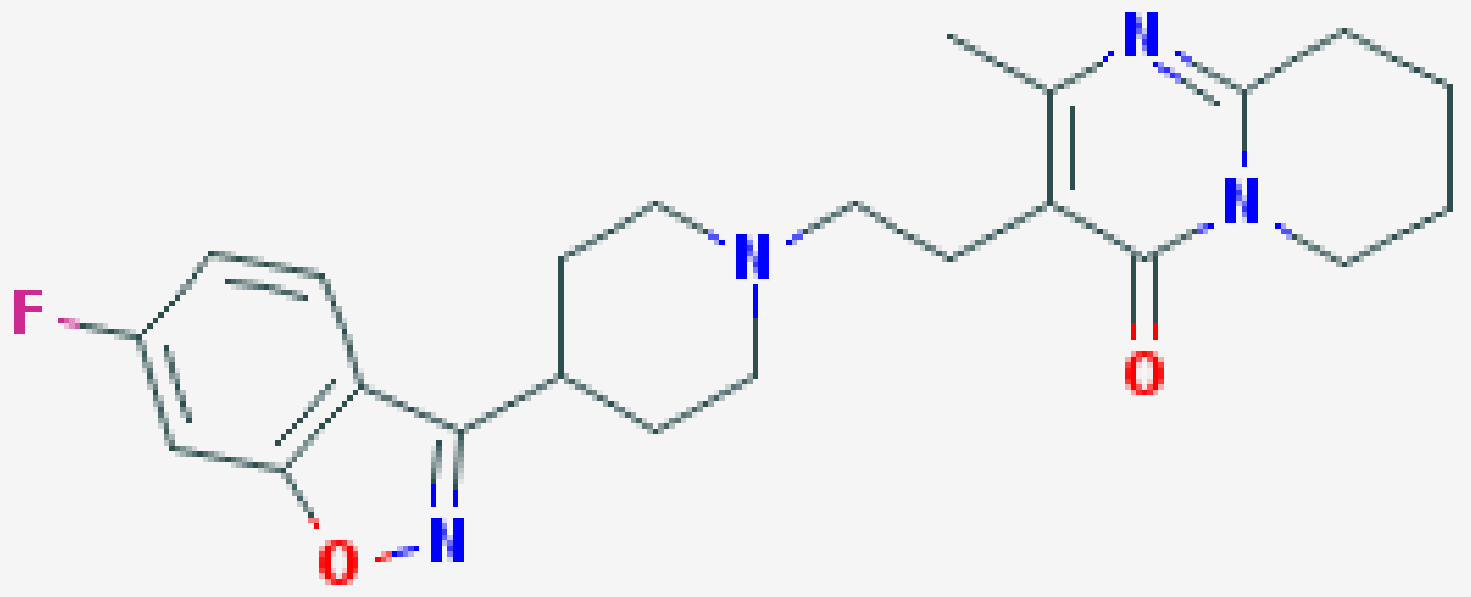

\section{Description of the condition}

Schizophrenia is a serious, chronic, and relapsing mental illness with a worldwide lifetime prevalence of about $1 \%$. It is characterised by positive symptoms such as hallucinations and delusions, and negative symptoms such as emotional numbness and withdrawal. One-third of those who experience an episode of schizophrenia recover and the illness does not recur. Another 30\% experience an unremitting illness. The remainder have a recurrent illness but with long episodes of considerable recovery from the positive symptoms. The overall cost of the illness to the individuals, their families, and the community is considerable.

\section{Description of the intervention}

Conventional antipsychotic drugs were introduced into widespread use in the 1950s, and have since formed the mainstay of drug treatment for schizophrenia. Although these drugs were indeed a revolution, their early promise of complete recovery was unfulfilled. Continued interests in further developments led to the

Risperidone versus placebo for schizophrenia (Review) 
formulation of clozapine in the early 1960s, which, in turn, paved the way for a series of new atypical antipsychotic drugs. This disparate grouping was said to be 'atypical' because they did not seem to cause movement disorders to the same extent as the older generation of drugs.

This series of newer drugs appeared on the market in the early 1990s, risperidone being one of the first. Initially, risperidone was compared with placebo and then with the older-generation antipsychotic drugs, especially haloperidol (Hunter 2003). More recently, risperidone has been used as the control compound when other new antipsychotic drugs are compared with a 'standard atypical'. In 2007 risperidone became off-licence, and it seems likely that this drug will emerge as the new standard care comparator, replacing the older and more problematic haloperidol (Joy 2006).

The absolute effects of a drug are often less well investigated when a standard treatment is widely used, and it is seen as unethical not to treat with drug therapy. With almost everyone having access to older drug treatments for schizophrenia, placebo-controlled trials in this area are now difficult to justify (Carpenter 2003; Laughren 2001). Yet in many physical diseases, such as angina pectoris, bronchial asthma, herpes simplex, and duodenal ulcers, placebo effects can account for up to $33 \%$ of clinical improvement (Benson 1996). When it comes to new drugs such as risperidone, clinicians and the public are often provided the evidence for the comparative effects, but the newer drug has been compared with a less-thanideal drug (Hunter 2003). We argue that knowledge of the effects of a drug compared with placebo assists development of a rational therapeutic approach (Vallance 2006).

\section{How the intervention might work}

Risperidone (4-[2-[4-(6-fluorobenzo[d]isoxazol-3-yl)-1piperidyl]ethyl]-3-methyl-2,6-diazabicyclo[4.4.0]deca-1,3-dien-5one) is a strong postsynaptic dopamine receptor antagonist, but also acts as a 5-HT2A antagonist and is called a serotonin/dopamine antagonist (Leysen 1994). Risperidone is rapidly and very well absorbed after administration orally, and less than $1 \%$ is excreted unchanged in the faeces (Heykants 1994). It reaches peak plasma levels quickly regardless of whether it is administered as a liquid or pill. It is $90 \%$ plasma protein bound (Darby 1997). Risperidone binds to D2 and D3 receptors with 50 and 20 times greater affinity than clozapine and is only 2 to 3 times less potent than haloperidol. Also, its affinity for D1 receptors is 100 times lower than for D4 receptors (Leysen 1994).

\section{Why it is important to do this review}

Comparing any drug with a placebo has always been an intriguing aspect of drug trials, and some authors, such as Vallance 2006, feel that outcome measures are best measured when compared with a placebo as it partly accounts for the philosophical obstacles such as the mind/body dichotomy, which are inherent in conceptualising these effects. In $60 \%$ to $90 \%$ of diseases, including angina pectoris, bronchial asthma, herpes simples, and duodenal ulcers, placebo effects can account for up to $33 \%$ of clinical improvement and yield clinical results (Benson 1996). The placebo effect ultimately allows a rationalised therapeutic approach to be developed to maximise the clinical benefit of the therapeutic encounter and evaluate various outcome measures (Vallance 2006).
Cochrane reviews to date have evaluated the efficacy of risperidone for schizophrenia by comparing it with typical and other atypical antipsychotics. This comparison of risperidone versus placebo is one of a set of reviews on risperidone (Table 1 ).

\section{O B JECTIVES}

To determine the clinical effects, safety, and cost-effectiveness of risperidone compared with placebo for treating schizophrenia.

\section{METHODS}

\section{Criteria for considering studies for this review}

\section{Types of studies}

We included all relevant RCTs. If a trial was described as 'doubleblind', but only implied that the study is randomised, then we included it in a sensitivity analysis. If in such a trial there was no implied randomisation, we contacted the authors to clarify the randomisation. We excluded trials where randomisation did not occur. If there was no substantive difference within primary outcomes (see Types of outcome measures) when these 'implied randomisation' studies were added, then we included these in the final analysis. If there was a substantive difference, we only used clearly randomised trials and described the results of the sensitivity analysis in the text. We excluded quasi-randomised studies, such as those allocated by using alternate days of the week.

\section{Types of participants}

We included people (above 17 years of age) with schizophrenia and other types of schizophrenia-like psychoses (schizophreniform and schizoaffective disorders), as evidence suggests that they are fundamentally not too dissimilar (Carpenter 1994).

\section{Types of interventions}

\section{Oral risperidone: any dose or form}

\section{Placebo}

\section{Types of outcome measures}

We grouped outcomes into short term (up to 12 weeks), medium term (13 to 26 weeks), and long term (over 26 weeks).

\section{Primary outcomes}

1. Mental state

1.1 Clinical response: no clinically significant response in psychotic symptoms, as defined by each of the studies (short term)

\section{Service utilisation}

2.1 Hospital admission and/or re-admission

\section{Secondary outcomes}

\section{Leaving the study early}

\section{Global state}

2.1 Average score/change in global state 2.2 No clinically significant response on global state, as defined by each of the studies

\section{Mental state}

3.1 Average score/change on psychotic symptoms 
3.2 No clinically significant response on positive symptoms, as defined by each of the studies

3.3 Average score/change in positive symptoms

3.4 No clinically significant response on negative symptoms, as defined by each of the studies

3.5 Average score/change in negative symptoms

3.6 Use of additional medication (other than anticholinergics) for psychiatric symptoms

\section{Extrapyramidal adverse effects}

4.1 Use of antiparkinson drugs

4.2 No clinically significant extrapyramidal adverse effects, as defined by each of the studies

4.3 Average score/change in extrapyramidal adverse effects

\section{Other adverse effects}

5.1 General and specific (including deaths by suicide or natural causes)

\section{Service utilisation outcomes}

6.1 Days in hospital

\section{Economic outcomes}

8. Quality of life/satisfaction with care for either recipients of care or carers

8.1 Significant change in quality of life/satisfaction, as defined by each of the studies

8.2 Average score/change in quality of life/satisfaction

\section{9. 'Summary of findings' table}

We used the GRADE approach to interpret findings and used GRADEpro to import data from RevMan 5.1 to create 'Summary of findings' tables (Schünemann 2008). These tables provide outcome-specific information concerning the overall quality of evidence from each included study in the comparison, the magnitude of effect of the interventions examined, and the sum of available data on all outcomes we rated as important to patient-care and decision making. We selected the following main outcomes for inclusion in the 'Summary of findings' table:

1. Mental state - no clinically significant response

2. Leaving the study early - for any reason

3. Global state - no significant clinical improvement

4. Adverse events - extrapyramidal effects

\section{Search methods for identification of studies}

\section{Electronic searches}

\section{Cochrane Schizophrenia Group Trials Register}

On 19th October 2015, the Trials Search Co-ordinator searched the Cochrane Schizophrenia Group Trials Register using the following search strategy:

((risperidone* or Risperdal ${ }^{\star}$ ) AND placebo*):ti,ab of REFERENCES or ((risperidone* or Risperdal $\left.^{\star}\right)$ AND placebo*):sin of STUDIES

The Cochrane Schizophrenia Group Trials Register is compiled by systematic searches of major resources (including AMED, BIOSIS, CINAHL, EMBASE, MEDLINE, PsycINFO, PubMed, and registries of clinical trials) and their monthly updates, handsearches, grey literature, and conference proceedings (see Group Module). There are no language, date, document type, or publication status limitations for inclusion of records into the register.

For details of the previous search, please see Appendix 1.

\section{Searching other resources}

\section{Reference lists}

We searched all references of the reports of included trials for further relevant studies.

\section{Authors of studies}

When necessary, we contacted authors of studies to clarify data and request additional studies, but received no response. We also contacted authors for information on any published or unpublished additional studies that they were aware of, but again, received no response.

\section{Pharmaceutical companies}

We contacted relevant pharmaceutical companies for additional studies and to clarify study data. However, we did not receive any further information.

\section{Data collection and analysis}

We have updated some text of the methods to reflect changes and updates in Cochrane methodology; please see Appendix 2 for details of methods used in original version.

\section{Selection of studies}

Two review authors (RR, MJ) independently inspected all reports of studies identified for the original search. Any disagreements were resolved by consensus; where doubt remained, we acquired the full article. Review authors (RR, BL and JX) independently decided whether these studies met the review criteria. We did not intend to blind the names of authors, institutions, and journal of publication. Again, any disagreements were resolved by consensus. When this was not possible, we sought further information and, in the interim, added these trials to the Studies awaiting classification list.

SS screended results from 2013 search and review authors SZ and $\mathrm{BL}$ independently inspected citations from the subsequent updated search (19th October 2015) to identify relevant abstracts. We obtained and inspected full reports of the abstracts meeting the review criteria.

\section{Data extraction and management}

\section{Extraction}

Review authors RR, MJ (original search), SS (2013 search), SZ, BL (2015 search) independently extracted data from all included studies. In addition, to ensure reliability, JX independently extracted data from a random sample of these studies comprising $10 \%$ of the total. Again, we discussed any disagreements and documented decisions. The need did not arise, but we had planned to extract data presented only in graphs and figures whenever possible, while only including the data if two review authors independently reached the same result. We also attempted to contact authors through an open-ended request in order to obtain missing information or for clarification whenever necessary. 


\section{Management}

\subsection{Forms}

We extracted data on to standard, simple forms.

\subsection{Scale-derived data}

We included continuous data from rating scales only if:

a. the psychometric properties of the measuring instrument have been described in a peer-reviewed journal (Marshall 2000); and b. the measuring instrument was not written or modified by one of the trialists for that particular trial.

\subsection{Endpoint versus change data}

Both endpoint and change data have advantages. Change data can remove a component of between-person variability from the analysis. On the other hand, calculation of change needs two assessments (baseline and endpoint), which can be difficult in unstable and hard-to-measure conditions such as schizophrenia. We decided to primarily use endpoint data, and only use change data if the former were not available. We combined endpoint and change data in the analysis, as we used mean differences (MD) rather than standardised mean differences (SMD) throughout (Higgins 2011, Chapter 9.4.5.2).

\subsection{Skewed data}

Continuous data on clinical and social outcomes are often not normally distributed. To avoid the pitfall of applying parametric tests to non-parametric data, we aimed to apply the following standards to all data before inclusion: a) standard deviations and means are reported in the paper or obtainable from the authors; b) when a scale starts from the finite number 0 , the standard deviation, when multiplied by 2 , is less than the mean (as otherwise the mean is unlikely to be an appropriate measure of the centre of the distribution (Altman 1996)); c) if a scale started from a positive value (such as the Positive and Negative Syndrome Scale (PANSS), which can have values from 30 to 210), we modified the calculation described above to take the scale starting point into account. In these cases, skew is present if $2 \mathrm{SD}>(\mathrm{S}-\mathrm{S} \mathrm{min})$, where $\mathrm{S}$ is the mean score and $\mathrm{S}$ min is the minimum score. Endpoint scores on scales often have a finite start and endpoint, and these rules can be applied. We entered skewed endpoint data from studies of fewer than 200 participants in 'other tables' within the Data and analyses section rather than into a statistical analysis. Skewed data pose less of a problem when looking at mean if the sample size is large; we entered such data from studies with over 200 participants into syntheses. When continuous data are presented on a scale that includes a possibility of negative values (such as change data), it is difficult to tell whether data are skewed or not, we entered skewed change data into analyses.

\subsection{Common measure}

Had we identified such data, we intended to convert variables that can be reported in different metrics, such as days in hospital (mean days per year, per week, or per month) to a common metric (for example mean days per month) to facilitate comparison between trials. However, we did not identify such data.

\subsection{Conversion of continuous to binary}

Where possible, we made efforts to convert outcome measures to dichotomous data. This can be done by identifying cutoff points on rating scales and dividing participants accordingly into 'clinically improved' or 'not clinically improved'. It is generally assumed that if there is a $50 \%$ reduction in a scale-derived score such as the Brief Psychiatric Rating Scale, Overall 1962, or the PANSS, Kay 1986 , this could be considered as a clinically significant response (Leucht 2005a; Leucht 2005b). If data based on these thresholds were not available, we used the primary cutoff the original authors presented. Some included studies provided a definition of response as a reduction in PANSS or Clinical Global Impression scores, in which case we employed the dichotomous data provided from the primary study report.

\subsection{Direction of graphs}

Where possible, we entered data in such a way that the area to the left of the line of no effect indicated a favourable outcome for risperidone.

\section{Assessment of risk of bias in included studies}

For the update, two review authors (SZ, BL) independently used the criteria described in the Cochrane Handbook for Systematic Reviews of Interventions Higgins 2011to assess trial quality (Higgins 2011). This new set of criteria is based on evidence of associations between overestimate of effect and high risk of bias of the article such as sequence generation, allocation concealment, blinding, incomplete outcome data, and selective reporting.

Where details of randomisation and other characteristics of trials were inadequate, we contacted authors of the studies to obtain additional information.

We have noted the level of risk of bias in both the text of the review and in Summary of findings table 1 and Summary of findings 2 .

\section{Measures of treatment effect}

\section{Binary data}

For binary outcomes, we calculated a standard estimation of the risk ratio (RR) and its 95\% confidence interval ( $\mathrm{Cl}$ ). It has been shown that RR is more intuitive than odds ratios and that clinicians tend to interpret odds ratios as RR (Boissel 1999; Deeks 2000). The number needed to treat to harm statistic with its $\mathrm{Cls}$ is intuitively attractive to clinicians but is problematic both in its accurate calculation in meta-analyses and in its interpretation (Hutton 2009). For binary data presented in the 'Summary of findings' table/s, where possible, we calculated illustrative comparative risks.

\section{Continuous data}

For continuous outcomes, we estimated MD between groups. We preferred not to calculate effect size measures (SMD). However, if scales of very considerable similarity were used, we presumed there was a small difference in measurement, and we calculated effect size and transformed the effect back to the units of one or more of the specific instruments.

\section{Unit of analysis issues}

To facilitate comparison between trials, we intended to convert variables (such as days in hospital) that can be reported in different metrics (mean days per year, per week, or per month) to a common metric (for example mean days per month), but no studies reported data for these types of outcomes. 


\section{Dealing with missing data}

\section{Overall loss of credibility}

At some degree of loss of follow-up, data loses credibility (Xia 2009). For outcomes where more than $50 \%$ of data were unaccounted for, we intended to not reproduce these data or use them within analyses. If more than $50 \%$ of data in one arm of a study were lost, but the total loss was less than $50 \%$, we intended to mark data with $\left({ }^{*}\right)$ to indicate that such a result may well be prone to bias.

\section{Binary}

In cases where attrition for a binary outcome was between $0 \%$ and $50 \%$ and where these data were not clearly described, we presented data on a 'once-randomised-always-analyse' basis wherever possible (an intention-to-treat (ITT) analysis). For every outcome with the exception of the outcome of death, we had planned to assume those participants leaving the study early to have the same rates of negative outcome as those who completed. However, doing this drastically changed the significance of many outcomes and sometimes the direction of significant results, so we only presented data that was already available from the studies to reduce the risk of making incorrect assumptions.

\section{Continuous}

\subsection{Attrition}

In cases where attrition for a continuous outcome was between $0 \%$ and $50 \%$ and completer-only data were reported, we reproduced these.

\subsection{Standard deviations}

We didn't need to calculate any standard deviations (SD) in this review, but our protocol stated that we would first try to obtain missing values from the authors. If not available, where measures of variance for continuous data were missing but an exact standard error (SE) and $\mathrm{Cl}$ were available for group means, and either the $P$ value or $t$ value was available for differences in means, we calculated SDs according to the rules described in the Cochrane Handbook for Systematic Reviews of Interventions (Higgins 2011). When only the SE was reported, we would calculate SDs using the formula $\mathrm{SD}=\mathrm{SE}{ }^{*}$ square root $(\mathrm{n})$. Sections 7.7.3 and 16.1.3 of the Cochrane Handbook for Systematic Reviews of Interventions Higgins 2011present detailed formulae for estimating SDs from $P$ values, $\mathrm{t}$ or $\mathrm{F}$ values, Cls, or other statistics (Higgins 2011). If these formulae did not apply, we would calculate the SDs according to a validated imputation method that is based on the SDs of the other included studies (Furukawa 2006). Although some of these imputation strategies can introduce error, the alternative would be to exclude a given study's outcome and thus to lose information. We would nevertheless examine the validity of the imputations in a sensitivity analysis excluding imputed values.

\subsection{Last observation carried forward}

We anticipated that some studies would employ the method of last observation carried forward (LOCF). As with all methods of imputation to deal with missing data, LOCF introduces uncertainty about the reliability of the results. Therefore, where a trial used LOCF data, if less than $50 \%$ of the data were assumed, we reproduced these data and indicated that they were the product of LOCF assumptions.

\section{Assessment of heterogeneity}

Firstly, we considered all the included studies within any comparison to judge clinical heterogeneity. We then visually inspected the graphs in order to investigate the possibility of statistical heterogeneity; to supplement this we used, primarily, the $1^{2}$ statistic, which provides an estimate of the percentage of variability due to heterogeneity rather than due to chance alone. Where the $1^{2}$ estimate was greater than or equal to $75 \%$, we interpreted this as indicating the presence of high levels of heterogeneity (Higgins 2003). If inconsistency became high, we did not summate data, but presented it separately, and we investigated the reasons for heterogeneity.

\section{Assessment of reporting biases}

In order to investigate the likelihood of overt publication bias, we entered all data from all identified and selected trials into a funnel graph (trial effect against trial size) (Egger 1997).

\section{Data synthesis}

We understand that there is no closed argument for preference for use of fixed-effect or random-effects models. We used the randomeffects model for all analyses due to the potential for heterogeneity between studies. The random-effects method incorporates an assumption that the different studies are estimating different, yet related, intervention effects. This often seems to be true to us, and the random-effects model takes into account differences between studies even if there is no statistically significant heterogeneity. However, there is a disadvantage to the random-effects model. It puts added weight on to small studies, which are often the most biased ones. Depending on the direction of effect, these studies can either inflate or deflate the effect size.

\section{Subgroup analysis and investigation of heterogeneity}

If data were clearly heterogeneous, we checked that they had been extracted and entered correctly, and that we had made no unit of analysis errors. If the high levels of heterogeneity remained, we did not undertake a meta-analysis at this point, because if there is considerable variation in results, and particularly if there is inconsistency in the direction of effect, it may be misleading to quote an average value for the intervention effect. We prespecified no characteristics of studies that may be associated with heterogeneity except quality of trial method.

\section{Sensitivity analysis}

If studies had high attrition rates, we analysed the effect of including these studies in a sensitivity analysis, but we did not include any figures with more than $50 \%$ attrition in the analysis of efficacy. Where a trial was described as 'double-blind', but it was implied that the study was randomised, we had intended to include such studies in the sensitivity analysis, but we did not come across any such studies.

\section{RESULTS}

\section{Description of studies}

For a substantial description of each study, please refer to the relevant tables:Characteristics of included studies, Characteristics of excluded studies, Characteristics of ongoing studies. 


\section{Results of the search}

The initial search resulted in 815 citations. We were able to include 42 references, relating to only 10 studies from which we could extract useable data. We used information regarding unpublished data from trials on risperidone available to the Cochrane Schizophrenia Group from drug companies. The update searches run in 2013 and 2015 yielded 94 citations, of which 5 new studies were included.
In total up to the current update, 909 citations were identified from the search process in total. After removing duplicates, 763 unique records were screened by viewing titles and abstracts. A total number of 116 studies with 406 full-text articles were screened for eligibility. Finally, 86 studies with 337 references were excluded, 14 studies with 24 references are awaiting assessment due to lack of full-texts and one study was onging trial, which resulted in 15 studies with 56 references being included in the data and analysis (see Figure 2 for study flow diagram).

Figure 2. Study flow diagram.

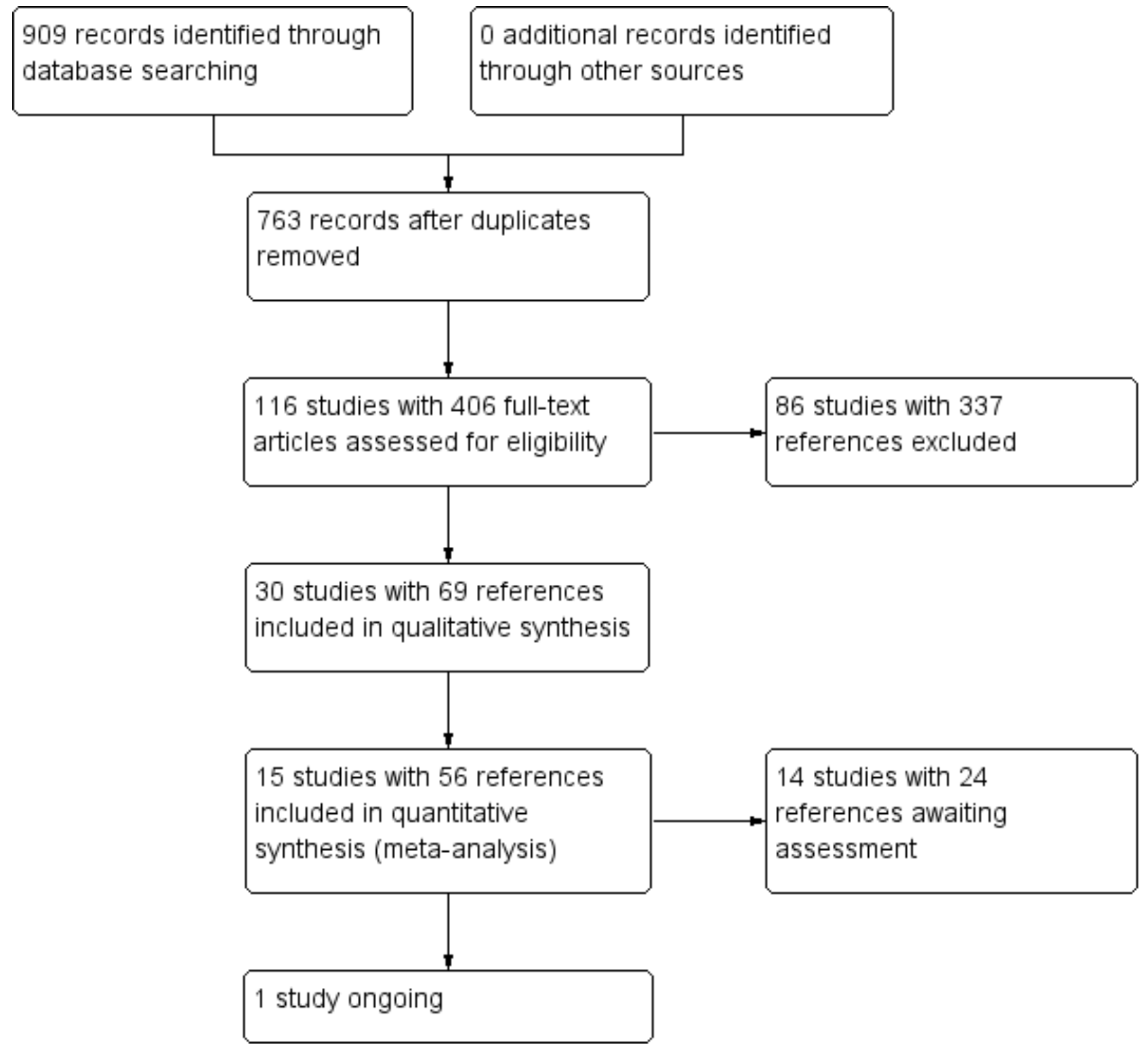

\section{Included studies}

\section{Length of trials}

Fourteen studies reported data on short-term follow-up, and only 1 study reported medium-term outcomes (Bachmann 2003), but even that was only at 16 weeks. Two studies were of 4 weeks duration (Potkin 1997; Potkin 2003), 6 studies were 6-weeks long (Borison 1992; Geffen 2010; Heisterberg 2007; Potkin 2006; Potkin
2007; Yagcioglu 2005), 3 studies were 8 weeks from start to finish (Chouinard 1992; Honer 2006; Marder 1994a), 2 studies were 9 weeks from start to finish (Downing 2014; Durgam 2014) and 1 study was 12 weeks in duration (Pai 2002).

\section{Participants}

Amongst our included studies, two included participants with no clear operational diagnostic criteria and simply stated 
"schizophrenia" (Potkin 1997; Potkin 2007). Nine studies included people with a sole diagnosis of schizophrenia as per Diagnostic Statistical Manual of Mental Disorders (DSM) criteria (Borison 1992; Chouinard 1992; Downing 2014; Durgam 2014; Geffen 2010; Heisterberg 2007; Marder 1994a; Pai 2002; Yagcioglu 2005), and the remaining four studies included participants with a diagnosis of schizophrenia or schizoaffective disorder as per DSM criteria (Bachmann 2003; Honer 2006; Potkin 2003; Potkin 2006).

Potkin 2007 did not report the sex of participants in the study. All other studies included both men and women, but the majority of participants were male. Most participants were aged between late 30 s and early 40 s.

Two studies did not have definitive exclusion criteria (Heisterberg 2007; Potkin 1997). The remaining studies excluded people with alcohol and substance misuse, as well as pregnant or breastfeeding women. Yagcioglu 2005 excluded people who were intolerant to risperidone in the past, Potkin 2003 excluded people being treated with risperidone at baseline, and Potkin 2006 excluded people who had received risperidone within the last seven days. Marder 1994a excluded people with schizoaffective disorder, and Potkin 2006 excluded people with borderline personality disorder. Potkin 2007 excluded people who had made a recent suicide attempt and who had serious suicidal thoughts.

\section{Setting}

Eight of the included studies took place in the inpatient setting (Borison 1992; Chouinard 1992; Downing 2014; Durgam 2014; Geffen 2010; Marder 1994a; Potkin 2003; Potkin 2006). Three studies involved both inpatients and outpatients (Bachmann 2003; Honer 2006; Yagcioglu 2005). We could not find any explicit information on setting for the remaining four studies (Heisterberg 2007; Pai 2002; Potkin 1997; Potkin 2007).

Studies were conducted in the USA (Bachmann 2003; Borison 1992; Geffen 2010; Marder 1994a; Potkin 1997; Potkin 2003; Potkin 2006; Potkin 2007), Canada (Chouinard 1992; Honer 2006), India (Geffen 2010), Romania (Geffen 2010), Denmark (Heisterberg 2007), and Turkey (Yagcioglu 2005). One studies recruited participants internationally from 65 study centres in the United States, India, Russia, Ukraine, and Malaysia.

\section{Study size}

The largest study was Downing 2014, which randmised 1009 people to four groups, among which, 437 participants were assigned to either resperidone or placebo group. Heisterberg 2007 randomised 303 people to receive either risperidone or placebo. Durgam 2014 randomised 729 people to five groups, however, only 291 participants were assigned to either resperidone or placebo group. Where a study randomised different doses of risperidone in different arms, as well as having a separate placebo arm, we tried to take data from the risperidone arm that best fitted with the average doses across studies. For example, as the mean dose of risperidone for all the other trials was $5.5 \mathrm{mg}$ per day, we took the $6 \mathrm{mg}$ arm from the Marder 1994a and Chouinard 1992 trials for efficacy measures in the meta-analysis. In Potkin 1997, which had two risperidone arms of $4 \mathrm{mg}$ and $8 \mathrm{mg}$, we took the $4 \mathrm{mg}$ arm for efficacy measures in the meta-analysis, as this was closer than the $8 \mathrm{mg}$ arm to the mean of 5.5 mg. Potkin 2006 randomised 226 people, Potkin 2003 202, Marder 1994a 130, Chouinard 1992 44, and Potkin 1997 168. The rest of the studies ranged between 24 and 121 participants.

\section{Interventions}

\subsection{Risperidone}

The dose of risperidone administered by the trialists varied from 2 $\mathrm{mg}$ up to $10 \mathrm{mg}$ per day.

\subsection{Placebo}

All studies had a placebo arm, and most had another arm with an active treatment in addition to risperidone. Borison 1992, Marder 1994a, and Chouinard 1992 had an arm for haloperidol. Downing 2014 had two arms for LY2140023 with low dosage or high dosage. Durgam 2014 had three arms of cariprazine with low, medium or high dosage. Geffen 2010 had two additional arms for a low dose and a high dose of BL-1020. Marder 1994a and Chouinard 1992 also had four different risperidone arms with daily doses of $2 \mathrm{mg}, 6 \mathrm{mg}$, $10 \mathrm{mg}$, and $16 \mathrm{mg}$. We used the $6 \mathrm{mg}$ arm from the Marder 1994a and Chouinard 1992 trials for efficacy measures in the meta-analysis and the $4 \mathrm{mg}$ arm data from Potkin 1997. Heisterberg 2007 used bifeprunox as the other arm, Potkin 2003 aripiprazole, Potkin 2006 quetiapine, and Potkin 2007 asenapine.

\subsection{Augmentation}

In three studies the risperidone and placebo arms were combined with clozapine (Bachmann 2003; Honer 2006; Yagcioglu 2005).

\section{Outcomes}

Our primary outcome measures were mental state and service utilisation; no data were available for service utilisation. Other outcomes of interest were leaving the study early, global state, adverse effects, and quality of life.

\subsection{Mental state}

The trials used several different rating scales to report on mental state. Heisterberg 2007 did not report useable data on mental state, and we could not use the Positive and Negative Symptom Scale (PANSS) data from Potkin 2007 as this trial had more than 50\% attrition. Downing 2014 only reported means of PANSS score in each group, therefore we are unable to use the data. All other trials used either the PANSS or the Brief Psychiatric Rating Scale to measure this outcome. Wherever possible, we used the binary data from these measures, but the validity of dichotomising these measures, although widely accepted, is, nevertheless, unclear.

\subsection{Leaving the study early}

All included trials provided useable data on the number of participants leaving the study early.

\subsection{Global state}

Five of the included studies reported global change using the Clinical Global Impression (CGI) scale (Durgam 2014, Honer 2006, Marder 1994a, Potkin 2003, Potkin 2006). Yagcioglu 2005 used both the CGI and the Global Assessment of Functioning Scale.

\subsection{Adverse effects}

Adverse effects are an important outcome measure from any trial. We were able to pool data on adverse effects from the majority of trials; some data was skewed and is presented in additional tables. 


\subsection{Quality of life}

were only presented by Only Yagcioglu 2005 presented quality of life data.

\subsection{Missing outcomes}

No data were available for service utilisation or economic outcomes.

\subsection{Outcome scales}

\subsubsection{Global state scales}

\subsubsection{Clinical Global Impression (Guy 1976)}

The CGI scale was used to assess both severity of illness and clinical improvement by comparing the conditions of the person standardised against other people with the same diagnosis. It is a seven-point scoring system with low scores showing decreased severity or overall improvement, or both.

\subsubsection{Global Assessment of Functioning Scale (DSM-IV-TR)} The GAF scale is a numeric scale ( 0 through 100 ) used by mentalhealth clinicians and doctors to rate the social, occupational, and psychological functioning of adults. The scale is presented and described in the DSM-IV-TR on page 32 (Table 2).

\subsubsection{Mental state scales}

\subsubsection{Positive and Negative Syndrome Scale (Kay 1986)}

The PANSS is used for measuring symptom severity of people with schizophrenia. It is widely used in the study of antipsychotic therapy. The name refers to the two types of symptoms in schizophrenia, as defined by the American Psychiatric Association: positive symptoms, which refer to an excess or distortion of normal functions, and negative symptoms, which represent a diminution or loss of normal functions.

\subsubsection{Brief Psychiatric Rating Scale (Overall 1962)}

The BPRS consists of 18 items on a 7-point severity scale. Initially published as a 16 -item scale in 1962, the standard 18-item version has been used since 1967 to successfully demonstrate efficacy of antidepressants, anti-anxiety drugs, and antipsychotics, including the newer 'atypical' antipsychotics. The BPRS has also been used in epidemiological studies, geropsychiatric research, and to compare diagnostic concepts between countries. It is most frequently used in schizophrenia. When using BPRS, rater training is a must and the use of a standardised interview is highly recommended in order to ascertain consistent results.

6.7.2.3 Calgary Depression Scale for Schizophrenia (Addington 1993)

Developed at the University of Calgary, the CDSS specifically assesses the level of depression in schizophrenia. It has been extensively evaluated in both relapsed and remitted patients and appears sensitive to change.

6.7.2.4 Scale for the Assessment of Negative Symptoms (Andreasen 1981)

The SANS assesses affective blunting, alogia, avolition/apathy, anhedonia/asociality, and disturbance of attention to measure negative symptoms in schizophrenia.

\subsubsection{Adverse effects scales}

\subsubsection{Barnes Akathisia Scale (Barnes 1989)}

The Barnes Akathisia Scale (commonly known as BAS or BARS) is a four-item rating scale administered by physicians to assess the severity of drug-induced akathisia. The most widely used scale for akathisia, it includes both objective items (e.g. observed restlessness) and subjective items (e.g. patient's awareness of restlessness and related distress), together with a global clinical assessment of akathisia. Global assessment is made on a scale of 0 to 5 , with comprehensive definitions provided for each anchor point on the scale: 0 = absent; 1 = questionable; 2 = mild akathisia; 3 = moderate akathisia; 4 = marked akathisia; 5 = severe akathisia.

6.7.3.2 Extrapyramidal Symptom Rating Scale (Chouinard 1993) The ESRS is a physician-rated scale for measuring extrapyramidal adverse effects from antipsychotic medication. It takes approximately 10 minutes and involves 6 questions about the person's subjective experience of extrapyramidal features (slowness, stiffness, and tremor); a standardised procedure for physical examination; and 7 rater-assessed items that address parkinsonian features (rigidity and tremor). The instrument may not differentiate effectively between dyskinesia and dystonia.

\subsubsection{Simpson Angus Scale (Simpson 1970)}

The SAS is a 10-item instrument used to evaluate the presence and severity of parkinsonian symptomatology specifically in patients who may be experiencing drug-induced parkinsonism and other extrapyramidal effects. For the past 25 years it has been the most commonly used rating scale for parkinsonism in clinical trials. The 10 items focus on rigidity rather than bradykinesia, and do not assess subjective rigidity or slowness. Items are rated for severity on a 0 to 4 scale, with definitions given for each anchor point.

\subsubsection{Abnormal Involuntary Movement Scale (Guy 1976)}

The AIMS is a 12 -item clinician-rated scale to assess severity of dyskinesias including orofacial movements, extremity and truncal movements in patients taking neuroleptic medications.

\subsubsection{The UKU side effect rating scale (Lingjaerde 1987)}

UKU is a 48 item clinician-rated scale to assess the side effects of psychopharmacological medications. The interview takes anywhere from 10-30 minutes depending on the number of symptoms reported, the complexity of the symptoms, and the patient's ability to provide good report.

\subsubsection{Quality of life scales}

\subsubsection{Quality of Life Scale (Carpenter 1994)}

The QLS is a 21-item scale rated from a semistructured interview providing information on symptoms and functioning during the preceding 4 weeks. It is intended to be administered by a trained clinician and requires about 45 minutes to complete. Each item is rated on a 7-point scale and, in all but 2 cases, requires a judgement by the clinician/interviewer. Each item is comprised of 3 parts: (1) a brief descriptive statement to focus the interviewer on the judgement to be made; (2) a set of suggested probes; and (3) the 7-point scale with descriptive anchors for every other point. The specific descriptions vary among items, but the high end of the scales (scores 5 and 6) reflects normal or unimpaired functioning, and the low end of the scales (scores 0 and 1 ) reflects severe impairment of the function in question. The interviewer is instructed to probe around each item until he or she has an adequate basis for making the required judgement, and is encouraged to go beyond the suggested probes with questions 
tailored for the individual patient. Thus the experience of both the patient and interviewer is similar to a careful clinical interview.

\subsubsection{Cognitive function scales}

6.7.5.1 Groton Maze Learning Test (Pietrzak 2008) (used in an ongoing study)

The GMLT assesses processing speed, working memory, and aspects of executive function in healthy adults. Performance on GMLT outcome measures can be compared to performance on tests of psychomotor speed, working memory, and learning from the Cogstate computerized cognitive test battery. Studies suggest that the GMLT measures of spatial learning efficiency and error monitoring correlate with Cogstate measures of attention, working memory, and learning. Exploratory factor analyses have yielded a two-factor solution of error monitoring and learning efficiency, which have been stable across repeated assessments.

\section{8 of note}

Borison 1992: In 1997 the first author and his colleague, Diamond, were convicted in the US courts (AHRP 2006; CBS News 2000CBS News 2000 AHRP 2006). For example, one website states: "Diamond, a Ph.D. pharmacologist who had performed more than 300 trials over the course of his career on patients who assumed he was an M.D., was convicted in 1997 on 53 criminal counts, including practicing medicine without a license, theft, prescribing medications without a license, fraud, false statements, tax evasion and bribery. Although he admitted to a growing greed that led to some of his illegal practices, Diamond maintained that the pair had never fabricated research data." We have continued to include data from this small study.

\section{Figure 3. Risk of bias graph: review authors' judgements about each risk of bias item presented as percentages} across all included studies.

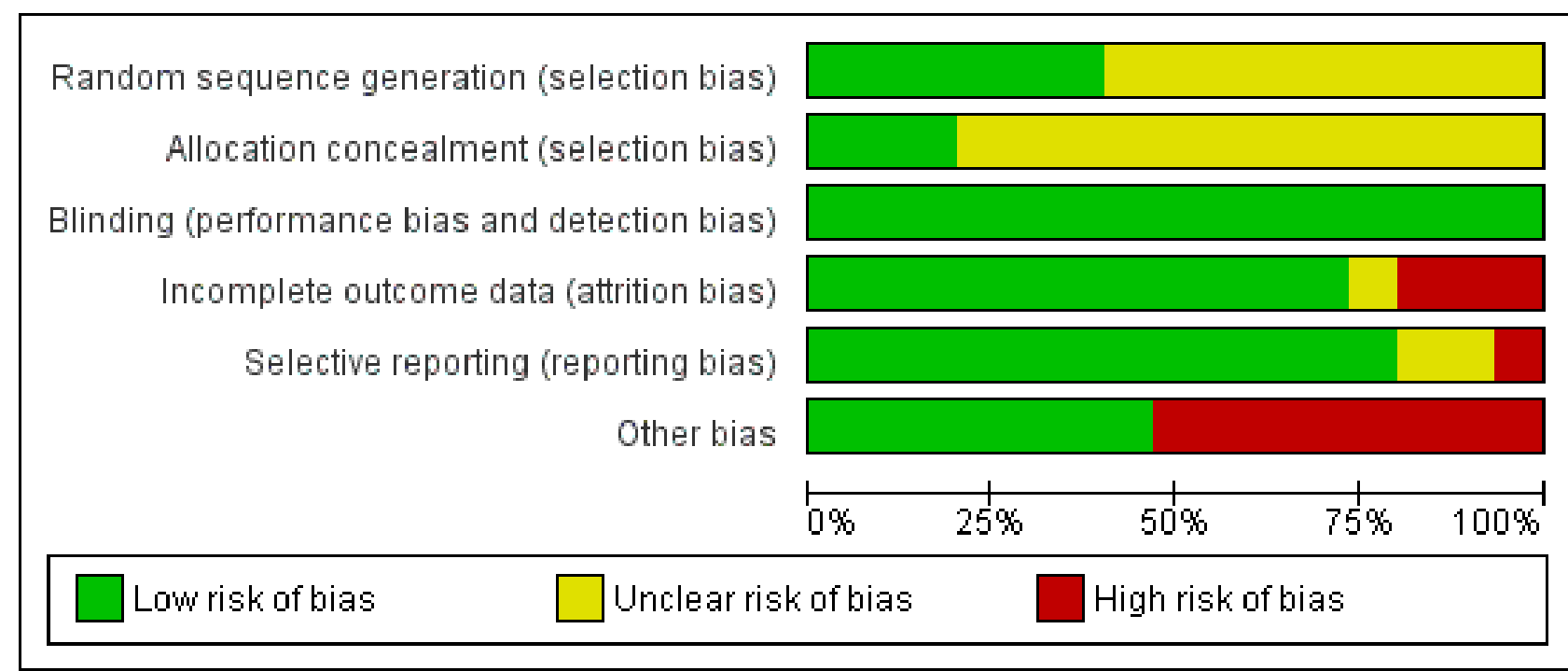

Risperidone versus placebo for schizophrenia (Review)

\section{Excluded studies}

We excluded 86 studies, 7 of which were not randomised (David 2000; Davis 2001; Baker 2012; Castle 2015; Kinon 2015; Marder 1991; Pikalov 2012). We excluded seven studies due to their populations not including people with schizophrenia (Anwunah 1999; Ayd 2001; NCT00088075; NCT00305474; Siever 2002; Anwunah 1999; Schmechtig 2010). The remaining excluded studies did not directly compare oral risperidone with placebo.

\section{Ongoing studies}

We identified one ongoing study. NCTO0174200 is assessing the effects of risperidone ( $2 \mathrm{mg}$ daily) on the differential sensitivity of two spatial working memory tests in non-agitated, drug-naive people suffering from first-episode schizophrenia or schizophreniform disorder. They intend to enrol 20 patients for the trial. Pfizer is sponsoring the study.

\section{Awaiting assessment}

Fourteen studies are awaiting assessment as sufficient information is not currently available (Anon 2010; Litman 2014; NCT 00694707; Vanover 2014; Nisenbaum 2013; Xu 2009; Bose 2010a; Cavazzoni 2002; DeMartinis 2012; GlaxoSmithKline 2006; NCT01086748; NCT01175135; NCT01363349; Rujescu 2009).

\section{Risk of bias in included studies}

Pharmaceutical companies funded 8 out of the 15 included trials. We did our best to collect as much information as possible from different sources about the types of biases that could have occurred during these trials, and have presented the results of our investigations in the following paragraphs. Figure 3 and Figure 4 presents the summary of risk of bias in included studies. 
Figure 4. Methodological quality summary: review authors' judgements about each methodological quality item for each included study.

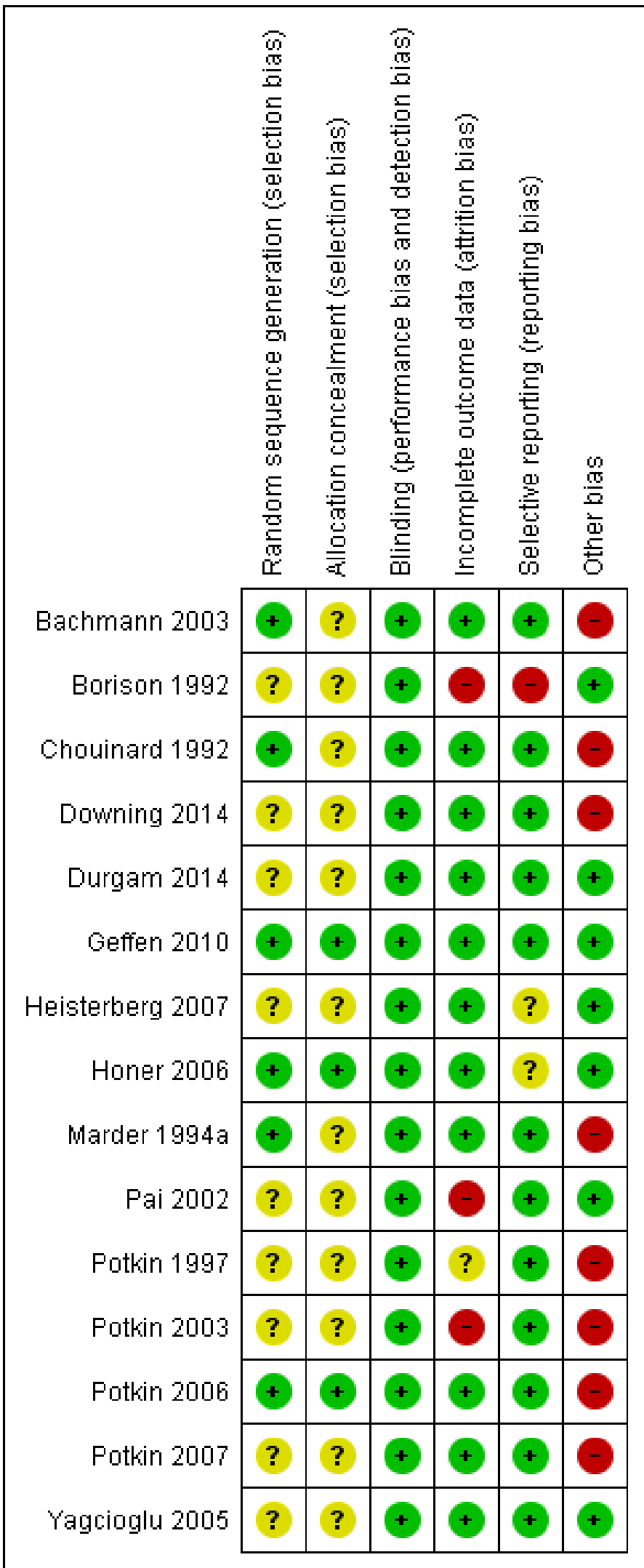




\section{Allocation}

All included studies were said to be randomised, but many did not explicitly describe the method by which this was undertaken. Bachmann 2003 utilised randomisation that was stratified by inpatient status; no further details were provided. Honer 2006 used a computer-generated schedule with a permuted-block design to generate sequences. Marder 1994a and Chouinard 1992 undertook randomisation in blocks of 12. Geffen 2010 and Potkin 2006 both used a centralised interactive voice response system for allocation concealment. Although Yagcioglu 2005 used a preassigned random sequence for each of their study sites that was developed before the start of their study no further details were provided. The rest of the studies provided no information about the process of randomisation (Borison 1992; Downing 2014; Durgam 2014; Heisterberg 2007; Pai 2002; Potkin 1997; Potkin 2003; Potkin 2007; Potkin 2003; Potkin 1997; Pai 2002; Heisterberg 2007; Borison 1992), despite this having been repeatedly shown to be of key importance in excluding selection biases (Juni 2001).

\section{Blinding}

All the included studies were described as double blind, with some describing how this was achieved. Blinding is important for minimising observation bias and, because many of the outcomes were subjective.

\section{Incomplete outcome data}

Bachmann 2003, Downing 2014, Durgam 2014, Geffen 2010 , Heisterberg 2007, Marder 1994a, Chouinard 1992, and Potkin 2006 used an intention-to-treat (ITT) analysis. Honer 2006, Yagcioglu 2005 and Durgam 2014 used the ITT principle in a mixed-model analysis. Potkin 2007 used ITT for the efficacy data and last observation carried forward (LOCF) for safety data.

We judged Pai 2002 and Borison 1992 to have a high risk of bias, as they did not consider in their analysis the data of participants who left early. We judged Potkin 1997 to be at unclear risk of bias, as no information about loss to follow-up was provided. Potkin 2003 used the LOCF method to manage their loss to follow-up, but as they had over $40 \%$ loss, we downgraded this category because such a high attrition rate makes data prone to bias. None of the trials attempted to validate assumptions by following up participants who did leave early.

\section{Selective reporting}

We were unable to obtain original study protocol, however, the included studies appear to have reported the results for all the outcomes listed in their methods sections. Based on the information available, we did not detect any obvious act of selective reporting.

\section{Other potential sources of bias}

\section{Poor reporting}

We could not use much data because of poor reporting. Findings that are presented as graphs, in percentiles, or simply reported as inexact $P$ values were of little use to us as review authors. Many studies failed to provide standard deviations (SDs) when reporting mean changes. We are seeking further data from the first authors of relevant trials.

\section{Industry}

Pharmaceutical companies funded 8 out of the 13 included trials, with the majority of these funded by a company that would profit from finding beneficial effects of risperidone.

\section{Effects of interventions}

See: Summary of findings for the main comparison RISPERIDONE compared to PLACEBO for schizophrenia; Summary of findings 2 RISPERIDONE + CLOZAPINE compared to PLACEBO + CLOZAPINE for schizophrenia

Studies relevant to this review fall into three comparisons. We identified 15 randomised trials from which it is possible to extract numerical data.

\section{COMPARISON 1: RISPERIDONE verSUS PLACEBO}

This comparison has 20 outcomes.

1.1 Mental state: no clinically significant response in psychotic symptoms (defined by various scale total score change) - short term (up to 12 weeks)

\subsection{1 defined by PANSS $<30 \%$ decline}

Three trials with a total of 707 participants provided data for this subset. We did find evidence that 'risperidone' was clearly different in its effects compared with 'placebo' (RR $0.74,95 \% \mathrm{Cl} 0.67$ to 0.83 ) (Analysis 1.1).

\subsection{2 defined by PANSS/BPRS $<20 \%$ decline}

Six trials with a total of 864 participants provided data for this subset. We did find evidence that 'risperidone' was clearly different in its effects compared with 'placebo' (RR $0.64,95 \% \mathrm{Cl} 0.52$ to 0.78 ). This subgroup had important levels of heterogeneity $\left(\mathrm{Chi}^{2}=12.27\right.$; $d f=5.0 ; P=0.03 ; I^{2}=59 \%$ ) (Analysis 1.1).

\subsection{Leaving the study early - short term (up to 12 weeks)}

\subsection{1 any reason}

There were 12 relevant trials, with a total of 2261 participants providing data for numbers leaving the study early for any reason. We did find evidence that 'risperidone' was clearly different in its effects compared with 'placebo' (RR $0.69,95 \% \mathrm{Cl} 0.62$ to 0.78 ). There are moderate levels of heterogeneity $\left(\mathrm{Chi}^{2}=14.73 ; \mathrm{df}=11 ; \mathrm{P}=0.20\right.$; $1^{2}=25 \%$ ) (Analysis 1.2).

\subsection{2 due to adverse events}

There were 10 relevant trials, with a total of 2081 participants, providing data for this subset. There was not a clear difference between 'risperidone' and 'placebo' (RR $0.78,95 \% \mathrm{Cl} 0.59$ to 1.03 ) (Analysis 1.2).

\subsection{3 due to lack of efficacy}

Eleven trials, with a total of 2211 participants provided data for this subset We found evidence of a clear difference between 'risperidone' and 'placebo' (RR $0.39,95 \% \mathrm{Cl} 0.29$ to 0.51 ). There are moderate levels of heterogeneity $\left(\mathrm{Chi}^{2}=14.70 ; \mathrm{df}=10 ; \mathrm{P}=0.14 ; \mathrm{I}^{2}\right.$ $=32 \%$ ) (Analysis 1.2). 


\subsection{4 due to non-compliance}

We found 4 trials to be relevant to this subset, with a total of 534 participants. For this subset, we did not find evidence of a clear difference between the two treatments (RR $1.15,95 \% \mathrm{Cl} 0.33$ to 4.05) (Analysis 1.2).

\subsection{5 lost to follow-up}

We found 6 trials to be relevant to this subset, with a total of 1545 participants. There was not a clear difference between 'risperidone' and 'placebo' within this subset ( $\mathrm{RR} 0.79,95 \% \mathrm{Cl} 0.25$ to 2.56 ). This subset had important levels of heterogeneity $\left(\mathrm{Chi}^{2}=11.97 ; \mathrm{df}=4.0\right.$; $\left.P=0.02 ;\left.\right|^{2}=67 \%\right)$ (Analysis 1.2).

\subsection{6 protocol violation}

We found 4 trials to be relevant to this subset, with a total of 1257 participants. There was not a clear difference between 'risperidone' and 'placebo' within this subset (RR $0.79,95 \% \mathrm{Cl} 0.39$ to 1.62 ) (Analysis 1.2).

\subsection{7 reported death}

There were 10 relevant trials in this subset, with a total of 1532 participants. There was not a clear difference between 'risperidone' and 'placebo' within this subset (RR $3.07,95 \% \mathrm{Cl} 0.13$ to 74.28 ) (Analysis 1.2).

\subsection{8 withdrawal of consent}

We found 7 trials to be relevant to this subset, with a total of 1589 participants. There was not a clear difference between 'risperidone' and 'placebo' within this subset (RR $1.12,95 \% \mathrm{Cl} 0.80$ to 1.56) (Analysis 1.2).

\subsection{9 other}

There were 3 relevant trials in this subset, with a total of 615 participants. For this subset, we did not find evidence of a clear difference between the two treatments (RR $1.03,95 \% \mathrm{Cl} 0.68$ to 1.57) (Analysis 1.2).

\subsection{Global state: 1 . average endpoint scores of CGI severity scale (high = poor) - short term (up to 12 weeks)}

We identified 3 studies relevant to this outcome, with a total of 457 participants. This outcome had no subsets. We found evidence of a clear difference between 'risperidone' and 'placebo' (MD -0.81, 95\% $\mathrm{Cl}-0.89$ to -0.73 ) (Analysis 1.3).

\subsection{Global state: 2 . no significant clinical improvement - short term (up to 12 weeks)}

For this outcome we found 4 relevant studies involving 594 participants. There were no subsets in this outcome. We found evidence of a clear difference between 'risperidone' and 'placebo' (RR $0.69,95 \% \mathrm{Cl} 0.57$ to 0.83 ). For this outcome heterogeneity was moderately high $\left(\mathrm{Chi}^{2}=5.43\right.$; $\mathrm{df}=3.0 ; \mathrm{P}=0.14$; $\mathrm{I}^{2}=44 \%$ ) (Analysis 1.4).

\subsection{Global state: 3 . needing additional medication - short term (up to 12 weeks)}

For this outcome we found six relevant studies, the data from which we divided into seven subsets.

\subsection{1 benzodiazepine}

There was a single trial in this subset, with a total of 42 participants. For this subset, we did not find evidence of a clear difference between the two treatments (RR $0.96,95 \% \mathrm{Cl} 0.77$ to 1.2) (Analysis 1.5).

\subsection{2 benzodiazepine derivatives - lorazepam}

There were 2 relevant trials in this subset, with a total of 228 participants. There was not a clear difference between 'risperidone' and 'placebo' within this subset (RR $0.93,95 \% \mathrm{Cl} 0.68$ to 1.27 ) (Analysis 1.5).

\subsection{3 benzodiazepine derivatives - Nitrazepam}

There was a single trial in this subset, with a total of 184 participants. For this subset, we did not find evidence of a clear difference between the two treatments (RR $0.51,95 \% \mathrm{Cl} 0.10$ to 2.72) (Analysis 1.5).

\subsection{4 benzodiazepine related drugs - Zolpidem}

We found 1 trial to be relevant to this subset, with a total of 184 participants. For this subset, we did not find evidence of a clear difference between the two treatments (RR $0.81,95 \% \mathrm{Cl} 0.53$ to 1.23) (Analysis 1.5).

\subsection{5 sedative/hypnotic}

We found 2 trials to be relevant to this subset, with a total of 230 participants. For this subset, we did not find evidence of a clear difference between the two treatments (RR $0.86,95 \% \mathrm{Cl} 0.69$ to 1.06) (Analysis 1.5).

\subsection{6 antiparkinsonian}

There were 2 relevant trials in this subset, with a total of 172 participants. There was not a clear difference between 'risperidone' and 'placebo' within this subset (RR $1.21,95 \% \mathrm{Cl} 0.79$ to 1.86 ) (Analysis 1.5).

\subsection{7 psychotropics}

We found 1 trial to be relevant to this subset, with a total of 186 participants. We found evidence of a clear difference between 'risperidone' and 'placebo' within this subset (RR 0.62, 95\% Cl 0.45 to 0.85 ) (Analysis 1.5).

\subsection{Mental state: 1. average endpoint scores on various scales on psychotic symptoms (high = poor) - short term (up to 12 weeks)}

We identified three studies relevant to this outcome, the data from which we divided into five subsets.

\subsubsection{BPRS total}

We found 2 trials to be relevant to this subset, with a total of 171 participants. We found evidence of a clear difference between 'risperidone' and 'placebo' within this subset (MD -12.69, 95\% Cl -17.06 to -8.32 ) (Analysis 1.6).

\subsubsection{PANSS total}

We found 3 trials to be relevant to this subset, with a total of 457 participants. For this outcome, within this subset, we did find evidence that 'risperidone' was clearly different in its effects 
compared with 'placebo' (MD $-17.81,95 \% \mathrm{Cl}-18.17$ to -17.45 ) (Analysis 1.6).

\subsubsection{PANSS general pathology}

There was a single trial in this subset, with a total of 44 participants. For this outcome, within this subset, we did find evidence that 'risperidone' was clearly different in its effects compared with 'placebo' (MD -13.20, 95\% Cl-20.15 to -6.25) (Analysis 1.6).

\subsubsection{PANSS negative symptom}

There were 3 relevant trials in this subset, with a total of 457 participants. We found evidence of a clear difference between 'risperidone' and 'placebo' within this subset (MD -3.10, 95\% Cl -3.19 to -3.01 ) (Analysis 1.6).

\subsubsection{PANSS positive symptom}

We found 3 trials to be relevant to this subset, with a total of 457 participants. For this outcome, within this subset, we did find evidence that 'risperidone' was clearly different in its effects compared with 'placebo' (MD $-5.49,95 \% \mathrm{Cl}-6.18$ to -4.80 ) (Analysis 1.6).

\subsection{Mental state: 2 . skewed data - short term (up to 12 weeks)}

These continuous data, from two trials were skewed. Therefore we have reported these data in a separate data table (Analysis 1.7).

\subsection{Adverse effects: 1a. extrapyramidal - various effects - short term (up to 12 weeks)}

We identified 11 studies relevant to this outcome, the data from which we divided into 12 subsets.

\subsection{1 general - any significant extrapyramidal symptom}

We found 7 trials to be relevant to this subset, with a total of 1511 participants. We found evidence of a clear difference between 'risperidone' and 'placebo' within this subset (RR 1.56, 95\% Cl 1.13 to 2.15) (Analysis 1.8).

\subsection{2 general - no improvement on AIMS score}

There was a single trial in this subset, with a total of 42 participants. We found evidence of a clear difference between 'risperidone' and 'placebo' within this subset (RR $0.30,95 \% \mathrm{Cl} 0.15$ to 0.61 ) (Analysis 1.8).

\subsection{3 general - no improvement on BAS score}

There was a single trial in this subset, with a total of 226 participants. For this outcome, within this subset, we did find evidence that 'risperidone' was clearly different in its effects compared with 'placebo' (RR $1.14,95 \% \mathrm{Cl} 1.01$ to 1.28 ) (Analysis 1.8).

\subsection{4 general - needing medication for EPS}

We found 2 trials to be relevant to this subset, with a total of 94 participants. For this subset, we did not find evidence of a clear difference between the two treatments (RR 1.14, 95\% Cl 0.78 to 1.67) (Analysis 1.8)

\subsection{5 specific - akathisia}

We found 5 trials to be relevant to this subset, with a total of 1204 participants. We found evidence of a clear difference between 'risperidone' and 'placebo' within this subset (RR 2.58, 95\% Cl 1.41 to 4.72$)$. For this subset heterogeneity was moderately high $\left(\mathrm{Chi}^{2}=\right.$ $5.63 ; \mathrm{df}=4.0 ; \mathrm{P}=0.23 ; \mathrm{I}^{2}=29 \%$ ). (Analysis 1.8 ).

\subsection{6 specific - bradykinesia}

We found 2 trials to be relevant to this subset, with a total of 485 participants. For this subset, we did not find evidence of a clear difference between the two treatments (RR $0.87,95 \% \mathrm{Cl} 0.6$ to 1.24 ) (Analysis 1.8).

\subsection{7 specific - dyskinesia}

We found 1 trial to be relevant to this subset, with a total of 303 participants. There was not a clear difference between 'risperidone' and 'placebo' within this subset (RR $0.32,95 \% \mathrm{Cl} 0.01$ to 7.86 ) (Analysis 1.8).

\subsection{8 specific - dystonia}

There were 3 relevant trials in this subset, with a total of 687 participants. For this subset, we did not find evidence of a clear difference between the two treatments (RR 3.40, 95\% Cl 0.26 to 44.46). This subset had important levels of heterogeneity $\left(\mathrm{Chi}^{2}=\right.$ $13.09 ; \mathrm{df}=2.0 ; \mathrm{P}=0.001 ; \mathrm{I}^{2}=84 \%$ ) (Analysis 1.8).

\subsection{9 specific - hypertonia}

There were 3 relevant trials in this subset, with a total of 505 participants. We found evidence of a clear difference between 'risperidone' and 'placebo' within this subset (RR 2.98, 95\% Cl 1.35 to 6.59$)$. For this subset heterogeneity was moderately high $\left(\mathrm{Chi}^{2}=\right.$ $2.87 ; \mathrm{df}=2.0 ; \mathrm{P}=0.24 ; \mathrm{I}^{2}=30 \%$ ) (Analysis 1.8 ).

\subsubsection{0 specific - parkinsonism}

We found 2 trials to be relevant to this subset, with a total of 485 participants. We found evidence of a clear difference between 'risperidone' and 'placebo' within this subset (RR 7.64, 95\% Cl 1.4 to 41.59) (Analysis 1.8)

\subsubsection{1 specific - tardive dyskinesia}

There was a single trial in this subset, with a total of 303 participants. For this subset, we did not find evidence of a clear difference between the two treatments (RR 6.77, 95\% Cl 0.35 to 130.03) (Analysis 1.8).

\subsubsection{2 specific - tremor}

We found 5 trials to be relevant to this subset, with a total of 1204 participants. There was not a clear difference between 'risperidone' and 'placebo' within this subset ( $\mathrm{RR} 1.60,95 \% \mathrm{Cl} 0.89$ to 2.88). This subset had moderate levels of heterogeneity $\left(\mathrm{Chi}^{2}=5.86\right.$; $\mathrm{df}=4.0$; $\mathrm{P}=0.21 ;\left.\right|^{2}=32 \%$ ) (Analysis 1.8).

\subsection{Adverse effects: 1b. extrapyramidal - AIMS average endpoint score - short term (up to 12 weeks)}

For this outcome we found a single study. A greater reduction in AIMS scores were seen for people in the risperidone arm compared to the placebo arm (1 RCT, N=42, MD $-5.5095 \% \mathrm{Cl}-8.60$ to -2.40 ) (Analysis 1.9). 
1.10 Adverse effects: 1c. extrapyramidal - skewed data (various scales) - short term (up to 12 weeks)

These continuous data (four RCTs) had such large SDs as to suggest that analysis within RevMan would be inadvisable. Therefore, we have reported these data in a separate table (Analysis 1.10).

\subsection{Adverse effects: 2 . any adverse event - short term (up to 12 weeks)}

For this outcome we found 9 relevant studies and categorised data into 16 subsets.

\subsection{1 any adverse event}

There were 7 relevant trials in this subset, with a total of 1610 participants. For this subset, we did not find evidence of a clear difference between the two treatments (RR 1.05, 95\% Cl 0.96 to 1.15). This subset had important levels of heterogeneity $\left(\mathrm{Chi}^{2}=\right.$ 14.46; $\mathrm{df}=6.0 ; \mathrm{P}=0.02 ; \mathrm{I}^{2}=58 \%$ ) (Analysis 1.11).

\subsection{2 asthenia}

There were 2 trials in this subset, with a total of 639 participants. For this subset, we did not find evidence of a clear difference between the two treatments (RR 1.93, 95\% $\mathrm{Cl} 0.62$ to 6.02) (Analysis 1.11).

\subsection{3 back pain}

There was a single trial in this subset, with a total of 202 participants. For this subset, we did not find evidence of a clear difference between the two treatments (RR 1.04, 95\% Cl 0.38 to 2.86) (Analysis 1.11).

\subsection{4 blurred vision}

There was a single trial in this subset, with a total of 202 participants. For this subset, we did not find evidence of a clear difference between the two treatments (RR 4.16, 95\% Cl 0.47 to 36.59) (Analysis 1.11).

\subsection{5 cogwheel rigidity}

We found 1 trial to be relevant to this subset, with a total of 226 participants. For this subset, we did not find evidence of a clear difference between the two treatments (RR 5.25, 95\% Cl 0.69 to 39.88) (Analysis 1.11).

\subsection{6 death}

We found 1 trial to be relevant to this subset, with a total of 182 participants. For this subset, we did not find evidence of a clear difference between the two treatments (RR 3.13, 95\% Cl 0.13 to 75.92) (Analysis 1.11).

\subsection{7 dental disorder}

There was a single trial in this subset, with a total of 202 participants. There was not a clear difference between 'risperidone' and 'placebo' within this subset (RR 3.64, 95\% $\mathrm{Cl} 0.78$ to 17.11 ) (Analysis 1.11).

\subsection{8 dysmenorrhoea}

There were two trials in this subset, with a total of 495 participants. There was not a clear difference between 'risperidone' and 'placebo' within this subset (RR $1.10,95 \% \mathrm{Cl} 0.04$ to 30.00 ) (Analysis 1.11).

\subsection{9 fatigue}

There were two trial in this subset, with a total of 558 participants. For this subset, we did not find evidence of a clear difference between the two treatments ( $\mathrm{RR} 2.23,95 \% \mathrm{Cl} 0.69$ to 7.22 ) (Analysis 1.11).

\subsubsection{0 fever}

We found 1 trial to be relevant to this subset, with a total of 130 participants. There was not a clear difference between 'risperidone' and 'placebo' within this subset (RR 9.28, 95\% Cl 0.51 to 168.9) (Analysis 1.11).

\subsubsection{1 infection}

We found 1 trial to be relevant to this subset, with a total of 202 participants. There was not a clear difference between 'risperidone' and 'placebo' within this subset (RR $0.52,95 \% \mathrm{Cl} 0.10$ to 2.78) (Analysis 1.11).

\subsubsection{2 salivation - increased}

There was a single trial in this subset, with a total of 202 participants. For this subset, we did not find evidence of a clear difference between the two treatments (RR $7.28,95 \% \mathrm{Cl} 0.38$ to 139.15) (Analysis 1.11).

\subsubsection{3 pyrexia}

We found 1 trial to be relevant to this subset, with a total of 182 participants. For this subset, we did not find evidence of a clear difference between the two treatments (RR 1.19, 95\% Cl 0.45 to 3.16) (Analysis 1.11).

\subsubsection{4 pain}

There was a single trial in this subset, with a total of 121 participants. There was not a clear difference between 'risperidone' and 'placebo' within this subset (RR $1.58,95 \% \mathrm{Cl} 0.47$ to 5.31 ) (Analysis 1.11).

\subsubsection{5 rash (skin)}

There was a single trial in this subset, with a total of 202 participants. There was not a clear difference between 'risperidone' and 'placebo' within this subset (RR $1.19,95 \% \mathrm{Cl} 0.45$ to 3.16) (Analysis 1.11).

\subsubsection{6 vaginitis}

There was a single trial in this subset, with a total of 58 participants. For this subset, we did not find evidence of a clear difference between the two treatments (RR $1.07,95 \% \mathrm{Cl} 0.07$ to 16.32) (Analysis 1.11).

\subsection{Adverse effects: 3. cardiovascular - short term (up to 12 weeks)}

For this outcome we found four relevant studies and categorised data into seven subsets.

\subsection{1 dizziness - orthostatic}

There was a single trial in this subset, with a total of 44 participants. For this subset, we did not find evidence of a clear difference between the two treatments (RR 3.0, 95\% Cl 0.13 to 69.87) (Analysis 1.12). 


\subsubsection{ECG abnormal}

We found 1 trial to be relevant to this subset, with a total of 182 participants. There was not a clear difference between 'risperidone' and 'placebo' within this subset (RR 9.40, 95\% Cl 0.51 to 172.11) (Analysis 1.12).

\subsection{3 heart rate decreased}

We found 1 trial to be relevant to this subset, with a total of 182 participants. There was not a clear difference between 'risperidone' and 'placebo' within this subset (RR $0.52,95 \% \mathrm{Cl} 0.05$ to 5.66) (Analysis 1.12).

\subsection{4 heart rate increased}

There was a single trial in this subset, with a total of 182 participants. There was not a clear difference between 'risperidone' and 'placebo' within this subset (RR $0.85,95 \% \mathrm{Cl} 0.37$ to 1.96 ) (Analysis 1.12).

\subsection{5 hypotension - postural}

There was a single trial in this subset, with a total of 44 participants. For this subset, we did not find evidence of a clear difference between the two treatments (RR $3.00,95 \% \mathrm{Cl} 0.13$ to 69.87) (Analysis 1.12).

\subsection{6 corrected QT interval > 450 milliseconds or $>10 \%$ increase from baseline}

We found 2 trials to be relevant to this subset, with a total of 380 participants. We found evidence of a clear difference between 'risperidone' and 'placebo' within this subset (RR 8.46, 95\% Cl 1.07 to 67.07 ) (Analysis 1.12).

\subsection{7 tachycardia}

We found 2 trials to be relevant to this subset, with a total of 332 participants. We found evidence of a clear difference between 'risperidone' and 'placebo' within this subset (RR 12.22, 95\% Cl 2.33 to 64.1) (Analysis 1.12).

\subsection{Adverse effects: 4. central nervous system - short term (up to 12 weeks)}

We identified ten studies relevant to this outcome, the data from which we divided into eight subsets.

\subsection{1 agitation}

There were 8 relevant trials in this subset, with a total of 1388 participants. For this subset, we did not find evidence of a clear difference between the two treatments (RR $0.93,95 \% \mathrm{Cl} 0.75$ to 1.17) (Analysis 1.13).

\subsection{2 anxiety}

We found 6 trials to be relevant to this subset, with a total of 1225 participants. There was not a clear difference between 'risperidone' and 'placebo' within this subset (RR $1.04,95 \% \mathrm{Cl} 0.73$ to 1.48) (Analysis 1.13).

\subsection{3 dizziness}

There were 5 relevant trials in this subset, with a total of 970 participants. There was not a clear difference between 'risperidone' and 'placebo' within this subset (RR $1.41,95 \% \mathrm{Cl} 0.65$ to 3.05 ). This subset had moderate levels of heterogeneity $\left(\mathrm{Chi}^{2}=7.37 ; \mathrm{df}=4.0 ; \mathrm{P}\right.$ $=0.12 ; 1^{2}=46 \%$ ) (Analysis 1.13).

\subsection{4 headache}

We found 10 trials to be relevant to this subset, with a total of 1905 participants. For this subset, we did not find evidence of a clear difference between the two treatments (RR $0.99,95 \% \mathrm{Cl} 0.81$ to 1.21) (Analysis 1.13).

\subsection{5 insomnia}

We found 10 trials to be relevant to this subset, with a total of 1905 participants. There was not a clear difference between 'risperidone' and 'placebo' within this subset (RR $1.16,95 \% \mathrm{Cl} 0.97$ to 1.39) (Analysis 1.13).

\subsection{6 sedation}

There were two trials in this subset, with a total of 517 participants. For this subset, we did not find evidence of a clear difference between the two treatments (RR 1.84, 95\% Cl 0.52 to 6.50) (Analysis 1.13).

\subsection{7 somnolence}

We found 6 trials to be relevant to this subset, with a total of 951 participants. We found evidence of a clear difference between 'risperidone' and 'placebo' within this subset (RR 1.61, 95\% Cl 1.06 to 2.45 ) (Analysis 1.13).

\subsection{8 restlessness}

There were two trials in this subset, with a total of 619 participants. For this subset, we did not find evidence of a clear difference between the two treatments (RR 1.16, 95\% Cl 0.49 to 2.74) (Analysis 1.13).

\subsection{Adverse effects: 5 . endocrine - serum prolactin increase above reference range $(23 \mathrm{ng} / \mathrm{ml}$ ) - short term (up to 12 weeks)}

For this outcome we found 2 relevant studies, with a total of 323 participants. There were no subsets in this outcome. We found evidence of a clear difference between 'risperidone' and 'placebo' (RR 12.14, 95\% Cl 4.38 to 33.68). For this outcome heterogeneity was high $\left(\mathrm{Chi}^{2}=2.14 ; \mathrm{df}=1.0 ; \mathrm{P}=0.14 ; \mathrm{I}^{2}=53 \%\right)$.

\subsection{Adverse effects: 6 . gastrointestinal system - short term (up to 12 weeks)}

For this outcome we found ten relevant studies and categorised data into six subsets.

\subsection{1 constipation}

We found 8 trials to be relevant to this subset, with a total of 1695 participants. We found evidence of a clear difference between 'risperidone' and 'placebo' within this subset (RR 1.88, 95\% Cl 1.19 to 2.96) (Analysis 1.15).

\subsection{2 diarrhoea}

There was a single trial in this subset, with a total of 202 participants. For this subset, we did not find evidence of a clear difference between the two treatments ( $R R 0.92,95 \% \mathrm{Cl} 0.37$ to 2.3 ) (Analysis 1.15). 


\subsection{3 dry mouth}

We found 1 trial to be relevant to this subset, with a total of 202 participants. There was not a clear difference between 'risperidone' and 'placebo' within this subset (RR $2.43,95 \% \mathrm{Cl} 0.65$ to 9.12) (Analysis 1.15).

\subsection{4 dyspepsia}

There were 5 relevant trials in this subset, with a total of 1058 participants. There was not a clear difference between 'risperidone' and 'placebo' within this subset (RR $1.24,95 \% \mathrm{Cl} 0.64$ to 2.40 ) (Analysis 1.15).

\subsection{5 nausea}

There were 6 relevant trials in this subset, with a total of 1225 participants. There was not a clear difference between 'risperidone' and 'placebo' within this subset (RR $1.18,95 \% \mathrm{Cl} 0.75$ to 1.86 ) (Analysis 1.15).

\subsection{6 vomiting}

There were 5 relevant trials in this subset, with a total of 1181 participants. There was not a clear difference between 'risperidone' and 'placebo' within this subset (RR $1.16,95 \% \mathrm{Cl} 0.65$ to 2.07) (Analysis 1.15).

\subsection{Adverse effects: 7a. metabolic - weight gain - short term (up to 12 weeks)}

For this outcome we found six relevant studies, the data from which we divided into two subsets.

\subsection{1 any gain}

We found 3 trials to be relevant to this subset, with a total of 910 participants. For this outcome, within this subset, we did find evidence that 'risperidone' was clearly different in its effects compared with 'placebo' (RR 3.77, 95\% Cl 1.34 to 10.63) (Analysis 1.16).

\subsection{2 > 7\% increase from baseline}

We found 3 trials to be relevant to this subset, with a total of 606 participants. For this outcome, within this subset, we did find evidence that 'risperidone' was clearly different in its effects compared with 'placebo' (RR $3.47,95 \% \mathrm{Cl} 1.64$ to 7.33 ) (Analysis 1.16).

\subsection{Adverse effects: 7b. metabolic - skewed data - average change value on lipid profile - short term (up to 12 weeks)}

These continuous data (two RCTs) had such large SDs as to suggest that analysis within RevMan would be inadvisable. Therefore, we presented them in an separate table (Analysis 1.17).

\subsection{Adverse effects: 8. musculoskeletal system - short term (up to 12 weeks)}

We identified one study relevant to this outcome and categorised data into two subsets.

\subsection{1 myalgia}

We found 1 trial to be relevant to this subset, with a total of 202 participants. There was not a clear difference between 'risperidone' and 'placebo' within this subset (RR $0.69,95 \% \mathrm{Cl} 0.12$ to 4.06 ). (Analysis 1.18).

\subsection{2 joint disorder}

We found 1 trial to be relevant to this subset, with a total of 202 participants. For this subset, we did not find evidence of a clear difference between the two treatments (RR 2.6, 95\% Cl 0.52 to 13.1) (Analysis 1.18).

\subsection{Adverse effects: 9. physiology - short term (up to 12 weeks)}

For this outcome we found two studies and categorised data into four subsets.

\subsection{1 alanine aminotransferase increased}

There was a single trial in this subset, with a total of 182 participants. For this subset, we did not find evidence of a clear difference between the two treatments (RR 1.04, 95\% Cl 0.07 to 16.45) (Analysis 1.19).

\subsection{2 aspartate aminotransferase increased}

There was a single trial in this subset, with a total of 182 participants. No increase occured in either group. (Analysis 1.19).

\subsection{3 blood creatine phosphokinase increased}

We found 2 trials to be relevant to this subset, with a total of 619 participants. For this subset, we did not find evidence of a clear difference between the two treatments (RR $0.67,95 \% \mathrm{Cl} 0.23$ to 1.95) (Analysis 1.19).

\subsection{4 blood pressure increased}

There was a single trial in this subset, with a total of 182 participants. There was not a clear difference between 'risperidone' and 'placebo' within this subset (RR $1.04,95 \% \mathrm{Cl} 0.15$ to 7.26 ) (Analysis 1.19).

\subsection{Adverse effects: 10 . respiratory system - short term (up to 12 weeks)}

For this outcome we found four relevant studies and categorised data into three subsets.

\subsection{1 upper respiratory infection}

There were 2 relevant trials in this subset, with a total of 323 participants. We found evidence of a clear difference between 'risperidone' and 'placebo' within this subset (RR 2.83, 95\% Cl 1.03 to 7.74 ) (Analysis 1.20).

\subsection{2 pharyngitis}

There was a single trial in this subset, with a total of 202 participants. For this subset, we did not find evidence of a clear difference between the two treatments (RR $0.42,95 \% \mathrm{Cl} 0.08$ to 2.1 ) (Analysis 1.20).

\subsection{3 rhinitis}

There were 2 relevant trials in this subset, with a total of 306 participants. For this outcome, within this subset, we found evidence that 'risperidone' was clearly different in its effects compared with 'placebo' (RR 10.81, 95\% $\mathrm{Cl} 2.58$ to 45.29) (Analysis 1.20). 


\subsubsection{Sinusitis}

There were 1 relevant trial in this subset, with a total of 437 participants. For this outcome, we did not find evidence of a clear difference between the two treatments (RR 1.04, 95\% Cl 0.09 to 11.36) (Analysis 1.20).

\section{COMPARISON 2: RISPERIDONE plus CLOZAPINE versus PLACEBO plus CLOZAPINE}

This particular comparison had 23 outcomes.

2.1 Mental state: no clinically significant response in psychotic symptoms (defined by PANSS/BPRS $<20 \%$ decline) - short term (up to 12 weeks)

For this outcome two relevant studies found no clear difference between treatments ( 2 RCTS, $\mathrm{N}=98, \mathrm{RR} 1.15,95 \% \mathrm{Cl} 0.93$ to 1.42 Analysis 2.1)

\subsection{Leaving the study early - short term (up to 12 weeks)}

For this outcome we found three relevant studies and categorised data into nine subsets.

\subsection{1 any reason}

We found 3 trials to be relevant to this subset, with a total of 167 participants. For this subset, we did not find evidence of a clear difference between the two treatments (RR $1.13,95 \% \mathrm{Cl} 0.53$ to 2.42) (Analysis 2.2).

\subsection{2 due to adverse events}

There were 2 relevant trials in this subset, with a total of 137 participants. There was not a clear difference between 'risperidone plus clozapine' and 'placebo plus clozapine' within this subset (RR $4.11,95 \% \mathrm{Cl} 0.47$ to 36.24 ) (Analysis 2.2).

\subsection{3 due to lack of efficacy}

We found 1 trial to be relevant to this subset, with a total of 69 participants. There was not a clear difference between 'risperidone plus clozapine' and 'placebo plus clozapine' within this subset (RR $0.55,95 \% \mathrm{Cl} 0.11$ to 2.78 ) (Analysis 2.2 ).

\subsection{4 due to noncompliance}

We found 1 trial to be relevant to this subset, with a total of 69 participants. For this subset, we did not find evidence of a clear difference between the two treatments (RR $0.36,95 \% \mathrm{Cl} 0.02$ to 8.61) (Analysis 2.2).

\subsection{5 lost to follow-up}

We found 1 trial to be relevant to this subset, with a total of 69 participants. For this subset, we did not find evidence of a clear difference between the two treatments (RR $0.36,95 \% \mathrm{Cl} 0.02$ to 8.61) (Analysis 2.2).

\subsection{6 reported death}

There was a single trial in this subset, with a total of 68 participants. No deaths were reported. (Analysis 2.2).

\subsection{7 withdrawal of consent}

There were 3 relevant trials in this subset, with a total of 167 participants. For this subset, we did not find evidence of a clear difference between the two treatments (RR $1.41,95 \% \mathrm{Cl} 0.28$ to 7.09) (Analysis 2.2).

\subsection{8 administrative reasons}

We found 1 trial to be relevant to this subset, with a total of 69 participants. For this subset, we did not find evidence of a clear difference between the two treatments (RR 5.44, 95\% Cl 0.27 to 109.34) (Analysis 2.2).

\subsection{9 abnormal lab results}

We found 1 trial to be relevant to this subset, with a total of 69 participants. For this subset, we did not find evidence of a clear difference between the two treatments (RR $0.36,95 \% \mathrm{Cl} 0.02$ to 8.61) (Analysis 2.2).

\subsection{Global state: 1. average endpoint scores of CGI severity scale (high = poor) - short term (up to 12 weeks)}

We identified 1 study relevant to this outcome involving 65 participants. This outcome had no subsets. We did not find evidence of a clear difference between the two treatments in this comparison (MD 0.51, 95\% $\mathrm{Cl} 0.02$ to 1.00 ).

\subsection{Global state: 2 . no significant clinical improvement - short term (up to 12 weeks)}

We identified 1 study relevant to this outcome, with a total of 68 participants. There were no subsets in this outcome. We did not find evidence of a clear difference between the two treatments in this comparison (RR 1.12, 95\% Cl 0.87 to 1.44 ) (Analysis 2.4).

\subsection{Global state: 3. general functioning - average endpoint GAF score $($ high $=$ good) - short term (up to 12 weeks)}

We identified 1 study relevant to this outcome involving 30 participants. This outcome had no subsets. We found evidence of a clear difference between 'risperidone plus clozapine' and 'placebo plus clozapine' (MD -4.50, $95 \% \mathrm{Cl}-8.38$ to -0.62 ) (Analysis 2.5).

\subsection{Mental state: 1. average endpoint scores on various scales on psychotic symptoms (high = poor) - short term (up to 12 weeks)}

For this outcome we found two relevant studies and categorised data into five subsets.

\subsubsection{PANSS total}

We found 2 trials to be relevant to this subset, with a total of 95 participants. We found evidence of a clear difference between 'risperidone plus clozapine' and 'placebo plus clozapine' within this subset (MD 5.56, 95\% Cl 1.59 to 9.53) (Analysis 2.6).

\subsubsection{PANSS general pathology}

There was a single trial in this subset, with a total of 30 participants. There was not a clear difference between 'risperidone plus clozapine' and 'placebo plus clozapine' within this subset (MD $2.50,95 \% \mathrm{Cl} 0.03$ to 4.97 ) (Analysis 2.6).

\subsubsection{PANSS delusion}

We found 1 trial to be relevant to this subset, with a total of 30 participants. There was not a clear difference between 'risperidone plus clozapine' and 'placebo plus clozapine' within this subset (MD $0.70,95 \% \mathrm{Cl} 0.09$ to 1.31 ) (Analysis 2.6 ). 


\subsubsection{PANSS negative symptom}

We found 2 trials to be relevant to this subset, with a total of 95 participants. For this subset, we did not find evidence of a clear difference between the two treatments (MD $0.69,95 \% \mathrm{Cl}-0.68$ to 2.05) (Analysis 2.6).

\subsubsection{PANSS positive symptom}

We found 2 trials to be relevant to this subset, with a total of 95 participants. For this subset, we did not find evidence of a clear difference between the two treatments (MD 2.30, 95\% Cl 0.98 to 3.62) (Analysis 2.6).

2.7 Mental state: 2 . average endpoint scores on various scales on psychotic symptoms (high = poor) - medium term (up to 26 weeks)

For this outcome we found a single study, the data from which we divided into four subsets.

\subsubsection{BPRS total}

We found 1 trial to be relevant to this subset, with a total of 53 participants. We found evidence of a clear difference between 'risperidone plus clozapine' and 'placebo plus clozapine' within this subset (MD -4.60, 95\% Cl -9.88 to 0.68) (Analysis 2.7).

\subsubsection{BPRS positive symptom}

There was a single trial in this subset, with a total of 53 participants. For this subset, we did not find evidence of a clear difference between the two treatments (MD $-0.90,95 \% \mathrm{Cl}-2.81$ to 1.01) (Analysis 2.7).

\subsubsection{BPRS anxiety/depression factor}

There was a single trial in this subset, with a total of 53 participants. We found evidence of a clear difference between 'risperidone plus clozapine' and 'placebo plus clozapine' within this subset (MD-1.00, $95 \% \mathrm{Cl}-2.80$ to 0.80 ) (Analysis 2.7).

\subsubsection{SANS total}

We found 1 trial to be relevant to this subset, with a total of 53 participants. There was not a clear difference between 'risperidone plus clozapine' and 'placebo plus clozapine' within this subset (MD $-3.10,95 \% \mathrm{Cl}-10.30$ to 4.10 ) (Analysis 2.7 ).

\subsection{Mental state: 3. skewed data - short term (up to 12 weeks)}

These continuous data (two RCTs) had such large SDs as to suggest that analysis within RevMan would be inadvisable. Therefore, we have presented them in a separate data table (Analysis 2.8).

\subsection{Adverse effects: 1a. extrapyramidal - average endpoint SAS score - short term (up to 12 weeks)}

For this outcome we found a single study. People in the risperidone + clozapine arm were less likely to experience extrapyramidal adverse events as reported on the SAS than those in the placebo + clozapine arm (1 RCT, N=30, MD $-0.9095 \% \mathrm{Cl}-1.97$ to 0.17 ) (Analysis 2.9).

\subsection{Adverse effects: 1b. extrapyramidal - skewed data} (various scales) - short term (up to 12 weeks)

These continuous data (two RCTs) had such large SDs as to suggest that analysis within RevMan would be inadvisable. Therefore, we have presented them in a separate data table (Analysis 2.10).

\subsection{Adverse effects: 1c. extrapyramidal - skewed data (various scales) - medium term (up to 26 weeks)}

These continuous data (one RCT) were too skewed to report in a graphic. Therefore, we have reported these data in a separate data table (Analysis 2.11).

\subsection{Adverse effects: 2 . any adverse event - short term (up to 12 weeks)}

We identified one study relevant to this outcome and categorised data into nine subsets.

\subsection{1 any adverse event}

We found 1 trial to be relevant to this subset, with a total of 64 participants. For this subset, we did not find evidence of a clear difference between the two treatments (RR $1.14,95 \% \mathrm{Cl} 0.83$ to 1.58) (Analysis 2.12).

\subsection{2 amenorrhoea}

There was a single trial in this subset, with a total of 64 participants. For this subset, we did not find evidence of a clear difference between the two treatments (RR 3.00, 95\% Cl 0.13 to 71.0 ) (Analysis 2.12).

\subsection{3 asthenia}

There was a single trial in this subset, with a total of 64 participants. There was not a clear difference between 'risperidone plus clozapine' and 'placebo plus clozapine' within this subset (RR $1.08,95 \% \mathrm{Cl} 0.61$ to 1.91 ) (Analysis 2.12 ).

\subsection{4 depression}

We found 1 trial to be relevant to this subset, with a total of 64 participants. There was not a clear difference between 'risperidone plus clozapine' and 'placebo plus clozapine' within this subset (RR $1.20,95 \% \mathrm{Cl} 0.61$ to 2.37 ) (Analysis 2.12 ).

\subsection{5 emotional indifference}

We found 1 trial to be relevant to this subset, with a total of 64 participants. There was not a clear difference between 'risperidone plus clozapine' and 'placebo plus clozapine' within this subset (RR $1.11,95 \% \mathrm{Cl} 0.52$ to 2.37 ) (Analysis 2.12).

\subsection{6 fatigue}

We found 1 trial to be relevant to this subset, with a total of 64 participants. For this subset, we did not find evidence of a clear difference between the two treatments (RR $1.08,95 \% \mathrm{Cl} 0.61$ to 1.91) (Analysis 2.12).

\subsection{7 failing memory}

There was a single trial in this subset, with a total of 64 participants. There was not a clear difference between 'risperidone plus clozapine' and 'placebo plus clozapine' within this subset (RR $0.67,95 \% \mathrm{Cl} 0.32$ to 1.41 ) (Analysis 2.12 ). 


\subsection{8 increased duration of sleep}

We found 1 trial to be relevant to this subset, with a total of 64 participants. There was not a clear difference between 'risperidone plus clozapine' and 'placebo plus clozapine' within this subset (RR $1.00,95 \% \mathrm{Cl} 0.51$ to 1.97 ) (Analysis 2.12 ).

\subsection{9 salivation - increased}

We found 1 trial to be relevant to this subset, with a total of 64 participants. For this subset, we did not find evidence of a clear difference between the two treatments (RR $1.25,95 \% \mathrm{Cl} 0.81$ to 1.94) (Analysis 2.12).

\subsection{Adverse effects: 3a. cardiovascular - short term (up to 12 weeks)}

For this outcome we found a single study and categorised data into three subsets (in keeping with our protocol).

\subsection{1 dizziness - orthostatic}

We found 1 trial to be relevant to this subset, with a total of 64 participants. There was not a clear difference between 'risperidone plus clozapine' and 'placebo plus clozapine' within this subset (RR $1.00,95 \% \mathrm{Cl} 0.43$ to 2.34 ) (Analysis 2.13).

\subsection{2 palpitation}

There was a single trial in this subset, with a total of 64 participants. For this subset, we did not find evidence of a clear difference between the two treatments (RR 1.00, 95\% Cl 0.27 to 3.66) (Analysis 2.13).

\subsection{3 tachycardia}

We found 1 trial to be relevant to this subset, with a total of 64 participants. There was not a clear difference between 'risperidone plus clozapine' and 'placebo plus clozapine' within this subset (RR $1.00,95 \% \mathrm{Cl} 0.27$ to 3.66 ) (Analysis 2.13 ).

\subsection{Adverse effects: 3b. cardiovascular - corrected QT interval - short term (up to 12 weeks)}

For this outcome we found a single study, with a total of 30 participants. There were no subsets in this outcome. We did not find evidence of a clear difference between the two treatments in this comparison (MD -19.70, 95\% Cl-42.08 to 2.68).

\subsection{Adverse effects: 4. central nervous system - short term (up to 12 weeks)}

For this outcome we found a single study and categorised data into three subsets.

\subsection{1 sedation}

There was a single trial in this subset, with a total of 64 participants. There was not a clear difference between 'risperidone plus clozapine' and 'placebo plus clozapine' within this subset (RR $1.46,95 \% \mathrm{Cl} 0.88$ to 2.43 ) (Analysis 2.15).

\subsection{2 somnolence}

We found 1 trial to be relevant to this subset, with a total of 64 participants. For this subset, we did not find evidence of a clear difference between the two treatments (RR 1.00, 95\% Cl 0.51 to 1.97) (Analysis 2.15).

\subsection{3 tension}

We found 1 trial to be relevant to this subset, with a total of 64 participants. For this subset, we did not find evidence of a clear difference between the two treatments (RR $1.23,95 \% \mathrm{Cl} 0.71$ to 2.12) (Analysis 2.15).

\subsection{Adverse effects: 5. gastrointestinal system - short term (up to 12 weeks)}

For this outcome we found a single study and categorised data into one subset.

\subsection{1 constipation}

We found 1 trial to be relevant to this subset, with a total of 64 participants. For this subset, we did not find evidence of a clear difference between the two treatments (RR $0.71,95 \% \mathrm{Cl} 0.25$ to 2.02) (Analysis 2.16).

\subsection{Adverse effects: 6a. haematological - short term (up to 12 weeks)}

We identified two studies relevant to this outcome and categorised data into three subsets.

\subsection{1 neutrophil count}

There was a single trial in this subset, with a total of 57 participants. For this subset, we did not find evidence of a clear difference between the two treatments (MD $0.37,95 \% \mathrm{Cl}-0.42$ to 1.16) (Analysis 2.17).

\subsection{2 prolactin level, $\mathrm{ng} / \mathrm{mL}$}

We found 1 trial to be relevant to this subset, with a total of 30 participants. For this outcome, within this subset, we did find evidence that 'risperidone plus clozapine' was clearly different in its effects compared with 'placebo plus clozapine' (MD 60.1, 95\% Cl 46.52 to 73.68 ) (Analysis 2.17).

\subsection{3 white cell count}

There was a single trial in this subset, with a total of 61 participants. For this subset, we did not find evidence of a clear difference between the two treatments (MD $0.66,95 \% \mathrm{Cl}-0.20$ to 1.52) (Analysis 2.17).

\subsection{Adverse effects: $6 \mathrm{~b}$. haematological - medium term (up to 26 weeks)}

For this outcome we found a single study, the data from which we divided into two subsets.

\subsection{1 prolactin level $\mathrm{ng} / \mathrm{mL}$}

There was a single trial in this subset, with a total of 44 participants. We found evidence of a clear difference between 'risperidone plus clozapine' and 'placebo plus clozapine' within this subset (MD 34.1, $95 \% \mathrm{Cl} 17.63$ to 50.57 ) (Analysis 2.18).

\subsection{2 fasting glucose}

There was a single trial in this subset, with a total of 40 participants. There was not a clear difference between 'risperidone plus clozapine' and 'placebo plus clozapine' within this subset (MD $-4.60,95 \% \mathrm{Cl}-17.09$ to 7.89 ) (Analysis 2.18). 
2.19 Adverse effects: 7 a. metabolic - weight gain - short term (up to 12 weeks)

There was a single trial in this subset, with a total of 64 participants. For this subset, we did not find evidence of a clear difference between the two treatments ( $R R 1.00,95 \% \mathrm{Cl} 0.40$ to 2.52) (Analysis 2.19).

\subsection{Adverse effects: 7a. metabolic - weight gain - medium term (up to 26 weeks)}

We found 1 trial to be relevant to this subset, with a total of 48 participants. There was not a clear difference between 'risperidone plus clozapine' and 'placebo plus clozapine' within this subset (RR $0.20,95 \% \mathrm{Cl} 0.01$ to 3.96 ) (Analysis 2.20).

2.21 Adverse effects: 7b. metabolic - average endpoint value on lipid profile - short term (up to 12 weeks)

For this outcome we found a single study and categorised data into four subsets.

\subsection{1 cholesterol - total $(\mathrm{mg} / \mathrm{dl})$}

We found 1 trial to be relevant to this subset, with a total of 56 participants. For this subset, we did not find evidence of a clear difference between the two treatments (MD $-6.60,95 \% \mathrm{Cl}-29.05$ to 15.85) (Analysis 2.21).

\subsection{2 high-density lipoprotein cholesterol ( $\mathrm{mg} / \mathrm{dl}$ )}

We found 1 trial to be relevant to this subset, with a total of 52 participants. For this subset, we did not find evidence of a clear difference between the two treatments (MD $0.00,95 \% \mathrm{Cl}-8.44$ to 8.44) (Analysis 2.21).

\subsection{3 low-density lipoprotein cholesterol (mg/dl)}

There was a single trial in this subset, with a total of 53 participants. There was not a clear difference between 'risperidone plus clozapine' and 'placebo plus clozapine' within this subset (MD $-6.90,95 \% \mathrm{Cl}-26.02$ to 12.22 ) (Analysis 2.21 ).

\subsection{4 triglycerides $(\mathrm{mg} / \mathrm{dl})$}

There was a single trial in this subset, with a total of 56 participants. For this subset, we did not find evidence of a clear difference between the two treatments (MD 6.20, 95\% Cl -57.57 to 69.97) (Analysis 2.21).

\subsection{Adverse effects: $7 c$. metabolic - average endpoint value -} short term (up to 12 weeks)

We identified two studies relevant to this outcome, the data from which we divided into four subsets.

\subsection{1 body mass index}

We found 1 trial to be relevant to this subset, with a total of 63 participants. There was not a clear difference between 'risperidone plus clozapine' and 'placebo plus clozapine' within this subset (MD $1.70,95 \% \mathrm{Cl}-0.99$ to 4.39 ) (Analysis 2.22 ).

\subsection{2 fasting glucose $(\mathrm{mg} / \mathrm{dl})$}

We found 1 trial to be relevant to this subset, with a total of 51 participants. There was not a clear difference between 'risperidone plus clozapine' and 'placebo plus clozapine' within this subset (MD $16.2095 \% \mathrm{Cl}-3.12$ to 35.52 ) (Analysis 2.22).

\subsection{3 waist circumference $(\mathrm{cm})$}

There was a single trial in this subset, with a total of 61 participants. There was not a clear difference between 'risperidone plus clozapine' and 'placebo plus clozapine' within this subset (MD $5.10,95 \% \mathrm{Cl}-4.14$ to 14.34 ) (Analysis 2.22 ).

\subsection{4 weight gain}

We found 2 trials to be relevant to this subset, with a total of 94 participants. For this subset, we did not find evidence of a clear difference between the two treatments (MD $0.34,95 \% \mathrm{Cl}-0.84$ to 1.53) (Analysis 2.22).

\subsection{Adverse effects: 8. sleep - skewed data - average change score (UKU) - short term (up to 12 weeks)}

These continuous data, from a single trial, had such large SDs as to suggest that analysis within RevMan would be inadvisable. Therefore, we have presented them in a separate data table (Analysis 2.23).

\subsection{Quality of life: average endpoint score (QLS, high = good) - short term (up to 12 weeks)}

We identified 1 study relevant to this outcome involving 30 participants. There were no subsets in this outcome. There was not a clear difference between 'risperidone plus clozapine' and 'placebo plus clozapine' (MD $0.80,95 \% \mathrm{Cl}-5.44$ to 7.04 ) (Analysis 2.24).

\section{COMPARISON 3: SENSITIVITY ANALYSIS: RISPERIDONE versus PLACEBO (based on attrition)}

This particular comparison had only one outcome.

\subsection{Mental state: 1. no clinically significant response (defined} by PANSS/BPRS) - short term (up to 12 weeks)

We identified six studies relevant to this outcome and categorised data into two subsets (in keeping with our protocol).

\subsection{1 defined by PANSS/BPRS $<20 \%$ decline}

We found 6 trials to be relevant to this subset, with a total of 864 participants. We found evidence of a clear difference between 'sensitivity analysis: risperidone' and 'placebo (based on attrition)' within this subset (RR $0.64,95 \% \mathrm{Cl} 0.52$ to 0.78 ). For this outcome heterogeneity was high $\left(\mathrm{Chi}^{2}=12.27 ; \mathrm{df}=5.0 ; \mathrm{P}=0.03 ; \mathrm{I}^{2}=59 \%\right)$ (Analysis 3.1).

\subsection{2 defined by PANSS/BPRS $<20 \%$ decline (without studies with $>50 \%$ leaving the study early)}

There were 3 relevant trials in this subset, with a total of 589 participants. We found evidence of a clear difference between 'sensitivity analysis: risperidone' and 'placebo (based on attrition)' within this subgroup (RR $0.77, \mathrm{Cl} 0.67$ to 0.88 ) (Analysis 3.1). 


\section{DISCUSSION}

\section{Summary of main results}

\section{COMPARISON 1: RISPERIDONE verSUS PLACEBO}

All of the included studies contributed data towards the comparison of risperidone versus placebo. Despite there being data from 15 studies in total, more often than not only a few studies contributed useable data towards each outcome. Most of the findings were based on few data, which in the majority of cases was of poor quality. The ratings within the Summary of findings table 1 reflect this, as we have judged the overall quality of evidence to be low or very low for each of the four main clinically relevant outcomes.

There is a clear difference in the treatment effect favouring risperidone group. Compared to placebo, people who received risperidone has a $36 \%$ risk reduction (very low quality of evidence) in not achieving clinically significant improvement in psychotic symptoms. The effect withstood, even when three studies with $>50 \%$ attrition rate were removed from the analysis ( $3 \mathrm{RCTs}, \mathrm{N}=589$, $\mathrm{RR} 0.77, \mathrm{Cl} 0.67$ to 0.88 ). Risperidone group also achieved greater reduction on BPRS score (a reduction of 12.69 compared to placebo group) and PANSS score (a reduction of 17.81 compared to placebo group). However the quality of evidence is compromised due to risk of bias of included studies, the slight heterogeneity and the involvement of industry sponsorship. Similarly, risperidone group are more likely to achieve significant clinical improvement than placebo group (a risk reduction of $31 \%$ in risperidone group, very low quality of evidence).

A variety of reasons have caused people to leave the study early, but most showed no clear difference between groups. However, placebo group had significantly more people left the study early due to lack of efficacy (a risk reduction of $61 \%$ if one receives risperidone, low quality evidence). Overall, risperidone group is $31 \%$ less likely to drop out early compared to placebo group (low quality evidence). The participants have also experienced a range of adverse events, but most had similar incidence rate between groups, but some clearly favoured placebo group including, EPS (1.56 times less likely compared to risperidone group), akathisia (2.58 times times less likely compared to risperidone group), hypertonia (2.98 times times less likely compared to risperidone group) and parkinsonism (7.64 times times less likely compared to risperidone group), somnolence (1.61 times times less likely compared to risperidone group), constipation (1.88 times less likely), weight gain (3.77 times less likely), upper respiratory infection (2.83 times less likely), rhinitis (10.81 times less likely).

\section{COMPARISON 2: RISPERIDONE plus CLOZAPINE versus PLACEBO plus CLOZAPINE}

When combined with clozapine, there was no obvious difference between groups in achieving clinically significant response in psychotic symptoms (low quality evidence). However, placebo plus clozapine group achieved greater reduction in PANSS score (MD = $5.56,95 \% \mathrm{Cl} 1.59$ to 9.53 ), while risperidone plus clozapine group appeared to produce more improvement in general functioning as assessed by GAF (MD $=-4.5,95 \% \mathrm{Cl}-8.38$ to -0.62 ). Participants left the study early for a variety of reasons, but none of which discriminated against any interventions (very low quality of evidence). Similarly, we did not find any clear difference in the adverse events experienced between groups.

\section{Overall completeness and applicability of evidence}

The review included 15 studies $(n=2428)$ of relatively short duration, between 8 and 16 weeks, hence limiting the applicability of the results of this review to long term use of risperidone. All participants in included trials were adults diagnosed with schizophrenia or schizoaffective disorder. The studies took place in both primary and secondary care settings, however, most were conducted in high income countries, hence the evidence should be applied with care in developing countries. There was a lack of data in included studies on the following outcome, including service utilisation and quality of life.

\section{Issue of placebo-controlled trials}

Placebo-controlled trials have been used as a licensing requirement by the US Food and Drug Administration (FDA) and other regulatory authorities for some time. Since 1964, the Helsinki Ethical Principles for Medical Research Involving Human Subjects WMA 2008 have been considered a benchmark for trialists around the world (WMA 2008). However, recently it has been argued that it is unethical to conduct trials involving placebo arms for conditions that have an established standard treatment. Also recently, the FDA has adopted the less rigorous Good Clinical Practice as an alternative to the Helsinki declaration, although this has invited numerous criticisms (Lurie 1997; Lurie 2005). Nevertheless, placebo trials do still have an important place, and some ethical bodies around the world do approve of trial methodologies with placebo arms. We suggest that the findings of this review support the continued need for placebo-controlled studies. risperidone is a widely used drug. That many of the effects of this compound are not that different from a placebo is important and would not have been highlighted but for the use of this type of study.

\section{Quality of the evidence}

The quality of reporting in most studies could have been much better (Figure 4). Well over half of the included studies have concerns in sequence generation and allocation concealment. There has also been some controversy over the trials conducted by Borison, with the author being accused of scientific fraud (see Included studies). Although, the trialists have not been found to have fabricated research data, this cast a shadow to the findings of his trials (AHRP 2006; CBS News 2000CBS News 2000 AHRP 2006).

Now, years after the first Consolidated Standards of Reporting Trials (CONSORT) statement (Begg 1996), it is expected that all relevant details of methodology that are likely to influence outcome, such as means of allocation and concealment of allocation, are documented and reported. Only 5 out of 13 studies provided information about sequence generation, and 3 out of 13 provided any details about allocation concealment. Good randomisation methodology is essential, and more so for smaller trials, as it ensures that confounding variables are as equally distributed as possible between the intervention and control groups. Poor quality or inadequate randomisation procedures would instead produce imbalance between groups in terms of participant selection and could potentially bias the result.

\section{Potential biases in the review process}

The authors of this review made every effort to minimise bias in the review process by strictly following the Cochrane Handbook and conduct expectations. The majority of data in this review 
were collected from published reports. Even though we identified substantial number of conference proceedings and unpublished reports, however, we were not able to extract much data from these reports due to either poor reporting or lack of collection at trial stage, therefore, could not be used in this review. For example, in some studies trialists reported mean without standard deviation. Our attempts to contact authors of trials for additional data were unsuccessful. This directly results in

\section{Omission of relevant data or studies}

As defined in our protocol, we had to omit efficacy measures from studies that had attrition rates of higher than $50 \%$ at study endpoint in a sensitivity analysis for our main outcomes. We are not sure if this is correct, but have identified no ready solution to the problem of missing data and when assumptions become too much and undermine credibility (Xia 2009). Certainly, high attrition rates, poor reporting, and poor methodology, combined with the rules we had set ourselves within our protocol, limited the information available for us to use. We feel that people can leave the trials for several reasons, most of which are not specified in the reports. Many studies carried the last observation of such people to the end of the trial period and used those data as if things stayed stable beyond leaving the study. This may or may not be correct but has gone untested. We have taken a conservative approach in presentation of the available data.

\section{Agreements and disagreements with other studies or reviews}

This review substantially updates the previous work in the area of risperidone. It also completes the series of direct comparison of risperidone with other drugs (Gilbody 2000; Hosalli 2003; Hunter 2003; Jayaram 2006; Kennedy 2000; Komossa 2007; Li 2009). The findings of this review were similar to the findings of other reviews involving risperidone.

\section{AUTHORS' CONCLUSIONS}

\section{Implications for practice}

\section{For people with schizophrenia}

Risperidone has a positive effect on the mental state of people with schizophrenia, but data in this review are of low to very low quality, suggesting that future research is very likely to have an important impact on our confidence in the estimate of effect and is likely to change the estimate.

\section{For clinicians}

While mental state and global state outcomes favoured risperidone, when used alone, there is a high amount of uncertainty regarding this these data and, even if credible, their direct clinical meaning is unclear. Due in large part to poor reporting, we are very uncertain about the effects of risperidone on adverse effects.

\section{For managers/policymakers}

We found some low quality evidence, which supported the efficacy of risperidone compared to placebo. Based on the same body of evidence, it appears risperidone also causes more adverse events than placebo, and from the available evidence, it is unclear if the benefit out weight the harm. In summary, there is insufficient evidence from this review to support preferential use of risperidone over placebo. Policymakers are encouraged to allocate resources to fund bigger trials with greater methodological quality.

\section{Implications for research}

\section{General}

Strict adherence to the CONSORT statement may well have resulted in this review having more data. Full availability of all data from each study could greatly help future review authors. Many of the studies included in this review did not always clearly present denominator data, did not mention allocation concealment, and frequently described results as "significant" without original data. Multiple publications is another concern. Authors of this review inspectd a large number of publications, which eventually were identified as salami publication of the same trial. Multiple publication poses a risk for reviewers, as if not discovered, the data could be double counted which inadvertently results in biased summary. If mutiple publication is unavoidable, quoting specific trial identifiers such as the International Standard Randomised Controlled Trial Number would greatly reduce confusion over identification of the source of trial.

\section{Specific}

Many excluded trials could find a place in new or existing systematic reviews, and although many of the 'risperidone versus (other antipsychotic)' reviews have been undertaken, there are many others still to do before a full overview of the effects of risperidone in every comparison is complete (Table 3 ).

More independent well-planned, well-conducted, and wellreported RCTs of longer duration are needed to address important, unanswered clinically relevant outcomes. In Table 4, we have a recommended study design for future trials. Even though we included 15 studies in this review, we could present few clinically meaningful results. As a result, we are uncertain of the short-, medium-, and long-term efficacy of using this popular treatment.

\section{ACKNOWLEDGEMENTS}

The Cochrane Schizophrenia Group Editorial Base in Nottingham, UK produces and maintains standard text for use in the Methods sections of their reviews. We have used this text as the basis of what appears here and adapted it as required. We wish to thank Julia Shaw for helpful comments on a draft of this review, and Michael Smith for carrying out the reliability checks of trial selection for the original version of this review.

Parts of this review were generated using RevMan HAL v 4.2. You can find more information about RevMan HAL here. 


\section{RE F E R E N C E S}

\section{References to studies included in this review}

Bachmann 2003 \{published data only\}

Bachmann M, Ramsey M, Buchanan RW, Conley RC, Weiner E. Clozapine treatment of schizophrenic patients. www.clinicaltrials.gov (accessed 9 October 2013). [NCT00056498]

\section{Borison 1992 \{published data only\}}

Borison R. Risperidone versus haloperidol versus placebo in the treatment of schizophrenia. Clinical report 1991.

\section{Chouinard 1992 \{published and unpublished data\}}

Chouinard G. Effects of risperidone in tardive dyskinesia: an analysis of the Canadian multicenter risperidone study. Journal of Clinical Psychopharmacology 1995;15(Suppl 1):S36-S44. [MEDLINE: 7537286]

Chouinard G, Albright PS. Economic and health state utility determinations for schizophrenic patients treated with risperidone or haloperidol. Journal of Clinical Psychopharmacology 1997;17(4):298-307. [MEDLINE: 9241010]

Chouinard G, Arnott W. An antidyskinetic effect of risperidone. 9th World Congress of Psychiatry; 1993 Jun 6-12; Rio de Janeiro, Brazil. 1993:22. [MEDLINE: 94350925]

Chouinard G, Arnott W. Antidyskinetic effect of risperidone in chronic schizophrenic patients. Clinical Neuropharmacology 1992;15(Suppl 1 Pt B):266. [MEDLINE: 94350925]

Chouinard G, Arnott W. The effect of risperidone on extrapyramidal symptoms in chronic schizophrenic patients. Biological Psychiatry 1992;31:158. [MEDLINE: 94350925]

* Chouinard G, Jones B, Remington G, Bloom D, Addington D, MacEwan GW, et al. A Canadian multicenter placebo-controlled study of fixed doses of risperidone and haloperidol in the treatment of chronic schizophrenic patients. Journal of Clinical Psychopharmacology 1993;13(1):25-40. [MEDLINE: 93253120]

Chouinard G, Vainer JL, Beauclair L. Dose regimens of neuroleptics in negative symptoms. 19th Collegium Internationale Neuro-Psychopharmacologicum Congress; 1994 Jun 27-Jul 1; Washington DC, USA 1994;10(3 Suppl 1):S363. [MEDLINE: 94350925]

\section{Downing 2014 \{published data only\}}

Downing A M, Kinon B J, Millen B A, Zhang L, Liu L, Morozova M $A$, et al. A double-blind, placebo-controlled comparator study of LY2140023 monohydrate in patients with schizophrenia. BMC Psychiatry 2014;14:351.

\section{Durgam 2014 \{published data only\}}

Durgam S, Starace A, Li D, Migliore R, Ruth A, Nemeth G, et al. An evaluation of the safety and efficacy of cariprazine in patients with acute exacerbation of schizophrenia: a phase II, randomized clinical trial. Schizophr Res 2014;152:450-7.
Geffen 2010 \{published data only\}

Geffen Y, Anand R, Keefe R, Davidson M. Results of phase 2b eagle trial; a double blind placebo control study evaluating the efficacy and safety of bl-1020, a gaba enhanced antipsychotic for the treatment of schizophrenia. Schizophrenia Research 2010;117(2-3):212.

\section{Heisterberg 2007 \{published data only\}}

Heisterberg J, Barbato LM, Yeung PP, Shapira NA. Lipid profile among patients with schizophrenia randomized to bifeprunox, placebo, or risperidone: a comparison of results. Schizophrenia Bulletin 2007;33(2):432-3.

Yeung PP, Barbato LM, Heisterberg J, Shapira NA. Changes in safety parameters in patients with schizophrenia treated with bifeprunox, placebo, or risperidone. Schizophrenia Bulletin 2007;33(2):466-7.

Yeung PP, Shapira NA, Heisterberg J. Changes in safety parameters in patients with schizophrenia treated with bifeprunox, placebo, or risperidone. Proceedings of the 11th International Congress on Schizophrenia Research; 2007 Mar 28-Apr 1, Colorado Springs, Colorado, USA. 2007.

\section{Honer 2006 \{published data only\}}

Honer W. International study of improving treatment for the most severely ill with schizophrenia. www.clinicaltrials.gov (accessed 9 October 2013). [NCT00272584]

Marder 1994a \{published and unpublished data\}

Ereshefsky L, Anderson C, True J, Saklad SR, Reisenman C, Toney G, et al. Plasma concentration of oral risperidone and active metabolite in schizophrenics. Pharmacotherapy 1993;13(3):292. [LMD96402]

Lindenmayer JP, The Risperidone Study Group. Incidence of EPS with risperidone compared with haloperidol and placebo in patients with chronic schizophrenia. 146th Annual Meeting of the American Psychiatric Association; 1993 May 22-27; San Francisco, California, USA. 1993. [MEDLINE: 94350925]

Marder S. Risperidone versus haloperidol versus placebo in the treatment of chronic schizophrenia. Clinical Research Report RIS-INT-3 1991. [MEDLINE: 1375802]

Marder SR. Risperidone: clinical development: North American results. Clinical Neuropharmacology 1992;15(Suppl 1 Pt A):92A-3A. [MEDLINE: 92361850]

Marder SR. Risperidone: efficacy. Journal of Clinical Psychiatry 1994;12:49-52. [MEDLINE: 94350925]

Marder SR, Davis JM, Chouinard G. The effects of risperidone on the five dimensions of schizophrenia derived by factor analysis: combined results of the North American trials. Journal of Clinical Psychological Medicine [\#\#\#\#\#\#\#] 1997;58(12):538-46.

* Marder SR, Meibach RC. Risperidone in the treatment of schizophrenia. American Journal of Psychiatry 1994;151(6):825-35. [EMBASE 1994202181] 
McEvoy JP. Efficacy of risperidone on positive features of schizophrenia. Journal of Clinical Psychiatry 1994;55(5 Suppl):18-21. [EMBASE 1994182002]

Meibach R. Risperidone versus haloperidol in acute exacerbations of chronic schizophrenia. 1st International Risperidone Investigators' Meeting; 1992 Mar 9-10; Paris, France. USA, 1992:28-9. [LMD94893]

Meibach RC, The Risperidone Study Group. A fixed dose, parallel group study of risperidone vs. haloperidol vs. placebo. Schizophrenia Research 1993;9(2,3):245. [MEDLINE: 94350925]

NCT00249132. Risperidone versus haloperidol versus placebo in the treatment of chronic schizophrenia. clinicaltrials.gov/show/ NCT00249132 (2005).

Schooler NR. Negative symptoms in schizophrenia: assessment of the effect of risperidone. Journal of Clinical Psychiatry 1994;55(Suppl 5):22-8. [MEDLINE: 94350925]

Simpson GM, Lindenmayer JP. Extrapyramidal symptoms in patients treated with risperidone. Journal of Clinical Psychopharmacology 1997;17(3):194-201. [MEDLINE: 97313564; PsycINFO 1997-06350-009]

\section{Pai 2002 \{published data only\}}

Bai YM, Yu SC, Lin CC. Risperidone for severe tardive dyskinesia: a 12-week randomized, double-blind, placebo-controlled study. Journal of Clinical Psychiatry 2003;64(11):1342-8.

Pai Y-M, Yu S-C, Lin C-C. Risperidone in reducing tardive dyskinesia: a double-blind, placebo-controlled study. Proceedings of the 154th Annual Meeting of the American Psychiatric Association; 2001 May 5-10; New Orleans, Louisiana, USA. Marathon Multimedia, 2001.

Pai Y-M, Yu S-C, Lin C-C. Risperidone in reducing tardive dyskinesia: a double-blind, placebo-controlled study. Proceedings of the 155th Annual Meeting of the American Psychiatric Association; 2002 May 18-23; Philadelphia, Pennsylvania, USA. 2002.

\section{Potkin 1997 \{published data only\}}

Potkin SG, Gutierrez R. Safety and efficacy of once-daily risperidone in the treatment of schizophrenia. Proceedings of the 150th Annual Meeting of the American Psychiatric Association; 1997 May 17-22; San Diego, California, USA. 1997.

Potkin 2003 \{published data only\}

Potkin SG, Kujawa M, Carson WH, Saha AR, Ali M, Ingenito G. Aripiprazole and risperidone versus placebo in schizophrenia and schizoaffective disorder. Schizophrenia Research 2003;60(1):300.

* Potkin SG, Saha AR, Kujawa MJ, Carson WH, Ali M, Stock E, et al. Aripiprazole, an antipsychotic with a novel mechanism of action, and risperidone vs placebo in patients with schizophrenia and schizoaffective disorder. Archives of General Psychiatry 2003;60(7):681-90.

Saha A, Carson W, Ali M, Dunbar G, Ingenito G. Efficacy and safety of aripiprazole and risperidone vs. placebo in patients with schizophrenia and schizoaffective disorder. Proceedings of the 7th World Congress of Biological Psychiatry; 2001 Jul 1-6; Berlin, Germany. 2001.

Yeung P, Kujawa M, Carson WH, Saha A, Alid M, Ingenito G. Aripiprazole and risperidone versus placebo in schizophrenia and schizoaffective disorder. Schizophrenia Research 2002;53(3 Suppl 1):185-6.

Yeung P, McQuade RD, Carson WH, Saha A, Ali MW, Ingenito G. Aripiprazole and risperidone versus placebo in schizophrenia. European Psychiatry 2002;17(Suppl 1):102s.

Yeung PP, Carson WH, Saha A, McQuade RD, Ali M, Stringfellow JC, et al. Efficacy of aripiprazole, a novel antipsychotic, in schizophrenia and schizoaffective disorder: results of a placebo-controlled trial with risperidone. European Neuropsychopharmacology 2001;11(3):259.

\section{Potkin 2006 \{published data only\}}

Gharabawi GM, Greenspan A, Rupnow MFT, Kosik-Gonzalez C, Bossie CA, Zhu Y, et al. Reduction in psychotic symptoms as a predictor of patient satisfaction with antipsychotic medication in schizophrenia: data from a randomized double-blind trial. BMC Psychiatry 2006;6(45):1-7.

Greenspan A, Kosik-Gonzalez C, Bossie C, Zhu Y, McLemore J, Gharabawi G. Atypical antipsychotics in patients with schizophrenia and comorbid substance abuse. Proceedings of the 158th Annual Meeting of the American Psychiatric Association; 2005 May 21-26; Atlanta, Georgia, USA. 2005:Nr279.

Greenspan A, Kosik-Gonzalez C, Moreau-Mallet V, Bossie CA, Rupnow MFT, Zhu Y, et al. Risperidone vs quetiapine in inpatients with schizophrenia: a double-blind placebocontrolled study. European Neuropsychopharmacology 2005;15(Suppl 3):S503.

NCT00061802. A randomized, double blind study to evaluate the efficacy and safety of two atypical antipsychotics vs placebo in patients with an acute exacerbation of either schizophrenia or schizoaffective disorder. clinicaltrials.gov/show/NCT00061802 (2003).

* Potkin SG, Gharabawi GM, Greenspan AJ, Mahmoud R, KosikGonzalez C, Rupnow MFT, et al. A double-blind comparison of risperidone, quetiapine and placebo in patients with schizophrenia experiencing an acute exacerbation requiring hospitalization. Schizophrenia Research 2006;85(1-3):254-65.

Potkin SG, Greenspan A, Kosik-Gonzalez C, Bossie C, Rupnow M, Zhu Y, et al. A placebo-controlled study of risperidone vs quetiapine for symptom response and readiness for discharge among agitated inpatients with schizophrenia. Schizophrenia Bulletin 2005;31:501.

Rupnow M, Greenspan A, Kosik-Gonzalez C, Bossie C, Zhu Y, Gharabawi G, et al. Polypharmacy in schizophrenia: data from a randomized, double-blind study. Proceedings of the 158th Annual Meeting of the American Psychiatric Association; 2005 May 21-26; Atlanta, Georgia, USA. 2005.

Stahl S, Rupnow M, Greenspan A, Kosik-Gonzalez C, Zhu Y, Gharabawi G. Use and cost of polypharmacy in schizophrenia: 
data from a randomized, double-blind study of risperidone and quetiapine. Neuropsychopharmacology 2004;29(Suppl 1):S227.

\section{Potkin 2007 \{published data only\}}

Potkin S, Fleming K, Binneman B, Keller DS, Alphs L, Panagides J. Asenapine improves cognitive function in acute schizophrenia: a placebo- and risperidone-controlled trial. Proceedings of the 160th Annual Meeting of the American Psychiatric Association; 2007 May 19-24; San Diego, CA 2007.

Potkin S, Fleming K, Binneman B, Keller S. Asenapine cognitive function effects in acute schizophrenia: a placeboand risperidone-controlled trial. Schizophrenia Bulletin 2007;33(2):454.

Potkin SG, Cohen M, Jina AS, Nettler S, Alphs L, Panagides J. Asenapine efficacy during acute episodes of schizophrenia: a randomized placebo and risperidone controlled trial. Proceedings of the 44th American College of Neuropsychopharmacology; 2005 December 11-15, Waikoloa, Hawaii 2005.

Potkin SG, Cohen M, Panagides J. Efficacy and tolerability of asenapine in acute schizophrenia: a placebo- and risperidone-controlled trial. Journal of Clinical Psychiatry 2007;68(10):1492-500.

* Potkin SG, Cohen M, Panagides J, Jina A. Asenapine safety and tolerability in acute schizophrenia: a placebo- and risperidone-controlled trial. European Neuropsychopharmacology 2006;16(Suppl 4):S401.

Potkin SG, Cohen M, Panagides J, Jina AS. Asenapine efficacy in acute schizophrenia: a randomized, placeboand risperidone-controlled trial. International Journal of Neuropsychopharmacology 2006;9(Suppl 1):S275.

Potkin SG, Cohen M, Panagides J, Jina AS. Asenapine efficacy, safety, and tolerability in the treatment of acute schizophrenia: a randomized, placebo- and risperidone-controlled trial. Biological Psychiatry 2006;59(8 Suppl):154S.

\section{Yagcioglu 2005 \{published data only\}}

Akdede BB, Anil Yaciolu AE, Alptekin K, Turgut TI, Tumuklu M, Yazici MK, et al. A double-blind study of combination of clozapine with risperidone in patients with schizophrenia: effects on cognition. Journal of Clinical Psychiatry 2006;67(12):1912-9.

Yagcioglu AE, Kivircik Akdede BB, Turgut TI, Tumuklu M, Yazici MK, Alptekin K, et al. A double-blind controlled study of adjunctive treatment with risperidone in schizophrenic patients partially responsive to clozapine: efficacy and safety. Journal of Clinical Psychiatry 2005;66(1):63-72.

\section{References to studies excluded from this review}

\section{Adler 1999 \{published data only\}}

Adler LA, Rotrosen J, Edson R, Lavori P, Lohr J, Hitzemann R, et al. Vitamin E treatment for tardive dyskinesia. Archives of General Psychiatry 1999;56(9):836-41.
Adler LA, Rotrosen J, Lavori P, Edson R. Vitamin E treatment of TD: development of a VA cooperative study. Biological Psychiatry 1994;35:730-1.

Caligiuri MP, Lohr JB, Rotrosen J, Adler L, Lavori P, Edson R, et al. Reliability of an instrumental assessment of tardive dyskinesia: results from VA Cooperative Study 394.

Psychopharmacology 1997;132(1):61-6.

\section{Akhondzadeh 2005 \{published data only\}}

Akhondzadeh S, Mackinejad K, Ahmadi-Abhari SA, Alem ZM. Does the addition of lamotrigine to risperidone improve psychotic symptoms and cognitive impairments in chronic schizophrenia?. Therapy 2005;2(3):399-406.

\section{Akhondzadeh 2007 \{published data only\}}

Akhondzadeh S, Tabatabaee M, Amini H, Ahmadi Abhari SA, Abbasi SH, Behnam B. Celecoxib as adjunctive therapy in schizophrenia: a double-blind, randomized and placebocontrolled trial. Schizophrenia Research 2007;90(1-3):179-85.

\section{Anwunah 1999 \{published data only\}}

Anwunah IJ, Mitropoulou V, Bushnoe L, Siever LJ. Risperidone treatment for schizotypal personality disorder. Proceedings of the 51st Institute on Psychiatric Services; 1999 Oct 25-Nov 2; New Orleans, Louisiana, USA. 1999.

\section{Ayd 2001 \{published data only\}}

Ayd FJ. Risperidone treatment for schizotypal personality disorder. International Drug Therapy Newsletter 2001;36(8):58.

\section{Azorin 2002 \{published data only\}}

Azorin J, Toumi M, Sloth-Nielsen M. Sertindole is well tolerated and superior to risperidone with respect to efficacy in patients with schizophrenia. Schizophrenia Research 2003;60(1):271-2.

Azorin JM, Toumi M, Sloth-Nielsen M. Sertindole is well tolerated and superior to risperidone with respect to efficacy in patients with schizophrenia. European Neuropsychopharmacology 2002;12(Suppl 3):S300.

\section{Azorin 2006 \{published data only\}}

Azorin J-M, Strub N, Loft H. A double-blind, controlled study of sertindole versus risperidone in the treatment of moderate-to-severe schizophrenia. International Clinical Psychopharmacology 2006;21(1):49-56.

\section{Bai 2005 \{published data only\}}

Bai Y-M, Yu S-C, Chen J-Y, Lin C-Y, Chou P, Lin C-C. Risperidone for pre-existing severe tardive dyskinesia: a 48-week prospective follow-up study. International Clinical Psychopharmacology 2005;20(2):79-85.

Bai Y-M, Yu S-C, Lin C-C. Risperidone for severe tardive dyskinesia: a 12-week randomized, double-blind, placebocontrolled study. Journal of Clinical Psychiatry 2003;64:1342-8.

Baker 2012 \{published data only\}

Baker RA, Jin N, Ali MW, Forbes RA, Offord SJ, Carson WH, Sanchez R, McQuade RD, Rahman Z. Long-term effects (up to 4 years) of aripiprazole on maintenance treatment for schizophrenia or schizoaffective disorder: A pooled open- 
label extension of two clinical trials. Schizophrenia research 2012;136:S154.

\section{Basson 2001 \{published data only\}}

Basson B, Kennedy J, Tollefson G, Tran P, Beasley C, Bymaster F. The comparative anti muscarinic like adverse event profiles of olanzapine and risperidone treatment in patients with schizophrenia spectrum psychosis. Proceeding of the 11th World Congress of Psychiatry; 1999 Aug 6-11; Hamburg, Germany. 1999.

Basson B, Kinon BJ, Gilmore JA, Taylor CC, Tollefson GD, Czekalla J. Factors influencing weight change in patients with schizophrenia treated with olanzapine verus haloperidol or risperidone. Journal of Psychopharmacology 2000;14(3 Suppl):A60.

Basson BR, Kennedy JS, Tran PV, Beasley CM, Bymaster FP, Tollefson GD. The comparative anti-muscarinic like side effect profiles of olanzapine and risperidone treatment in patients with schizophrenia spectrum psychosis. Schizophrenia Research 1999;36(1-3):270.

* Basson BR, Kinon BJ, Taylor CC, Szymanski KA, Gilmore JA, Tollefson GD. Factors influencing acute weight change in patients with schizophrenia treated with olanzapine, haloperidol, or risperidone. Journal of Clinical Psychiatry 2001;62(4):231-8.

\section{Beasley 1996 \{published data only\}}

Beasley C Jr, Tollefson GD, Beuzen JN, Dellva MA, Sanger TM, Paul S. Acute and long-term results of the North American double-blind olanzapine trial. Proceedings of the 4th International Conference on Schizophrenia: Breaking Down the Barriers; 1996 Oct 6-9; Vancouver, Canada. 1996.

Beasley C, Tran P, Beuzen JN, Tamura R, Dellva MA, Bailey J, et al. Olanzapine versus haloperidol: long-term results of the multi-center international trial. Proceedings of the 20th Collegium Internationale Neuro-Psychopharmacologicum Congress; 1996 Jun 23-27; Melbourne, Australia. 1996.

* Beasley C, Tran P, Satterlee W, Tollefson G, Lu Y, Kuntz A, et al. Olanzapine versus placebo, results of the United States doubleblind olanzapine trial. Proceedings of the 20th Collegium Internationale Neuro-Psychopharmacologicum Congress; 1996 Jun 23-27; Melbourne, Australia. 1996.

Beasley CM. Safety of olanzapine. Journal of Clinical Psychiatry 1997;15(2):19-21.

Beasley CM Jr, Sanger T, Satterlee W, Tollefson G, Tran P, Hamilton S. Olanzapine versus placebo - results of a doubleblind, fixed dose olanzapine trial. Psychopharmacology 1996;124(1-2):159-67.

Beasley CM, Berg PH, Dananberg J, Kwong KC, Taylor CCM, Breier A. Treatment-emergent potential impaired glucose tolerance and potential diabetes with olanzapine compared to other antipsychotic agents and placebo. Biological Psychiatry 2001;49(8):121S.
Beasley CM, Dellva MA, Tamura RN, Morgenstern H, Glazer WM, Ferguson $\mathrm{K}$, et al. A randomised double-blind comparison of the incidence of tardive dyskinesia in patients with schizophrenia during long-term treatment with olanzapine or haloperidol. British Journal of Psychiatry 1999;174:23-30.

Beasley CM, Hamilton SH, Crawford AM, Dellva MA, Tollefson GD, Tran PV, et al. Olanzapine versus haloperidol: acute phase results of the international double-blind olanzapine trial. European Neuropsychopharmacology 1997;7(2):125-37.

Beasley CM, Sayler ME, Keisler GM, Potvin JH, Sanger TM, Tollefson GD. The influence of pharamacotherapy on selfdirected and externally-directed aggression in schizophrenia. Schizophrenia Research 1998;29(1-2):28.

Beasley CM, Sowell MO, Carlson C, Mukhopadhyay N, Dananberg J, Henry R, et al. Prospective evaluation of insulin sensitivity by the hyperinsulinemic, euglycemic clamp in healthy volunteers treated with olanzapine, risperidone or placebo. Schizophrenia Research 2003;60(1):309.

Beasley CM, Sutton VK, Hamilton SH, Walker DJ, Dossenbach M, Taylor CC, et al. A double-blind, randomized, placebo-controlled trial of olanzapine in the prevention of psychotic relapse. Journal of Clinical Psychopharmacology 2003;23(6):582-94.

Beasley CM, Tollefson G, Tran P, Satterlee W, Sanger T, Hamilton S. Olanzapine versus placebo and haloperidol: acute phase results of the North American double-blind olanzapine trial. Neuropyschopharmacology 1996;14(2):111-23.

Beasley CM, Tollefson GD, Dellva MA, Tamura R, Glazer WM, Morgenstern $\mathrm{H}$. The differential risk of tardive dyskinesia with olanzapine. Proceedings of the 151st Annual Meeting of the American Psychiatric Association; 1998 May 30-Jun 4; Toronto, Ontario, Canada. 1998.

\section{Bondolfi 1998 \{published data only\}}

Bondolfi G, Baumann P, Dufour H. Treatment-resistant schizophrenia - clinical experience with new antipsychotics. European Neuropsychopharmacology 1996;6(Suppl 2):S21-5.

Bondolfi G, Baumann P, Patris M, May J, Billeter U, Dufour $\mathrm{H}$, et al. A randomized double-bind trial of risperidone versus clozapine for treatment-resistant chronic schizophrenia. Proceedings of the 8th European College of Neuropsychopharmacology Congress; 1995 Sep 30-Oct 4; Venice, Italy. 1995.

Bondolfi G, Baumann P, Patris M, May JP, Billeter U, Dufour H. A randomised double-blind trial of risperidone versus clozapine for treatment-resistant chronic schizophrenia. Proceedings of the 148th Annual Meeting of the American Psychiatric Association; 1995 May 20-25; Miami, Florida, USA. 1995.

Bondolfi G, Baumann P, Patris M, May JP, Billeter U, Dufour H. A randomized double-blind trial of risperidone versus clozapine for treatment-resistant chronic schizophrenia. Proceedings of the Workshop on Critical Issues in the Treatment of Schizophrenia; 1995 Mar 10-12; Florence, Italy. 1995. 
* Bondolfi G, Dufour H, Patris M, May JP, Billeter U, Eap CB, et al. Risperidone versus clozapine in treatment-resistant chronic schizophrenia: a randomized double-blind study. The Risperidone Study Group. American Journal of Psychiatry 1998;155(4):499-504.

\section{Borison 1992a \{published data only\}}

* Borison R. Risperidone versus haloperidol in acute exacerbations of chronic schizophrenia. Proceedings of the 1st International Risperidone Investigators' Meeting; 1992 Mar 9-10; Paris, France. 1992.

Borison R, Pathiraja A, Diamond B, Meibach R. Risperidone and schizophrenia. Biological Psychiatry 1991;29:417.

Borison RL, Diamond BI, Augusta GA. Serotonin modulation of dopaminergic-medicated extrapyramidal side effects. Neurology 1991;41(Suppl 1):396.

Borison RL, Diamond BI, Pathiraja A, Meibach RC. Clinical profile of risperidone in chronic schizophrenia. Proceedings of the 17th Collegium Internationale Neuro-Psychopharmacologicum Congress; 1990 Sep 10-14; Kyoto, Japan. 1991.

Borison RL, Pathiraja AP, Diamond BI, Meibach RC. Risperidone - clinical safety and efficacy in schizophrenia. Psychopharmacology Bulletin 1992;28(2):213-8.

Borison RL, Pathiraja AP, Diamond BI, Meibach RC. Risperidone in the treatment of acute exacerbation of chronic schizophrenia. Schizophrenia Research 1991;4(3):314-5.

Borison Rl, Pathiraja AP, Diamond BI, Meibach RC. Antidopaminergic and antiserotonergic actions of risperidone in schizophrenia. Biological Psychiatry 1991;29(Suppl):114a.

\section{Boyer 1995 \{published data only\}}

Boyer P, Lecrubier Y, Puech AJ. Treatment of positive and negative symptoms: pharmacologic approaches. In: Andreasen NC editor(s). Modern problems of pharmacopsychiatry. Vol. 24, Basel, Switzerland: S. Karger, 1990:152-74.

* Boyer P, Lecrubier Y, Puech AJ, Dewailly J, Aubin F. Treatment of negative symptoms in schizophrenia with amisulpride. British Journal of Psychiatry 1995;166(1):68-72.

Boyer P, Puech AJ. Determinants for clinical activity of neuroleptic drugs: chemical substances, doses, assessment tools [Modalities d'action clinique des neuroleptiques: substances, doses, instruments de mesure utilises]. Psychiatrie and Psychobiologie 1987;2(4):296-305.

Boyer P, Puech AJ, Lecrubier Y. Double blind trial versus placebo of low dose amisulpride (Solian 50) in schizophrenia with exclusively negative symptoms. Preliminary analysis of results [Etude en double insu contre placebo de l'amisulpride (Solian (r) 50) a faible dose chez des schizophrenes purement deficitaires. Premiere analyse des resultats]. Annales de Psychiatrie 1988;3(3):321-5.

\section{Brecher 1998 \{published data only\}}

Brecher M. Risperidone versus olanzapine in the treatment of patients with schizophrenia or schizoaffective disorder. Proceedings of the 11th European College of Neuropsychopharmacology Congress; 1998 Oct 31-Nov 4; Paris, France. 1998.

Brecher M, The Risperidone Olanzapine Study Group. Risperidone versus olanzapine in the treatment of patients with schizophrenia or schizoaffective disorder. Proceedings of the 21st Collegium Internationale Neuro-Psychopharmacologicum Congress; 1998 Jul 12-16; Glasgow, UK. 1998.

* Brecher M, The Risperidone-Olanzapine Study Group. Risperidone versus olanzapine in the treatment of patients with schizophrenia or schizoaffective disorder conference abstract. Schizophrenia Research 1999;36(1-3):271.

\section{Cada 2004 \{published data only\}}

Cada DJ, Levien T, Baker DE. Risperidone long-acting injection. Hospital Pharmacy 2004;39(4):353-62.

\section{Carson 2002 \{published data only\}}

Carson W, Cornblatt B, Saha A, Ali M, Kern R, Green M. Neurocognitive benefits of aripiprazole versus olanzapine in stable psychosis. European Neuropsychopharmacology 2002;12(Suppl 3):S291.

Carson W, McQuade R, Saha A, Torbeyns A, Stock E. Aripiprazole versus placebo for relapse prevention in patients with chronic schizophrenia. European Neuropsychopharmacology 2002;12(Suppl 3):S288.

Carson W, Pigott T, Saha A, Ali M, McQuade RD, Torbeyns AF, et al. Aripiprazole vs placebo in the treatment of stable, chronic schizophrenia. Proceedings of the 156th Annual Meeting of the American Psychiatric Association; 2003 May 17-22; San Francisco, California, USA. 2003.

Carson WH, Ali M, Dunbar G, Ingenito G, Saha AR. A doubleblind, placebo-controlled trial of aripiprazole and haloperidol. Schizophrenia Research 2001;49(1,2):221-2.

Carson WH, Ali M, Saha AR, Dunbar GC, Ingenito G. A doubleblind, placebo-controlled trial of aripiprazole and haloperidol in patients with schizophrenia or schizoaffective disorder. Proceedings of the 39th Annual Meeting of the American College of Neuropsychopharmacology; 2000 Dec 10-14; San Juan, Puerto Rico. 2000.

Carson WH, Ingenito GG, Mcquade RD, Stock EG, Iwamoto T. Schizophrenia: safety / tolerability of aripiprazole. Proceedings of the 12th World Congress of Psychiatry; 2002 Aug 24-29; Yokohama, Japan. 2002.

Carson WH, Kane JM, Ali M, Dunbar GC, Ingenito G. Efficacy of aripiprazole in psychotic disorders: comparison with haloperidol and placebo. European Neuropsychopharmacology 2000;10(Suppl 3):S309.

Carson WH, Pigott TA, Saha AR, Ali MW, McQuade RD, Torbeyns AF, et al. Aripiprazole vs placebo in the treatment of chronic schizophrenia. International Journal of Neuropsychopharmacology 2002;5(Suppl 1):S187.

Carson WH, Saha AR, Ali M, Dunbar GC, Ingenito G. Aripiprazole and risperidone versus placebo in schizophrenia and 
schizoaffective disorder. Proceedings of the 154th Annual Meeting of the American Psychiatric Association; 2001 May 5-10; New Orleans, Louisiana, USA. 2001.

* Carson WHJ, Saha AR, Ali M, Dunbar GC, Ingenito G. Aripiprazole and risperidone versus placebo in schizophrenia and schizoaffective disorder. Proceedings of the 155th Annual Meeting of the American Psychiatric Association; 2002 May 18-23; Philadelphia, Pennsylvania, USA. 2002.

\section{Casey 2003 \{published data only\}}

Casey D, Barbato LM, Heisterberg J, Yeung PP, Shapira NA. Results of a bifeprunox dose-finding study in patients with acutely exacerbated schizophrenia. Schizophrenia Bulletin 2007;33(2):425.

* Casey D, Saha A, Marcus R, Carson WH, McQuade RD, Torbeyns AF, et al. Aripiprazole versus placebo for relapse prevention in patients with chronic schizophrenia. Schizophrenia Research 2003;60(1):276.

Casey D, Saha AR, Ali MW, Jody DN, Kujawa MJ, Stock EG, et al. Switching to aripiprazole monotherapy. International Journal of Neuropsychopharmacology 2002;5(Suppl 1):S187.

Casey DE, Barbato LM, Heisterberg J, Yeung PP, Shapira NA. Results of a bifeprunox dose-finding study in patients with acutely exacerbated schizophrenia. Proceedings of the 11th International Congress on Schizophrenia Research; 2007 Mar 28-Apr 1, Colorado Springs, Colorado, USA 2007.

Casey DE, Carson WH, Saha AR, Liebeskind A, Ali MW, Jody D, et al. Switching patients to aripiprazole from other antipsychotic agents: A multicenter randomized study. Psychopharmacology 2003;166(4):391-9.

Casey DE, Daniel DG, Wassef AA, Tracy KA, Wozniak P, Sommerville KW. Effect of divalproex combined with olanzapine or risperidone in patients with an acute exacerbation of schizophrenia. Neuropyschopharmacology 2003;28(1):182-92.

Casey DE, Saha AR, Ali MW, Jody D, Kujawa MJ, Stock EG, et al. Switching to aripiprazole monotherapy. Proceedings of the 155th Annual Meeting of the American Psychiatric Association; 2002 May 18-23; Philadelphia, Pennsylvania, USA. 2002.

\section{Castle 2015 \{published data only\}}

Castle DJ, Jensen JKS. Management of depressive symptoms in schizophrenia: A pooled, post hoc analysis from the asenapine development program. Clinical Schizophrenia and Related Psychoses 2015;9:13-20.

\section{Chan 2007 \{published data only\}}

Chan H-Y, Lin W-W, Lin S-K, Hwang T-J, Su T-P, Chiang S-C, et al. Efficacy and safety of aripiprazole in the acute treatment of schizophrenia in Chinese patients with risperidone as an active control: a randomized trial. Journal of Clinical Psychiatry 2007;68(1):29-36.

\section{Chue 2002 \{published data only\}}

Chue P, Eerdekens M, Augustyns I, Lachaux B, Molcan P, Eriksson $\mathrm{L}$, et al. Comparative efficacy and safety of long- acting risperidone and risperidone oral tablets. European Neuropsychopharmacology 2005;15(1):111-7.

* Chue P, Eerdekens M, Augustyns I, Lachaux B, Molcan P, Eriksson L, et al. Efficacy and safety of long-acting risperidone microspheres and risperidone oral tables. Schizophrenia Research 2002;53(3 Suppl 1):174.

Chue P, Eerdekens M, Augustyns I, Lachaux B, Molcan P, Eriksson L, et al. Efficacy and safety of long-acting risperidone microspheres and risperidone oral tablets. Proceedings of the 11th Biennial Winter Workshop on Schizophrenia; 2002 Feb 24 Mar 1; Davos, Switzerland. 2002.

Chue P, Eerdekens M, Augustyns I, Lachaux B, Molcan P, Eriksson $\mathrm{L}$, et al. Maintenance of efficacy when switching from oral risperdal to risperdal consta RIS-INT-61. Poster supplied by Company 2002.

\section{Ciliberto 2005 \{published data only\}}

Ciliberto N, Bossie CA, Urioste R, Lasser RA. Lack of impact of race on the efficacy and safety of long-acting risperidone versus placebo in patients with schizophrenia or schizoaffective disorder. International Clinical Psychopharmacology 2005;20(4):207-12

\section{Citrome 2004 \{published data only\}}

* Citrome L, Casey DE, Daniel DG, Wozniak P, Kochan LD, Tracy KA. Adjunctive divalproex and hostility among patients with schizophrenia receiving olanzapine or risperidone. Psychiatric Services 2004;55(3):290-4.

Citrome LL, Daniel DG, Wassef AA, Tracy KA, Wozniak P, Casey DE. Antipsychotic monotherapy versus combination treatment with valporate in hospitalized patients with acute schizophrenia: a double-blind, multi-center study. Proceedings of the 155th Annual Meeting of the American Psychiatric Association; 2002 May 18-23; Philadelphia, Pennsylvania, USA. 2002.

\section{Claus 1992 \{published data only\}}

Claus A, Bollen J, De Cuyper H, Eneman M, Malfroid M, Peuskens J, et al. Risperidone versus haloperidol in the treatment of chronic schizophrenic inpatients: a multicentre double-blind comparative study. Acta Psychiatrica Scandinavica 1992;85(4):295-305.

\section{Conley 1998 \{published data only\}}

* Conley RR, Brecher M, The Risperidone/Olanzapine Study Group. Risperidone versus olanzapine in patients with schizophrenia or schizoaffective disorders. Proceedings of the 11th European College of Neuropsychopharmacology Congress; 1998 Oct 31-Nov 4; Paris, France. 1998.

Conley RR, Brecher MB, Olanzapine-Risperidone Study Group. Risperidone versus olanzapine in the treatment of patients with schizophrenia or schizoaffective disorder. Proceedings of the 152nd Annual Meeting of the American Psychiatric Association; 1999 May 15-20; Washington DC, USA. 1999.

Conley RR, Mahmoud R. A randomized double-blind study of risperidone and olanzapine in the treatment of schizophrenia or 
schizoaffective disorder. American Journal of Psychiatry 2001; Vol. 158, issue 5:765-74.

Conley RR, Mahmoud R. Efficacy of risperidone vs. olanzapine in the treatment of patients with schizophrenia or schizoaffective disorder. European Neuropsychopharmacology 2000;10(Suppl 3):S343. [13th Congress of the European College of Neuropsychopharmacology [CD-ROM]: Conifer, Excerpta Medica Medical Communications BV, 2000 P3021]

Conley RR, Mahmoud R. Efficacy of risperidone vs. olanzapine in the treatment of patients with schizophrenia or schizoaffective disorder. International Journal of Neuropsychopharmacology 2000;3(Suppl 1):S151.

Conley RR, Mahmoud R. Risperidone and olanzapine in people with schizophrenia or schizoaffective disorder: a randomised double-blind study. Poster supplied by Company 2001.

Conley RR, Mahmoud R. Risperidone vs olanzapine in patients with schizophrenia \& schizoaffective disorder. Proceedings of the 40th Annual Meeting of the New Clinical Drug Evaluation Unit; 2000 May 30-Jun 2; Boca Raton, Florida, USA. 2000.

Conley RR, Mahmoud R. Risperidone vs. olanzapine in the treatment of patients with schizophrenia or schizoaffective disorder: safety comparisons. European Neuropsychopharmacology 2000;10(Suppl 3):S342. [13th Congress of the European College of Neuropsychopharmacology [CD-ROM]: Conifer, Excerpta Medica Medical Communications BV, 2000 P3020]

Conley RR, Mahmoud R. Risperidone vs. olanzapine in the treatment of patients with schizophrenia or schizoaffective disorder: safety comparisons. International Journal of Neuropsychopharmacology 2000;3(Suppl 1):S151.

Conley RR, Mahmoud R, Risperidone Study Group. Risperidone versus olanzapine in patients with schizophrenia and schizoaffective disorder. Proceedings of the 10th Biennial Winter Workshop on Schizophrenia; 2000 Feb 5-11; Davos, Switzerland. 2000.

Conley RR, Mahmoud R, Risperidone Study Group. Risperidone versus olanzapine in patients with schizophrenia and schizoaffective psychosis [Risperidon versus olanzapin bei patienten mit schizophrenie und schizoaffektiven psychosen]. Nervenheilkunde 2000;19(5):110-2.

Conley RR, Mahmoud R, Risperidone Study Group. Risperidone vs. olanzapine in patients with schizophrenia and schizoaffective disorder. Biological Psychiatry 2000;47:32S.

Conley RR, Mahmoud RA. Risperidone versus olanzapine in patients with schizophrenia and schizoaffective disorder. 155th Annual Meeting of the American Psychiatric Association; 2002 May 18-23; Philadelphia, Pennsylvania, USA. 2002. [NR1 Monday, May 15, 9:00 a.m.-10:30 a.m]

Conley RR, Mahmoud RA. Risperidone versus olanzapine in patients with schizophrenia and schizoaffective disorder. Proceedings of the 153rd Annual Meeting of the American Psychiatric Association; 2000 May 13-18; Chicago, Illinois, USA. 2000.
Conley RR, Mahmoud RA. Risperidone vs olanzapine in patients with schizophrenia and schizo-affective disorder. International Drug Therapy Newsletter 2000;35(10):77-8.

\section{Cooper 1997 \{published data only\}}

* Cooper SJ, Butler A, Tweed J, Raniwalla J, Welch C. Zotepine in the prevention of relapse. Proceedings of the 6th World Congress of Biological Psychiatry; 1997 Jun 22-27; Nice, France. 1997.

Cooper SJ, Butler A, Tweed JA, Welch CP, Wighton AJ, Appleby P, et al. Zotepine is effective in preventing recurrence in patients with chronic schizophrenia. Proceedings of the 11th European College of Neuropsychopharmacology Congress; 1998 Oct 31Nov 4; Paris, France. 1998

Cooper SJ, Butler A, Tweed JA, Welch CP, Wighton AJ, Appleby $P$, et al. Zotepine is effective in preventing recurrence in patients with chronic schizophrenia. Schizophrenia Research 2000;41(1):207-8.

Cooper TB, Volavka J, Czobor P. Plasma drug level and clinical response. Journal of Clinical Psychopharmacology 1992;12(2):134-6.

\section{Cornblatt 2002 \{published data only\}}

Cornblatt B, Kern RS, Carson WH, Ali MW, Luo X, Green M. Neurocognitive effects of aripiprazole versus olanzapine in stable psychosis. International Journal of Neuropsychopharmacology 2002;5(Suppl 1):S185.

Cornblatt B, Kern RS, Carson WH, Stock E, Ali M, Ingenito G, et al. Neurocognitive effects of aripiprazole versus olanzapine in patients with stabile psychosis. Journal of Psychopharmacology 2002;16(Suppl 3):A15.

* Cornblatt B, Kern RS, Carson WH, Stock E, Ali M, Ingenito G, et al. Neurocognitive effects of aripiprazole versus olanzapine in patients with stable psychosis. Schizophrenia Research 2002;53(3 Suppl 1):27.

\section{Crawford 1997 \{published data only\}}

Crawford AM, Beasley CM, Tollefson GD. Olanzapine - impact of an atypical antipsychotic candidate on prolactin release. Proceedings of the 149th Annual Meeting of the American Psychiatric Association; 1996 May 4-9, New York, New York, USA. 1996.

Crawford AM, Beasley CM, Tollefson GD. The acute and long-term effect of olanzapine compared with placebo and haloperidol on serum prolactin concentrations. European Neuropsychopharmacology 1997;7(Suppl 2):199.

* Crawford AM, Beasley CM, Tollefson GD. The acute and long-term effect of olanzapine compared with placebo and haloperidol on serum prolactin concentrations. Schizophrenia Research 1997;26(1):41-54.

Crawford AMK, Beasley CM, Tollefson GD. The acute and long-term effect of olanzapine compared with placebo and haloperidol on serum prolactin concentration. Proceedings of the 10th European College of Neuropsychopharmacology Congress; 1997 Sep 13-17; Vienna, Austria. 1997. 
Crawford AMK, Gomez JC, Beasley CM Jr, Tollefson GD. Olanzapine versus haloperidol: analysis of schizophrenic patients from the multi-center international trial. European Neuropsychopharmacology 1997;7:2.015.

\section{Csernansky 1999 \{published data only\}}

Csernansky J. Do novel antipsychotics optimize long term outcomes in schizophrenia. International Journal of Neuropsychopharmacology 2000;3(Suppl 1):S1.

* Csernansky J, Brecher M, Okamoto A. Risperidone vs haloperidol: relapse prevention in schizophrenia and schizoaffective disorders: a long-term double-blind comparison. Proceedings of the 11th World Congress of Psychiatry; 1999 Aug 6-11; Hamburg, Germany. 1999.

Csernansky J, Okamoto A. A long term double blind comparison of risperidone and haloperidol in stable outpatients with schizophrenia or schizoaffective disorder. International Journal of Neuropsychopharmacology 2000;3(Suppl 1):S155.

Csernansky J, Okamoto A. Risperidone versus haloperidol for prevention of relapse in schizophrenia and schizoaffective disorders: long term double blind comparison.

Proceedings of the 22nd Collegium Internationale NeuroPsychopharmacologicum Congress; 2000 Jul 9-13; Brussels, Belgium. 2000.

Csernansky J, Okamoto A. Risperidone versus haloperidol for prevention of relapse in schizophrenia and schizoaffective disorders: long term double blind comparison. Schizophrenia Research 2000;41(1):198.

Csernansky JG, Mahmoud R, Brenner R, The RisperidoneUSA-79 Study Group. A comparison of risperidone and haloperidol for the prevention of relapse in patients with schizophrenia. The New England Journal of Medicine 2002;346(1):16-22.

Csernansky JG, Okamoto A. Risperidone versus haloperidol for prevention of relapse in patients with schizophrenia and schizoaffective disorder: a long-term double blind comparison. Proceedings of the 38th Annual Meeting of the American College of Neuropsychopharmacology; 1999 Dec 12-16; Acapulco, Mexico. 1999.

Csernansky JG, Okamoto A. Risperidone versus haloperidol for relapse prevention in schizophrenia and schizoaffective disorder: a long-term double-blind placebo controlled comparison. Proceedings of the 40th Annual Meeting of the New Clinical Drug Evaluation Unit; 2000 May 30-Jun 2; Boca Raton, Florida, USA. 2000

Csernansky JG, Okamoto A. Risperidone vs haloperidol for relapse prevention in schizophrenia and schizoaffective disorder: a long-term double-blind comparison. Biological Psychiatry 2000;47:31-2S.

Csernansky JG, Okamoto A, Brecher M. Risperidone vs haloperidol: prevention of relapse in schizophrenia. European Neuropsychopharmacology 1999;9:S268.

Csernansky JG, Okamoto A, Brecher MB. Risperidone versus haloperidol for prevention of relapse in schizophrenia and schizoaffective disorder: a long-term, double-blind comparison. Proceedings of the 51st Institute on Psychiatric Services; 1999 Oct 25-Nov 2; New Orleans, Louisiana, USA. 1999.

David 2000 \{published data only\}

David S, Crawford AM, Breier A. Prolactin levels in olanzapine versus typical and atypical antipsychotics. European Neuropsychopharmacology 1998;8(Suppl 2):s229.

David SR, Meehan KM, Sutton VK, Taylor CC. Treatment of negative symptoms with olanzapine in comparison with other novel antipsychotic agents. European Neuropsychopharmacology 1999;9:S292.

* David SR, Taylor CC, Kinon BJ, Breier A. The effects of olanzapine, risperidone, and haloperidol on plasma prolactin levels in patients with schizophrenia. Clinical Therapeutics 2000;22(9):1085-96.

\section{Davis 2001 \{published data only\}}

* Davis JM, Chen N. Evidence of efficacy of risperidone in schizophrenia. Schizophrenia Research 2001;49(1-2):224-5.

Davis SM, Koch GG, Davis CE, La Vange LM. Statistical approaches to effectiveness measurement and outcomedriven re-randomizations in the clinical antipsychotic trials of intervention effectiveness (CATIE) studies. Schizophrenia Bulletin 2003;29(1):73-80.

\section{Dossenbach 1997 \{published data only\}}

* Dossenbach M, Friedel P, Jakovljevic M, Hotujac L, Folnegovic V, Uglesic B, et al. Olanzapine versus fluphenazine six weeks' treatment of acute schizophrenia. Proceedings of the 10th European College of Neuropsychopharmacology Congress; 1997 Sep 13-17; Vienna, Austria. 1997.

Dossenbach M, Jakovljevic M, Folnegovic F, Uglesic B, Dodig G, Friedel $P$, et al. Olanzapine versus fluphenazine -6 weeks treatment of anxiety symptoms during acute schizophrenia. Schizophrenia Research 1998;29(1,2):203.

\section{Dubitsky 2002 \{published data only\}}

* Dubitsky GM, Harris R, Laughren T, Hardeman S. Abilify (aripiprazole) tablets; medical review part 1. www.fda.gov/ cder/foi/nda/2002/21-436_Abilify.htm 2002 (accessed 9 October 2013):1-50.

Dubitsky GM, Harris R, Laughren T, Hardeman S. Abilify (aripiprazole) tablets; medical review part 2. www.fda.gov/ cder/foi/nda/2002/21-436_Abilify.htm. U.S. Food and Drug Administration CDER, 2002 (accessed 9 October 2013):50-110.

Dubitsky GM, Harris R, Laughren T, Hardeman S. Abilify (aripiprazole) tablets; medical review part 3. www.fda.gov/ cder/foi/nda/2002/21-436_Abilify.htm. U.S. Food and Drug Administration CDER, 2002 (accessed 9 October 2013):111-75.

Dubitsky GM, Harris R, Laughren T, Hardeman S. Abilify (aripiprazole) tablets; medical review part 4. www.fda.gov/ cder/foi/nda/2002/21-436_Abilify.htm. U.S. Food and Drug Administration CDER, 2002 (accessed 9 October 2013):176-232. 


\section{Edgell 2000 \{published data only\}}

Edgell ET, Andersen SW, Grainger D, Wang J. Resource use and quality of life of olanzapine compared with risperidone: results from an international randomized clinical trial. Proceedings of the 21st Collegium Internationale NeuroPsychopharmacologicum Congress; 1998 Jul 12-16; Glasgow, UK. 1998

* Edgell ET, Andersen SW, Johnstone BM, Dulisse B, Revicki D, Breier A. Olanzapine versus risperidone: a prospective comparison of clinical and economic outcomes in schizophrenia. International Journal of Neuropsychopharmacology 2000;3(Suppl 1):S92.

Edgell ET, Andersen SW, Johnstone BM, Dulisse B, Revicki D, Breier A. Olanzapine versus risperidone: a prospective comparison of clinical and economic outcomes in schizophrenia. Pharmacoeconomics 2000;18(6):567-79.

Edgell ET, Andersen SW, Johnstone BM, Dulisse B, Revicki D, Breier A, et al. Olanzapine versus risperidone: a prospective comparison of clinical and economic outcomes in schizophrenia. European Psychiatry 2000;15(Suppl 2):408s.

Edgell ET, Grainger DL, Andersen SW, Wang J. Resource use and quality of life associated with olanzapine compared with risperidone. Proceedings of the 151st Annual Meeting of the American Psychiatric Association; 1998 May 30-Jun 4; Toronto, Ontario, Canada. 1998.

Edgell ET, Hamilton SH, Revicki DA, Genduso LA, Tollefson GD. Costs of olanzapine treatment compared with haloperidol for schizophrenia: results from a randomized clinical trial. Proceedings of the 21st Collegium Internationale NeuroPsychopharmacologicum Congress; 1998 Jul 12-6; Glasgow, UK. 1998.

\section{Fleming 2007a \{published data only\}}

Fleming K, Potkin SG, Binneman B, Keller D, Alphs L, Panagides J. Effects of asenapine on cognitive function in acute schizophrenia: a placebo- and risperidone-controlled trial. European Neuropsychopharmacology 2007;17(Suppl 4):S466.

\section{Friedman 2000 \{published data only\}}

* Friedman J, Adler D, Temporini H, Harvey P, Kemether E, Davis K. Alpha2 agonists enhance cognition of schizophrenia patients in combination with atypical but not typical neuroleptics. International Journal of Neuropsychopharmacology 2000;3(Suppl 1):S155.

Friedman JI, Adler D, Temporini HD, Harvey PD, Kemether EM, Davis KL. Alpha-2 agonists enhance cognition of schizophrenia patients in combination with atypical but not typical neuroleptics. Proceedings of the 155th Annual Meeting of the American Psychiatric Association; 2002 May 18-23; Philadelphia, Pennsylvania, USA. 2002.

Friedman JI, Adler DN, Howanitz E, Harvey PD, Brenner G, Temporini $\mathrm{H}$, et al. A double blind placebo controlled trial of donepezil adjunctive treatment to risperidone for the cognitive impairment of schizophrenia. Biological Psychiatry 2002;51:349-57.
Friedman JI, Adler DN, Howanitz E, Harvey PD, Brenner G, Temporini $\mathrm{H}$, et al. A double blind placebo controlled trial of donepezil adjunctive treatment to risperidone for the cognitive impairment of schizophrenia. Schizophrenia Research 2002;53(3 Suppl 1):9.

Friedman JI, Adler DN, Howanitz E, Temporini H, Harvey PD, Davis KL. Effects of donepezil on cognition, symptoms, and movement disorders in patients with chronic schizophrenia. Proceedings of the 39th Annual Meeting of the American College of Neuropsychopharmacology; 2000 Dec 10-14; San Juan, Puerto Rico. 2000.

Friedman JI, Adler DN, Temporini HD, Harvey PD, Davis KL. Alpha-2 agonists enhance cognition of schizophrenic patients in combination with atypical but not typical neuroleptics. Proceedings of the 38th Annual Meeting of the American College of Neuropsychopharmacology; 1999 Dec 12-16; Acapulco, Mexico. 1999.

Friedman JI, Adler DN, Temporini HD, Kemether E, Harvey PD, White L, et al. Guanfacine treatment of cognitive impairment in schizophrenia. Neuropyschopharmacology 2001;25(3):402-9.

NCT00488163. Pilot study of atomoxetine to enhance cognition in patients with schizophrenia. clinicaltrials.gov/show/ NCT00488163 (2007).

\section{Gismondi 2004 \{published data only\}}

Gismondi R, Meltzer H, Kujawa M, Carson W, Stringfellow J, Iwamoto T, et al. Aripiprazole versus perphenazine in treatmentresistant schizophrenia. Proceedings of the XXIVth Collegium Internationale Neuro-Psychopharmacologicum Congress; 2004 June 20-24, Paris, France 2004.

\section{Gregor 2000 \{published data only\}}

Gregor K, Hamilton S, Edgell E. Functional outcomes in schizophrenia: a European comparison of olanzapine and haloperidol. Proceedings of the 11th World Congress of Psychiatry; 1999 Aug 6-11; Hamburg, Germany. 1999.

* Gregor KJ, Allicar MP, Lilliu H, Olivier V, Le Pen C, Gavart S. An economic comparison of olanzapine versus haloperidol in the treatment of schizophrenia in France. International Journal of Neuropsychopharmacology 2000;3(Suppl 1):S161.

Gregor KJ, Hamilton SH, Edgell ET. Functional outcomes in schizophrenia: a European comparison of olanzapine and haloperidol. European Neuropsychopharmacology 1999;9/Suppl 1):S11.

Gregor KJ, Hamilton SH, Edgell ET. Functional outcomes in schizophrenia: a European comparison of olanzapine and haloperidol. European Neuropsychopharmacology 1999;9:S289.

Gregor KJ, Hamilton SH, Edgell ET. Functional outcomes in schizophrenia: a European comparison of olanzapine and haloperidol. Schizophrenia Research 2000;41(1):189.

\section{Harvey 2001 \{published data only\}}

Harvey K, Burns T, Sedgwick P, Higgitt A, Creed F, Fahy T. Relatives of patients with severe psychotic disorders: factors 
that influence contact frequency. Report from the UK700 trial. British Journal of Psychiatry 2001;178:248-54.

Harvey P, Meltzer H, Green M. Long term cognitive effects of risperidone treatment in schizophrenia. International Journal of Neuropsychopharmacology 2000;3(Suppl 1):S154.

Harvey P, Meltzer H, Green M. Risperidone cognitive effects in schizophrenia and schizoaffective patients. International Drug Therapy Newsletter 2001;36(8):59.

* Harvey P, Meltzer HY, Green MP. Cognitive effects of risperidone versus olanzapine in patients with schizophrenia or schizoaffective disorder. Proceedings of the 7th World Congress of Biological Psychiatry; 2001 Jul 1-6; Berlin, Germany. 2001.

Harvey P, Melzer H, Green M. Cognitive effects of risperidone and olanzapine in patients with schizophrenia or schizoaffective disorder. Biological Psychiatry 2001;49(8):123S.

Harvey PD. Cognitive effects of risperidone and olanzapine in patients with schizophrenia. Proceedings of the 52nd Institute on Psychiatric Services; 2000 Oct 25-29; Philadelphia, Pennsylvania, USA. 2000

Harvey PD. Cognitive effects of risperidone and olanzapine in patients with schizophrenia or schizoaffective disorder. Proceedings of the 153rd Annual Meeting of the American Psychiatric Association; 2000 May 13-18; Chicago, Illinois, USA. 2000.

Harvey PD. Long-term cognitive effects of risperidone treatment in schizophrenia. Proceedings of the 52nd Institute on Psychiatric Services; 2000 Oct 25-29; Philadelphia, Pennsylvania, USA. 2000.

Harvey PD, Gharabawi G. Risperidone and cognition in schizophrenic elderly. Proceedings of the 12th World Congress of Psychiatry; 2002 Aug 24-29; Yokohama, Japan. 2002.

Harvey PD, Green MF, McGurk SR, Meltzer HY. Changes in cognitive functioning with risperidone and olanzapine treatment: a large-scale, double-blind, randomized study. Psychopharmacology 2003;169(3-4):404-11.

Harvey PD, Lyons BE, Mahmoud R. Long term cognitive effects of risperidone. Schizophrenia Research 2000;41(1):200-1.

Harvey PD, Mahmoud R, Meltzer HY, Green MP. Cognitive effects of risperidone and olanzapine in patients with schizophrenia or schizoaffective disorder. European Neuropsychopharmacology 2001;11(3):257.

Harvey PD, Meltzer HY, Green M. Cognitive effects of risperidone and olanzapine in patients with schizophrenia or schizoaffective disorder. Proceedings of the 39th Annual Meeting of the American College of Neuropsychopharmacology; 2000 Dec 10-14; San Juan, Puerto Rico. 2000.

Harvey PD, Meltzer HY, Green MF. Cognitive effects of risperidone and olanzapine in patients with schizophrenia or schizoaffective disorder. Proceedings of the 40th Annual Meeting of the New Clinical Drug Evaluation Unit; 2000 May 30Jun 2; Boca Raton, Florida, USA. 2000.
Harvey PD, Meltzer HY, Green MF. Long-term cognitive effects of risperidone treatment in schizophrenia. Proceedings of the 39th Annual Meeting of the American College of Neuropsychopharmacology; 2000 Dec 10-14; San Juan, Puerto Rico. 2000.

\section{Hwang 2003 \{published data only\}}

Hwang TJ, Lee S-M, Sun HJ, Lin H-N, Tsai S-J, Lee Y-C, et al. Amisulpride versus risperidone in the treatment of schizophrenic patients: a double-blind pilot study in Taiwan. Journal of the Formosan Medical Association 2003;102(1):30-6.

Hwang 2005 \{published data only\}

Hwang TJ, Chan HY, Lin WW, Lin SK, Hwu HG, Cheng MY, et al. Aripiprazole versus risperidone in the treatment of acutely relapsed patients with schizophrenia in Taiwan: a randomized controlled trial. European Neuropsychopharmacology 2005;15(Suppl 3):S497.

\section{Kane 2005 \{published data only\}}

Kane J, Carson Wh, Kujawa M, Stringfellow J, Marcus R, Sanchez R, et al. Aripiprazole in treatment-resistant schizophrenia: a 6-week double-blind comparison study versus perphenazine. Schizophrenia Research 2004;67(1):155-6.

Kane J, Eerdekens M, Keith S, Lesem M, Karcher K, Lindenmayer J-P. Efficacy and safety of Risperdal Consta, a long-acting injection risperidone formulation RIS-USA-121. Promotional slides on file from Janssen-Cilag UK Ltd 2002.

Kane J, Eerdekens M, Keith S, Lesem M, Karcher K, Lindenmayer J-P. Efficacy and safety of a novel long-acting risperidone formulation. European Psychiatry 2002;17(Suppl 1):S193.

Kane J, Eerdekens M, Keith S, Lesem M, Karcher K, Lindenmayer J-P. Efficacy and safety of a novel long-acting risperidone microspheres formulation. Proceedings of the 11 th Biennial Winter Workshop on Schizophrenia; 2002 Feb 24-Mar 1; Davos, Switzerland. 2002.

Kane J, Eerdekens M, Keith S, Lesem M, Karcher K, Lindenmayer JP. Long-acting risperidone microspheres for treatment of patients with schizophrenia. European Neuropsychopharmacology 2001;11(3):291.

Kane J, Eerdekens M, Keith SJ, Lesem M, Karcher K, Lindenmayer JP. Efficacy and safety of risperdal constatm, the long-acting injection risperidone formulation. International Journal of Neuropsychopharmacology 2002;5(Suppl 1):S188.

Kane J, Ingenito G, Ali M. Efficacy of aripiprazole in psychotic disorders: comparison with haloperidol and placebo. Schizophrenia Research 2000;41(1):39.

Kane JM. Preventing morbidity in first-episode schizophrenia. clinicaltrials.gov/ct2/show/NCT00000374 (accessed 16 Feb 2001).

Kane JM. The latest advance in long-acting antipsychotic therapy. Proceedings of the 156th Annual Meeting of the American Psychiatric Association; 2003 May 17-22; San Francisco, California, USA. 2003. 
Kane JM, Carson WH, Saha AR, McQuade RD, Ingenito GG, Zimbroff DL, et al. Efficacy and safety of aripiprazole and haloperidol versus placebo in patients with schizophrenia and schizoaffective disorder. Journal of Clinical Psychiatry 2002;63(9):763-71.

Kane JM, Conley RR, Keith SJ, Nasrallah HA, Turner M. Guidelines for the use of long-acting injectable atypical antipsychotics. Journal of Clinical Psychiatry 2004;65(1):120-31.

Kane JM, Eerdekens M, Keith SJ, Lesem M, Karcher K, Lindenmayer J-P. Efficacy and safety of a novel long-acting risperidone microspheres formulation. Schizophrenia Research 2002;53(3 Suppl 1):174.

Kane JM, Eerdekens M, Keith SJ, Lesem M, Karcher K, Lindenmayer JP. Long-acting injectable risperidone: Efficacy and safety. European Neuropsychopharmacology 2002;12(Suppl 3):S325.

Kane JM, Eerdekens M, Lindenmayer JP, Keith SJ, Lesem M, Karcher K. Long-acting injectable risperidone: efficacy and safety of the first long-acting atypical antipsychotic. American Journal of Psychiatry 2003;160:1125-32.

Kane JM, Ingenito G, Ali M. Efficacy of aripiprazole in psychotic disorders: comparison with haloperidol and placebo. 155th Annual Meeting of the American Psychiatric Association; 2002 May 18-23; Philadelphia, Pennsylvania, USA. 2002. [NR345 Tuesday, May 16, 3:00 p.m.-5:00 p.m]

Kane JM, Ingenito G, Ali M. Efficacy of aripiprazole in psychotic disorders: comparison with haloperidol and placebo. International Journal of Neuropsychopharmacology 2000;3(Suppl 1):S124.

Kane JM, Ingenito G, Ali M. Efficacy of aripiprazole in psychotic disorders: comparison with haloperidol and placebo. Proceedings of the 153rd Annual Meeting of the American Psychiatric Association; 2000 May 13-18; Chicago, Illinois, USA. 2000.

* Kane JM, Potkin S, Buckley P, Daniel DG. Safety and efficacy of sertindole and risperidone in treatment resistant patients with schizophrenia. Schizophrenia Bulletin 2005;31:490.

Kane JM, William HCJ, Kujawa MJ, Stringfellow J, Marcus RN, Sanchez R, et al. Aripiprazole vs perphenazine in treatmentresistant schizophrenia. Proceedings of the 156th Annual Meeting of the American Psychiatric Association; 2003 May 17-22; San Francisco, California, USA. 2003.

\section{Kinon 1998 \{published data only\}}

Kinon B, Basson B, Malcolm S, Breier A. Strategies for switching from conventional antipsychotic drugs or risperidone to olanzapine. Proceedings of the 39th Annual Meeting of the New Clinical Drug Evaluation Unit; 1999 Jun 1-4; Boca Raton, Florida, USA. 1999.

Kinon B, Basson B, Tollefson GD. Gender-specific prolactin olanzapine versus haloperidol in schizophrenia. 151st Annual Meeting of the American Psychiatric Association; 1998 May 30Jun 4; Toronto, Ontario, Canada. 1998. [151st Annual Meeting of the American Psychiatric Association [CD-ROM]: MARATHON
Multimedia, 1988 NR449; 151st Annual Meeting of the American Psychiatric Association [CD-ROM]: MARATHON Multimedia, 1988 NR739]

Kinon B, Basson B, Tollefson GD. Gender-specific prolactin olanzapine versus haloperidol in schizophrenia. Proceedings of the 151st Annual Meeting of the American Psychiatric Association; 1998 May 30-Jun 4; Toronto, Ontario, Canada. 1998.

Kinon B, Basson BR, Malcolm SK, Tollefson G. Strategies for switching from conventional antipsychotic drugs to olanzapine. Proceedings of the 152nd Annual Meeting of the American Psychiatric Association; 1999 May 15-20; Washington, DC, USA. 1999.

Kinon B, Breier A, Malcolm S, Basson B. Strategies for switching from conventional antipsychotic drugs or risperidone to olanzapine. Proceedings of the 11th World Congress of Psychiatry; 1999 Aug 6-11; Hamburg, Germany. 1999.

Kinon BJ, Basson B, Hill AL, Berg PH. Effective resolution of acute presentation of behavioral agitation and positive psychotic symptoms in schizophrenia with olanzapine. European Neuropsychopharmacology 2000;10(Suppl 3):S305.

Kinon BJ, Basson B, Szymanski K, Tollefson GD. Predictors of weight gain during olanzapine treatment. Proceedings of the 11th European College of Neuropsychopharmacology Congress; 1998 Oct 31-Nov 4; Paris, France. 1998.

Kinon BJ, Basson B, Wang J, Malcolm SK. Rapid reduction in hyperprolactinemia upon switching treatment to olanzapine from conventional antipsychotic drugs or risperidone. Schizophrenia Research 2000;41(1):194-5.

Kinon BJ, Basson B, Wang J, Malcolm SK, Stauffer VL. Rapid reduction in hyperprolactinemia upon switching treatment to olanzapine from conventional antipsychotic drugs or risperidone. European Neuropsychopharmacology 2000;10(Suppl 3):S306.

Kinon BJ, Basson B, Wang J, Malcolm SK, Stauffer VL. Rapid reduction in hyperprolactinemia upon switching treatment to olanzapine from conventional antipsychotic drugs or risperidone. International Journal of Neuropsychopharmacology 2000;3(Suppl 1):S155.

Kinon BJ, Basson B, Wang J, Malcolm SK, Stauffer VL. Rapid reduction in hyperprolactinemia upon switching treatment to olanzapine from conventional antipsychotic drugs or risperidone. Proceedings of the 40th Annual Meeting of the New Clinical Drug Evaluation Unit; 2000 May 30-Jun 2; Boca Raton, Florida, USA. 2000.

Kinon BJ, Basson BR, Gilmore JA, Malcolm S, Stauffer VL. Strategies for switching from conventional antipsychotic drugs or risperidone to olanzapine. Journal of Clinical Psychiatry 2000;61(11):833-40.

Kinon BJ, Basson BR, Gilmore JA, Tollefson GD. Long-term olanzapine treatment: weight change and weight-related health factors in schizophrenia. Journal of Clinical Psychiatry 2001;62(2):92-100. 
Kinon BJ, Basson BR, Malcolm SK, Tollefson GD. Strategies for switching from conventional antipsychotic drugs or risperidone to olanzapine conference abstract. Schizophrenia Research 1999;36(1-3):285-6.

Kinon BJ, Basson BR, Wang J. Rapid reduction in hyperprolactinemia upon switching treatment to olanzapine from conventional antipsychotic drugs or risperidone. Proceedings of the 52nd Institute on Psychiatric Services; 2000 Oct 25-29; Philadelphia, Pennsylvania, USA. 2000.

Kinon BJ, Basson BR, Wang J, Malcolm SK, Stauffer VL. Rapid reduction in hyperprolactinemia. Proceedings of the 153rd Annual Meeting of the American Psychiatric Association; 2000 May 13-18; Chicago, Illinois, USA. 2000.

* Kinon BJ, Basson MS, Tollefson GD. Gender-specific prolactin response to treatment with olanzapine versus haloperidol in schizophrenia. Proceedings of the 9th Biennial Winter Workshop on Schizophrenia; 1998 Feb 7-13; Davos, Switzerland 1998.

Kinon BJ, Gilmore JA, Gottschalk LA. Continued improvement in quality of life despite weight change during olanzapine treatment. Proceedings of the 39th Annual Meeting of the American College of Neuropsychopharmacology; 2000 Dec 10-14; San Juan, Puerto Rico. 2000.

Kinon BJ, Liu-Seifert H, Ahl J, Ahmed S, Baker RW. Longitudinal effect of olanzapine on fasting serum lipids: a randomized, prospective, 4-month study. Annals of the New York Academy of Sciences 2004;1032:295-6.

Kinon BJ, Milton DR, Gilmore JA. Continued improvement in quality of life despite weight change during olanzapine treatment. International Journal of Neuropsychopharmacology 2000;3(Suppl 1):S154.

Kinon BJ, Milton DR, Hill AL. Effective resolution of acute presentation of behavioral agitation and positive psychotic symptoms in schizophrenia with olanzapine. International Journal of Neuropsychopharmacology 2000;3(Suppl 1):S154.

Kinon BJ, Milton DR, Hill AL, Williamson DJ. Effective resolution of acute presentation of behavioral agitation and positive psychotic symptoms in schizophrenia with olanzapine. Journal of Psychopharmacology 2000;14(3 Suppl):A60.

Kinon BJ, Roychowdhury SM, Milton DR, Hill AL. Effective resolution with olanzapine of acute presentation of behavioral agitation and positive psychotic symptoms in schizophrenia. Journal of Clinical Psychiatry 2001;62(Suppl 2):17-21.

\section{Kinon 2015 \{published data only\}}

Kinon BJ, Millen BA, Zhang L, McKinzie DL. Exploratory analysis for a targeted patient population responsive to the metabotropic glutamate $2 / 3$ receptor agonist pomaglumetad methionil in schizophrenia. Biological psychiatry 2015;InPress:InPress.

\section{Lauriello 2005 \{published data only\}}

Lauriello J, McEvoy JP, Rodriguez S, Bossie CA, Lasser RA. Long-acting risperidone vs. placebo in the treatment of hospital inpatients with schizophrenia. Schizophrenia Research 2005;72(2-3):249-58.

\section{Lemmens 1994 \{published data only\}}

Lemmens P, de Smedt G, Gheuens J, Tritsmans L. Efficacy of risperidone in the treatment of schizophrenia. Proceedings of the 7th Biennial Winter Workshop on Schizophrenia; 1994 Jan 23-28; Les Diablerets, Switzerland 1994; Vol. 11, issue 2:106.

\section{Lieberman 2005 \{published data only\}}

Lieberman J, McEnvoy J, Stroup S. Protocol: comparative effectiveness of antipsychotic medications in patients with schizophrenia: revised in response to DSMB comments. National Institute of Mental Health. Chapel Hill, USA: University of North Carolina, 2000.

Lieberman J, McEvoy J, Stroup S. Trial design summary: Comparative effectiveness of antipsychotic medications in patients with schizophrenia: Draft. National Institute of Mental Health. Chapel Hill, USA: University of North Carolina, 2002.

Lieberman J, McEvoy JP, Perkins D, Hamer RH. Comparison of atypicals in first-episode psychosis: a randomized, 52week comparison of olanzapine, quetiapine, and risperidone. European Neuropsychopharmacology 2005;15(Suppl 3):S525.

Lieberman JA. Comparative effectiveness of antipsychotic medications in patients with schizophrenia (CATIE schizophrenia trial). clinicaltrials.gov/ct2/show/NCT00014001 2001 (accessed 9 October 2013).

Lieberman JA. Research gaps and current research initiatives to improve the treatment of schizophrenia. Proceedings of the 156th Annual Meeting of the American Psychiatric Association; 2003 May 17-22; San Francisco, California, USA. 2003.

Lieberman JA, Schneider LS, McEroy J, Pariot P, Stroup S, Adiao J, et al. Effectiveness trials of antipsychotic drugs. 155th Annual Meeting of the American Psychiatric Association; 2002 May 18-23; Philadelphia, Pennsylvania, USA. 2002. [No. 103D]

Lieberman JA, Schneider LS, McEroy J, Pariot P, Stroup S, Adiao J, et al. Effectiveness trials of antipsychotic drugs. Proceeding of the 154th Annual Meeting of the American Psychiatric Association; 2001 May 5-10; New Orleans, Louisiana, USA. Marathon Multimedia, 2001.

Lieberman JA, Stroup TS. Schizophrenia, VI: treatments. American Journal of Psychiatry 2003;160(10):1748.

Lieberman JA, Stroup TS, McEvoy JP, Swartz MS, Keefe R, Perkins DO, et al. CATIE trial results. European Neuropsychopharmacology 2006;16(Suppl 4):S184.

* Lieberman JA, Stroup TS, McEvoy JP, Swartz MS, Rosenheck RA, Perkins DO, et al. Effectiveness of antipsychotic drugs in patients with chronic schizophrenia. The New England Journal of Medicine 2005;353(12):1209-23.

Lieberman JA, Tollefson G, Tohen M, Green AI, Gur RE, Kahn R, et al. Comparative efficacy and safety of atypical and conventional antipsychotic drugs in first-episode psychosis: a randomized, double-blind trial of olanzapine 
versus haloperidol. American Journal of Psychiatry 2003;160(8):1396-404.

\section{Lindstrom 1994 \{published data only\}}

Lindstrom E, von Knorring L. Changes in single symptoms and separate factors of the schizophrenic syndrome after treatment with risperidone or haloperidol. Pharmacopsychiatry 1994;27(3):108-13.

\section{Loo 1997 \{published data only\}}

Loo H, Poirier Littre MF, Theron M, Rein W, Fleurot O. Amisulpride versus placebo in the medium-term treatment of the negative symptoms of schizophrenia. British Journal of Psychiatry 1997;170:18-22. [MEDLINE: 9068769]

\section{Lopez 1996 \{published data only\}}

Lopez Ibor JJ, Ayuso JL, Gutierrez M, Guimon J, Herraiz ML, Chinchilla $A$, et al. Risperidone in the treatment of chronic schizophrenia: multicenter study comparative to haloperidol [Risperidona en el tratamiento de la esquizofrenia cronica: estudio multicentrico comparativo versus haloperidol]. Actas Luso Espanolas de Neurologia Psiquiatria y Ciencias Afines 1996;24(4):165-72.

\section{Lopez-Ibor 1992 \{published data only\}}

Lopez-Ibor JJ. Safety profile of risperidone in the multicentre trials. Proceedings of the 1st International Risperidone Investigators' Meeting; 1992 Mar 9-10; Paris, France. 1992.

\section{Luo 2011 \{published data only\}}

罗燕. Palley risperidone sustained release tablets and olanzapine tablets in the treatment of exacerbations and readmission of patients with schizophrenia in a randomized double-blind placebo-controlled study. Chinese Journal of Mental Health [\#\#\#\#\#] 2011;23(05):560-3.

\section{Marder 1991 \{published data only\}}

Marder SR, Chouinard G, Davis JM. The clinical actions of risperidone. Proceedings of the 6th World Congress of Biological Psychiatry 1997; Jun 22-27:Nice, France.

\section{McClellan 2009 \{published data only\}}

McClellan J. Risperidone for schizophrenia. Stanley Foundation Research Programs 2009

\section{McClure 2009 \{published data only\}}

McClure MM, Koenigsberg HW, Reynolds D, Goodman M, New A, Trestman R, Silverman J, Harvey PD, Siever LJ. The effects of risperidone on the cognitive performance of individuals with schizotypal personality disorder. Journal of clinical psychopharmacology 2009;29:396-398.

\section{McKenna 2004 \{published data only\}}

McKenna PJ. An international study of improving treatment for the most severely ill with schizophrenia. National Research Register 2004.

\section{Nasrallah 2004a \{published data only\}}

Nasrallah HA, Duchesne I, Mehnert A, Janagap C, Eerdekens M. Correction. Journal of Clinical Psychiatry [linchuang jingshen yixue zazhi] [\#\#\#\#\#\#\#] 2004;65(8):1150.
Nasrallah HA, Duchesne I, Mehnert A, Janagap C, Eerdekens M. Health-related quality of life in patients with schizophrenia during treatment with long-acting, injectable risperidone. Journal of Clinical Psychiatry 2004;65(4):531-6.

\section{NCT00034892 \{published data only\}}

NCT00034892. Efficacy and tolerability of olanzapine, quetiapine and risperidone in the treatment of first episode psychosis: a randomized double blind 52-week comparison. clinicaltrials.gov/ct2/show/NCT00034892 (2002) (accessed 9 October 2013).

\section{NCT00088075 \{published data only\}}

NCT00088075. A randomized, double-blind, placebo-controlled clinical study of the efficacy and safety of risperidone for the treatment of schizophrenia in adolescents. clinicaltrials.gov/ ct2/show/NCT00088075 (2004) (accessed 9 October 2013).

\section{NCT00202007 \{published data only\}}

NCT00202007. A multi-center, randomized, double-blind study, comparing with risperidone, to evaluate the efficacy and safety of aripiprazole in the treatment of patients with schizophrenia. clinicaltrials.gov/ct2/show/NCT00202007 (2005) (accessed 9 October 2013).

\section{NCT00249119 \{published data only\}}

NCT00249119. Risperidone in the treatment of chronic schizophrenic patients: an international multicentre doubleblind parallel-group comparative study versus haloperidol. clinicaltrials.gov/ct2/show/NCT00249119 (2005) (accessed 9 October 2013).

NCT00253136 \{published data only\}

NCT00253136. Risperidone depot (microspheres) vs placebo in the treatment of subjects with schizophrenia. clinicaltrials.gov/ ct2/show/NCT00253136 (2005) (accessed 9 October 2013).

\section{NCT00305474 \{published data only\}}

NCT00305474. Identification and treatment of the liability to develop schizophrenia. clinicaltrials.gov/ct2/show/results/ NCT00305474 (2006) (accessed 9 October 2013).

\section{NCT 02109562 \{published data only\}}

Nct02109562. A Phase 3, Randomized, Double-Blind, PlaceboControlled, Multicenter Study to Evaluate the Efficacy, Safety and Tolerability of RBP-7000 (90mg and 120mg) as a Treatment in Subjects With Acute Schizophrenia Over 8 Weeks (2 Subcutaneous Doses). http://Clinicaltrials.gov/show/ NCT02109562.

\section{Peuskens 1995 \{published data only\}}

Peuskens J, Risperidone Study Group. Risperidone in the treatment of patients with chronic schizophrenia: a multi-national, multi-centre, double-blind, parallel-group study versus haloperidol. British Journal of Psychiatry 1995;166:712-26.

\section{Peuskens 2001 \{published data only\}}

Peuskens J, Kasper S. Amisulpride versus risperidone in schizophrenia: comparing clinical and functional outcome in 
a 6 months study. Proceedings of the 7th World Congress of Biological Psychiatry; 2001 Jul 1-6; Berlin, Germany. 2001.

\section{Peuskens 2001a \{published data only\}}

Peuskens J, Moller HJ. Amisulpride improves depressive symptoms in acute exacerbations of schizophrenia: comparison with haloperidol and risperidone. European Neuropsychopharmacology 2001;11(3):255.

\section{Pikalov 2012 \{published data only\}}

Pikalov A, Cucchiaro J, Ogasa M, Silva R, Hsu J, Xu J, Loebel A. Effect of lurasidone on weight and metabolic parameters: $A$ comprehensive database analysis. Schizophrenia research 2012;136:S278.

\section{Rabinowitz 2001 \{published data only\}}

Rabinowitz J, Davidson M. Risperidone versus haloperidol in long-term hospitalized chronic patients in a double blind randomized trial: a post hoc analysis. Schizophrenia Research 2001;50(1-2):89-93.

\section{Rein 2002 \{published data only\}}

Rein W, Fleurot O. Efficacy of amisulpride vs risperidone in the long-term treatment of chronic schizophrenia: Results from a 12 month double-blind study. European Neuropsychopharmacology 2002;12(Suppl 3):S302.

Rein W, Fleurot O. Safety of amisulpride vs risperidone in the long-term treatment of chronic schizophrenia: Results from a 12 month double-blind study. European Neuropsychopharmacology 2002;12(Suppl 3):S309.

\section{Revicki 1996 \{published data only\}}

Revicki D, Genduso LA, Hamilton SL, Martin C, Reblando J, Tran PV. Quality of life outcomes for olanzapine and haloperidol treatment for schizophrenia and related psychotic disorders. Proceedings of the 149th Annual Meeting of the American Psychiatric Association; 1996 May 4-9, New York, New York, USA. 1996.

\section{Riedel 2003 \{published data only\}}

Riedel M, Möller HJ, Müller N. Rational and efficacy of cox-2inhibitors as adjunctive therapy in schizophrenia. European Neuropsychopharmacology 2003;13(4):S96.

\section{Schmechtig 2010 \{published data only\}}

Schmechtig A, Dourish C, Craig K, Dawson GR, Williams S, Deakin W, Lees J, Wilkinson L, Ettinger U. Effects of risperidone, amisulpride and nicotine on eye movement control and their modulation by high schizotypy. Pharmacopsychiatry 2011;21:A99.

\section{Siever 2002 \{published data only\}}

Siever LJ, Koenigsberg HW, Mitropoulou V, Goodman M, Buchsbaum MS. Neurobiology and pharmacologic treatment of schizotypal personality: implications for pharmacology. Proceeding of the 155th Annual Meeting of the American Psychiatric Association; 2002 May 18-23; Philadelphia, Pennsylvania, USA. 2002.
Tollefson 1996 \{published data only\}

* Tollefson G, Beasley C, Tran P, Dellva MA, Krueger J, Tamura R. Olanzapine versus haloperidol: acute results of the multicenter international trial. Psychopharmacology Bulletin 1996;32(3):401.

Tollefson G, Beasley C, Tran P, Sanger T. Olanzapine: an exciting atypical antipsychotic; the clinical experience. Proceedings of the 8th European College of Neuropsychopharmacology Congress; 1995 Sep 30-Oct 4; Venice, Italy. 1995.

Tollefson G, Lu Y. Comorbid mood disturbance in schizophrenia. Schizophrenia Research 1997;24:192.

Tollefson GD. Olanzapine: a novel antipsychotic with a broad spectrum profile. Neuropyschopharmacology 1994;10(Suppl 3 Pt 1):805S.

Tollefson GD. The value of atypical antipsychotic medications. Proceedings of the 150th Annual Meeting of the American Psychiatric Association; 1997 May 17-22; San Diego, California, USA. 1997.

Tollefson GD. Treatment consideration for comorbid mood disorders in schizophrenic patients. Proceedings of the 6th World Congress of Biological Psychiatry; 1997 Jun 22-27; Nice, France. 1997.

Tollefson GD. Update on new atypical antipsychotics. Proceedings of the 8th European College of Neuropsychopharmacology Congress; 1995 Sep 30-Oct 4; Venice, Italy. 1995.

Tollefson GD, Andersen SW. Should we consider mood disturbance in schizophrenia as an important determinant of quality of life?. Journal of Clinical Psychiatry 1999;60(Suppl 5):23-9.

Tollefson GD, Andersen SW, Tran PV. The course of depressive symptoms in predicting relapse in schizophrenia: a double blind, randomized comparison of olanzapine and risperidone. Biological Psychiatry 1999;46(3):365-73.

Tollefson GD, Beasley CM, Tamura RN, Tran PV, Potvin JH. Blind, controlled, long term study of the comparative incidence of treatment emergent tardive dyskinesia with olanzapine or haloperidol. American Journal of Psychiatry 1997;154(9):1248-54.

Tollefson GD, Beasley CM, Tran PV, Street JS, Krueger JA, Tamura RN, et al. Olanzapine versus haloperidol in the treatment of schizophrenia and schizoaffective and schizophreniform disorders: results of an international collaborative trial. American Journal of Psychiatry 1997;154(4):457-65.

Tollefson GD, Lu Y. Comorbid mood disturbance in schizophrenia. Biological Psychiatry 1997;41:101S.

Tollefson GD, Lu Y. Comorbid mood disturbance in schizophrenia. Proceedings of the 20th Collegium Internationale Neuro-Psychopharmacologicum Congress; 1996 Jun 23-27; Melbourne, Australia. 1996. 
Tollefson GD, Lu Y. Comorbid mood disturbance in schizophrenia. Proceedings of the 9th European College of Neuropsychopharmacology Congress; 1996 Sep 21-25; Amsterdam, Netherlands. 1996.

Tollefson GD, Lu Y, Sanger TM, Beasley CM, Tran PV. Olanzapine in the treatment of schizoaffective disorder. Schizophrenia Research 1997;24(1, 2):92-3.

Tollefson GD, Sanger TD, Lieberman JA. Olanzapine versus haloperidol in the treatment of first episode psychosis. Biological Psychiatry 1997;41:73S.

Tollefson GD, Sanger TM. A blinded trial on the course and relationship of depressive symptoms in schizophrenia. Schizophrenia Research 1998;29(1, 2):205.

Tollefson GD, Sanger TM. Negative symptoms: a path analytic approach to a double-blind, placebo- and haloperidolcontrolled clinical trial with olanzapine. American Journal of Psychiatry 1997;154(4):466-74.

Tollefson GD, Sanger TM, Beasley CM. The course of primary and secondary negative symptoms in a controlled trial with olanzapine. 20th Collegium Internationale NeuroPsychopharmacologicum Congress; 1996 Jun 23-27; Melbourne, Australia. 1996. [MEDLINE: 97245664]

Tollefson GD, Sanger TM, Beasley CM. The course of primary and secondary negative symptoms in a controlled trial with olanzapine. Proceedings of the 149th Annual Meeting of the American Psychiatric Association; 1996 May 4-9, New York, New York, USA. 1996.

Tollefson GD, Sanger TM, Beasley CM. The course of primary and secondary negative symptoms in a controlled trial with olanzapine. Schizophrenia Research 1997;24(1, 2):192.

Tollefson GD, Sanger TM, Beasley CM. The course of primary and secondary negative symptoms in a placebo- and comparator-controlled trial of the typical antipsychotic olanzapine. Proceedings of the 9th European College of Neuropsychopharmacology Congress; 1996 Sep 21-25; Amsterdam, Netherlands. 1996.

Tollefson GD, Sanger TM, Beasley CM, Tran PV. A double blind, controlled comparison of the novel antipsychotic olanzapine versus haloperidol or placebo on anxious and depressive symptoms accompanying schizophrenia. Biological Psychiatry 1998;43(11):803-10.

Tollefson GD, Sanger TM, Leiberman JA. Olanzapine versus haloperidol in the treatment of first episode psychosis. Schizophrenia Research 1997;24(1, 2):193.

Tollefson GD, Tran PV, Hamilton S, Kuntz A. Olanzapine versus risperidone in the treatment of psychosis. Preliminary report. Biological Psychiatry 1997;41:20S.

Tollefson GD, Tran PV, Hamilton S, Kuntz A. Olanzapine versus risperidone in the treatment of psychosis. Preliminary report. Schizophrenia Research 1997;24(1, 2):191-2.

\section{Tran 1997 \{published data only\}}

Tran P, Beasley C, Street J, Tamura R, Dellva MA, Graffeo K, et al. Olanzapine versus haloperidol: acute results of the multicenter international trial. Proceedings of the 20th Collegium Internationale Neuro-Psychopharmacologicum Congress; 1996 Jun 23-27; Melbourne, Australia. 1996.

Tran P, Beasley C, Tollefson G, Beuzen J, Dellva M, Sanger T, et al. Acute and long-term results of the North American doubleblind olanzapine trial. Proceedings of the 8th European College of Neuropsychopharmacology Congress; 1995 Sep 30-Oct 4; Venice, Italy. 1995.

Tran P, Beasley C, Tollefson G, Crawford A, Dellva M, Gusman S, et al. Acute and long-term results of the dose ranging doubleblind olanzapine trial. Proceedings of the 20th Collegium Internationale Neuro-Psychopharmacologicum Congress; 1996 Jun 23-27; Melbourne, Australia. 1996.

Tran P, Lu Y, Sanger T, Beasley C, Tollefson G. Olanzapine in the treatment of schizoaffective disorder. Proceedings of the 21st Collegium Internationale Neuro-Psychopharmacologicum Congress; 1998 Jul 12-16; Glasgow, UK. 1998.

Tran P, Sanger TM, Satterlee W, Beasley CJr, Tamura RN, Tollefson GD. Olanzapine vs haloperidol - results of a large multi-centre international trial. Proceedings of the 4th International Conference on Schizophrenia - 1996: Breaking down the Barriers; 1996 Oct 6-9; Vancouver, Canada. 1996.

Tran PV, Basson BR, Kennedy JS, Beasley Jr CM, Bymaster FP, Tollefson GD. The comparative anti-muscarinic-like side effect profiles of olanzapine and risperidone treatment in patients with schizophrenia spectrum psychosis. European Neuropsychopharmacology 1999;9:S290.

Tran PV, Beasley CM, Tollefosn GD, Sanger T, Satterlee WG. Clinical efficacy and safety of olanzapine, a new atypical antipsychotic agent. Neuropsychopharmacology 1994;10(3S):267S.

Tran PV, Beasley CM, Tollefson GD, Beuzen JN, Holman SL, Sanger TM, et al. Olanzapine: a promising "atypical" antipsychotic agent. Schizophrenia Research 1995;15(1, 2):169.

Tran PV, Dellva MA, Beasley CM Jr, Satterlee WG, Cousins LM, Tollefson GD. Clinical experience with long-term continuation treatment with olanzapine. Proceedings of the 149th Annual Meeting of the American Psychiatric Association; 1996 May 4-9, New York, New York, USA. 1996.

Tran PV, Dellva MA, Tollefson GD, Beasley CM Jr, Potvin JH, Kiesler GM. Extrapyramidal symptoms and tolerability of olanzapine versus haloperidol in the acute treatment of schizophrenia. Journal of Clinical Psychiatry 1997;58(5):205-11.

Tran PV, Hamiliton SH, Kuntz AJ, Tollefson GD. Olanzapine versus risperidone in the treatment of psychosis disorders: a preliminary report. Proceedings of the 35th Annual Meeting of the American College of Neuropsychopharmacology; 1996 Dec 9-13; San Juan, Puerto Rico. 1996.

* Tran PV, Hamilton SH, Kuntz AJ, Potvin JH, Andersen SW, Beasley C, et al. Double-blind comparison of olanzapine 
versus risperidone in the treatment of schizophrenia and other psychotic disorders. Journal of Clinical Psychopharmacology 1997;17(5):407-18.

Tran PV, Tollefson GD, Andersen SW, Kuntz AJ, Hamilton SH. Olanzapine versus risperidone in the treatment of schizophrenia and other psychotic disorders. Proceedings of the 10th European College of Neuropsychopharmacology Congress; 1997 Sep 13-17; Vienna, Austria. 1997.

Tran PV, Tollefson GD, Anderson SW, Kuntz A, Hamilton SH. Olanzapine versus risperidone in the treatment of schizophrenia and other psychotic disorders. Schizophrenia Research 1998;29(1, 2):205.

Tran PV, Tollefson GD, Crawford AM, Dossenbach M, Friedel P, Folnegovic V, et al. Olanzapine versus fluphenazine in schizophrenia. Proceedings of the 151st Annual Meeting of the American Psychiatric Association; 1998 May 30-Jun 4; Toronto, Ontario, Canada. 1998.

Tran PV, Tollefson GD, Hamilton S. Olanzapine versus risperidone in the treatment of schizophrenia and other psychotic disorders. Proceedings of the 150th Annual Meeting of the American Psychiatric Association; 1997 May 17-22; San Diego, California, USA. 1997.

Tran PV, Tollefson GD, Hamilton S, Kuntz A. Olanzapine vs. risperidone in the treatment of psychosis. Proceedings of the 6th World Congress of Biological Psychiatry; 1997 Jun 22-27; Nice, France. 1997.

\section{Tsai 2004 \{published data only\}}

Tsai G, Lane HY, Yang P, Chong MY, Lange N. Glycine transporter I inhibitor, N-Methylglycine (sarcosine), added to antipsychotics for the treatment of schizophrenia. Biological Psychiatry 2004;55(5):452-6.

\section{Tsai 2006 \{published data only\}}

Tsai GE, Yang P, Chang Y-C, Chong M-Y. D-alanine added to antipsychotics for the treatment of schizophrenia. Biological Psychiatry 2006;59(3):230-4.

\section{Urioste 2004 \{published data only\}}

Urioste R, Bossie C, Zhu Y, Ciliberto N, Trinh B, Lasser R. Clinical improvement with long-acting risperidone: no impact of race. Proceedings of the 157th Annual Meeting of the American Psychiatric Association; 2004 May 1-6; New York, New York, USA. 2004.

\section{Wang 2003 \{published data only}

Wang G. 60 week, randomized, double-blind, placebocontrolled trial of valproate added to risperidone in 200 treatment-naive, first-episode patients with schizophrenia. Stanley Foundation Research Programs 2003.

\section{Weickert 2003 \{published data only\}}

Weickert TW, Goldberg TE, Marenco S, Bigelow LB, Egan MF, Weinberger DR. Comparison of cognitive performances during a placebo period and an atypical antipsychotic treatment period in schizophrenia: critical examination of confounds. Neuropsychopharmacology 2003;28(8):1491-500.

\section{Weiden 2005 \{unpublished data only\}}

Weiden P, Radulovic L, Wang C, Allison D. Sibutramine for the treatment of obesity in schizophrenia: randomized, placebo controlled pilot study. 2005.

\section{Wirshing 1995 \{published data only\}}

Wirshing DA, Marshall BD Jr, Green MF, Mintz J, Marder SR, Wirshing WC. Risperidone in treatmentrefractory schizophrenia. American Journal of Psychiatry 1999;156(9):1374-9.

* Wirshing WC, Ames D, Green M, Marshall BD, Marder SR. Risperidone versus haloperidol in treatment-refractory schizophrenia: preliminary results. Psychopharmacology Bulletin 1995;31(3):633.

Wirshing WC, Ames D, Marder SR, Marshall BD, Green MF, McGurk S. Risperidone vs haloperidol in treatment resistant schizophrenia: preliminary results. Schizophrenia Research 1996;18(2, 3):130.

Wirshing WC, Ames D, Marder SR, Marshall BD, Green MF, McGurk SR. Risperidone in treatment resistant schizophrenia. Proceedings of the 34th Annual Meeting of the American College of Neuropsychopharmacology; 1995 Dec 11-15; San Juan, Puerto Rico. 1995.

Wirshing WC, Ames D, Marshall BD, Green MF, McGurk S. Risperidone in treatment resistant schizophrenia. Proceeding of the 8th Biennial Winter Workshop on Schizophrenia; 1996 Mar 16-22; Crans Montana, Switzerland. 1996.

Wirshing WC, Ames D, Palmer Bray M, Marshall BD, Green MF, Marder SR. Risperidone versus haloperidol in treatment refractory schizophrenia: preliminary results. Proceeding of the 148th Annual Meeting of the American Psychiatric Association; 1995 May 20-25; Miami, Florida, USA. 1995.

Wirshing WC, Green MF, Ames D, Marshall BD, McGurk SR, Mintz J, et al. Risperidone vs. haloperidol in treatment-resistant schizophrenia. Proceedings of the 6th World Congress of Biological Psychiatry; 1997 Jun 22-27; Nice, France. 1997.

\section{Yamawaki 1996 \{published data only\}}

Yamawaki S, Hayashi T, Yokota N, Takahashi T, Sato G, Tahara Y. Serotonin-dopamine antagonists in elderly schizophrenics. Proceedings of the 20th Collegium Internationale NeuroPsychopharmacologicum Congress; 1996 Jun 23-27; Melbourne, Australia. 1996

\section{Zhang 2002 \{published data only\}}

Zhang CZ. A study of the therapeutic effectiveness of risperidone in combination with antioxidants in the treatment of schizophrenia. Herald of Medicine 2002;21(10):629-30.

\section{Zhong 2006 \{published data only\}}

Zhong Z-Y, Tao J, Wang X-L, Wu X-L, Zhang J-B. Effect of antipsychotic plus buflomedil hydrochloride in ameliorating the negative symptoms of patients with schizophrenia. Chinese Journal of Clinical Rehabilitation [Zhongguo lin chuang kang fu] 2006;10(2):30-2. 


\section{References to studies awaiting assessment}

\section{Anon 2010 \{published data only\}}

Anon. An assessment of the long-term efficacy and safety of org 5222 , risperidone and placebo in subjects with schizophrenia. http://www.clinicalstudyresults.org/ (2010).

\section{Bose 2010a \{published data only\}}

Bose A, Li D, Migliore R, Werner P, Nemeth G, Laszlovsky I. The efficacy and safety of the novel antipsychotic cariprazine in acute exacerbation of schizophrenia. European Psychiatry 2011;26(1):1354

Bose A, Li D, Migliore R, Werner P, Nemeth G, Laszlovszky I. The efficacy and safety of the novel antipsychotic cariprazine in acute exacerbation of schizophrenia. European Neuropsychopharmacology 2010:493-4.

\section{Cavazzoni 2002 \{published data only\}}

Cavazzoni P, Berg P, Millikan M, Carlson C, Beasley C. An integrated analysis of treatment-emergent extrapyramidal syndrome in schizophrenic patients during olanzapine clinical trials versus placebo, haloperidol, risperidone or clozapine. International Journal of Neuropsychopharmacology 2002;5(Suppl 1):S164.

* Cavazzoni P, Berg PH, Millikan M, Carlson C, Beasley CM. An integrated analysis of treatment-emergent extrapyramidal syndrome in schizophrenic patients during olanzapine clinical trials versus placebo, haloperidol, risperidone or clozapine. Schizophrenia Research 2002;53(3 Suppl 1):171.

\section{DeMartinis 2012 \{published data only\}}

DeMartinis NA. Results of a phase 2a proof-of-concept trial with a pde10a inhibitor in the treatment of acute exacerbation of schizophrenia. Biological Psychiatry 2012;8(Suppl 1):17S-8S.

\section{GlaxoSmithKline 2006 \{published data only\}}

NCT00049946. A multicenter, double-blind, double-dummy, placebo-controlled, randomized, parallel group evaluation of the efficacy and safety of a fixed-dose of talnetant versus placebo versus risperidone in subjects with schizophrenia. clinicaltrials.gov/show/NCT00049946 (2002).

NCT00103727. A multicenter, double-blind, double-dummy, placebo-controlled, randomized, parallel group evaluation of the efficacy and safety of a fixed-dose of talnetant versus placebo versus risperidone in subjects with schizophrenia. clinicaltrials.gov/show/NCT00103727 (2005). [NCT00103727]

NCT00300963. A multicenter, double-blind, double-dummy, placebo-controlled, randomized, parallel group evaluation of the efficacy and safety of a fixed-dose of talnetant versus placebo versus risperidone in subjects with schizophrenia. clinicaltrials.gov/show/NCT00300963 (2006). [NCT00300963]

\section{Litman 2014 \{published data only\}}

Litman R, Smith M, Doherty J, Cross A, Raines S, Zukin S. AZD8529, a positive allosteric modulator at the MGGLUR2 receptor, does not improve symptoms in schizophrenia: A proof of principle study. European neuropsychopharmacology 2014;24:S508-S509.
Litman RE, Smith MA, Doherty J, Cross A, Raines S, Zukin S. AZD8529, a positive allosteric modulator at the $\mathrm{MGLuR2}$ receptor, does not improve symptoms in schizophrenia: A proof of principle study. Schizophrenia research 2014;153:S176.

NCT00921804. Study to assess the efficacy, safety, and tolerability of AZD8529 in adult schizophrenia patients. clinicaltrials.gov/show/NCT00921804 (2009).

\section{NCT 00694707 \{published data only\}}

Debelle M, Faradzs-zade S, Szatmari B, Nagy K, Nemeth G, Durgam S, Laszlovszky I. Cariprazine in negative symptoms of schizophrenia: Post hoc analyses of a fixed-dose, placebo-and active-controlled trial. European neuropsychopharmacology 2014;24:S534.

NCT01086748 \{published data only\}

NCT01086748. A study in schizophrenia patients. ClinicalTrials.gov/show/NCT01086748 (2010).

\section{NCT01175135 \{published data only\}}

NCT01175135. An inpatient study of the efficacy, safety, and tolerability of pf- 02545920 in the treatment of acute exacerbation of schizophrenia. ClinicalTrials.gov/show/ NCT01175135 (2010).

\section{NCT01363349 \{published data only\}}

NCT01363349. Phase iib-iii study of bl-1020 small molecule for schizophrenia. ClinicalTrials.gov/show/NCT01363349 (2011).

\section{Nisenbaum 2013 \{published data only\}}

Nisenbaum L, Millen B A, Zhao F, Downing A, Quigley A, Kohler J, et al. LY 2140023 monohydrate in the treatment of patients with schizophrenia: Pharmacogenetic analysis within a clinical trial assessing efficacy in treating acutely ill patients. Schizophrenia Bulletin 2013;39:S105.

Rujescu 2009 \{published data only\}

Rujescu D. Riluzole for schizophrenia. Stanley Foundation Research Programs 2009.

\section{Vanover 2014 \{published data only\}}

Nct02469155. A Trial to Assess the Antipsychotic Efficacy of ITI-007 Over 6 Weeks of Treatment. https://ClinicalTrials.gov/ show/NCT02469155 2015.

Vanover K, Davis RE, Ereshefsky L, Mates S. Positive results with ITI-007 for the treatment of schizophrenia: A randomized double-blind placebo- and active-controlled phase 2 study. Schizophrenia research 2014;153:S278-S279.

Vanover KE, Davis RE, Mates S. ITI-007 for the treatment of schizophrenia: A differentiating response profile. Biological psychiatry 2014;1:325S.

Vanover KE, Davis RE, Mates S. ITI-007, a new approach to the treatment of schizophrenia. Schizophrenia research 2014;153:S21.

Vanover KE, Mates S, Greengard P, Davis RE. Phase 2 evaluation of ITI-007, a novel approach to the treatment of schizophrenia. Neuropsychopharmacology 2013;38:S386-S387. 
Xu 2009 \{published data only\}

Xu Z. LDXGW for schizophrenia. Stanley Foundation Research Programs 2009.

\section{References to ongoing studies}

NCT00174200 \{published data only\}

NCT00174200. A randomized, double-blind, crossover addon study to assess the differential sensitivity of 2 spatial working memory tests (the groton maze learning test [gmlt] and the motor delayed response test [mdr]) in non-agitated, antipsychotic drug-naive first-episode schizophrenic or schizophreniform patients treated with risperidone $2 \mathrm{mg}$ daily or placebo. clinicaltrials.gov/show/NCT00174200 (2005). Date accessed: 9/10/2013.

\section{Additional references}

\section{Adams 2013}

Adams CE, Bergman H, Irving CB, Lawrie S. Haloperidol versus placebo for schizophrenia. Cochrane Database of Systematic Reviews 2013, Issue 11. [DOI: 10.1002/14651858.CD003082.pub3; PUBMED: 24242360]

\section{Addington 1993}

Addington D, Addington J, Maticka-Tyndale E. Assessing depression in schizophrenia: the Calgary Depression Scale. British Journal of Psychiatry 1993;22:39-44.

\section{Ahmed 2011}

Ahmed U, Rehman F, Jones H, Adams Clive E. Risperidone for psychosis induced aggression or agitation. Cochrane Database of Systematic Reviews 2011, Issue 11. [DOI: 10.1002/14651858.CD009412; CD009412]

\section{AHRP 2006}

Hassner VS. Scientific fraud: Eric Poehlman / Richard Borison. Alliance for Human Research Protection (http://www.ahrp.org/ cms/content/view/370/29/) 29 Oct 2006 (accessed 5 Nov 2009).

\section{Altman 1996}

Altman DG, Bland JM. Detecting skewness from summary information. BMJ 1996;313(7066):1200.

\section{Andreasen 1981}

Andreasen, NC. Scale for the assessment of negative symptoms: SANS. Lowa: the University of Lowa. 1981.

\section{Asmal 2013}

Asmal L, Flegar SJ, Wang J, Rummel-Kluge C, Komossa K, Leucht S. Quetiapine versus other atypical antipsychotics for schizophrenia. Cochrane Database of Systematic Reviews 2013 Issue 11. [DOI: 10.1002/14651858.CD006625.pub3; PUBMED: 24249315]

\section{Bagnall 2007}

Bagnall A, Fenton M, Kleijnen J, Lewis R. Molindone for schizophrenia and severe mental illness. Cochrane Database of Systematic Reviews 2007, Issue 1. [DOI: 10.1002/14651858.CD002083.pub2; PUBMED: 17253473]

\section{Barnes 1989}

Barnes TR. A rating scale for drug-induced akathisia. British Journal of Psychiatry 1989;154:672-6.

\section{Begg 1996}

Begg C, Cho M, Eastwood S, Horton R, Moher D, Olkin I, et al. Improving the quality of reporting of randomized controlled trials. The CONSORT statement. JAMA 1996;276(8):637-9.

\section{Belgamwar 2011}

Belgamwar RB, El-Sayeh HG. Aripiprazole versus placebo for schizophrenia. Cochrane Database of Systematic Reviews 2011 , Issue 8. [DOI: 10.1002/14651858.CD006622.pub2; PUBMED: 21833956]

\section{Benson 1996}

Benson H, Friedman R. Harnessing the power of the placebo effect and renaming it "remembered wellness". Annual Review of Medicine 1996;47:193-9.

\section{Bhattacharjee 2008}

Bhattacharjee J, El-Sayeh HG. Aripiprazole versus typical antipsychotic drugs for schizophrenia. Cochrane Database of Systematic Reviews 2008, Issue 3. [DOI: 10.1002/14651858.CD006617.pub3; PUBMED: 18646161$]$

\section{Bland 1997}

Bland JM. Statistics notes. Trials randomised in clusters. BMJ 1997;315:600.

\section{Boissel 1999}

Boissel JP, Cucherat M, Li W, Chatellier G, Gueyffier F, Buyse $M$, et al. The problem of therapeutic efficacy indices. 3. Comparison of the indices and their use [Apercu sur la problematique des indices d'efficacite therapeutique, 3 : comparaison des indices et utilisation. Groupe d'Etude des Indices D'efficacite]. Therapie 1999;54(4):405-11. [PUBMED: 10667106]

\section{Carpenter 1994}

Carpenter WT Jr, Buchanan RW. Schizophrenia. The New England Journal of Medicine 1994;330(10):681-90.

\section{Carpenter 2003}

Carpenter WT, Appelbaum PS, Levine RJ. The Decleration of Helsinki and clinical trials: a focus on placebo-controlled trials in schizophrenia. American Journal of Psychiatry 2003;160(2):356-62.

\section{CBS News 2000}

Augusta G. Drug money: Patients worsened; little oversight provided. CBS News (http://www.cbsnews.com/ stories/2000/07/31/48hours/main220233.shtml) $31 \mathrm{Jul} 2000$ (accessed 5 November 2009).

\section{Chouinard 1993}

Chouinard G, Arnott W. Clinical review of risperidone. Canadian Journal of Psychiatry 1993;38(Suppl 3):89-95. 


\section{Darby 1997}

Darby JK, Pasta DJ, Elfand L, Dabiri L, Clark L, Herbert J. Risperidone dose and blood level variability: accumulation effects and interindividual and intraindividual variability in the nonresponder patient in the clinical practice setting. Journal of Clinical Psychopharmacology 1997;17(6):478-84.

\section{Deeks 2000}

Deeks J. Issues in the selection for meta-analyses of binary data. Proceedings of the 8 th International Cochrane Colloquium; 2000 Oct 25-28; Cape Town. Cape Town: The Cochrane Collaboration, 2000.

\section{Divine 1992}

Divine GW, Brown JT, Frazier LM. The unit of analysis error in studies about physicians' patient care behavior. Journal of General Internal Medicine 1992;7(6):623-9.

\section{Donner 2002}

Donner A, Klar N. Issues in the meta-analysis of cluster randomized trials. Statistics in Medicine 2002;21:2971-80.

\section{DSM-IV-TR}

American Psychiatric Association. Diagnostic and Statistical Manual of Mental Disorders. Washington, DC: American Psychiatric Association, 1994.

\section{Duggan 2005}

Duggan L, Fenton M, Rathbone J, Dardennes R, ElDosoky A, Indran S. Olanzapine for schizophrenia. Cochrane Database of Systematic Reviews 2005, Issue 2. [DOI: 10.1002/14651858.CD001359.pub2; PUBMED: 15846619]

\section{Egger 1997}

Egger M, Davey-Smith G, Schneider M, Minder CSO. Bias in meta-analysis detected by a simple, graphical test. BMJ 1997;13:629-34.

\section{Furukawa 2006}

Furukawa TA, Barbui C, Cipriani A, Brambilla P, Watanabe N. Imputing missing standard deviations in meta-analyses can provide accurate results. Journal of Clinical Epidemiology 2006;59(7):7-10.

\section{Gilbody 2000}

Gilbody SM, Bagnall AM, Duggan L, Tuunainen A. Risperidone versus other atypical antipsychotic medication for schizophrenia. Cochrane Database of Systematic Reviews 2000 Issue 3. [DOI: 10.1002/14651858.CD002306]

\section{Gulliford 1999}

Gulliford MC. Components of variance and intraclass correlations for the design of community-based surveys and intervention studies: data from the Health Survey for England 1994. American Journal of Epidemiology 1999;149:876-83.

\section{Guy 1976}

Guy U. ECDEU assessment manual for psychopharmacology. Revised. Rockville: National Institute of Mental Health, 1976.

\section{Heykants 1994}

Heykants J, Huang ML, Mannens G, Meuldermans W, Snoeck E, Van Beijsterveldt $L$, et al. The pharmacokinetics of risperidone in humans: a summary. Journal of Clinical Psychiatry 1994;55(Suppl):13-7.

\section{Higgins 2003}

Higgins JP, Thompson SG, Deeks JJ, Altman DG. Measuring inconsistency in meta-analyses. BMJ 2003;327:557-60.

\section{Higgins 2008}

Higgins JPT, Green S (editors). Cochrane Handbook for Systematic Reviews of Interventions. Chichester: John Wiley \& Sons, 2008.

\section{Higgins 2011}

Higgins JPT, Green S (editors). Cochrane Handbook for Systematic Reviews of Interventions Version 5.1.0. Available from www.cochrane-handbook.org: The Cochrane Collaboration, 2011.

\section{Hosalli 2003}

Hosalli P, Davies JM. Depot risperidone for schizophrenia. Cochrane Database of Systematic Reviews 2003, Issue 4. [DOI: 10.1002/14651858.CD004161]

\section{Hunter 2003}

Hunter RH, Joy CB, Kennedy E, Gilbody SM, Song F. Risperidone versus typical antipsychotic medication for schizophrenia. Cochrane Database of Systematic Reviews 2003, Issue 2. [DOI: 10.1002/14651858.CD000440]

\section{Hutton 2009}

Hutton JL. Number needed to treat and number needed to harm are not the best way to report and assess the results of randomised clinical trials. British Journal of Haematology 2009;146(1):27-30

\section{Hutton 2012}

Hutton P, Morrison AP, Yung AR, Taylor PJ, French P, Dunn G. Effects of drop-out on efficacy estimates in five Cochrane reviews of popular antipsychotics for schizophrenia. Acta Psychiatrica Scandinavicia 2012;126(1):1-11. [DOI: 10.1111/ j.1600-0447.2012.01858.x; PUBMED: 22486554]

\section{Jayaram 2006}

Jayaram MB, Hosalli P, Stroup S. Risperidone versus olanzapine for schizophrenia. Cochrane Database of Systematic Reviews 2006, Issue 2. [DOI: 10.1002/14651858.CD005237]

\section{Jayaram 2007}

Jayaram MB, Hosalli PM, Stroup TS. Risperidone versus olanzapine for treatment of schizophrenia. Schizophrenia Bulletin 2007;33(6):1274-6. [PUBMED: 17921477]

\section{Joy 2006}

Joy CB, Adams CE, Lawrie SM. Haloperidol versus placebo for schizophrenia. Cochrane Database of Systematic Reviews 2006, Issue 4. [DOI: 10.1002/14651858.CD003082.pub2] 


\section{Juni 2001}

Juni P, Altman DG, Egger M. Systematic reviews in health care: Assessing the quality of controlled clinical trials. BMJ 2001;323:42-6

\section{Kay 1986}

Kay SR, Opler LA, Fiszbein A. Positive and Negative Syndrome Scale (PANSS) Manual. North Tonawanda, NY: Multi-Health Systems, 1986.

\section{Kennedy 2000}

Kennedy E, Song F, Hunter R, Clarke A, Gilbody S. Risperidone versus typical antipsychotic medication for schizophrenia. Cochrane Database of Systematic Reviews 2000, Issue 2. [DOI: 10.1002/14651858.CD002306]

\section{Khanna 2014}

Khanna P, Suo T, Komossa K, Ma H, RummelKluge C, El-Sayeh HG, et al. Aripiprazole versus other atypical antipsychotics for schizophrenia. Cochrane Database of Systematic Reviews 2014, Issue 1. [DOI: 10.1002/14651858.CD006569.pub5; PUBMED: 24385408]

\section{Komossa 2007}

Komossa K, Rummel C, Hunger H, Schmidt F, Schwarz S, Leucht S. Risperidone versus other atypical antipsychotics for schizophrenia. Cochrane Database of Systematic Reviews 2007, Issue 3. [DOI: 10.1002/14651858.CD006626.pub2]

\section{Komossa 2009}

Komossa K, Rummel-Kluge C, Hunger H, Schwarz S, Schmidt F Lewis R, et al. Sertindole versus other atypical antipsychotics for schizophrenia. Cochrane Database of Systematic Reviews 2009, Issue 2. [DOI: 10.1002/14651858.CD006752.pub2; PUBMED: 19370652]

\section{Komossa 2010}

Komossa K, Rummel-Kluge C, Hunger H, Schmid F, Schwarz S, Silveira da Mota Neto JI, et al. Amisulpride versus other atypical antipsychotics for schizophrenia. Cochrane Database of Systematic Reviews 2010, Issue 1. [DOI: 10.1002/14651858.CD006624.pub2; PUBMED: 20091599]

\section{Kumar 2005}

Kumar A, Strech D. Zuclopenthixol dihydrochloride for schizophrenia. Cochrane Database of Systematic Reviews 2005, Issue 4. [DOI: 10.1002/14651858.CD005474; PUBMED: 16235403]

\section{Laughren 2001}

Laughren TP. The scientific and ethical basis for placebocontrolled trials in depression and schizophrenia: an FDA perspective. European Psychiatry 2001;16(7):418-23.

\section{Leucht 2005a}

Leucht S, Kane JM, Kissling W, Hamann J, Etschel E, Engel R. Clinical implications of brief psychiatric rating scale scores. British Journal of Psychiatry 2005;187:366-71.

\section{Leucht 2005b}

Leucht S, Kane JM, Kissling W, Hamann J, Etschel E, Engel RR. What does the PANSS mean?. Schizophrenia Research 2005; 79(2-3):231-8.

\section{Leysen 1994}

Leysen JE, Janssen PM, Megens AA, Schotte A. Risperidone: a novel antipsychotic with balanced serotonin-dopamine antagonism, receptor occupancy profile, and pharmacologic activity. Journal of Clinical Psychiatry 1994;55(Suppl):5-12.

\section{Li 2009}

Li C, Xia J, Wang J. Risperidone dose for schizophrenia. Cochrane Database of Systematic Reviews 2009, Issue 4. [DOI: 10.1002/14651858.CD007474.pub2]

\section{Lingjaerde 1987}

Lingjaerde O, Ahlfors UG, Bech P, Dencker SJ, Elgen K. The UKU side effect rating scale. A new comprehensive rating scale for psychotropic drugs and a crosssectional study of side effects in neuroleptic-treated patients. Acta Psychiatr Scand 1987;76((suppl. 334)):1-100.

\section{Lurie 1997}

Lurie P, Wolfe SM. Unethical trials of interventions to reduce perinatal transmission of the human immunodeficiency virus in developing countries. The New England Journal of Medicine 1997;337:853-6.

\section{Lurie 2005}

Lurie P, Greco DB. US exceptionalism comes to research ethics. The Lancet 2005;365:1117-9.

\section{Marshall 2000}

Marshall M, Lockwood A, Bradley C, Adams C, Joy C, Fenton M. Unpublished rating scales: a major source of bias in randomised controlled trials of treatments for schizophrenia. British Journal of Psychiatry 2000;176:249-52.

\section{Mota 2002}

Mota NE, Lima MS, Soares BG. Amisulpride for schizophrenia. Cochrane Database of Systematic Reviews 2002, Issue 2. [DOI: 10.1002/14651858.CD001357; PUBMED: 12076408]

\section{Nussbaum 2012}

Nussbaum AM, Stroup TS. Paliperidone palmitate for schizophrenia. Cochrane Database of Systematic Reviews 2012, Issue 6. [DOI: 10.1002/14651858.CD008296.pub2; PUBMED: 22696377]

\section{Overall 1962}

Overall JE, Gorham DR. The Brief Psychiatric Rating Scale. Psychological Reports 1962;10:799-812.

\section{Pietrzak 2008}

Pietrzak RH, Maruffb P, Mayesc LC, Romand SA, Sosad JA, Snyde PJ. An examination of the construct validity and factor structure of the Groton Maze Learning Test, a new measure of spatial working memory, learning efficiency, and error monitoring. Archives of Clinical Neuropsychology 2008;23(4):433-45. 


\section{Schünemann 2008}

Schünemann HJ, Oxman AD, Vist GE, Higgins JPT, Deeks JJ, Glasziou P, et al. Chapter 12: Interpreting results and drawing conclusions. Higgins JPT, Green S editor(s). Cochrane Handbook for Systematic Reviews of Interventions. The Cochrane Collaboration, 2008:359-83.

\section{Simpson 1970}

Simpson GM, Angus JWS. A rating scale for extrapyramidal side-effects. Acta Psychiatrica Scandinavica Supplementum 1970;212:11-9.

\section{Vallance 2006}

Vallance AK. Something out of nothing: the placebo effect. Advances in Psychiatric Treatment 2006;12:287-96.

\section{CHARACTERISTICS OF STUDIES}

\section{Characteristics of included studies [ordered by study ID]}

\section{WMA 2008}

World Medical Association. Ethical principles for medical research involving human subjects. World Medical Association 2008.

\section{Xia 2009}

Xia J, Adams C, Bhagat N, Bhagat V, Bhoopathy P, El-Sayeh H, et al. Losing participants before the trial ends erodes credibility of findings. Psychiatric Bulletin 2009;33:254-7.

* Indicates the major publication for the study

Bachmann 2003

\begin{tabular}{|c|c|}
\hline \multirow[t]{4}{*}{ Methods } & $\begin{array}{l}\text { Allocation: randomised. } \\
\text { Blindness: double. }\end{array}$ \\
\hline & Duration: 16 weeks. \\
\hline & Setting: inpatients and outpatients, USA. \\
\hline & Design: parallel groups. \\
\hline \multirow[t]{9}{*}{ Participants } & Diagnosis: people with schizophrenia or schizoaffective (DSM-IV). \\
\hline & $N=69$ \\
\hline & Age: $18-65$ years. \\
\hline & Sex: male and female (data only available for completers). \\
\hline & $\begin{array}{l}\text { Inclusion criteria: Those who met DSM-IV criteria for schizophrenia or schizoaffective disorder were } \\
\text { selected for study entry. BPRS total score of }>45 \text { or CGI severity of illness item score of }>4 \text {; and BPRS }\end{array}$ \\
\hline & positive symptom item total score of $>8$, with 1 or more item rated $>4$. They were required to have had \\
\hline & $\begin{array}{l}\text { an adequate clozapine trial, defined as clozapine treatment for }>6 \text { months on a dose that produced a } \\
\text { clozapine plasma level of X350 ng/ml or a clozapine + norclozapine plasma level of X450 ng/ml. }\end{array}$ \\
\hline & $\begin{array}{l}\text { Exclusion criteria: Participants who met DSM-IV diagnosis of alcohol or substance abuse (other than } \\
\text { nicotine) within the past month alcohol or substance dependence (other than nicotine) within the past }\end{array}$ \\
\hline & $\begin{array}{l}6 \text { months, mental retardation, unstable medical condition, or those treated previously with adjunctive } \\
\text { risperidone at } \mathrm{X} 8 \mathrm{mg} / \text { day for at least } 6 \text { weeks. }\end{array}$ \\
\hline
\end{tabular}

Interventions $\quad 1$. Risperidone (dose $4 \mathrm{mg}$ ) plus clozapine (dose not reported). $\mathrm{N}=33$.

2. Placebo plus clozapine (dose not reported). $\mathrm{N}=36$.

Outcomes Mental state: BPRS, SANS.

Leaving the study early (the week that participants left the study early were reported; all left before 12 weeks).

Adverse effects: metabolic, extrapyramidal, haematological.

Notes

\section{Risk of bias}


Bachmann 2003 (Continued)

Random sequence genera- Low risk "Randomization was stratified by in-patient status" (p2276). tion (selection bias)

\begin{tabular}{ll}
\hline $\begin{array}{l}\text { Allocation concealment } \\
\text { (selection bias) }\end{array}$ & Unclear risk information available.
\end{tabular}

$\begin{array}{ll}\begin{array}{l}\text { Blinding (performance } \\ \text { bias and detection bias) }\end{array} & \text { Low risk } \\ \text { All raters were blind to treatment assignment" (p2275). "Risperidone 4mg }\end{array}$

All outcomes

Incomplete outcome data Low risk ITT analysis and completers-only analysis undertaken.
(attrition bias)
All outcomes

\begin{tabular}{|c|c|c|}
\hline $\begin{array}{l}\text { Selective reporting (re- } \\
\text { porting bias) }\end{array}$ & Low risk & Outcomes listed in paper all reported. \\
\hline Other bias & High risk & $\begin{array}{l}\text { Double-blind medications were provided by Ortho-McNeil-Janssen Scientific } \\
\text { Affairs, LLC. Authors have associations with Eli Lilly, Astra-Zeneca, Pfizer, Glax- } \\
\text { oSmithKline, Cephalon, Otsuka, Bioscience, Abbott, Cypress, Merck, Organon, } \\
\text { Sanofi-Aventis, Bristol-Myers Squibb, Janssen, Solvay, Wyeth, Zeneca, and } \\
\text { Roche either as employees, stockholders, or members of advisory boards. }\end{array}$ \\
\hline
\end{tabular}

\section{Borison 1992}

\begin{tabular}{|c|c|}
\hline Methods & $\begin{array}{l}\text { Allocation: randomised. } \\
\text { Blindness: double. } \\
\text { Duration: } 3 \text { days washout period for oral medications plus } 6 \text { weeks treatment course }(2 \text { weeks for de- } \\
\text { pot medications). } \\
\text { Setting: inpatients. } \\
\text { Design: parallel groups. }\end{array}$ \\
\hline Participants & $\begin{array}{l}\text { Diagnosis: schizophrenia (DSM-III-R). } \\
\mathrm{N}=160 . \\
\text { Age: } 18-65 \text { years. } \\
\text { Sex: male }=154 \text { and female }=6 . \\
\text { Length of illness: ranged from } 10 \text { to } 17 \text { years. } \\
\text { Inclusion criteria: BPRS score more than } 30 . \\
\text { Exclusion criteria: poor general health, cardiopulmonary disease, head trauma or epilepsy, or drug or } \\
\text { alcohol abuse in the last year. }\end{array}$ \\
\hline Interventions & $\begin{array}{l}\text { 1. Risperidone: dose } 2 \mathrm{mg} / \text { day to } 10 \mathrm{mg} / \text { day, } \mathrm{N}=53 \text {. } \\
\text { 2. Haloperidol: dose } 4 \mathrm{mg} / \text { day to } 20 \mathrm{mg} / \text { day, } \mathrm{N}=53^{\star} \text {. } \\
\text { 3. Placebo: } \mathrm{N}=54 \text {. }\end{array}$ \\
\hline Outcomes & $\begin{array}{l}\text { Mental state. } \\
\text { Leaving the study early. } \\
\text { Global state: needing additional medication. } \\
\text { Adverse effects: any, gastrointestinal, central nervous system, respiratory. } \\
\text { Unable to use: } \\
\text { Global state: CGI (SD not reported). } \\
\text { Mental state: BPRS (SD not reported), SANS (SD not reported). }\end{array}$ \\
\hline
\end{tabular}


Adverse effects: AIMS, ESRS (SD not reported). Use of medication for EPS is reported as percentage, but we are unclear at which point the data was measured or the $\mathrm{N}$ number, thus unable to convert the data into binary outcome.

Physiological measures: vital signs, ECG, blood and urine chemistries (no data reported).

No information available on funding, but one of the papers has a Janssen logo.
*We did not use the data from this group, as the intervention is not relevant.
The 'leaving the study early rate' was high in this trial, but the overall leaving the study early rate was
less than $50 \%$.

\section{Risk of bias}

\begin{tabular}{lll}
\hline Bias & Authors' judgement & Support for judgement \\
\hline $\begin{array}{l}\text { Random sequence genera- } \\
\text { tion (selection bias) }\end{array}$ & Unclear risk & Randomised, no further information. \\
\hline $\begin{array}{l}\text { Allocation concealment } \\
\text { (selection bias) }\end{array}$ & Unclear risk & Not stated. \\
\hline $\begin{array}{l}\text { Blinding (performance } \\
\text { bias and detection bias) } \\
\text { All outcomes }\end{array}$ & Low risk & Double blinded. \\
\hline $\begin{array}{l}\text { Incomplete outcome data } \\
\text { (attrition bias) } \\
\text { All outcomes }\end{array}$ & High risk & $\begin{array}{l}\text { 26/53 participants left from the risperidone group, 37/54 left from the placebo } \\
\text { group. }\end{array}$ \\
\hline $\begin{array}{l}\text { Selective reporting (re- } \\
\text { porting bias) }\end{array}$ & High risk & All outcomes measured were reported, but without SD. \\
\hline \begin{tabular}{l} 
Other bias \\
\hline
\end{tabular} & Low risk & None obvious. \\
\hline
\end{tabular}

\begin{tabular}{|c|c|}
\hline Methods & $\begin{array}{l}\text { Allocation: randomised. } \\
\text { Blindness: double blind. } \\
\text { Duration: 7-day single-blind placebo washout period plus 8-week treatment period. } \\
\text { Setting: inpatients, at six centres in Canada. } \\
\text { Design: multicentre, parallel group. }\end{array}$ \\
\hline Participants & $\begin{array}{l}\text { Diagnosis: chronic schizophrenia (DSM III-R). } \\
\mathrm{N}=135 . \\
\text { Age: } 19-67 \text { years. } \\
\text { Sex: male and female. } \\
\text { Length of illness: mean } 2.0 \text { years, SD } 3.4 \text { years. } \\
\text { Inclusion criteria: total PANSS score between } 60 \text { and } 120 \text {. } \\
\text { Exclusion criteria: pregnant or lactating women or women without adequate contraception, mental } \\
\text { disorders other than schizophrenia, neurological disorders, psychoactive substance use or alcohol } \\
\text { abuse. }\end{array}$ \\
\hline Interventions & $\begin{array}{l}\text { 1. Risperidone: dose } 2 \mathrm{mg} / \mathrm{day}, \mathrm{N}=24 .^{*} \\
\text { 2. Risperidone: dose } 6 \mathrm{mg} / \mathrm{day}, \mathrm{N}=22 \text {. } \\
\text { 3. Risperidone: dose } 10 \mathrm{mg} / \text { day, } \mathrm{N}=22 \text {. }\end{array}$ \\
\hline
\end{tabular}


Chouinard 1992 (Continued)

4. Risperidone: dose $16 \mathrm{mg} /$ day, $\mathrm{N}=24$.

5. Placebo, $\mathrm{N}=22$.

6. Haloperidol: dose $20 \mathrm{mg} /$ day, $\mathrm{N}=21$.

\begin{tabular}{ll}
\hline Outcomes & Mental state: PANSS, BPRS. \\
& Leaving the study early. \\
Global state: CGI. \\
Adverse effects: ESRS, UKU Side Effect Rating Scale, concomitant sedative/hypnotic use. \\
Unable to use: \\
Physiological measures: blood pressure, heart rate in supine and standing positions, ECG, biochem- \\
istry, hematology, urine analysis (no data reported). \\
*Fixed dose. We included data only from the $6 \mathrm{mg} /$ day arm, as this was the closest dose to what would \\
be used in routine clinical practice. This arm had a differential leaving the study early rate with $45 \%$ in \\
the risperidone arm leaving the study early compared to $68 \%$ in the placebo arm (overall participants \\
leaving the study early was greater than $50 \%$ ).
\end{tabular}

\section{Risk of bias}

\begin{tabular}{lll}
\hline Bias & Authors' judgement & Support for judgement \\
\hline $\begin{array}{l}\text { Random sequence genera- } \\
\text { tion (selection bias) }\end{array}$ & Low risk & Randomised, blocks of 12. \\
\hline $\begin{array}{l}\text { Allocation concealment } \\
\text { (selection bias) }\end{array}$ & Unclear risk & Not stated. \\
\hline $\begin{array}{l}\text { Blinding (performance } \\
\text { bias and detection bias) } \\
\text { All outcomes }\end{array}$ & Low risk & Double blind: "identical tablets" (p27). \\
\hline $\begin{array}{l}\text { Incomplete outcome data } \\
\text { (attrition bias) } \\
\text { All outcomes }\end{array}$ & Low risk & LOCF, ITT analysis used. \\
\hline $\begin{array}{l}\text { Selective reporting (re- } \\
\text { porting bias) }\end{array}$ & Low risk & Outcomes listed in papers all reported. \\
\hline \begin{tabular}{l} 
Other bias \\
\hline
\end{tabular} & High risk & Supported by a grant from the Janssen Research Foundation. \\
\hline
\end{tabular}

\section{Downing 2014}

\begin{tabular}{ll}
\hline Methods & Allocation: multicenter, randomised. \\
& Blindness: double blind; Quote: 'the raters were blind to the study design, entrance criteria, and pa- \\
tient treatment assignment.' p.3) \\
Duration: 2 weeks study entry + 7 days placebo lead-in treatment phrase + 6 weeks treatment duration. \\
Settings: inpatients. \\
Design: parallel. \\
Diagnosis: schizophrenia (historical documentation and Structured Clinical Interview for DSM-IV Disor- \\
ders [SCID] interview). \\
N = 1009. (1013 participants were randomised, however, the author analysed data on an Intention-to- \\
treat basis) \\
Age: mean 39.8 years, SD 11.4 years.
\end{tabular}


Length of illness: mean 14.5 years, SD 10.7 years.

Inclusion criteria: those with an accurate and reliable diagnosis of schizophrenia (based upon historical documentation and Structured Clinical Interview for DSMIV Disorders [SCID] interview), who experienced an exacerbation of their illness 2 weeks prior to study entry (Visit 1), leading to a need for intensification of psychiatric care. Patients could be antipsychotic treatment naive or have had prior exposure to antipsychotic medications and were not treatment refractory in the opinion of the investigator.

Exclusion criteria: those who had any other current Axis I psychiatric diagnoses in addition to schizophrenia, a diagnosis of substance dependence or substance abuse, a history of one or more seizures, answered yes to any suiciderelated behaviors within 1 month of Visit 1, participated in any clinical trial for which they received a studyrelated medication in the 6 months prior to Visit 1, were treatment refractory, or had demonstrated an inadequate response to treatment with risperidone, or for whom treatment with risperidone, LY2140023, or placebo was contraindicated.

Interventions
2. Placeboridone: $2 \mathrm{mg} / \mathrm{d}$ on the first day and $4 \mathrm{mg} / \mathrm{d}$ therafter, $\mathrm{N}=142$.
3. LY2140023 low dose: twice daily, $40 \mathrm{mg} / \mathrm{d}, \mathrm{N}=292^{\star}$.
4. LY2140023 high dose: twice daily, $80 \mathrm{mg} / \mathrm{d}, \mathrm{N}=280^{\star}$.

\begin{tabular}{l} 
Leaving the study early. \\
Adverse effects ${ }^{\star \star}$. \\
Unable to use \\
Mental state: PANSS (only means of change score were reported). \\
\hline Notes \\
${ }^{* \star}$ We did not use the data from these groups, as the interventions are not relevant. \\
our protocol.
\end{tabular}

\section{Risk of bias}

\begin{tabular}{lll}
\hline Bias & Authors' judgement & Support for judgement \\
\hline $\begin{array}{l}\text { Random sequence genera- } \\
\text { tion (selection bias) }\end{array}$ & Unclear risk & $\begin{array}{l}\text { Randomised, no further information. Quote: "multicenter, randomized, dou- } \\
\text { bleblind, parallel..." (p.2). }\end{array}$ \\
\hline $\begin{array}{l}\text { Allocation concealment } \\
\text { (selection bias) }\end{array}$ & Unclear risk & No information available. \\
\hline $\begin{array}{l}\text { Blinding (performance } \\
\text { bias and detection bias) } \\
\text { All outcomes }\end{array}$ & Low risk & $\begin{array}{l}\text { Quote: 'the raters were blind to the study design, entrance criteria, and patient } \\
\text { treatment assignment.' (p.3) }\end{array}$ \\
\hline
\end{tabular}

Incomplete outcome data Low risk $\quad$ ITT analysis was performed.
(attrition bias)

All outcomes

Selective reporting (re- Low risk $\quad$ All the measured outcomes were reported.
porting bias)

Other bias High risk $\quad$ All authors were from Eli Lilly and Company.


Duration: 9 weeks duration including 7 days wash out period, 6 weeks treatment period and 2 weeks safety follow up.

Settings: inpatients, 65 study centres in the United States, India, Russia, Ukraine, and Malaysia. Design: parallel.

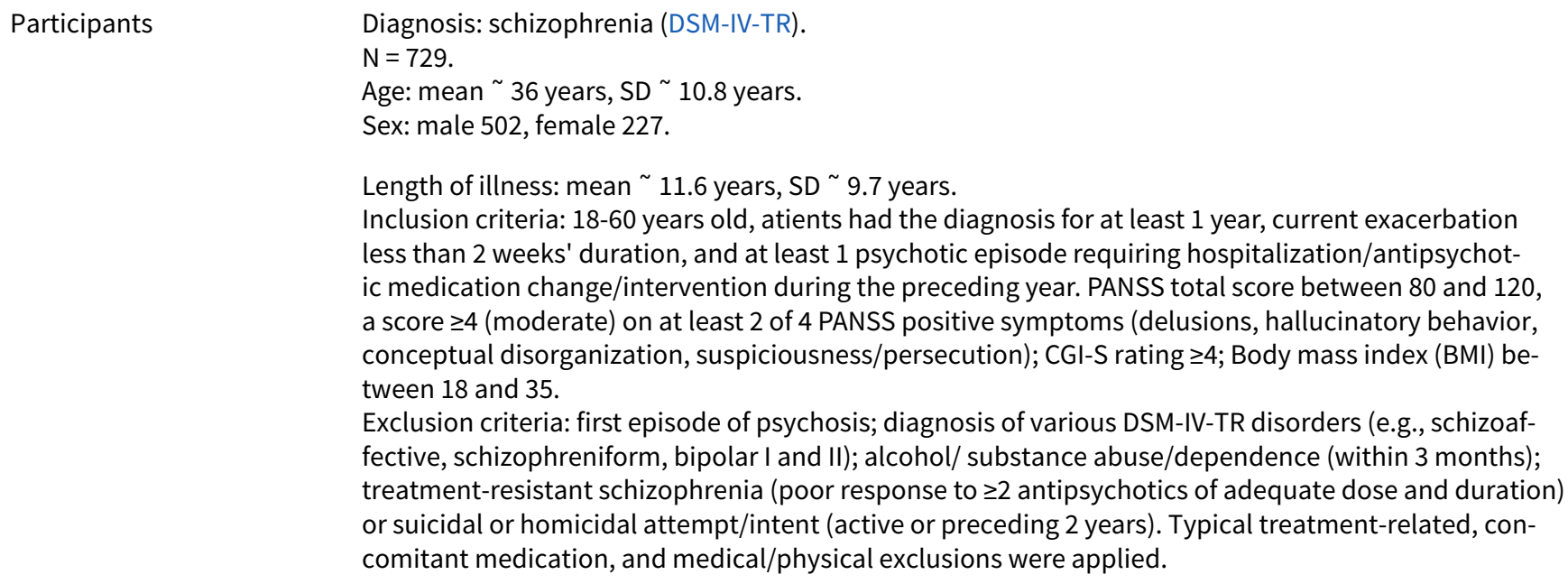

Interventions
2. Placebo: once daily, $\mathrm{N}=151$.
3. Cariprazine low dose: $1.5 \mathrm{mg} / \mathrm{d}, \mathrm{N}=145^{\star}$.
4. Cariprazine medium dose: $3 \mathrm{mg} / \mathrm{d}, \mathrm{N}=146^{\star}$.
5. Cariprazine high dose: $4.5 \mathrm{mg} / \mathrm{d}, \mathrm{N}=147^{\star}$.

Outcomes Mental state: no clinical response ${ }^{\star \star}$, PANSS, Negative Symptom Assessment (NSA-16).

Leaving the study early.

Global state: Clinical Global Impressions-Improvement (CGI-I).

Adverse effects ${ }^{\star \star \star}$ : Treatment-emergent adverse events (TEAEs).

Unable to use:

physical examination, laboratory evaluations, vital signs, weight, and 12-lead ECG.

Notes *We did not use the data from these groups, as the interventions are not relevant.

${ }^{\star \star}$ defined as the decrease rate of PANSS score $<30 \%$ improvement from baseline)

${ }^{\star \star \star}$ For the concomitant medications rate reported in this study, we only extracted 2 drugs mentioned in our protocol.

\section{Risk of bias}

Bias Authors' judgement Support for judgement


Durgam 2014 (Continued)

Random sequence genera- Unclear risk Randomised, no further information. Quote: "A 9-week, multinational, rantion (selection bias)

domized, double-blind..." (p.451).

$\begin{aligned} & \text { Allocation concealment } \\ & \text { (selection bias) }\end{aligned}$
Unclear risk information available.

(selection bias)

Blinding (performance Low risk Double blinded.
bias and detection bias)

All outcomes

\begin{tabular}{|c|c|c|}
\hline $\begin{array}{l}\text { Incomplete outcome data } \\
\text { (attrition bias) } \\
\text { All outcomes }\end{array}$ & Low risk & $\begin{array}{l}\text { Seventy-two out of } 151 \text { participants left the study early from placebo group, } \\
\text { while } 39 \text { out of } 140 \text { participants left the study early from risperidone group. In- } \\
\text { tention to treat analysis was used to analyzed the data and sensitivity analysis } \\
\text { was also conducted by using mixed effects model for repeated measures. }\end{array}$ \\
\hline $\begin{array}{l}\text { Selective reporting (re- } \\
\text { porting bias) }\end{array}$ & Low risk & All the measured outcomes were reported. \\
\hline Other bias & Low risk & None obvious. \\
\hline
\end{tabular}

Geffen 2010

\begin{tabular}{ll}
\hline Methods & Allocation: randomised, a central randomisation scheme. \\
Blindness: double blind, but unclear who is blinded. \\
Duration: 5-14 days suspension of other antipsychotics plus 6 weeks treatment period. \\
Settings: inpatients, 40 sites in India, Romania, and USA. \\
Design: parallel. \\
Diagnosis: schizophrenia (DSM-IV-TR). \\
N $=363$. \\
Age: mean 34.2 years, SD 10.34 years. \\
Sex: male 245, female 118. \\
Length of illness: mean 8.26 years, SD 8.92 years. \\
Inclusion criteria: $18-65$ years old, acute exacerbation within 30 days, PANSS total score $\geq 70$, at least \\
4 on any 2 of PANSS items (delusions, hallucinatory behaviours, conceptual disorganization, or suspi- \\
ciousness/persecution), CGI $\geq 4$. \\
Exclusion criteria: a score of greater than 9 on the modified ISST, treatment refractory psychosis follow- \\
ing 2 years of exposure to a therapeutic dose of antipsychotics, substance abuse, TD, use of mood sta- \\
bilisers, history of blood cell disorder.
\end{tabular}

Interventions $\quad$ 1. Risperidone: $2 \mathrm{mg} / \mathrm{d}$ to $8 \mathrm{mg} / \mathrm{d}, \mathrm{N}=91$.

2. Placebo: no details, $\mathrm{N}=93$.

3. BL-1020 low dose: $10 \mathrm{mg} / \mathrm{d}, \mathrm{N}=90^{*}$.

4. BL-1020 high dose: $20 \mathrm{mg} / \mathrm{d}$ to $30 \mathrm{mg} / \mathrm{d}, \mathrm{N}=89^{\star}$.

$\begin{array}{ll}\text { Outcomes } & \text { Mental state. } \\ \text { Leaving the study early. } \\ \text { Global state: needing additional medication. } \\ \text { Adverse effects }{ }^{\star \star} . \\ \text { Unable to use: }\end{array}$


Clinical response. Global state: CGI-I, CGI-S. Mental state: PANSS score. Cognitive function: Mean and SD of each outcome were not reported.

\begin{tabular}{|c|c|}
\hline \multirow[t]{2}{*}{ Notes } & $\begin{array}{l}{ }^{*} \text { We did not use the data from these groups, as the interventions are not relevant. } \\
{ }^{\star \star} \text { For the concomitant medications rate reported in this study, we only extracted } 2 \text { drugs mentioned in } \\
\text { our protocol. }\end{array}$ \\
\hline & Overall leaving the study early rate is less than $50 \%$. \\
\hline
\end{tabular}

\section{Risk of bias}

\begin{tabular}{|c|c|c|}
\hline Bias & Authors' judgement & Support for judgement \\
\hline $\begin{array}{l}\text { Random sequence genera- } \\
\text { tion (selection bias) }\end{array}$ & Low risk & $\begin{array}{l}\text { Randomisation was performed via an interactive voice system. } \\
\text { Quote: "Randomisation was performed using an interactive voice response } \\
\text { system, one randomisation scheme was generated across all sites (i.e. a cen- } \\
\text { tral randomisation scheme)". (p1169) }\end{array}$ \\
\hline $\begin{array}{l}\text { Allocation concealment } \\
\text { (selection bias) }\end{array}$ & Low risk & $\begin{array}{l}\text { Allocation sequence was concealed by the "voice response system". } \\
\text { Quote: "when the drug was dispensed, the investigator called the interactive } \\
\text { voice response system to assign the treatment code. This code number was } \\
\text { used to identify the medication kit to be dispensed to the patient". (p1169) }\end{array}$ \\
\hline $\begin{array}{l}\text { Blinding (performance } \\
\text { bias and detection bias) } \\
\text { All outcomes }\end{array}$ & Low risk & $\begin{array}{l}\text { Double blind. } \\
\text { Quote: "This was a 6-week, randomised, double-blind, placebo-controlled, } \\
\text { parallel group phase } 2 \text { study". (p1168) }\end{array}$ \\
\hline $\begin{array}{l}\text { Incomplete outcome data } \\
\text { (attrition bias) } \\
\text { All outcomes }\end{array}$ & Low risk & $\begin{array}{l}20 \text { participants in risperidone group and } 37 \text { participants in placebo group did } \\
\text { not complete the trial, but ITT analysis was applied. }\end{array}$ \\
\hline $\begin{array}{l}\text { Selective reporting (re- } \\
\text { porting bias) }\end{array}$ & Low risk & All the measured outcomes were reported. \\
\hline Other bias & Low risk & None obvious. \\
\hline
\end{tabular}

\section{Heisterberg 2007}

\begin{tabular}{ll}
\hline Methods & Allocation: randomised. \\
& Blindness: double. \\
& Duration: 6 weeks. \\
& Setting: no information available. \\
& Design: multicentre, parallel groups. \\
\hline Participants & Diagnosis: schizophrenia as per DSM-IV-TR. \\
& Age: 1899 - 69 years. \\
& Sex: male and female. \\
& History: having an acute exacerbation of schizophrenia. \\
& Inclusion criteria: baseline PANSS score of 70 to 120 and CGI score of $\geq 4$. \\
& Exclusion criteria: no information available. \\
\hline Interventions & 1. Risperidone: dose 6 mg/day, $\mathrm{N}=154$.
\end{tabular}


Heisterberg 2007 (Continued)

2. Placebo: $\mathrm{N}=149$.

3. Bifeprunox: $\mathrm{N}=296$.

\begin{tabular}{ll}
\hline Outcomes & Adverse events: lipid parameters*, EPS. \\
& Leaving the study early. \\
& Unable to use: \\
Adverse effects: weight change (no SD reported). \\
\hline Notes & Study attrition was $60 \%$ at the end of 6 weeks -- no data included in efficacy analysis. \\
& *We reported this data as the paper used LOCF to account for missing values. \\
\hline
\end{tabular}

\section{Risk of bias}

Bias Authors' judgement Support for judgement

Random sequence genera- Unclear risk Randomised, no further information. Quote: "...patients with acutely exacertion (selection bias) ～bated schizophrenia were randomly assigned to..."

\begin{tabular}{lll}
\hline $\begin{array}{l}\text { Allocation concealment } \\
\text { (selection bias) }\end{array}$ & Unclear risk & No information available. \\
\hline $\begin{array}{l}\text { Blinding (performance } \\
\text { bias and detection bias) }\end{array}$ & Low risk & Double blinded. \\
All outcomes & \\
\hline
\end{tabular}

\begin{tabular}{lll}
$\begin{array}{l}\text { Incomplete outcome data } \\
\text { (attrition bias) } \\
\text { All outcomes }\end{array}$ & Low risk & ITT analysis done. \\
\hline $\begin{array}{l}\text { Selective reporting (re- } \\
\text { porting bias) }\end{array}$ & Unclear risk & Outcomes listed in the methods were reported. \\
\hline Other bias & Low risk & None obvious. \\
\hline
\end{tabular}

Honer 2006

$\begin{array}{ll}\text { Methods } & \text { Allocation: randomised. } \\ & \text { Blindness: double. } \\ \text { Duration: } 8 \text { weeks. } & \\ & \text { Setting: inpatient and community settings. } \\ & \text { Design: multicentre, parallel-group study. } \\ & \text { Diagnosis: schizophrenia or schizoaffective disorder (DSM-IV). } \\ \mathrm{N}=68 . & \text { Age: } 18-65 \text { years. } \\ \text { Sex: male and female. } \\ \text { History: poor response to clozapine. } \\ \text { Inclusion criteria: all participants on clozapine at a stable dose of } 400 \text { mg or more for at least } 12 \text { weeks, } \\ \text { baseline PANSS score of } 80 \text { or greater, baseline CGI score of } 4 \text { or greater, baseline SOFAS score of } 40 \text { or } \\ \text { less. } \\ \text { Exclusion criteria: alcohol or substance misuse in the past } 3 \text { months, pregnant, breastfeeding, people } \\ \text { needing anticonvulsants, developmental disabilities, current treatment with clozapine for the primary } \\ \text { indication of movement disorder. }\end{array}$


Honer 2006 (Continued)

Interventions $\quad 1$. Risperidone ( $3 \mathrm{mg} /$ day) combined with clozapine ( $400 \mathrm{mg}$ or more/day), $\mathrm{N}=34$.

2. Placebo combined with clozapine (400 mg or more/day), $\mathrm{N}=34$.

Outcomes

Mental state: PANSS.

Leaving the study early.

Global state: CGI-S.

Adverse effects: ESRS, BAS, dystonia, dyskinesia, parkinsonism, lipid profile, weight, waist circumfer-

ence, BMI, fasting blood glucose, white cell count, neutrophil count.

Unable to use:

Cognitive functions: frontal lobe cognitive functions (no data reported). Verbal working-memory index (not peer-reviewed scale).

Adverse effects: UKU Side Effect Rating Scale (no data reported).

\section{Notes}

Supported by Stanley Medical Research Institute. The investigators had assessed 595 people for eligibility for the study, of which 458 (77\%) did not meet the inclusion criteria and 69 (12\%) declined to participate.

Leaving the study early rate is less than $50 \%$.

\section{Risk of bias}

\begin{tabular}{|c|c|c|}
\hline Bias & Authors' judgement & Support for judgement \\
\hline $\begin{array}{l}\text { Random sequence genera- } \\
\text { tion (selection bias) }\end{array}$ & Low risk & $\begin{array}{l}\text { Computer-generated schedule with a permuted-block design. Quote: "ran- } \\
\text { domisation was performed according to a computer-generated schedule with } \\
\text { a permuted-block design. The fixed block size was four patients". p473. }\end{array}$ \\
\hline $\begin{array}{l}\text { Allocation concealment } \\
\text { (selection bias) }\end{array}$ & Low risk & $\begin{array}{l}\text { Quote: "the site investigators did not know the block size. The person generat- } \\
\text { ing the randomization schedule was not involved in determining patients' eli- } \\
\text { gibility, administering treatment, or determining outcome." p473. }\end{array}$ \\
\hline $\begin{array}{l}\text { Blinding (performance } \\
\text { bias and detection bias) } \\
\text { All outcomes }\end{array}$ & Low risk & $\begin{array}{l}\text { Triple blinding (participants, investigator, and assessor blind) done but not } \\
\text { tested out. Quote: "randomly assigned to double-blind treatment with risperi- } \\
\text { done or a placebo of identical appearance". p473. }\end{array}$ \\
\hline $\begin{array}{l}\text { Incomplete outcome data } \\
\text { (attrition bias) } \\
\text { All outcomes }\end{array}$ & Low risk & ITT principle using mixed-model analysis. \\
\hline $\begin{array}{l}\text { Selective reporting (re- } \\
\text { porting bias) }\end{array}$ & Unclear risk & Outcomes listed in the methods were reported. \\
\hline Other bias & Low risk & $\begin{array}{l}\text { Janssen-Ortho, Canada, provided the risperidone and matching placebo } \\
\text { and reviewed the protocol, but no request for amendment. The data were } \\
\text { analysed and the manuscript was written solely by the listed authors. }\end{array}$ \\
\hline
\end{tabular}

\section{Marder 1994a}

Methods
Allocation: randomised.
Blindness: double.
Duration: 7-day single-blind placebo washout period plus 8-week treatment period.
Setting: inpatients, 20 centres in USA.
Design: parallel-group study.


Marder 1994a (Continued)

Participants
$\begin{aligned} & \text { Diagnosis: schizophrenia (DSM III-R). } \\ & \text { Age: } 188^{\star}-67 \text { years. } \\ & \text { Sex: male and female. } \\ & \text { Inclusion criteria: total PANSS score betweer } \\ & \text { Exclusion criteria: pregnant or lactating wo } \\ & \text { disorders other than schizophrenia, neurolo } \\ & \text { abuse, and schizoaffective disorder. } \\ & \text { 1. Risperidone: dose } 2 \mathrm{mg} / \text { day, } \mathrm{N}=63^{\star \star} . \\ & \text { 2. Risperidone: dose } 6 \mathrm{mg} / \text { day, } \mathrm{N}=64^{\star \star} . \\ & \text { 3. Risperidone: dose } 10 \mathrm{mg} / \text { day, } \mathrm{N}=65 . \\ & \text { 4. Risperidone: dose } 16 \mathrm{mg} / \text { day, } \mathrm{N}=64 . \\ & \text { 5. Placebo: } \mathrm{N}=66 . \\ & \text { 6. Haloperidol: dose } 20 \mathrm{mg} / \text { day, } \mathrm{N}=66 .\end{aligned}$

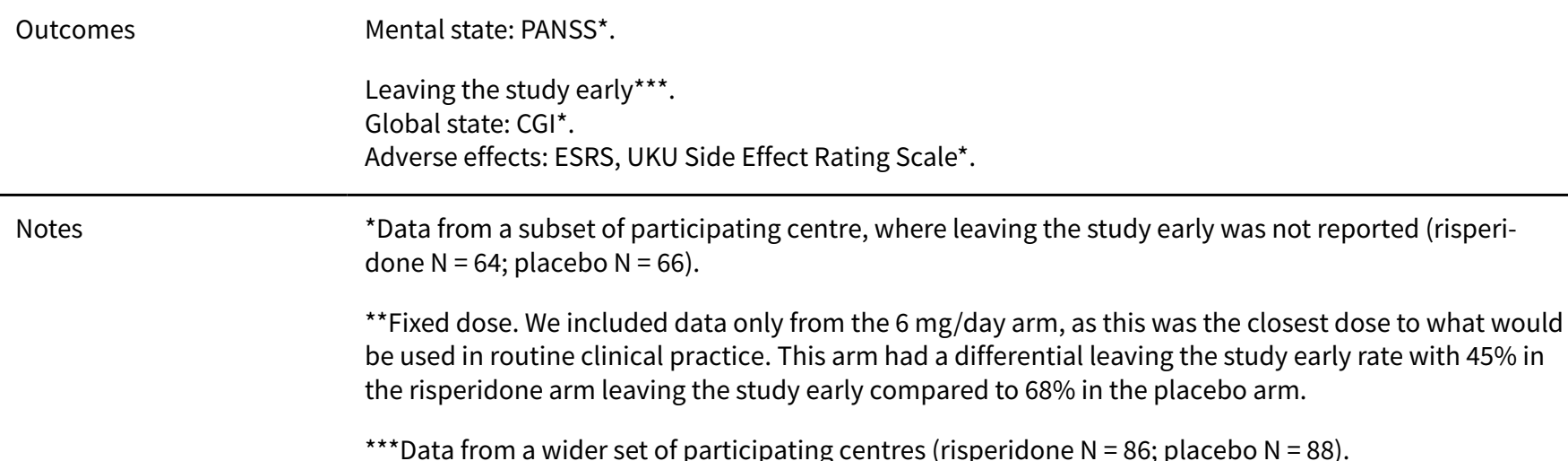

${ }^{\star \star \star}$ Data from a wider set of participating centres (risperidone $N=86$; placebo $N=88$ ).

\section{Risk of bias}

\section{Bias}

Random sequence genera- Low risk tion (selection bias)

\begin{tabular}{lll}
\hline $\begin{array}{l}\text { Allocation concealment } \\
\text { (selection bias) }\end{array}$ & Unclear risk & No information available.
\end{tabular}

\section{Authors' judgement Support for judgement}

Blinding (performance Low risk Double blind.

bias and detection bias)

All outcomes

\begin{tabular}{lll}
$\begin{array}{l}\text { Incomplete outcome data } \\
\text { (attrition bias) } \\
\text { All outcomes }\end{array}$ & Low risk & ITT analysis was used. \\
\hline $\begin{array}{l}\text { Selective reporting (re- } \\
\text { porting bias) }\end{array}$ & Low risk & All outcomes measured were reported.
\end{tabular}

Other bias High risk Supported by a grant from the Janssen Research Foundation.

Methods Allocation: randomised.


Pai 2002 (Continued)

Blindness: double blind, a placebo with an identical appearance to the risperidone, but unclear who is blinded.

Duration: 12 weeks.

Settings: not stated.

Design: parallel.

Participants
N $=50^{\star}$.
Age: mean $~ 50.2$ years, SD 9.6 years.
Sex: male $=20$ and female $=10$.
Length of illness: mean 11.86 years, SD 10.1 years.
Inclusion criteria: age between 18 and 65 years, maintenance on conventional antipsychotics for more
than 1 year with an equivalent dosage of less than 200 mg/day of chlorpromazine, BPRS total scores of
less than 20 , and no record of any violent or aggressive behavior within the last 6 months, to minimise
the risk of psychotic exacerbation after withdrawing antipsychotics.
Exclusion criteria: comorbidity of organic mental disorder or major physical illness, ever being pre-
scribed any atypical antipsychotic, and neuroleptic depot administration within the last 6 months.

Interventions 1 . Risperidone: titration period 6 weeks from $2 \mathrm{mg} / \mathrm{d}$ to $6 \mathrm{mg} / \mathrm{d}$, then with fixed dosage of $6 \mathrm{mg} / \mathrm{d}$ for the remaining 6 weeks, $\mathrm{N}=22$.

2. Placebo: titration period 6 weeks from $2 \mathrm{mg} / \mathrm{d}$ to $6 \mathrm{mg} / \mathrm{d}$, then with fixed dosage of $6 \mathrm{mg} / \mathrm{d}$ for the remaining 6 weeks, $\mathrm{N}=20$.

\begin{tabular}{|c|c|c|}
\hline \multirow[t]{5}{*}{ Outcomes } & \multicolumn{2}{|l|}{ Mental state: BPRS. } \\
\hline & \multicolumn{2}{|c|}{ Leaving the study early. } \\
\hline & \multicolumn{2}{|c|}{$\begin{array}{l}\text { Global state: needing additional medication; CGI. } \\
\text { Adverse effects: ESRS-parkinsonism score, ESRS-dystonia score, AIMS total score, concomitant with } \\
\text { benzodiazepine, concomitant with antiparkinsonism drug. }\end{array}$} \\
\hline & \multicolumn{2}{|l|}{ Unable to use: } \\
\hline & \multicolumn{2}{|c|}{$\begin{array}{l}\text { The number of participants leaving the study early in each group was not reported. Change score of } \\
\text { ESRS, change score of AIMS. Change scores were not used, as endpoint scores of the same scales were } \\
\text { available. }\end{array}$} \\
\hline Notes & \multicolumn{2}{|c|}{${ }^{\star} 2$ of the references reported $N=50,1$ reference reported $N=49$. We assume $N=50$ in this review. } \\
\hline \multicolumn{3}{|l|}{ Risk of bias } \\
\hline Bias & Authors' judgement & Support for judgement \\
\hline \multirow{2}{*}{$\begin{array}{l}\text { Random sequence genera- } \\
\text { tion (selection bias) }\end{array}$} & \multirow[t]{2}{*}{ Unclear risk } & Randomised, no further information: \\
\hline & & $\begin{array}{l}\text { Quote: "subjects were randomly assigned to the risperidone or placebo } \\
\text { groups". (Bai 2003, p1343) }\end{array}$ \\
\hline $\begin{array}{l}\text { Allocation concealment } \\
\text { (selection bias) }\end{array}$ & Unclear risk & Not stated. \\
\hline $\begin{array}{l}\text { Blinding (performance } \\
\text { bias and detection bias) } \\
\text { All outcomes }\end{array}$ & Low risk & $\begin{array}{l}\text { Quote: "double blind, a placebo with an identical appearance to the risperi- } \\
\text { done, but unclear who is blinded." (p1343) }\end{array}$ \\
\hline $\begin{array}{l}\text { Incomplete outcome data } \\
\text { (attrition bias) } \\
\text { All outcomes }\end{array}$ & High risk & $\begin{array}{l}42 \text { participants completed the } 12 \text {-week study and } 7 \text { participants withdrew. } 4 \\
\text { participants left the study early due to psychotic symptom exacerbation, an- } \\
\text { other } 3 \text { participants withdrew due to a medical condition. }\end{array}$ \\
\hline
\end{tabular}


Pai 2002 (Continued)

Selective reporting (re- Low risk $\quad$ All the measured outcomes were reported.
porting bias)

porting bias)

Other bias

Low risk

None obvious.

Potkin 1997

\begin{tabular}{ll}
\hline Methods & Allocation: randomised. \\
Blindness: double blind. \\
Duration: 4 weeks. \\
Setting: multicentre, USA. \\
Design: parallel.
\end{tabular}

\begin{tabular}{|c|c|}
\hline Participants & $\begin{array}{l}\text { Diagnosis: schizophrenia. } \\
N=246 \text {. } \\
\text { Age: no information available. } \\
\text { Sex: male and female. } \\
\text { Inclusion criteria: PANSS score of } 80 \text { to } 120, \geq 8 \text { on at least } 2 \text { items on the PANSS positive subscale. } \\
\text { Exclusion criteria: no information available. }\end{array}$ \\
\hline Interventions & $\begin{array}{l}\text { 1. Risperidone: dose } 4 \mathrm{mg} / \text { day, } \mathrm{N}=85 \text {. } \\
\text { 2. Risperidone: dose } 8 \mathrm{mg} / \mathrm{day}, \mathrm{N}=78^{\star} \text {. } \\
\text { 3. Placebo: } \mathrm{N}=83 \text {. }\end{array}$ \\
\hline Outcomes & $\begin{array}{l}\text { Mental state: PANSS. } \\
\text { Leaving the study early. } \\
\text { Adverse effects: any adverse event. } \\
\text { Unable to use: } \\
\text { Adverse effects: ESRS (SD not reported). }\end{array}$ \\
\hline Notes & $\begin{array}{l}\text { *We adopted data from the } 4 \mathrm{mg} \text { arm, as it's more representative of the dosage used in a normal } \mathrm{c} \\
\text { cal setting. }\end{array}$ \\
\hline
\end{tabular}

\section{Risk of bias}

\begin{tabular}{lll}
\hline Bias & Authors' judgement & Support for judgement \\
\hline $\begin{array}{l}\text { Random sequence genera- } \\
\text { tion (selection bias) }\end{array}$ & Unclear risk & Randomised, no further description. \\
\hline $\begin{array}{l}\text { Allocation concealment } \\
\text { (selection bias) }\end{array}$ & Unclear risk & Not reported. \\
\hline $\begin{array}{l}\text { Blinding (performance } \\
\text { bias and detection bias) } \\
\text { All outcomes }\end{array}$ & Low risk & Double blind. \\
\hline $\begin{array}{l}\text { Incomplete outcome data } \\
\text { (attrition bias) } \\
\text { All outcomes }\end{array}$ & Unclear risk & No information available. \\
\hline $\begin{array}{l}\text { Selective reporting (re- } \\
\text { porting bias) }\end{array}$ & Low risk & All outcomes measured were reported. \\
\hline
\end{tabular}


Potkin 1997 (Continued)

Other bias High risk Funded by Janssen Research Foundation.

Potkin 2003

Methods $\begin{aligned} & \text { Allocation: randomised. } \\ & \text { Blindness: double. } \\ & \text { Duration: } 4 \text { weeks. } \\ & \text { Setting: inpatients, } 40 \text { centres in USA. } \\ & \text { Design: parallel. } \\ & \text { Diagnosis: schizophrenia and schizoaffective disorder (DSM-IV). } \\ & \text { N = 404. } \\ & \text { Age: the mean age for each treatment group ranged from } 38.1 \text { to } 40.2 \text { years. } \\ & \text { Sex: male = 283, female = 121. } \\ & \text { Length of illness: not reported. } \\ & \text { Inclusion criteria: men and non-pregnant, non-lactating women, evidence of responsiveness to an- } \\ & \text { tipsychotic medications (were not refractory to antipsychotics and had previously shown an improve- } \\ & \text { ment with an antipsychotic drug other than clozapine and had been an outpatient for at least } 13- \\ & \text { month period during the last year, PANSS score of at least } 60 \text { and a minimum score of } 4 \text { (moderate) on } \\ & \text { at least } 2 \text { items of the psychotic item subscale. } \\ & \text { Exclusion criteria: history of violence, recent history of suicide attempt or serious suicide thoughts, } \\ & \text { neurological disorders other than TD or EPS, psychoactive substance dependence or history of drug or } \\ & \text { alcohol abuse within } 1 \text { month, treatment with an investigational drug within } 4 \text { weeks of the investiga- } \\ & \text { tional period, any acute or unstable medical condition. }\end{aligned}$

Interventions
2. Aripipriprazole: dose $20 \mathrm{mg} /$ day $\mathrm{N}=101^{\star}$.
3. Aripiprazole: dose $30 \mathrm{mg} /$ day $\mathrm{N}=101^{*}$.
4. Placebo: $\mathrm{N}=103$.

\section{Outcomes}

Mental State: PANSS.

Leaving the study early.

Adverse effects.

Unable to use:

Global State: CGI (no SD reported).

Mental state: BPRS, PANSS change score (no SD reported).

Adverse effects: EPS, SAS, BAS, AIMS (no data reported). Body weight, serum prolactin, corrected QT (no SD reported). Pain was reported as "pain", "extremity pain", and "back pain"; since we are unsure if participants overlapped in these categories, we selected "back pain" to report to avoid double counting.

\section{Notes}

Lorazepam was used for anxiety and insomnia.

Intramuscular lorazepam was used for agitation.

Benztropine up to $6 \mathrm{mg}$ per day was permitted for EPS.

Psychotropics other than those prescribed by the study protocol were prohibited.

*Data from these 2 arms were not used in this review.

\section{Risk of bias}


Potkin 2003 (Continued)

Random sequence genera- Unclear risk Quote: "This was a randomised, 4-week, inpatient, double-blind, placebo-contion (selection bias)

trolled, parallel-group study". (p682).

$\begin{aligned} & \text { Allocation concealment } \\ & \text { (selection bias) }\end{aligned}$
Unclear risk information available.

(selection bias)

Blinding (performance Low risk
bias and detection bias)

Quote: "This was a randomised, 4-week, inpatient, double-blind, placebo-con-

All outcomes

\begin{tabular}{lll}
\hline Incomplete outcome data & High risk & Attrition was 40\% (162/242) in this study. Although 392 participants were in- \\
(attrition bias) & & cluded in efficacy analysis using LOCF and 403 were included in safety analy- \\
All outcomes & sis, we feel that the high attrition rate made any results from this trial prone to \\
& bias.
\end{tabular}

\begin{tabular}{l}
\hline $\begin{array}{l}\text { Selective reporting (re- } \\
\text { porting bias) }\end{array}$ \\
\hline
\end{tabular}

Other bias High risk Supported by Bristol-Myers Squibb and Otsuka Pharmaceutical.

\section{Potkin 2006}

Methods $\begin{aligned} & \text { Allocation: randomised. } \\ & \text { Blindness: double. } \\ & \text { Duration: } 6 \text { weeks }{ }^{\star} . \\ & \text { Setting: inpatients, } 30 \text { sites, USA. } \\ & \text { Design: parallel. } \\ & \text { Diagnosis: schizophrenia or schizoaffective disorder (DSM-IV). } \\ & \text { N }=381 . \\ & \text { Age: mean } 34.8 \text { years, SD } 9.7 \text { years. } \\ & \text { Sex: male }=228 \text { and female }=153 . \\ & \text { Length of illness: not reported. } \\ & \text { Inclusion criteria: } 18-64 \text { years old, acute exacerbation of schizophrenia of recent onset (within } 4 \text { weeks), } \\ & \text { have a score of } \geq 4 \text { at least } 2 \text { of the following items on the PANSS: Hostility, Excitment, Tension, Unco- } \\ & \text { operativeness, and Poor Impulse Control, and a total score on the } 5 \text { items of at least } 17 \text {, CGI } \geq 5 . \\ & \text { Exclusion criteria: comorbid Axis } 1 \text { diagnosis with the exception of substance abuse/dependence, bor- } \\ & \text { derline personality disorder, mental retardation or clinically significant medical illness, also exclud- } \\ & \text { ed were people who received risperidone or quetiapine within } 7 \text { days of baseline, clozapine within } 60 \\ & \text { days, or depot antipsychotic or electroconvulsive therapy within the study period. }\end{aligned}$

\begin{tabular}{ll}
\hline Interventions & 1. Risperidone: dose $4.7 \pm 0.9 \mathrm{mg} / \mathrm{day}, \mathrm{N}=153$. \\
2. Quetiapine: dose $579.5 \pm 128.9 \mathrm{mg} / \mathrm{day}, \mathrm{N}=156$. \\
3. Placebo: $\mathrm{N}=73$. \\
Zolpidem, zopiclone, and zaleplon used to treat insomnia. \\
Injectable lorazepam, sodium amytal, or midazolam used for treating agitation or restlessness. \\
Benztropine mesylate or an equivalent treatment for movement disorder was permitted throughout \\
study as needed. \\
Mental state: PANSS. \\
Leaving the study early. \\
Global state: CGI-Severity, CGI-Change. \\
Adverse effects: SAS, BAS, prolactin, EPS.
\end{tabular}


Potkin 2006 (Continued)

Unable to use:

Readiness for discharge questionnaire (not a validated scale).

Study medication satisfaction (not a validated scale).

Notes

* 2 weeks monotherapy phase followed by a 4-week additive therapy phase. In the additive therapy phase, all the participants in the 3 groups received other antipsychotic drugs. As the data in these two phases is reported separately, we only use the data from the 2-week monotherapy phase.

\section{Risk of bias}

\begin{tabular}{lll}
\hline Bias & Authors' judgement & Support for judgement \\
\hline $\begin{array}{l}\text { Random sequence genera- } \\
\text { tion (selection bias) }\end{array}$ & Low risk & Randomised using a centralised interactive voice response system. \\
& $\begin{array}{l}\text { Quote: "A non-centralised randomisation strategy was used to ensure that } \\
\text { subjects were balanced across the three treatments within each investigate } \\
\text { site... subjects were assigned to a double blind treatment using a centralized } \\
\text { interactive voice response system (IVRS)" (p255) }\end{array}$ \\
\hline
\end{tabular}

\begin{tabular}{|c|c|c|}
\hline $\begin{array}{l}\text { Allocation concealment } \\
\text { (selection bias) }\end{array}$ & Low risk & Concealed with centralised IVRS. \\
\hline $\begin{array}{l}\text { Blinding (performance } \\
\text { bias and detection bias) } \\
\text { All outcomes }\end{array}$ & Low risk & Double blind by using a centralised IVRS ( $\mathrm{p} 255$ ) \\
\hline $\begin{array}{l}\text { Incomplete outcome data } \\
\text { (attrition bias) } \\
\text { All outcomes }\end{array}$ & Low risk & ITT analysis was used. \\
\hline $\begin{array}{l}\text { Selective reporting (re- } \\
\text { porting bias) }\end{array}$ & Low risk & All outcomes measured were reported. \\
\hline Other bias & High risk & Supported by Janssen Pharmaceutica. \\
\hline
\end{tabular}

\section{Potkin 2007}

\begin{tabular}{ll}
\hline Methods & Allocation: randomised. \\
& Blindness: double. \\
& Duration: 6 weeks. \\
& Setting: 21 sites in USA. \\
& Design: parallel. \\
\hline Participants & Diagnosis: schizophrenia. \\
N $=180$. & Age: 18 to 65 years. \\
Sex: not reported. & History: participants with acute exacerbation were included in the trial. \\
Inclusion criteria: baseline PANSS score $>60$. \\
Exclusion criteria: recent history of suicide attempt or serious suicide thoughts, neurological disorders \\
other than TD or EPS, psychoactive substance dependence or history of drug or alcohol abuse within 1 \\
month.
\end{tabular}


Potkin 2007 (Continued)

3. Asenapine: dose $10 \mathrm{mg} /$ day, $\mathrm{N}=59$.

Leaving the study early.
Adverse effects.
Unable to use:
Global state: $C G I$ ( $>50 \%$ loss to follow-up, thus data was not reported).
Mental state: PANSS (> 50\% loss to follow-up, thus data was not reported).
Function: battery of neurocognitive test (no SD reported), WCST (no data reported).

\section{Notes}

\section{Risk of bias}

\begin{tabular}{lll}
\hline Bias & Authors' judgement & Support for judgement \\
\hline $\begin{array}{l}\text { Random sequence genera- } \\
\text { tion (selection bias) }\end{array}$ & Unclear risk & Randomised, no further information. \\
\hline $\begin{array}{l}\text { Allocation concealment } \\
\text { (selection bias) }\end{array}$ & Unclear risk & No information available. \\
\hline $\begin{array}{l}\text { Blinding (performance } \\
\text { bias and detection bias) } \\
\text { All outcomes }\end{array}$ & Low risk & $\begin{array}{l}\text { Double dummy placebo design was employed to maintain blinding. Quote: } \\
\text { "this double-blind, double-dummy, 3-arm, fixed-dose..." (p1493). }\end{array}$ \\
\hline $\begin{array}{l}\text { Incomplete outcome data } \\
\text { (attrition bias) } \\
\text { All outcomes }\end{array}$ & Low risk & ITT for efficacy data and LOCF for safety data. \\
\hline $\begin{array}{l}\text { Selective reporting (re- } \\
\text { porting bias) }\end{array}$ & Low risk & All outcomes measured were reported. \\
\hline \begin{tabular}{l} 
Other bias \\
\hline
\end{tabular} & High risk & Funded by Organon USA Inc and Pfizer Inc. \\
\hline
\end{tabular}

\section{Yagcioglu 2005}

\begin{tabular}{ll}
\hline Methods & Allocation: randomised. \\
Blindness: double. \\
Duration: 6 weeks. \\
Setting: inpatients and outpatients, 2 sites in Turkey. \\
Design: parallel. \\
Diagnosis: schizophrenia (DSM-IV). \\
N $=30$. \\
Age: 18 to 55 years. \\
Sex: male $=20$ and female $=10$. \\
Length of illness: mean 14.4 years, SD 9.1 years. \\
Inclusion criteria: patients had been receiving clozapine treatment (300 mg/d to 900 mg/d) for at least \\
6 months prior to the study; people diagnosed as having residual schizophrenia in whom negative \\
symptoms were more prominent than positive symptoms; failed to respond adequately; positive symp- \\
toms was stable by clinical criteria and reported in written notes for at least 3 months prior to study en- \\
try; PANSS $\geq 72$, CGI-S $\geq 4$, a score of at least 3 on any one of the PANSS POS items.
\end{tabular}


Yagcioglu 2005 (Continued)

Exclusion criteria: concomitantly receiving mood stabilisers, including lithium carbonate, antidepressants, and antipsychotic medication other than clozapine; alcohol or substance dependence; history of intolerance to risperidone for reasons other than EPS.

Interventions 1 . Risperidone combined with clozapine: dose $2 \mathrm{mg} /$ day to $6 \mathrm{mg} /$ day, $\mathrm{N}=16$.

2. Placebo combined with clozapine, $\mathrm{N}=14$.

\begin{tabular}{|c|c|c|}
\hline \multirow[t]{7}{*}{ Outcomes } & \multicolumn{2}{|l|}{ Clinical response*. } \\
\hline & \multicolumn{2}{|l|}{ Leaving the study early. } \\
\hline & \multicolumn{2}{|l|}{ Global state: CGI-S. } \\
\hline & \multicolumn{2}{|l|}{ Functioning: GAF. } \\
\hline & \multicolumn{2}{|c|}{ Mental state: PANSS, CDS. } \\
\hline & \multicolumn{2}{|c|}{ Adverse effect: weight gain, serum prolactin, SAS, BAS, AIMS score. } \\
\hline & \multicolumn{2}{|l|}{ Quality of life: QLS. } \\
\hline Notes & \multicolumn{2}{|c|}{ *no clinical improvement: PANSS positive subscale score $<20 \%$. } \\
\hline \multicolumn{3}{|l|}{ Risk of bias } \\
\hline Bias & Authors' judgement & Support for judgement \\
\hline $\begin{array}{l}\text { Random sequence genera- } \\
\text { tion (selection bias) }\end{array}$ & Unclear risk & $\begin{array}{l}\text { Unclear how the "pre-assigned random sequence" was achieved. Quote: "Ran- } \\
\text { domisation was planned by one of the unblinded investigators prior to the } \\
\text { initiation of the study in a 1:1 ratio, and pre-assigned random sequence was } \\
\text { determined for each site. The patients arriving at each site were assigned the } \\
\text { study medication according to this sequence in order with their enrolmen- } \\
\text { t." (p65) }\end{array}$ \\
\hline $\begin{array}{l}\text { Allocation concealment } \\
\text { (selection bias) }\end{array}$ & Unclear risk & $\begin{array}{l}\text { Not stated. Quote: "pre-assigned random sequence was determined for each } \\
\text { site." (p65) }\end{array}$ \\
\hline $\begin{array}{l}\text { Blinding (performance } \\
\text { bias and detection bias) } \\
\text { All outcomes }\end{array}$ & Low risk & Double blind, investigators were blinded, no further information. \\
\hline $\begin{array}{l}\text { Incomplete outcome data } \\
\text { (attrition bias) } \\
\text { All outcomes }\end{array}$ & Low risk & $\begin{array}{l}\text { One participant in the risperidone group withdrew consent just prior to final } \\
\text { visit ratings. This is unlikely to have any significant impact on the outcome as- } \\
\text { sessment. }\end{array}$ \\
\hline $\begin{array}{l}\text { Selective reporting (re- } \\
\text { porting bias) }\end{array}$ & Low risk & All the outcomes were reported. \\
\hline Other bias & Low risk & None obvious. \\
\hline
\end{tabular}

AIMS: Abnormal Involuntary Movement Scale

BACS: Brief Assessment of Cognition in Schizophrenia

BAS: Barnes Akathisia Scale

BMI: body mass index

BPRS: Brief Psychiatric Rating Scale

CDS: Calgary Depression Scale 
CGI: Clinical Global Impression

DSM: Diagnostic and Statistical Manual of Mental Disorders

ECG: electrocardiogram

EPS: extrapyramidal symptom

ESRS: Extrapyramidal Symptom Rating Scale

GAF: Global Assessment of Functioning

HAM-D: Hamilton Rating Scale for Depression

ISST: InterSePT Scale for Suicidal Thinking

ITT: intention to treat

IVRS: interactive voice response system

LOCF: last observation carried forward

PANSS: Positive and Negative Syndrome Scale

QLS: Quality of Life Scale

SANS: Scale for the Assessment of Negative Symptoms

SAS: Simpson Angus Scale

SD: standard deviation

SOFAS: Social and Occupational Functioning Assessment Scale

TD: tardive dyskinesia

WCST: Wisconsin Card Sorting Test

Characteristics of excluded studies [ordered by study ID]

\begin{tabular}{|c|c|}
\hline Study & Reason for exclusion \\
\hline Adler 1999 & $\begin{array}{l}\text { Allocation: randomised. } \\
\text { Participants: people with non-organic psychosis. } \\
\text { Interventions: vitamin E versus placebo. }\end{array}$ \\
\hline Akhondzadeh 2005 & $\begin{array}{l}\text { Allocation: randomised. } \\
\text { Participants: people with chronic schizophrenia. } \\
\text { Interventions: risperidone plus lamotrigine versus risperidone plus placebo. }\end{array}$ \\
\hline Akhondzadeh 2007 & $\begin{array}{l}\text { Allocation: randomised. } \\
\text { Participants: people with chronic schizophrenia. } \\
\text { Interventions: risperidone plus celecoxib versus risperidone plus placebo. }\end{array}$ \\
\hline Anwunah 1999 & $\begin{array}{l}\text { Allocation: randomised. } \\
\text { Participants: people with schizotypal personality disorder. }\end{array}$ \\
\hline Ayd 2001 & $\begin{array}{l}\text { Allocation: randomised. } \\
\text { Participants: people with schizotypal personality disorder. }\end{array}$ \\
\hline Azorin 2002 & $\begin{array}{l}\text { Allocation: randomised. } \\
\text { Participants: people with schizophrenia. } \\
\text { Interventions: risperidone versus sertindole. }\end{array}$ \\
\hline Azorin 2006 & $\begin{array}{l}\text { Allocation: randomised. } \\
\text { Participants: people with schizophrenia. } \\
\text { Interventions: risperidone versus sertindole. }\end{array}$ \\
\hline
\end{tabular}




\section{Study}

Bai 2005

\section{Reason for exclusion}

Allocation: randomised.

Participants: people with schizophrenia.

Intervention: risperidone versus other atypicals (no placebo arm).

\begin{tabular}{ll} 
Baker 2012 & Allocation: not RCT but pooled data from RCTs. \\
\hline Basson 2001 & Allocation: randomised. \\
& $\begin{array}{l}\text { Participants: people with schizophrenia. } \\
\text { Intervention: olanzapine versus haloperidol versus risperidone. }\end{array}$
\end{tabular}

\begin{tabular}{ll}
\hline Beasley 1996 & Allocation: randomised. \\
& Participants: people with schizophrenia. \\
Intervention: olanzapine versus placebo versus haloperidol.
\end{tabular}

\begin{tabular}{ll}
\hline Bondolfi 1998 & $\begin{array}{l}\text { Allocation: randomised. } \\
\text { Participants: people with resistant schizophrenia. } \\
\text { Intervention: clozapine versus risperidone. }\end{array}$ \\
\hline Borison 1992a & $\begin{array}{l}\text { Allocation: randomised. } \\
\text { Participants: people with chronic schizophrenia. } \\
\text { Intervention: risperidone versus haloperidol. }\end{array}$ \\
\hline Boyer 1995 & $\begin{array}{l}\text { Allocation: randomised. } \\
\text { Participants: people with negative schizophrenia. } \\
\text { Intervention: amisulpride versus placebo. }\end{array}$
\end{tabular}

\begin{tabular}{ll}
\hline Brecher 1998 & $\begin{array}{l}\text { Allocation: randomised. } \\
\text { Participants: people with schizophrenia. } \\
\text { Interventions: risperidone versus olanzapine. }\end{array}$ \\
\hline Cada 2004 & $\begin{array}{l}\text { Allocation: randomised. } \\
\text { Participants: people with schizophrenia. } \\
\text { Intervention: risperidone long-acting injection versus placebo. }\end{array}$ \\
\hline Carson 2002 & $\begin{array}{l}\text { Allocation: randomised. } \\
\text { Participants: people with schizophrenia. } \\
\text { Intervention: aripiprazole versus haloperidol versus placebo. }\end{array}$
\end{tabular}

\begin{tabular}{ll}
\hline Casey 2003 & Allocation: randomised. \\
& Participants: people with schizophrenia. \\
& Intervention: aripiprazole versus placebo.
\end{tabular}

\begin{tabular}{ll}
\hline Castle 2015 & Allocation: not RCT but pooled data from RCTs. \\
\hline Chan 2007 & $\begin{array}{l}\text { Allocation: randomised. } \\
\text { Participants: people with schizophrenia. } \\
\text { Interventions: risperidone versus aripiprazole. }\end{array}$ \\
\hline Chue 2002 & $\begin{array}{l}\text { Allocation: randomised. } \\
\text { Participants: people with schizophrenia. } \\
\text { Interventions: risperidone long-acting injection versus olanzapine. }\end{array}$ \\
\hline Ciliberto 2005 & $\begin{array}{l}\text { Allocation: randomised. } \\
\text { Participants: people with schizophrenia. } \\
\text { Interventions: risperidone long-acting injection versus placebo. }\end{array}$ \\
\hline Citrome 2004 & Allocation: randomised. \\
\hline
\end{tabular}




\begin{tabular}{ll}
\hline Study & Reason for exclusion \\
\hline Participants: people with schizophrenia. \\
Intervention: antipsychotic monotherapy versus antipsychotic plus valproate.
\end{tabular}

\begin{tabular}{ll}
\hline Claus 1992 & Allocation: randomised. \\
& Participants: people with schizophrenia. \\
& Interventions: risperidone versus haloperidol. \\
\hline
\end{tabular}

\begin{tabular}{ll}
\hline Conley 1998 & Allocation: randomised. \\
& Participants: people with schizophrenia. \\
& Intervention: risperidone versus olanzapine.
\end{tabular}

\begin{tabular}{ll}
\hline Cooper 1997 & Allocation: randomised. \\
& Participants: people with schizophrenia. \\
& Interventions: risperidone versus olanzapine versus quetiapine.
\end{tabular}

\begin{tabular}{ll}
\hline Cornblatt 2002 & Allocation: randomised. \\
& Participants: people with schizophrenia. \\
& Intervention: aripiprazole versus olanzapine.
\end{tabular}

\begin{tabular}{ll}
\hline Crawford 1997 & Allocation: randomised. \\
& Participants: people with schizophrenia. \\
& Intervention: olanzapine versus haloperidol versus placebo.
\end{tabular}

\begin{tabular}{ll}
\hline Csernansky 1999 & $\begin{array}{l}\text { Allocation: randomised. } \\
\text { Participants: people with schizophrenia. } \\
\text { Interventions: risperidone versus haloperidol. }\end{array}$ \\
\hline David 2000 & Allocation: not randomised. \\
\hline Davis 2001 & Allocation: not randomised. \\
\hline Dossenbach 1997 & Allocation: randomised. \\
Participants: people with schizophrenia. \\
Interventions: olanzapine versus fluphenazine.
\end{tabular}

\begin{tabular}{ll}
\hline Dubitsky 2002 & Allocation: randomised. \\
& Participants: people with schizophrenia. \\
& Intervention: aripiprazole versus risperidone.
\end{tabular}

\begin{tabular}{ll}
\hline Edgell 2000 & Allocation: randomised. \\
& Participants: people with schizophrenia. \\
& Intervention: risperidone versus olanzapine.
\end{tabular}

Fleming 2007a Allocation: randomised.

Participants: people with schizophrenia.

Intervention: asenapine versus risperidone versus placebo.

\begin{tabular}{ll}
\hline Friedman 2000 & Allocation: randomised. \\
& Participants: people with schizophrenia. \\
& Interventions: risperidone versus haloperidol.
\end{tabular}

\begin{tabular}{ll}
\hline Gismondi 2004 & Allocation: randomised. \\
& Participants: people with schizophrenia. \\
& Interventions: aripiprazole versus perphenazine.
\end{tabular}




\begin{tabular}{ll}
\hline Study & Reason for exclusion \\
\hline & Participants: people with schizophrenia. \\
Interventions: olanzapine versus haloperidol.
\end{tabular}

\begin{tabular}{ll}
\hline Harvey 2001 & Allocation: randomised. \\
& Participants: people with schizophrenia and schizoaffective disorder. \\
Interventions: risperidone versus olanzapine.
\end{tabular}

\begin{tabular}{ll}
\hline Hwang 2003 & $\begin{array}{l}\text { Allocation: randomised. } \\
\text { Participants: people with schizophrenia. } \\
\text { Interventions: risperidone versus amisulpride. }\end{array}$ \\
\hline Hwang 2005 & $\begin{array}{l}\text { Allocation: randomised. } \\
\text { Participants: people with schizophrenia. } \\
\text { Interventions: risperidone versus aripiprazole. }\end{array}$ \\
\hline Kane 2005 & $\begin{array}{l}\text { Allocation: randomised. } \\
\text { Participants: people with schizophrenia. } \\
\text { Interventions: risperidone, sertindole, and aripiprazole. }\end{array}$
\end{tabular}

\begin{tabular}{ll}
\hline Kinon 1998 & Allocation: randomised. \\
& Participants: people with schizophrenia. \\
& Interventions: olanzapine versus haloperidol.
\end{tabular}

\begin{tabular}{ll}
\hline Lemmens 1994 & Allocation: randomised. \\
& Participants: people with schizophrenia. \\
& Intervention: risperidone versus zuclopenthixol dihydrochloride.
\end{tabular}

\begin{tabular}{ll}
\hline Lieberman 2005 & $\begin{array}{l}\text { Allocation: randomised. } \\
\text { Participants: people with schizophrenia. } \\
\text { Interventions: olanzapine versus haloperidol. }\end{array}$ \\
\hline Lindstrom 1994 & $\begin{array}{l}\text { Allocation: randomised. } \\
\text { Participants: people with schizophrenia. } \\
\text { Intervention: risperidone versus haloperidol. }\end{array}$ \\
\hline Loo 1997 & $\begin{array}{l}\text { Allocation: randomised. } \\
\text { Participants: people with deficit schizophrenia. } \\
\text { Interventions: amisulpride versus placebo. }\end{array}$ \\
\hline Lopez 1996 & $\begin{array}{l}\text { Allocation: randomised. } \\
\text { Participants: people with schizophrenia. } \\
\text { Interventions: risperidone versus haloperidol. }\end{array}$ \\
\hline Lopez-Ibor 1992 & $\begin{array}{l}\text { Allocation: randomised. } \\
\text { Intervention: risperidone versus haloperidol. }\end{array}$ \\
\hline Luo 2011 & Allocation: randomised. \\
Participants: people with schizophrenia. \\
Intervention: paliperidone versus olanzapine versus placebo.
\end{tabular}




\begin{tabular}{ll}
\hline Study & Reason for exclusion \\
\hline Marder 1991 & Allocation: not RCT, but pooled data from two RCTs. \\
\hline McClellan 2009 & Allocation: randomised. \\
& Participants: people with schizophrenia. \\
& Interventions: risperidone versus olanzapine or molindone. \\
\hline
\end{tabular}

$\begin{array}{ll}\text { McClure } 2009 & \text { Allocation: randomised. } \\ \text { Patients: Schizotypal personality disorder. }\end{array}$

\begin{tabular}{ll}
\hline McKenna 2004 & $\begin{array}{l}\text { Allocation: randomised. } \\
\text { Participants: people with refractory schizophrenia. } \\
\text { Intervention: clozapine versus clozapine plus risperidone. }\end{array}$ \\
\hline Nasrallah 2004a & $\begin{array}{l}\text { Allocation: randomised. } \\
\text { Participants: people with schizophrenia. } \\
\text { Intervention: risperidone long-acting injection versus placebo. }\end{array}$ \\
\hline NCT 02109562 & $\begin{array}{l}\text { Allocation: randomised. } \\
\text { Participants: people with schizophrenia. }\end{array}$ \\
& Interventions: resperidone injections versus placebo. \\
\hline NCT00034892 & $\begin{array}{l}\text { Allocation: randomised. } \\
\text { Participants: people with schizophrenia, schizophreniform disorder, and schizoaffective disorder. } \\
\text { Interventions: risperidone versus quetiapine versus olanzapine. }\end{array}$ \\
\hline
\end{tabular}

$\begin{array}{ll}\text { NCT00088075 } & \begin{array}{l}\text { Allocation: randomised. } \\ \text { Participants: adolescents with schizophrenia. }\end{array}\end{array}$

\begin{tabular}{ll}
\hline NCT00202007 & Allocation: randomised. \\
& Participants: people with schizophrenia. \\
& Interventions: risperidone versus aripiprazole.
\end{tabular}

NCT00249119 Allocation: randomised.

Participants: people with schizophrenia.

Interventions: risperidone long-acting injection versus placebo.

\begin{tabular}{ll}
\hline NCT00253136 & $\begin{array}{l}\text { Allocation: randomised. } \\
\text { Participants: people with schizophrenia. } \\
\text { Interventions: risperidone versus haloperidol. }\end{array}$ \\
\hline NCT00305474 & $\begin{array}{l}\text { Allocation: randomised. } \\
\text { Participants: non-psychotic relatives of people with schizophrenia. }\end{array}$ \\
\hline Peuskens 1995 & $\begin{array}{l}\text { Allocation: randomised. } \\
\text { Participants: people with schizophrenia. } \\
\text { Intervention: risperidone versus haloperidol. }\end{array}$ \\
\hline Peuskens 2001 & $\begin{array}{l}\text { Allocation: randomised. } \\
\text { Participants: people with schizophrenia. } \\
\text { Intervention: risperidone versus amisulpride. }\end{array}$ \\
\hline Peuskens 2001a & $\begin{array}{l}\text { Allocation: randomised. } \\
\text { Participants: people with schizophrenia. }\end{array}$ \\
\hline
\end{tabular}




\begin{tabular}{ll}
\hline Study & Reason for exclusion \\
\hline & Intervention: risperidone versus amisulpride plus haloperidol. \\
\hline Pikalov 2012 & Allocation: not RCT, but pooled data from seven RCTs. \\
\hline
\end{tabular}

\begin{tabular}{ll}
\hline Rabinowitz 2001 & Allocation: randomised. \\
& Participants: people with schizophrenia. \\
& Intervention: risperidone versus haloperidol.
\end{tabular}

\begin{tabular}{ll}
\hline Rein 2002 & $\begin{array}{l}\text { Allocation: randomised. } \\
\text { Participants: people with schizophrenia. } \\
\text { Intervention: risperidone versus amisulpride. }\end{array}$ \\
\hline Revicki 1996 & $\begin{array}{l}\text { Allocation: randomised. } \\
\text { Participants: people with schizophrenia. } \\
\text { Interventions: olanzapine versus haloperidol. }\end{array}$ \\
\hline Riedel 2003 & $\begin{array}{l}\text { Allocation: randomised. } \\
\text { Participants: people with schizophrenia. } \\
\text { Intervention: risperidone plus celecoxib versus risperidone plus placebo. }\end{array}$
\end{tabular}

\begin{tabular}{|c|c|}
\hline Schmechtig 2010 & $\begin{array}{l}\text { Allocation: randomised. } \\
\text { Participants: health volunteers. }\end{array}$ \\
\hline Siever 2002 & $\begin{array}{l}\text { Allocation: randomised. } \\
\text { Participants: people with schizotypal personality disorder. }\end{array}$ \\
\hline Tollefson 1996 & $\begin{array}{l}\text { Allocation: randomised. } \\
\text { Participants: people with schizophrenia. } \\
\text { Intervention: olanzapine versus risperidone. }\end{array}$ \\
\hline Tran 1997 & $\begin{array}{l}\text { Allocation: randomised. } \\
\text { Participants: people with schizophrenia. } \\
\text { Intervention: risperidone versus olanzapine. }\end{array}$ \\
\hline Tsai 2004 & $\begin{array}{l}\text { Allocation: randomised. } \\
\text { Participants: people with schizophrenia. } \\
\text { Intervention: risperidone plus sarcosine versus risperidone plus placebo. }\end{array}$ \\
\hline Tsai 2006 & $\begin{array}{l}\text { Allocation: randomised. } \\
\text { Participants: people with schizophrenia. } \\
\text { Intervention: risperidone plus D-alanine versus risperidone plus placebo. }\end{array}$ \\
\hline Urioste 2004 & $\begin{array}{l}\text { Allocation: randomised. } \\
\text { Participants: people with schizophrenia and schizoaffective disorder. } \\
\text { Intervention: risperidone long-acting injection versus placebo. }\end{array}$ \\
\hline Wang 2003 & $\begin{array}{l}\text { Allocation: randomised. } \\
\text { Participants: people with schizophrenia. } \\
\text { Intervention: risperidone plus valproate versus risperidone plus placebo. }\end{array}$ \\
\hline Weickert 2003 & $\begin{array}{l}\text { Allocation: randomised. } \\
\text { Participants: people with schizophrenia. } \\
\text { Intervention: antipsychotic drugs (risperidone, olanzapine, quetiapine) versus placebo. }\end{array}$ \\
\hline Weiden 2005 & $\begin{array}{l}\text { Allocation: randomised. } \\
\text { Participants: schizophrenia with obesity. } \\
\text { Intervention: sibutramin vs placebo }\end{array}$ \\
\hline
\end{tabular}




\begin{tabular}{ll}
\hline Study & Reason for exclusion \\
\hline Wirshing 1995 & $\begin{array}{l}\text { Allocation: randomised. } \\
\text { Participants: people with schizophrenia. } \\
\text { Intervention: risperidone versus haloperidol. }\end{array}$ \\
\hline Yamawaki 1996 & $\begin{array}{l}\text { Allocation: randomised. } \\
\text { Participants: people with schizophrenia. } \\
\text { Intervention: risperidone versus clocapramine (an atypical antipsychotic of the imidobenzyl class). }\end{array}$ \\
\hline Zhang 2002 & $\begin{array}{l}\text { Allocation: randomised. } \\
\text { Participants: people with schizophrenia. } \\
\text { Intervention: risperidone plus antioxidants versus risperidone plus placebo. }\end{array}$ \\
\hline Zhong 2006 & Allocation: randomised. \\
Participants: people with schizophrenia. \\
Intervention: risperidone plus buflomedil versus risperidone plus placebo.
\end{tabular}

Characteristics of studies awaiting assessment [ordered by study ID]

\section{Anon 2010}

\begin{tabular}{ll}
\hline Methods & Allocation: no information. \\
\hline Participants & Diagnosis: schizophrenia. \\
\hline Interventions & 1. Risperidone. \\
& 2. Placebo. \\
\hline Outcomes & Long-term efficacy. \\
\hline Notes & Awaiting for full text. \\
\hline
\end{tabular}

Bose 2010a

\begin{tabular}{ll}
\hline Methods & Randomised. \\
\hline Participants & People with schizophrenia. \\
\hline Interventions & Placebo versus cariprazine versus risperidone \\
\hline Outcomes & no useable data reported. \\
\hline Notes & $\begin{array}{l}\text { The paper didn't report any data relevant to pre-defined outcomes of this review. We have contact- } \\
\text { ed trial authors for further data, but haven't received any reply. }\end{array}$ \\
\hline
\end{tabular}

\section{Cavazzoni 2002}

\begin{tabular}{ll}
\hline Methods & Randomised. \\
\hline Participants & People with schizophrenia. \\
\hline \hline
\end{tabular}


Cavazzoni 2002 (Continued)

Interventions Risperidone versus olanzapine versus clozapine versus placebo.

\begin{tabular}{ll}
\hline Outcomes & No useable data. \\
\hline Notes & $\begin{array}{l}\text { The paper didn't report any data relevant to pre-defined outcomes of this review. We have contact- } \\
\text { ed trial authors for further data, but haven't received any reply. }\end{array}$
\end{tabular}

DeMartinis 2012

\begin{tabular}{ll}
\hline Methods & Randomised. \\
\hline Participants & People with schizophrenia. \\
\hline Interventions & Placebo versus risperidone versus PF-02545920. \\
\hline Outcomes & No useable data reported. \\
\hline Notes & $\begin{array}{l}\text { The paper didn't report any data relevant to pre-defined outcomes of this review. We have contact- } \\
\text { ed trial authors for further data, but haven't received any reply. }\end{array}$ \\
\hline
\end{tabular}

GlaxoSmithKline 2006

\begin{tabular}{ll}
\hline Methods & Randomised. \\
\hline Participants & People with schizophrenia. \\
\hline Interventions & Talnetant (a neurokinin 3 receptor antagonist) versus placebo versus risperidone. \\
\hline Outcomes & No usable data. \\
\hline Notes & $\begin{array}{l}\text { The paper didn't report any data relevant to pre-defined outcomes of this review. We have contact- } \\
\text { ed trial authors for further data, but haven't received any reply. }\end{array}$ \\
\hline
\end{tabular}

\section{Litman 2014}

\begin{tabular}{ll}
\hline Methods & $\begin{array}{l}\text { Allocation: randomised. } \\
\text { Blindness: double blind. } \\
\text { Duration: } 28 \text { days. } \\
\text { Design: parallel. }\end{array}$ \\
\hline Participants & Diagnosis: people with schizophrenia. \\
& $\mathrm{N}=151$. \\
& Age: not reported. \\
& Sex: not reported. \\
\hline Interventions & 2. Placeboridone: 4 mg. \\
\end{tabular}


Litman 2014 (Continued)

$$
\text { 3. AZD8529: } 40 \mathrm{mg} \text {. }
$$

\begin{tabular}{ll}
\hline Outcomes & Unable to use: \\
& PANSS, CGI. \\
\hline Notes & Full text is not available. \\
\hline
\end{tabular}

\section{NCT 00694707}

\begin{tabular}{|c|c|}
\hline Methods & $\begin{array}{l}\text { Allocation: randomised. } \\
\text { Blindness: double. } \\
\text { Duration: } 6 \text { weeks. } \\
\text { Design: parallel. }\end{array}$ \\
\hline Participants & Diagnosis: people with schizophrenia. \\
\hline Interventions & $\begin{array}{l}\text { 1. Risperidone: dose } 4 \mathrm{mg} / \text { day. } \\
\text { 2. Placebo. } \\
\text { 3. Cariprazine } 1.5 \mathrm{mg} / \mathrm{d} \text {. } \\
\text { 4. Cariprazine } 3 \mathrm{mg} / \mathrm{d} \text {. } \\
\text { 5. Cariprazine } 4.5 \mathrm{mg} / \mathrm{d} \text {. }\end{array}$ \\
\hline Outcomes & Not reported. \\
\hline Notes & Awaiting for full text. \\
\hline
\end{tabular}

\section{NCT01086748}

\begin{tabular}{ll}
\hline Methods & Randomised. \\
\hline Participants & People with schizophrenia. \\
\hline Interventions & Risperidone versus placebo versus LY2140023. (no further detail of the drug was available) \\
\hline Outcomes & No usable data available. \\
\hline Notes & $\begin{array}{l}\text { The paper didn't report any data relevant to pre-defined outcomes of this review. We have contact- } \\
\text { ed trial authors for further data, but haven't received any reply. }\end{array}$ \\
\hline
\end{tabular}

NCT01175135

\begin{tabular}{ll}
\hline Methods & Randomised. \\
\hline Participants & People with schizophrenia. \\
\hline Interventions & Risperidone versus placebo versus PF-02545920. (no further detail of the drug was available). \\
\hline
\end{tabular}


NCT01175135 (Continued)

Outcomes No useable data available.

Notes

The paper didn't report any data relevant to pre-defined outcomes of this review. We have contacted trial authors for further data, but haven't received any reply.

NCT01363349

\begin{tabular}{ll}
\hline Methods & Randomised \\
\hline Participants & People with schizophrenia. \\
\hline Interventions & Risperidone versus placebo versus BL-1020. \\
\hline Outcomes & No useable data*. \\
\hline Notes & *This trial has terminated with the following reason stated: \\
& $\begin{array}{l}\text { Pre-planned interim analysis of the Phase II/III CLARITY trial of BL-1020 indicate that the trial would } \\
\text { not meet the pre-specified primary efficacy endpoint } \\
\text { We have contacted trial authors for data, but not received any reply yet. }\end{array}$
\end{tabular}

Nisenbaum 2013

$\begin{array}{ll}\text { Methods } & \text { Allocation: randomised. } \\ & \text { Blindness: double blind, but unclear who is blinded. } \\ & \text { Duration: } 6 \text { weeks. } \\ \text { Design: parallel. }\end{array}$

\begin{tabular}{ll}
\hline Participants & Diagnosis: schizophrenia (DSM-IV). \\
& $\mathrm{N}=100$. \\
& Age: $18-65$ years old. \\
& Sex: not reported. \\
& Length of illness: not reported. \\
& Inclusion criteria: not reported. \\
& Exclusion criteria: not reported. \\
\hline Interventions & 1. Risperidone: 3 mg/d, $\mathrm{N}=38$. \\
& 2. Placebo: not reported, $\mathrm{N}=78$. \\
& 3. Pomaglumetad methionil: $\mathrm{N}=83$.
\end{tabular}

\section{Outcomes}

Unable to use:

PANSS total score.

Notes Full text is not available.

\section{Rujescu 2009}

Methods Randomised.


Rujescu 2009 (Continued)

Participants People with schizophrenia.

\begin{tabular}{ll}
\hline Interventions & Riluzole (a drug used to treat amyotrophic lateral sclerosis) versus risperidone versus placebo. \\
\hline Outcomes & No useable data. (The grant was terminated due to slow enrolment.) \\
\hline Notes & $\begin{array}{l}\text { The paper didn't report any data relevant to pre-defined outcomes of this review. We have contact- } \\
\text { ed trial authors for further data, but haven't received any reply. }\end{array}$
\end{tabular}

Vanover 2014

\begin{tabular}{ll}
\hline Methods & Allocation: randomised. \\
& Blindness: double blind. \\
& Duration: 28 days. \\
& Design: parallel. \\
\hline Participants & Diagnosis: acute exacerbated schizophrenia (DSM-IV). \\
N = not reported. & Age: not reported. \\
& Sex: not reported. \\
& Length of illness: not reported. \\
& Inclusion criteria: not reported. \\
& Exclusion criteria: not reported. \\
& 1. Risperidone: $4 \mathrm{mg} / \mathrm{d}$. \\
2. Placebo. & \\
3. ITI-007 $60 \mathrm{mg} / \mathrm{d}$. \\
4. ITI-007 $120 \mathrm{mg} / \mathrm{d}$.
\end{tabular}

\section{Outcomes}

Uable to use:

PANSS, CDSS.

\section{Notes}

No full text available, we contacted the author (Kimberly Vanover, Ph.D. kvanover@intracellulartherapies.com) but havn't received a reply yet.

\section{Xu 2009}

$\begin{array}{ll}\text { Methods } & \text { Allocation: randomised. } \\ \text { Blindness: double blind, but unclear who is blinded. } \\ \text { Duration: } 90 \text { days. } \\ \text { Design: parallel. }\end{array}$

\section{Participants}

Diagnosis: schizophrenia (DSM-IV).

$\mathrm{N}=200$.

Age: not reported.

Sex: not reported.

Length of illness: not reported.

Inclusion criteria: not reported.

Exclusion criteria: not reported. 
Xu 2009 (Continued)
Interventions
1. Risperidone: $3 \mathrm{mg} / \mathrm{d}$ to $6 \mathrm{mg} / \mathrm{d}$.
2. Placebo.
3. LDXGW plus risperidone $3 \mathrm{mg} / \mathrm{d}$ to $6 \mathrm{mg} / \mathrm{d}$.
4. LDXGW plus risperidone $<3 \mathrm{mg} / \mathrm{d}$.

\begin{tabular}{ll}
\hline Outcomes & Unable to use: \\
& CGI, BPRS, SANS, SAPS. \\
\hline Notes & No full text available, we contacted the author but did not receive a reply.
\end{tabular}

BPRS: Brief Psychiatric Rating Scale

CGI: Clinical Global Impression

DSM: Diagnostic and Statistical Manual of Mental Disorders

PANSS: Positive and Negative Syndrome Scale

SANS: Scale for the Assessment of Negative Symptoms

SAPS: Scale for the Assessment of Positive Symptoms

CDSS: the Calgary Depression Scale for Schizophrenia

\section{Characteristics of ongoing studies [ordered by study ID]}

\section{NCT00174200}

Trial name or title Study to assess differential sensitivity of 2 spatial working memory tests in people with schizophrenia treated with risperidone.

\begin{tabular}{ll}
\hline Methods & $\begin{array}{l}\text { Allocation: randomised. } \\
\text { Blindness: double. }\end{array}$ \\
\hline Participants & Diagnosis: people with schizophrenia. \\
\hline Interventions & $\begin{array}{l}\text { 1. Risperidone: dose } 2 \mathrm{mg} / \text { day. } \\
\text { 2. Placebo. }\end{array}$ \\
\hline Outcomes & $\begin{array}{l}\text { Cognitive functions: GMLT. } \\
\text { Adverse effects: ESRS. } \\
\text { Mental state: PANSS. }\end{array}$ \\
\hline Starting date & July 2007. \\
\hline Contact information & Pfizer CT.gov Call Center, Study Director, Pfizer. \\
\hline Notes & Study ID: A9001229. \\
\hline
\end{tabular}

ESRS: Extrapyramidal Symptom Rating Scale GMLT: Groton Maze Learning Test

PANSS: Positive and Negative Syndrome Scale

\section{DATA AND ANALYSES}


Comparison 1. RISPERIDONE vs PLACEBO

\begin{tabular}{|c|c|c|c|c|}
\hline Outcome or subgroup title & No. of studies & $\begin{array}{l}\text { No. of partici- } \\
\text { pants }\end{array}$ & Statistical method & Effect size \\
\hline $\begin{array}{l}1 \text { Mental state: no clinically signif- } \\
\text { icant response in psychotic symp- } \\
\text { toms (defined by various scale total } \\
\text { score change) - short term (up to } 12 \\
\text { weeks) }\end{array}$ & 7 & & $\begin{array}{l}\text { Risk Ratio (M-H, Random, } \\
95 \% \mathrm{Cl})\end{array}$ & Subtotals only \\
\hline 1.1 defined by PANSS $<30 \%$ decline & 3 & 707 & $\begin{array}{l}\text { Risk Ratio (M-H, Random, } \\
95 \% \mathrm{CI})\end{array}$ & $0.74[0.67,0.83]$ \\
\hline $\begin{array}{l}1.2 \text { defined by PANSS/BPRS }<20 \% \\
\text { decline }\end{array}$ & 6 & 864 & $\begin{array}{l}\text { Risk Ratio (M-H, Random, } \\
95 \% \mathrm{CI})\end{array}$ & $0.64[0.52,0.78]$ \\
\hline $\begin{array}{l}2 \text { Leaving the study early - short } \\
\text { term (up to } 12 \text { weeks) }\end{array}$ & 12 & & $\begin{array}{l}\text { Risk Ratio (M-H, Random, } \\
95 \% \mathrm{CI})\end{array}$ & Subtotals only \\
\hline 2.1 any reason & 12 & 2261 & $\begin{array}{l}\text { Risk Ratio (M-H, Random, } \\
95 \% \mathrm{Cl})\end{array}$ & $0.69[0.62,0.78]$ \\
\hline 2.2 due to adverse events & 10 & 2081 & $\begin{array}{l}\text { Risk Ratio (M-H, Random, } \\
95 \% \mathrm{Cl})\end{array}$ & $0.78[0.59,1.03]$ \\
\hline 2.3 due to lack of efficacy & 11 & 2211 & $\begin{array}{l}\text { Risk Ratio (M-H, Random, } \\
95 \% \mathrm{CI})\end{array}$ & $0.39[0.29,0.51]$ \\
\hline 2.4 due to noncompliance & 4 & 534 & $\begin{array}{l}\text { Risk Ratio (M-H, Random, } \\
95 \% \mathrm{Cl})\end{array}$ & $1.15[0.33,4.05]$ \\
\hline 2.5 lost to follow-up & 6 & 1545 & $\begin{array}{l}\text { Risk Ratio (M-H, Random, } \\
95 \% \mathrm{CI})\end{array}$ & $0.79[0.25,2.56]$ \\
\hline 2.6 protocol violation & 4 & 1257 & $\begin{array}{l}\text { Risk Ratio (M-H, Random, } \\
95 \% \mathrm{CI})\end{array}$ & $0.79[0.39,1.62]$ \\
\hline 2.7 reported death & 10 & 1532 & $\begin{array}{l}\text { Risk Ratio (M-H, Random, } \\
95 \% \mathrm{Cl})\end{array}$ & $3.07[0.13,74.28]$ \\
\hline 2.8 withdrawal of consent & 7 & 1589 & $\begin{array}{l}\text { Risk Ratio (M-H, Random, } \\
95 \% \mathrm{Cl})\end{array}$ & $1.12[0.80,1.56]$ \\
\hline 2.9 other & 3 & 615 & $\begin{array}{l}\text { Risk Ratio (M-H, Random, } \\
95 \% \mathrm{Cl})\end{array}$ & $1.03[0.68,1.57]$ \\
\hline $\begin{array}{l}3 \text { Global state: } 1 \text {. average end- } \\
\text { point scores of CGI severity scale } \\
\text { (high=poor) - short term (up to } 12 \\
\text { weeks) }\end{array}$ & 3 & 457 & $\begin{array}{l}\text { Mean Difference (IV, Random, } \\
95 \% \mathrm{Cl})\end{array}$ & $-0.81[-0.89,-0.73]$ \\
\hline $\begin{array}{l}4 \text { Global state: } 2 \text {. no significant clin- } \\
\text { ical improvement CGI - short term } \\
\text { (up to } 12 \text { weeks) }\end{array}$ & 4 & 594 & $\begin{array}{l}\text { Risk Ratio (M-H, Random, } \\
95 \% \mathrm{CI})\end{array}$ & $0.69[0.57,0.83]$ \\
\hline $\begin{array}{l}5 \text { Global state: } 3 \text {. needing addition- } \\
\text { al medication - short term (up to } 12 \\
\text { weeks) }\end{array}$ & 6 & & $\begin{array}{l}\text { Risk Ratio (M-H, Random, } \\
95 \% \mathrm{Cl})\end{array}$ & Subtotals only \\
\hline
\end{tabular}




\begin{tabular}{|c|c|c|c|c|}
\hline Outcome or subgroup title & No. of studies & $\begin{array}{l}\text { No. of partici- } \\
\text { pants }\end{array}$ & Statistical method & Effect size \\
\hline 5.1 benzodiazepine & 1 & 42 & $\begin{array}{l}\text { Risk Ratio (M-H, Random, } \\
95 \% \mathrm{Cl})\end{array}$ & $0.96[0.77,1.20]$ \\
\hline $\begin{array}{l}5.2 \text { benzodiazepine derivatives - Lo- } \\
\text { razepam }\end{array}$ & 2 & 228 & $\begin{array}{l}\text { Risk Ratio (M-H, Random, } \\
95 \% \mathrm{Cl})\end{array}$ & $0.93[0.68,1.27]$ \\
\hline $\begin{array}{l}5.3 \text { benzodiazepine derivatives - } \mathrm{Ni} \text { - } \\
\text { trazepam }\end{array}$ & 1 & 184 & $\begin{array}{l}\text { Risk Ratio (M-H, Random, } \\
95 \% \mathrm{Cl})\end{array}$ & $0.51[0.10,2.72]$ \\
\hline $\begin{array}{l}5.4 \text { benzodiazepine related drugs - } \\
\text { Zolpidem }\end{array}$ & 1 & 184 & $\begin{array}{l}\text { Risk Ratio (M-H, Random, } \\
95 \% \mathrm{Cl})\end{array}$ & $0.81[0.53,1.23]$ \\
\hline 5.5 sedative/hypnotic & 2 & 230 & $\begin{array}{l}\text { Risk Ratio (M-H, Random, } \\
95 \% \mathrm{Cl})\end{array}$ & $0.86[0.69,1.06]$ \\
\hline 5.6 antiparkinsonian & 2 & 172 & $\begin{array}{l}\text { Risk Ratio (M-H, Random, } \\
95 \% \mathrm{Cl})\end{array}$ & $1.21[0.79,1.86]$ \\
\hline 5.7 psychotropics & 1 & 186 & $\begin{array}{l}\text { Risk Ratio (M-H, Random, } \\
95 \% \mathrm{Cl})\end{array}$ & $0.62[0.45,0.85]$ \\
\hline $\begin{array}{l}6 \text { Mental state: } 1 \text {. average endpoint } \\
\text { scores on various scales on psychot- } \\
\text { ic symptoms (high=poor) - short } \\
\text { term (up to } 12 \text { weeks) }\end{array}$ & 3 & & $\begin{array}{l}\text { Mean Difference (IV, Random, } \\
95 \% \mathrm{CI} \text { ) }\end{array}$ & Subtotals only \\
\hline 6.1 BPRS total & 2 & 171 & $\begin{array}{l}\text { Mean Difference (IV, Random, } \\
95 \% \mathrm{CI})\end{array}$ & $\begin{array}{l}-12.69[-17.06 \\
-8.32]\end{array}$ \\
\hline 6.2 PANSS total & 3 & 457 & $\begin{array}{l}\text { Mean Difference (IV, Random, } \\
95 \% \mathrm{CI} \text { ) }\end{array}$ & $\begin{array}{l}-17.81[-18.17 \\
-17.45]\end{array}$ \\
\hline 6.3 PANSS general pathology & 1 & 44 & $\begin{array}{l}\text { Mean Difference (IV, Random, } \\
95 \% \mathrm{CI})\end{array}$ & $\begin{array}{l}-13.20[-20.15 \\
-6.25]\end{array}$ \\
\hline 6.4 PANSS negative symptom & 3 & 457 & $\begin{array}{l}\text { Mean Difference (IV, Random, } \\
95 \% \mathrm{CI})\end{array}$ & $-3.10[-3.19,-3.01]$ \\
\hline 6.5 PANSS positive symptom & 3 & 457 & $\begin{array}{l}\text { Mean Difference (IV, Random, } \\
95 \% \mathrm{CI})\end{array}$ & $-5.49[-6.18,-4.80]$ \\
\hline $\begin{array}{l}7 \text { Mental state: } 2 \text {. skewed data - } \\
\text { short term (up to } 12 \text { weeks) }\end{array}$ & & & Other data & No numeric data \\
\hline $\begin{array}{l}7.1 \text { average endpoint score BPRS to- } \\
\text { tal (high=poor) }\end{array}$ & & & Other data & No numeric data \\
\hline $\begin{array}{l}7.2 \text { average change score of CGI-C } \\
\text { (larger decline=good) }\end{array}$ & & & Other data & No numeric data \\
\hline $\begin{array}{l}7.3 \text { average change score of CGI-SI } \\
\text { (larger decline=good) }\end{array}$ & & & Other data & No numeric data \\
\hline $\begin{array}{l}7.4 \text { average change score of HAM- } \\
\text { D-17 (larger decline }=\text { good) }\end{array}$ & & & Other data & No numeric data \\
\hline
\end{tabular}




\begin{tabular}{|c|c|c|c|c|}
\hline Outcome or subgroup title & No. of studies & $\begin{array}{l}\text { No. of partici- } \\
\text { pants }\end{array}$ & Statistical method & Effect size \\
\hline $\begin{array}{l}7.5 \text { average change score of PANSS } \\
\text { total (larger decline=good) }\end{array}$ & & & Other data & No numeric data \\
\hline $\begin{array}{l}7.6 \text { average change score of PANSS } \\
\text { negative symptom (larger de- } \\
\text { cline=good) }\end{array}$ & & & Other data & No numeric data \\
\hline $\begin{array}{l}7.7 \text { average change score of PANSS } \\
\text { positive symptom (larger de- } \\
\text { cline=good) }\end{array}$ & & & Other data & No numeric data \\
\hline $\begin{array}{l}8 \text { Adverse effects: } 1 \text { a. extrapyrami- } \\
\text { dal - various effects - short term (up } \\
\text { to } 12 \text { weeks) }\end{array}$ & 11 & & $\begin{array}{l}\text { Risk Ratio (M-H, Random, } \\
95 \% \mathrm{Cl} \text { ) }\end{array}$ & Subtotals only \\
\hline 8.1 general - any significant EPS & 7 & 1511 & $\begin{array}{l}\text { Risk Ratio (M-H, Random, } \\
95 \% \mathrm{Cl})\end{array}$ & $1.56[1.13,2.15]$ \\
\hline $\begin{array}{l}8.2 \text { general - no improvement on } \\
\text { AIMS score }\end{array}$ & 1 & 42 & $\begin{array}{l}\text { Risk Ratio (M-H, Random, } \\
95 \% \mathrm{Cl})\end{array}$ & $0.30[0.15,0.61]$ \\
\hline $\begin{array}{l}8.3 \text { general - no improvement on } \\
\text { BAS score }\end{array}$ & 1 & 226 & $\begin{array}{l}\text { Risk Ratio (M-H, Random, } \\
95 \% \mathrm{Cl} \text { ) }\end{array}$ & $1.14[1.01,1.28]$ \\
\hline $\begin{array}{l}8.4 \text { general - needing medication for } \\
\text { EPS }\end{array}$ & 2 & 94 & $\begin{array}{l}\text { Risk Ratio (M-H, Random, } \\
95 \% \mathrm{Cl} \text { ) }\end{array}$ & $1.14[0.78,1.67]$ \\
\hline 8.5 specific - akathisia & 5 & 1204 & $\begin{array}{l}\text { Risk Ratio (M-H, Random, } \\
95 \% \mathrm{Cl})\end{array}$ & $2.58[1.41,4.72]$ \\
\hline 8.6 specific - bradykinesia & 2 & 485 & $\begin{array}{l}\text { Risk Ratio (M-H, Random, } \\
95 \% \mathrm{Cl} \text { ) }\end{array}$ & $0.87[0.60,1.24]$ \\
\hline 8.7 specific - dyskinesia & 1 & 303 & $\begin{array}{l}\text { Risk Ratio (M-H, Random, } \\
95 \% \mathrm{Cl} \text { ) }\end{array}$ & $0.32[0.01,7.86]$ \\
\hline 8.8 specific - dystonia & 3 & 687 & $\begin{array}{l}\text { Risk Ratio (M-H, Random, } \\
95 \% \mathrm{Cl} \text { ) }\end{array}$ & $3.40[0.26,44.46]$ \\
\hline 8.9 specific - hypertonia & 3 & 505 & $\begin{array}{l}\text { Risk Ratio (M-H, Random, } \\
95 \% \mathrm{Cl} \text { ) }\end{array}$ & $2.98[1.35,6.59]$ \\
\hline 8.10 specific - parkinsonism & 2 & 485 & $\begin{array}{l}\text { Risk Ratio (M-H, Random, } \\
95 \% \mathrm{Cl} \text { ) }\end{array}$ & $7.64[1.40,41.59]$ \\
\hline 8.11 specific - tardive dyskinesia & 1 & 303 & $\begin{array}{l}\text { Risk Ratio (M-H, Random, } \\
95 \% \mathrm{Cl})\end{array}$ & $6.77[0.35,130.03]$ \\
\hline 8.12 specific - tremor & 5 & 1204 & $\begin{array}{l}\text { Risk Ratio (M-H, Random, } \\
95 \% \mathrm{Cl} \text { ) }\end{array}$ & $1.60[0.89,2.88]$ \\
\hline $\begin{array}{l}9 \text { Adverse effects: } 1 \text { b. extrapyrami- } \\
\text { dal - AlMS average endpoint score - } \\
\text { short term (up to } 12 \text { weeks) }\end{array}$ & 1 & & $\begin{array}{l}\text { Mean Difference (IV, Random, } \\
95 \% \mathrm{CI})\end{array}$ & Subtotals only \\
\hline
\end{tabular}




\begin{tabular}{|c|c|c|c|c|}
\hline Outcome or subgroup title & No. of studies & $\begin{array}{l}\text { No. of partici- } \\
\text { pants }\end{array}$ & Statistical method & Effect size \\
\hline $\begin{array}{l}10 \text { Adverse effects: 1c. extrapyrami- } \\
\text { dal - skewed data (various scales) - } \\
\text { short term (up to } 12 \text { weeks) }\end{array}$ & & & Other data & No numeric data \\
\hline 10.1 average change score of AIMS & & & Other data & No numeric data \\
\hline $\begin{array}{l}10.2 \text { average change score of CGI } \\
\text { severity dyskinesia }\end{array}$ & & & Other data & No numeric data \\
\hline $\begin{array}{l}10.3 \text { average change score of } \mathrm{CGI} \\
\text { severity parkinsonism }\end{array}$ & & & Other data & No numeric data \\
\hline 10.4 average change score of ESRS & & & Other data & No numeric data \\
\hline $\begin{array}{l}10.5 \text { average change score of ESRS - } \\
\text { akathisia }\end{array}$ & & & Other data & No numeric data \\
\hline $\begin{array}{l}10.6 \text { average change score of ESRS - } \\
\text { dystonia }\end{array}$ & & & Other data & No numeric data \\
\hline $\begin{array}{l}10.7 \text { average change score of ESRS - } \\
\text { dyskinesia }\end{array}$ & & & Other data & No numeric data \\
\hline $\begin{array}{l}10.8 \text { average change score of ESRS - } \\
\text { parkinsonism }\end{array}$ & & & Other data & No numeric data \\
\hline $\begin{array}{l}11 \text { Adverse effects: } 2 \text {. any adverse } \\
\text { event - short term (up to } 12 \text { weeks) }\end{array}$ & 9 & & $\begin{array}{l}\text { Risk Ratio (M-H, Random, } \\
95 \% \mathrm{Cl} \text { ) }\end{array}$ & Subtotals only \\
\hline 11.1 any adverse event & 7 & 1610 & $\begin{array}{l}\text { Risk Ratio (M-H, Random, } \\
95 \% \mathrm{Cl} \text { ) }\end{array}$ & $1.05[0.96,1.15]$ \\
\hline 11.2 asthenia & 2 & 639 & $\begin{array}{l}\text { Risk Ratio (M-H, Random, } \\
95 \% \mathrm{Cl} \text { ) }\end{array}$ & $1.93[0.62,6.02]$ \\
\hline 11.3 back pain & 1 & 202 & $\begin{array}{l}\text { Risk Ratio (M-H, Random, } \\
95 \% \mathrm{Cl} \text { ) }\end{array}$ & $1.04[0.38,2.86]$ \\
\hline 11.4 blurred vision & 1 & 202 & $\begin{array}{l}\text { Risk Ratio (M-H, Random, } \\
95 \% \mathrm{Cl} \text { ) }\end{array}$ & $4.16[0.47,36.59]$ \\
\hline 11.5 cogwheel rigidity & 1 & 226 & $\begin{array}{l}\text { Risk Ratio (M-H, Random, } \\
95 \% \mathrm{Cl} \text { ) }\end{array}$ & $5.25[0.69,39.88]$ \\
\hline 11.6 death & 1 & 182 & $\begin{array}{l}\text { Risk Ratio (M-H, Random, } \\
95 \% \mathrm{Cl} \text { ) }\end{array}$ & $3.13[0.13,75.92]$ \\
\hline 11.7 dental disorder & 1 & 202 & $\begin{array}{l}\text { Risk Ratio (M-H, Random, } \\
95 \% \mathrm{Cl} \text { ) }\end{array}$ & $3.64[0.78,17.11]$ \\
\hline 11.8 dysmenorrhoea & 2 & 495 & $\begin{array}{l}\text { Risk Ratio (M-H, Random, } \\
95 \% \mathrm{Cl} \text { ) }\end{array}$ & $1.10[0.04,30.00]$ \\
\hline 11.9 fatigue & 2 & 558 & $\begin{array}{l}\text { Risk Ratio (M-H, Random, } \\
95 \% \mathrm{Cl} \text { ) }\end{array}$ & $2.23[0.69,7.22]$ \\
\hline
\end{tabular}




\begin{tabular}{|c|c|c|c|c|}
\hline Outcome or subgroup title & No. of studies & $\begin{array}{l}\text { No. of partici- } \\
\text { pants }\end{array}$ & Statistical method & Effect size \\
\hline 11.10 fever & 1 & 130 & $\begin{array}{l}\text { Risk Ratio (M-H, Random, } \\
95 \% \mathrm{Cl} \text { ) }\end{array}$ & $9.28[0.51,168.90]$ \\
\hline 11.11 infection & 1 & 202 & $\begin{array}{l}\text { Risk Ratio (M-H, Random, } \\
95 \% \mathrm{Cl})\end{array}$ & $0.52[0.10,2.78]$ \\
\hline 11.12 salivation - increased & 1 & 202 & $\begin{array}{l}\text { Risk Ratio (M-H, Random, } \\
95 \% \mathrm{CI})\end{array}$ & $7.28[0.38,139.15]$ \\
\hline 11.13 pyrexia & 1 & 182 & $\begin{array}{l}\text { Risk Ratio (M-H, Random, } \\
95 \% \mathrm{Cl})\end{array}$ & $1.19[0.45,3.16]$ \\
\hline 11.14 pain & 1 & 121 & $\begin{array}{l}\text { Risk Ratio (M-H, Random, } \\
95 \% \mathrm{Cl})\end{array}$ & $1.58[0.47,5.31]$ \\
\hline 11.15 rash (skin) & 1 & 202 & $\begin{array}{l}\text { Risk Ratio (M-H, Random, } \\
95 \% \mathrm{Cl} \text { ) }\end{array}$ & $1.19[0.45,3.16]$ \\
\hline 11.16 vaginitis & 1 & 58 & $\begin{array}{l}\text { Risk Ratio (M-H, Random, } \\
95 \% \mathrm{Cl} \text { ) }\end{array}$ & $1.07[0.07,16.32]$ \\
\hline 11.17 hyperhidrosis & 1 & 437 & $\begin{array}{l}\text { Risk Ratio (M-H, Random, } \\
95 \% \mathrm{Cl} \text { ) }\end{array}$ & $10.35[0.50,214.17]$ \\
\hline $\begin{array}{l}12 \text { Adverse effects: } 3 \text {. cardiovascular } \\
\text { - short term (up to } 12 \text { weeks) }\end{array}$ & 4 & & $\begin{array}{l}\text { Risk Ratio (M-H, Random, } \\
95 \% \mathrm{Cl})\end{array}$ & Subtotals only \\
\hline 12.1 dizziness - orthostatic & 1 & 44 & $\begin{array}{l}\text { Risk Ratio (M-H, Random, } \\
95 \% \mathrm{Cl})\end{array}$ & $3.0[0.13,69.87]$ \\
\hline 12.2 ECG abnormal & 1 & 182 & $\begin{array}{l}\text { Risk Ratio (M-H, Random, } \\
95 \% \mathrm{Cl})\end{array}$ & $9.40[0.51,172.11]$ \\
\hline 12.3 heart rate decreased & 1 & 182 & $\begin{array}{l}\text { Risk Ratio (M-H, Random, } \\
95 \% \mathrm{Cl})\end{array}$ & $0.52[0.05,5.66]$ \\
\hline 12.4 heart rate increased & 1 & 182 & $\begin{array}{l}\text { Risk Ratio (M-H, Random, } \\
95 \% \mathrm{Cl} \text { ) }\end{array}$ & $0.85[0.37,1.96]$ \\
\hline 12.5 hypotension - postural & 1 & 44 & $\begin{array}{l}\text { Risk Ratio (M-H, Random, } \\
95 \% \mathrm{Cl})\end{array}$ & $3.0[0.13,69.87]$ \\
\hline $\begin{array}{l}12.6 \text { QTc }>450 \text { milliseconds or }>10 \% \\
\text { increase from baseline }\end{array}$ & 2 & 380 & $\begin{array}{l}\text { Risk Ratio (M-H, Random, } \\
95 \% \mathrm{Cl})\end{array}$ & $8.46[1.07,67.07]$ \\
\hline 12.7 tachycardia & 2 & 332 & $\begin{array}{l}\text { Risk Ratio (M-H, Random, } \\
95 \% \mathrm{Cl} \text { ) }\end{array}$ & $12.22[2.33,64.10]$ \\
\hline $\begin{array}{l}13 \text { Adverse effects: } 4 \text {. central ner- } \\
\text { vous system - short term (up to } 12 \\
\text { weeks) }\end{array}$ & 10 & & $\begin{array}{l}\text { Risk Ratio (M-H, Random, } \\
95 \% \mathrm{Cl})\end{array}$ & Subtotals only \\
\hline 13.1 agitation & 8 & 1388 & $\begin{array}{l}\text { Risk Ratio (M-H, Random, } \\
95 \% \mathrm{Cl} \text { ) }\end{array}$ & $0.93[0.75,1.17]$ \\
\hline
\end{tabular}




\begin{tabular}{|c|c|c|c|c|}
\hline Outcome or subgroup title & No. of studies & $\begin{array}{l}\text { No. of partici- } \\
\text { pants }\end{array}$ & Statistical method & Effect size \\
\hline 13.2 anxiety & 6 & 1225 & $\begin{array}{l}\text { Risk Ratio (M-H, Random, } \\
95 \% \mathrm{Cl} \text { ) }\end{array}$ & $1.04[0.73,1.48]$ \\
\hline 13.3 dizziness & 5 & 970 & $\begin{array}{l}\text { Risk Ratio (M-H, Random, } \\
95 \% \mathrm{Cl} \text { ) }\end{array}$ & $1.41[0.65,3.05]$ \\
\hline 13.4 headache & 10 & 1905 & $\begin{array}{l}\text { Risk Ratio (M-H, Random, } \\
95 \% \mathrm{Cl} \text { ) }\end{array}$ & $0.99[0.81,1.21]$ \\
\hline 13.5 insomnia & 10 & 1905 & $\begin{array}{l}\text { Risk Ratio (M-H, Random, } \\
95 \% \mathrm{Cl} \text { ) }\end{array}$ & $1.16[0.97,1.39]$ \\
\hline 13.6 sedation & 2 & 517 & $\begin{array}{l}\text { Risk Ratio (M-H, Random, } \\
95 \% \mathrm{Cl} \text { ) }\end{array}$ & $1.84[0.52,6.50]$ \\
\hline 13.7 somnolence & 6 & 951 & $\begin{array}{l}\text { Risk Ratio (M-H, Random, } \\
95 \% \mathrm{Cl} \text { ) }\end{array}$ & $1.61[1.06,2.45]$ \\
\hline 13.8 restlessness & 2 & 619 & $\begin{array}{l}\text { Risk Ratio (M-H, Random, } \\
95 \% \mathrm{Cl} \text { ) }\end{array}$ & $1.16[0.49,2.74]$ \\
\hline $\begin{array}{l}14 \text { Adverse effects: } 5 \text {. endocrine - } \\
\text { serum prolactin increase above ref- } \\
\text { erence range ( } 23 \mathrm{ng} / \mathrm{ml} \text { ) - short term } \\
\text { (up to } 12 \text { weeks) }\end{array}$ & 2 & 323 & $\begin{array}{l}\text { Risk Ratio (M-H, Random, } \\
95 \% \mathrm{Cl} \text { ) }\end{array}$ & $12.14[4.38,33.68]$ \\
\hline $\begin{array}{l}15 \text { Adverse effects: } 6 \text {. gastrointesti- } \\
\text { nal system - short term (up to } 12 \\
\text { weeks) }\end{array}$ & 10 & & $\begin{array}{l}\text { Risk Ratio (M-H, Random, } \\
95 \% \mathrm{Cl} \text { ) }\end{array}$ & Subtotals only \\
\hline 15.1 constipation & 8 & 1695 & $\begin{array}{l}\text { Risk Ratio (M-H, Random, } \\
95 \% \mathrm{Cl} \text { ) }\end{array}$ & $1.88[1.19,2.96]$ \\
\hline 15.2 diarrhoea & 1 & 202 & $\begin{array}{l}\text { Risk Ratio (M-H, Random, } \\
95 \% \mathrm{Cl} \text { ) }\end{array}$ & $0.92[0.37,2.30]$ \\
\hline 15.3 dry mouth & 1 & 202 & $\begin{array}{l}\text { Risk Ratio (M-H, Random, } \\
95 \% \mathrm{Cl} \text { ) }\end{array}$ & $2.43[0.65,9.12]$ \\
\hline 15.4 dyspepsia & 5 & 1058 & $\begin{array}{l}\text { Risk Ratio (M-H, Random, } \\
95 \% \mathrm{Cl} \text { ) }\end{array}$ & $1.24[0.64,2.40]$ \\
\hline 15.5 nausea & 6 & 1225 & $\begin{array}{l}\text { Risk Ratio (M-H, Random, } \\
95 \% \mathrm{Cl} \text { ) }\end{array}$ & $1.18[0.75,1.86]$ \\
\hline 15.6 vomiting & 5 & 1181 & $\begin{array}{l}\text { Risk Ratio (M-H, Random, } \\
95 \% \mathrm{Cl} \text { ) }\end{array}$ & $1.16[0.65,2.07]$ \\
\hline $\begin{array}{l}16 \text { Adverse effects: } 7 \text { a. metabolic - } \\
\text { weight gain - short term (up to } 12 \\
\text { weeks) }\end{array}$ & 6 & & $\begin{array}{l}\text { Risk Ratio (M-H, Random, } \\
95 \% \mathrm{Cl} \text { ) }\end{array}$ & Subtotals only \\
\hline 16.1 any gain & 3 & 910 & $\begin{array}{l}\text { Risk Ratio (M-H, Random, } \\
95 \% \mathrm{Cl} \text { ) }\end{array}$ & $3.77[1.34,10.63]$ \\
\hline
\end{tabular}




\begin{tabular}{|c|c|c|c|c|}
\hline Outcome or subgroup title & No. of studies & $\begin{array}{l}\text { No. of partici- } \\
\text { pants }\end{array}$ & Statistical method & Effect size \\
\hline $16.2>7 \%$ increase from baseline & 3 & 606 & $\begin{array}{l}\text { Risk Ratio (M-H, Random, } \\
95 \% \mathrm{Cl} \text { ) }\end{array}$ & $3.47[1.64,7.33]$ \\
\hline $\begin{array}{l}17 \text { Adverse effects: } 7 b \text {. metabolic - } \\
\text { skewed data - average change value } \\
\text { on lipid profile - short term (up to } 12 \\
\text { weeks) }\end{array}$ & & & Other data & No numeric data \\
\hline 17.1 cholesterol - total & & & Other data & No numeric data \\
\hline $17.2 \mathrm{HDL}$ & & & Other data & No numeric data \\
\hline $17.3 \mathrm{LDL}$ & & & Other data & No numeric data \\
\hline 17.4 triglycerides & & & Other data & No numeric data \\
\hline 17.5 VLDL & & & Other data & No numeric data \\
\hline $\begin{array}{l}18 \text { Adverse effects: } 8 \text {. musculoskele- } \\
\text { tal system - short term (up to } 12 \\
\text { weeks) }\end{array}$ & 1 & & $\begin{array}{l}\text { Risk Ratio (M-H, Random, } \\
95 \% \mathrm{Cl} \text { ) }\end{array}$ & Subtotals only \\
\hline 18.1 myalgia & 1 & 202 & $\begin{array}{l}\text { Risk Ratio (M-H, Random, } \\
95 \% \mathrm{Cl} \text { ) }\end{array}$ & $0.69[0.12,4.06]$ \\
\hline 18.2 Joint disorder & 1 & 202 & $\begin{array}{l}\text { Risk Ratio (M-H, Random, } \\
95 \% \mathrm{Cl} \text { ) }\end{array}$ & $2.60[0.52,13.10]$ \\
\hline $\begin{array}{l}19 \text { Adverse effects: } 9 . \text { physiology - } \\
\text { short term (up to } 12 \text { weeks) }\end{array}$ & 2 & & $\begin{array}{l}\text { Risk Ratio (M-H, Random, } \\
95 \% \mathrm{Cl} \text { ) }\end{array}$ & Subtotals only \\
\hline 19.1 ALT increased & 1 & 182 & $\begin{array}{l}\text { Risk Ratio (M-H, Random, } \\
95 \% \mathrm{Cl} \text { ) }\end{array}$ & $1.04[0.07,16.45]$ \\
\hline 19.2 AST increased & 1 & 182 & $\begin{array}{l}\text { Risk Ratio (M-H, Random, } \\
95 \% \mathrm{Cl} \text { ) }\end{array}$ & $0.0[0.0,0.0]$ \\
\hline 19.3 blood CPK increased & 2 & 619 & $\begin{array}{l}\text { Risk Ratio (M-H, Random, } \\
95 \% \mathrm{Cl} \text { ) }\end{array}$ & $0.67[0.23,1.95]$ \\
\hline 19.4 blood pressure increased & 1 & 182 & $\begin{array}{l}\text { Risk Ratio (M-H, Random, } \\
95 \% \mathrm{Cl} \text { ) }\end{array}$ & $1.04[0.15,7.26]$ \\
\hline $\begin{array}{l}20 \text { Adverse effects: } 10 \text {. respiratory } \\
\text { system - short term (up to } 12 \text { weeks) }\end{array}$ & 4 & & $\begin{array}{l}\text { Risk Ratio (M-H, Random, } \\
95 \% \mathrm{Cl} \text { ) }\end{array}$ & Subtotals only \\
\hline 20.1 upper respiratory infection & 2 & 323 & $\begin{array}{l}\text { Risk Ratio (M-H, Random, } \\
95 \% \mathrm{Cl} \text { ) }\end{array}$ & $2.83[1.03,7.74]$ \\
\hline 20.2 pharyngitis & 1 & 202 & $\begin{array}{l}\text { Risk Ratio (M-H, Random, } \\
95 \% \mathrm{Cl} \text { ) }\end{array}$ & $0.42[0.08,2.10]$ \\
\hline 20.3 rhinitis & 2 & 306 & $\begin{array}{l}\text { Risk Ratio (M-H, Random, } \\
95 \% \mathrm{Cl} \text { ) }\end{array}$ & $10.81[2.58,45.29]$ \\
\hline
\end{tabular}




\begin{tabular}{lllll}
\hline Outcome or subgroup title & No. of studies & $\begin{array}{l}\text { No. of partici- } \\
\text { pants }\end{array}$ & Statistical method & Effect size \\
\hline 20.4 sinusitis & 1 & 437 & $\begin{array}{l}\text { Risk Ratio (M-H, Random, } \\
95 \% \mathrm{Cl})\end{array}$ & $1.04[0.09,11.36]$ \\
\hline
\end{tabular}

Analysis 1.1. Comparison 1 RISPERIDONE vs PLACEBO, Outcome 1 Mental state: no clinically significant response in psychotic symptoms (defined by various scale total score change) - short term (up to 12 weeks).

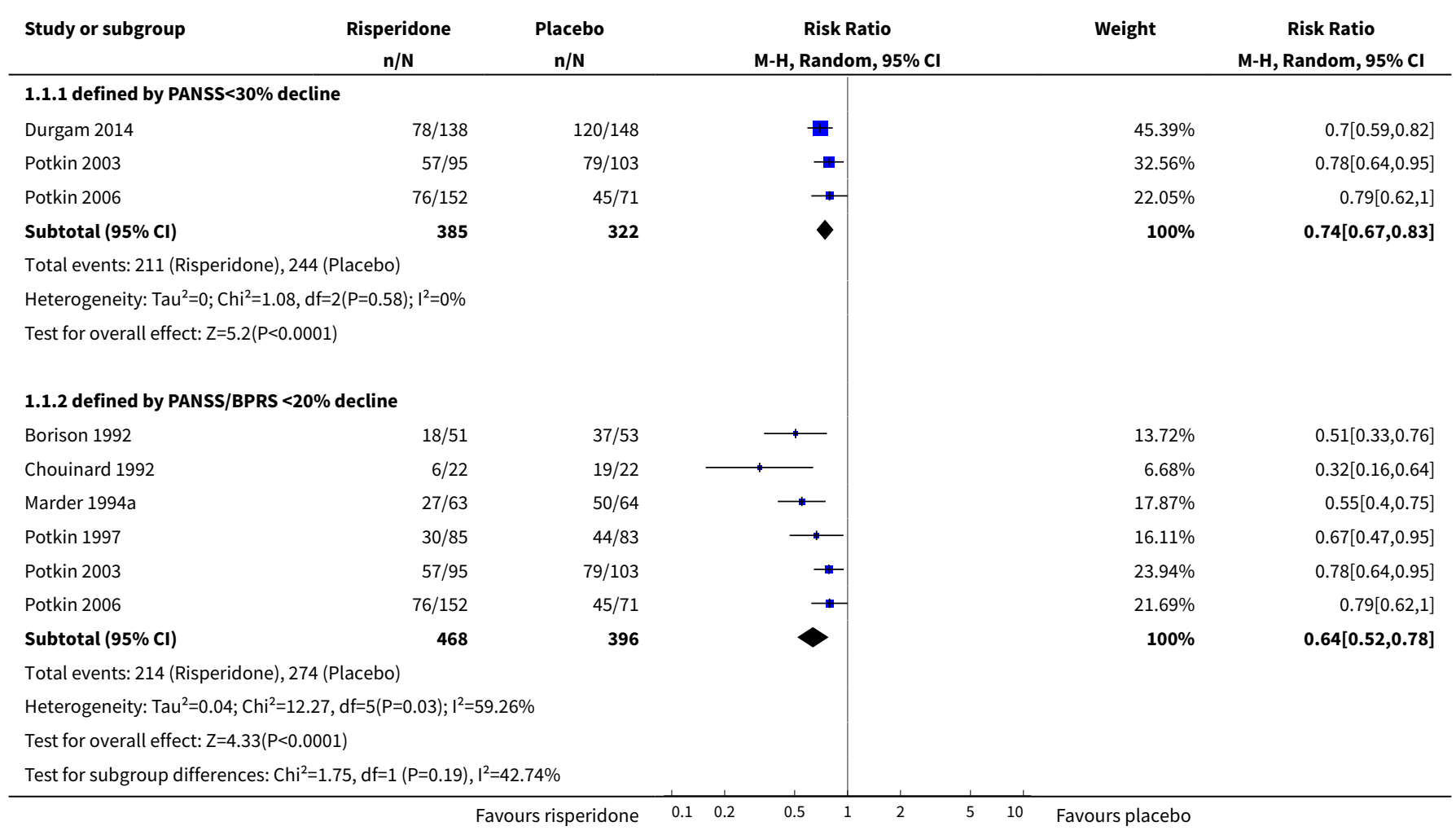

Analysis 1.2. Comparison 1 RISPERIDONE vs PLACEBO, Outcome 2 Leaving the study early - short term (up to 12 weeks).

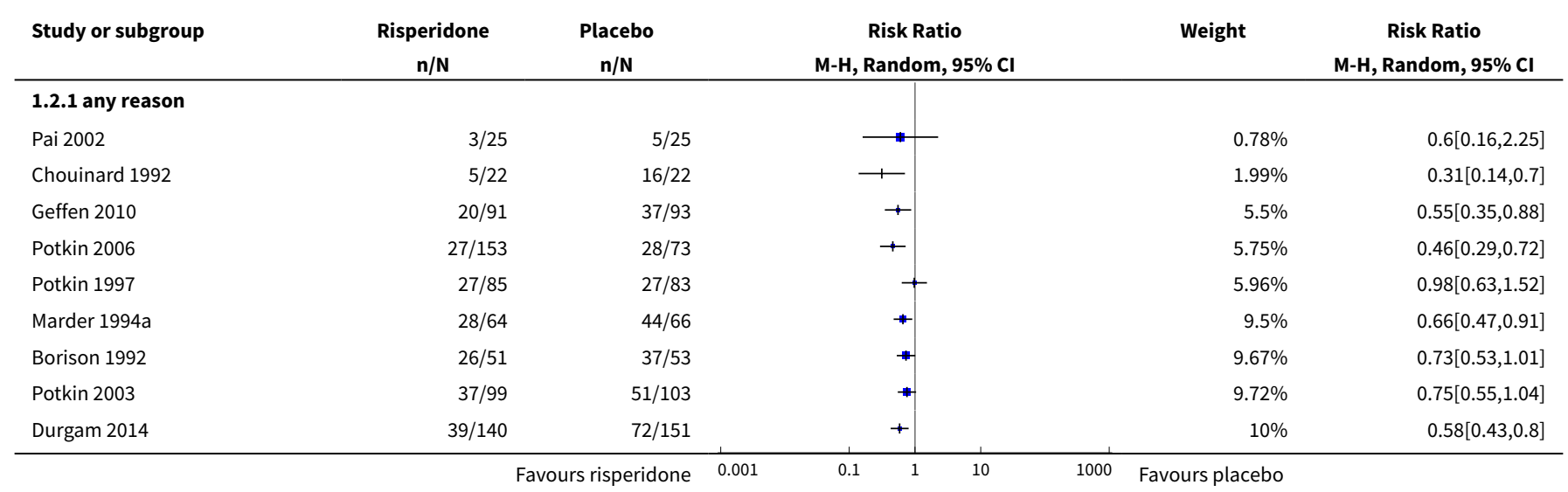




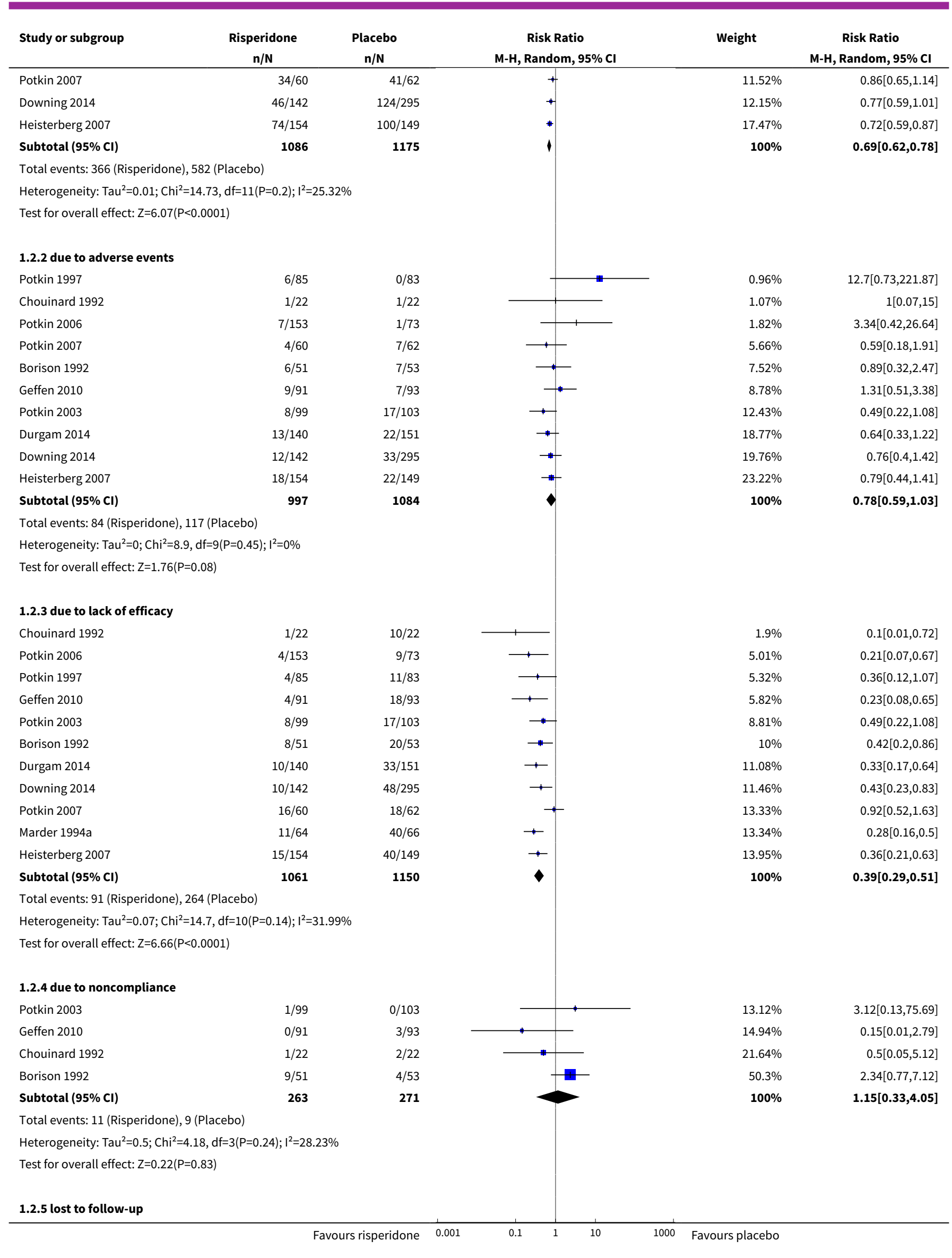

Risperidone versus placebo for schizophrenia (Review) 


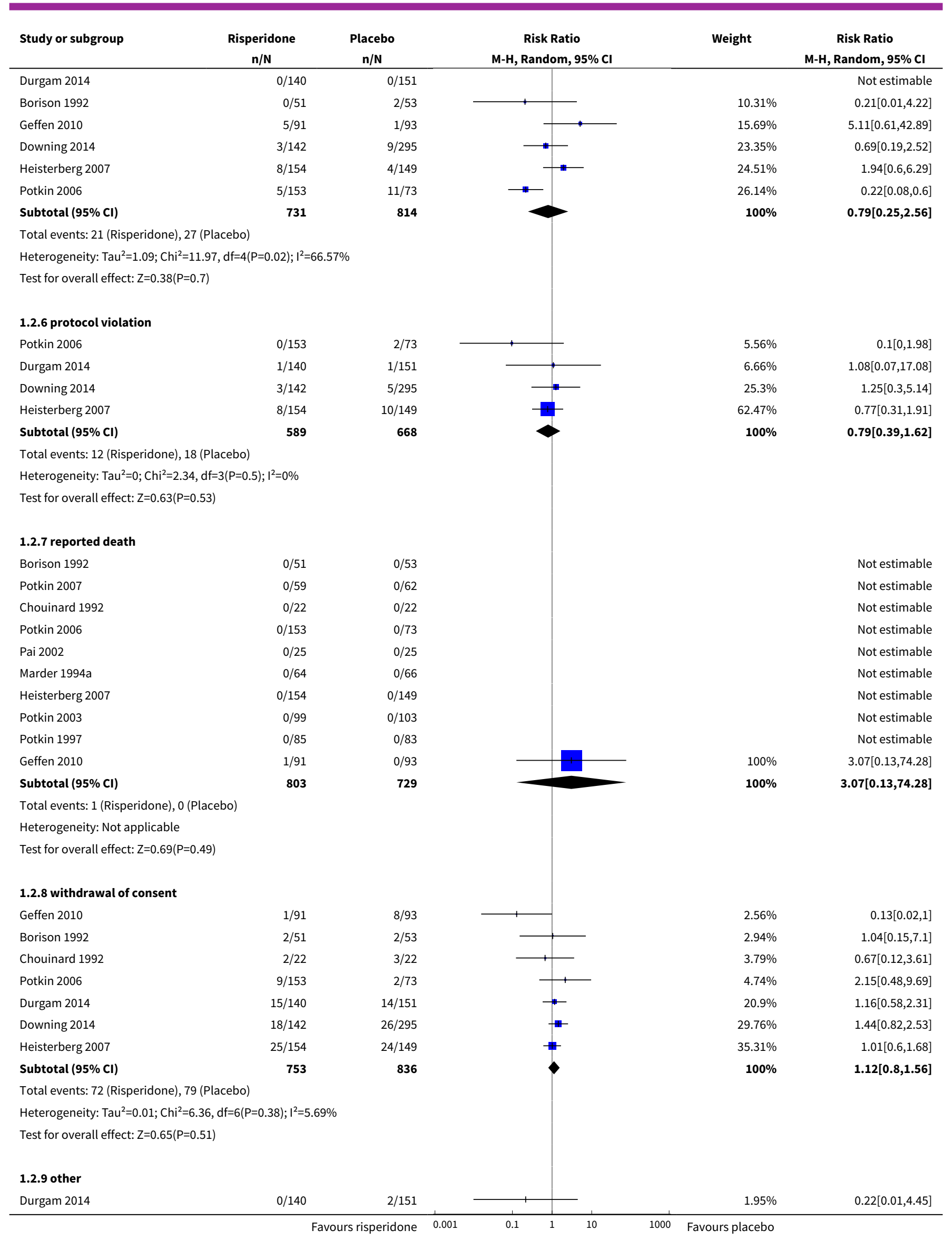

Risperidone versus placebo for schizophrenia (Review)

Copyright (c) 2016 The Cochrane Collaboration. Published by John Wiley \& Sons, Ltd. 


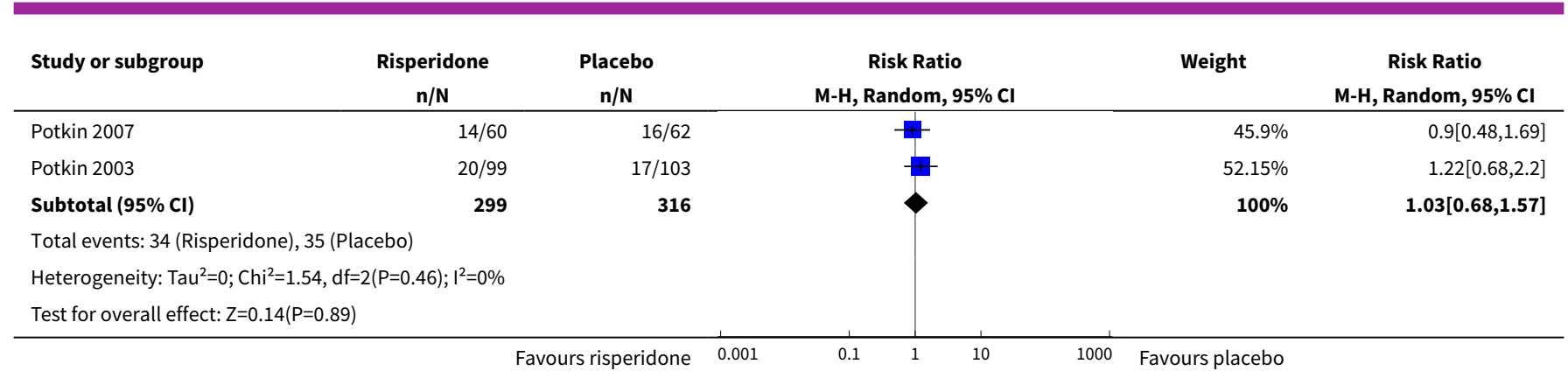

Analysis 1.3. Comparison 1 RISPERIDONE vs PLACEBO, Outcome 3 Global state: 1. average endpoint scores of CGI severity scale (high=poor) - short term (up to 12 weeks).

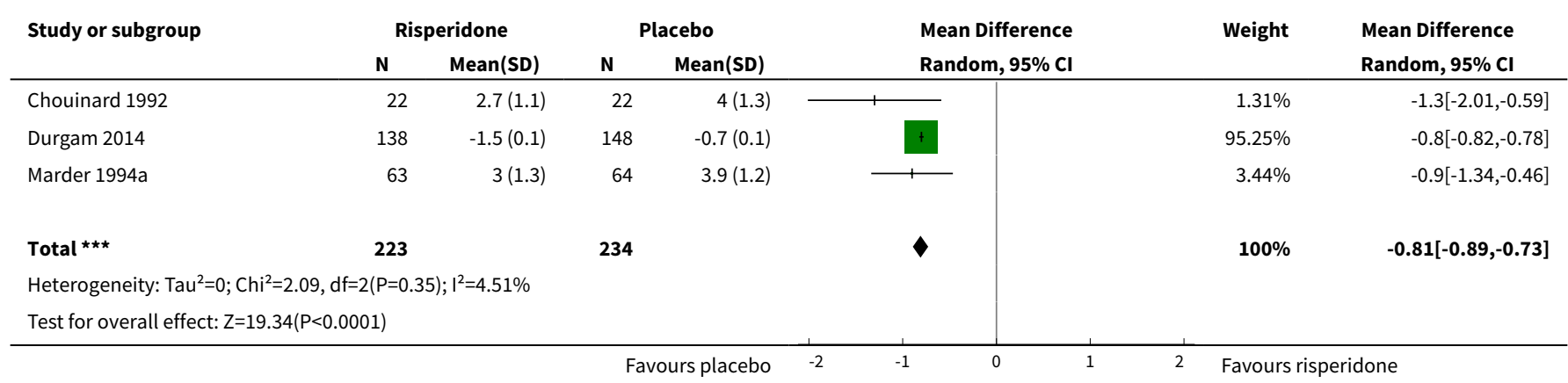

Analysis 1.4. Comparison 1 RISPERIDONE vs PLACEBO, Outcome 4 Global state: 2. no significant clinical improvement CGI - short term (up to 12 weeks).

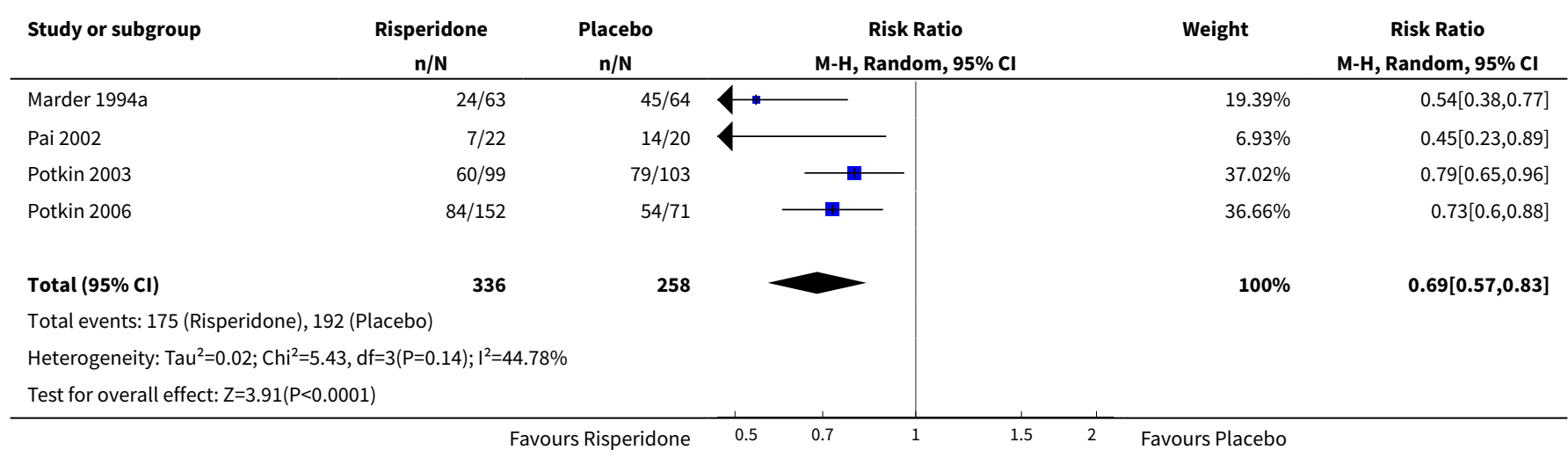

Analysis 1.5. Comparison 1 RISPERIDONE vs PLACEBO, Outcome 5 Global state: 3. needing additional medication - short term (up to 12 weeks).

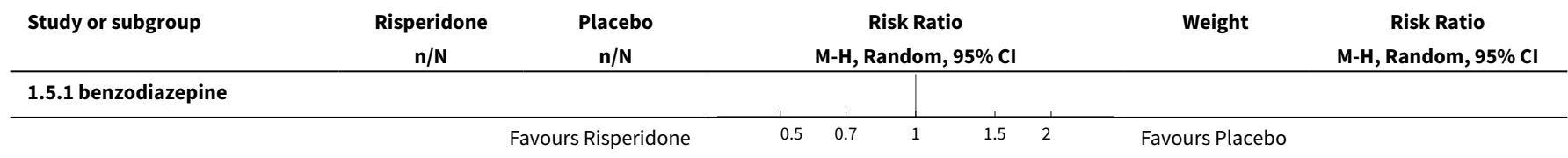




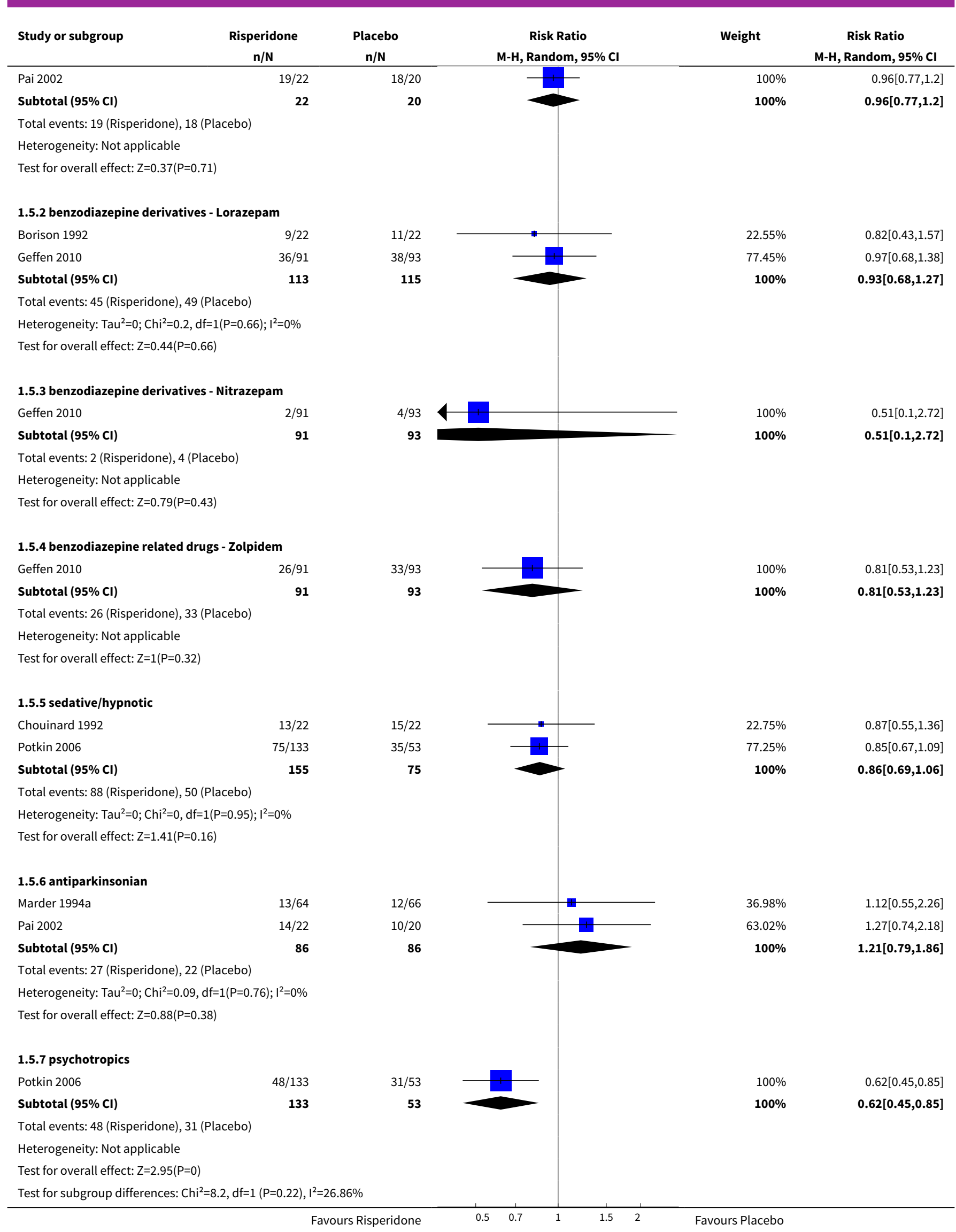

Risperidone versus placebo for schizophrenia (Review) 
Analysis 1.6. Comparison 1 RISPERIDONE vs PLACEBO, Outcome 6 Mental state: 1. average endpoint scores on various scales on psychotic symptoms (high=poor) - short term (up to 12 weeks).

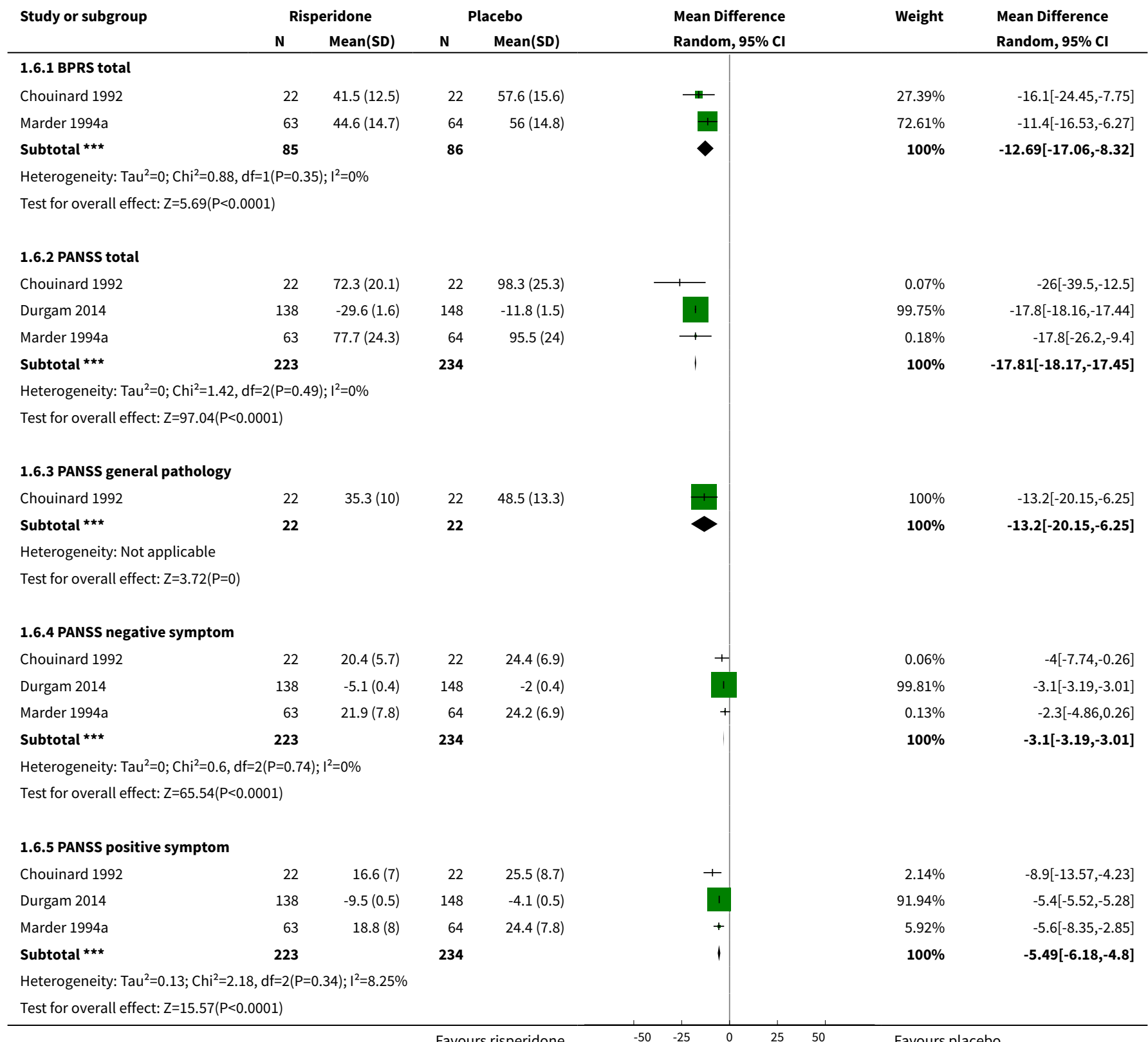

\section{Analysis 1.7. Comparison 1 RISPERIDONE vs PLACEBO, Outcome \\ 7 Mental state: 2 . skewed data - short term (up to 12 weeks).}

Mental state: 2. skewed data - short term (up to 12 weeks)

\begin{tabular}{|c|c|c|c|c|}
\hline Study & Intervention & Mean & SD & $\mathbf{N}$ \\
\hline \multicolumn{5}{|c|}{ average endpoint score BPRS total (high=poor) } \\
\hline Pai 2002 & Resperidone & 14.7 & 7.4 & 22 \\
\hline Pai 2002 & Placebo & 19.0 & 12.2 & 20 \\
\hline \multicolumn{5}{|c|}{ average change score of CGI-C (larger decline=good) } \\
\hline
\end{tabular}

Risperidone versus placebo for schizophrenia (Review) 
Mental state: 2. skewed data - short term (up to 12 weeks)

\begin{tabular}{|c|c|c|c|c|}
\hline Study & Intervention & Mean & SD & $\mathbf{N}$ \\
\hline Potkin 2006 & Resperidone & 2.4 & 1.23 & 152 \\
\hline Potkin 2006 & Placebo & 2.9 & 0.84 & 71 \\
\hline \multicolumn{5}{|c|}{ average change score of CGI-SI (larger decline=good) } \\
\hline Potkin 2006 & Resperidone & -1.84 & 1.23 & 152 \\
\hline Potkin 2006 & Placebo & -1.1 & 0.84 & 71 \\
\hline \multicolumn{5}{|c|}{ average change score of HAM-D-17 (larger decline=good) } \\
\hline Potkin 2006 & Placebo & -4.4 & 4.21 & 71 \\
\hline \multicolumn{5}{|c|}{ average change score of PANSS total (larger decline=good) } \\
\hline Potkin 2006 & Resperidone & -27.7 & 18.49 & 152 \\
\hline Potkin 2006 & Placebo & -20.2 & 16.85 & 71 \\
\hline \multicolumn{5}{|c|}{ average change score of PANSS negative symptom (larger decline=good) } \\
\hline Potkin 2006 & Resperidone & -4.0 & 4.93 & 152 \\
\hline \multicolumn{5}{|c|}{ average change score of PANSS positive symptom (larger decline=good) } \\
\hline Potkin 2006 & Resperidone & -8.7 & 6.16 & 152 \\
\hline Potkin 2006 & Placebo & -5.3 & 5.9 & 71 \\
\hline
\end{tabular}

Analysis 1.8. Comparison 1 RISPERIDONE vs PLACEBO, Outcome 8 Adverse effects: 1a. extrapyramidal - various effects - short term (up to 12 weeks).

\begin{tabular}{|c|c|c|c|c|c|}
\hline Study or subgroup & $\begin{array}{c}\text { Risperidone } \\
\mathrm{n} / \mathrm{N} \\
\end{array}$ & $\begin{array}{c}\text { Placebo } \\
\text { n/N }\end{array}$ & $\begin{array}{c}\text { Risk Ratio } \\
\text { M-H, Random, } 95 \% \mathrm{Cl}\end{array}$ & Weight & $\begin{array}{c}\text { Risk Ratio } \\
\text { M-H, Random, } 95 \% \text { CI }\end{array}$ \\
\hline \multicolumn{6}{|c|}{ 1.8.1 general - any significant EPS } \\
\hline Borison 1992 & $11 / 51$ & $11 / 53$ & $\longrightarrow$ & $16.97 \%$ & $1.04[0.49,2.18]$ \\
\hline Chouinard 1992 & $5 / 22$ & $4 / 22$ & + & $7.18 \%$ & $1.25[0.39,4.05]$ \\
\hline Downing 2014 & $0 / 142$ & $3 / 295$ & & $1.17 \%$ & $0.3[0.02,5.69]$ \\
\hline Durgam 2014 & $18 / 140$ & $7 / 151$ & $\longrightarrow$ & $13.46 \%$ & $2.77[1.19,6.44]$ \\
\hline Marder 1994a & $7 / 64$ & $7 / 66$ & + & $9.95 \%$ & $1.03[0.38,2.77]$ \\
\hline Potkin 2003 & $31 / 99$ & $21 / 103$ & + & $35.86 \%$ & $1.54[0.95,2.48]$ \\
\hline Subtotal $(95 \% \mathrm{Cl})$ & 672 & 839 & & $100 \%$ & $1.56[1.13,2.15]$ \\
\hline \multicolumn{6}{|c|}{ Total events: 93 (Risperidone), 61 (Placebo) } \\
\hline \multicolumn{6}{|c|}{ Heterogeneity: $\mathrm{Tau}^{2}=0.01 ; \mathrm{Chi}^{2}=6.48, \mathrm{df}=6(\mathrm{P}=0.37) ; \mathrm{I}^{2}=7.44 \%$} \\
\hline \multicolumn{6}{|c|}{ Test for overall effect: $Z=2.72(P=0.01)$} \\
\hline \multicolumn{6}{|c|}{ 1.8.2 general - no improvement on AIMS score } \\
\hline Pai 2002 & $6 / 22$ & $18 / 20$ & 7 & $100 \%$ & $0.3[0.15,0.61]$ \\
\hline Subtotal $(95 \% \mathrm{Cl})$ & 22 & 20 & & $100 \%$ & $0.3[0.15,0.61]$ \\
\hline \multicolumn{6}{|c|}{ Total events: 6 (Risperidone), 18 (Placebo) } \\
\hline \multicolumn{6}{|c|}{ Heterogeneity: Not applicable } \\
\hline \multicolumn{6}{|c|}{ Test for overall effect: $\mathrm{Z}=3.35(\mathrm{P}=0)$} \\
\hline \multicolumn{6}{|c|}{ 1.8.3 general - no improvement on BAS score } \\
\hline Potkin 2006 & $143 / 153$ & $60 / 73$ & & $100 \%$ & $1.14[1.01,1.28]$ \\
\hline Subtotal $(95 \% \mathrm{CI})$ & 153 & 73 & $\checkmark$ & $100 \%$ & $1.14[1.01,1.28]$ \\
\hline \multicolumn{6}{|c|}{ Total events: 143 (Risperidone), 60 (Placebo) } \\
\hline \multicolumn{6}{|c|}{ Heterogeneity: Not applicable } \\
\hline Test for overall effect & & & & & \\
\hline
\end{tabular}




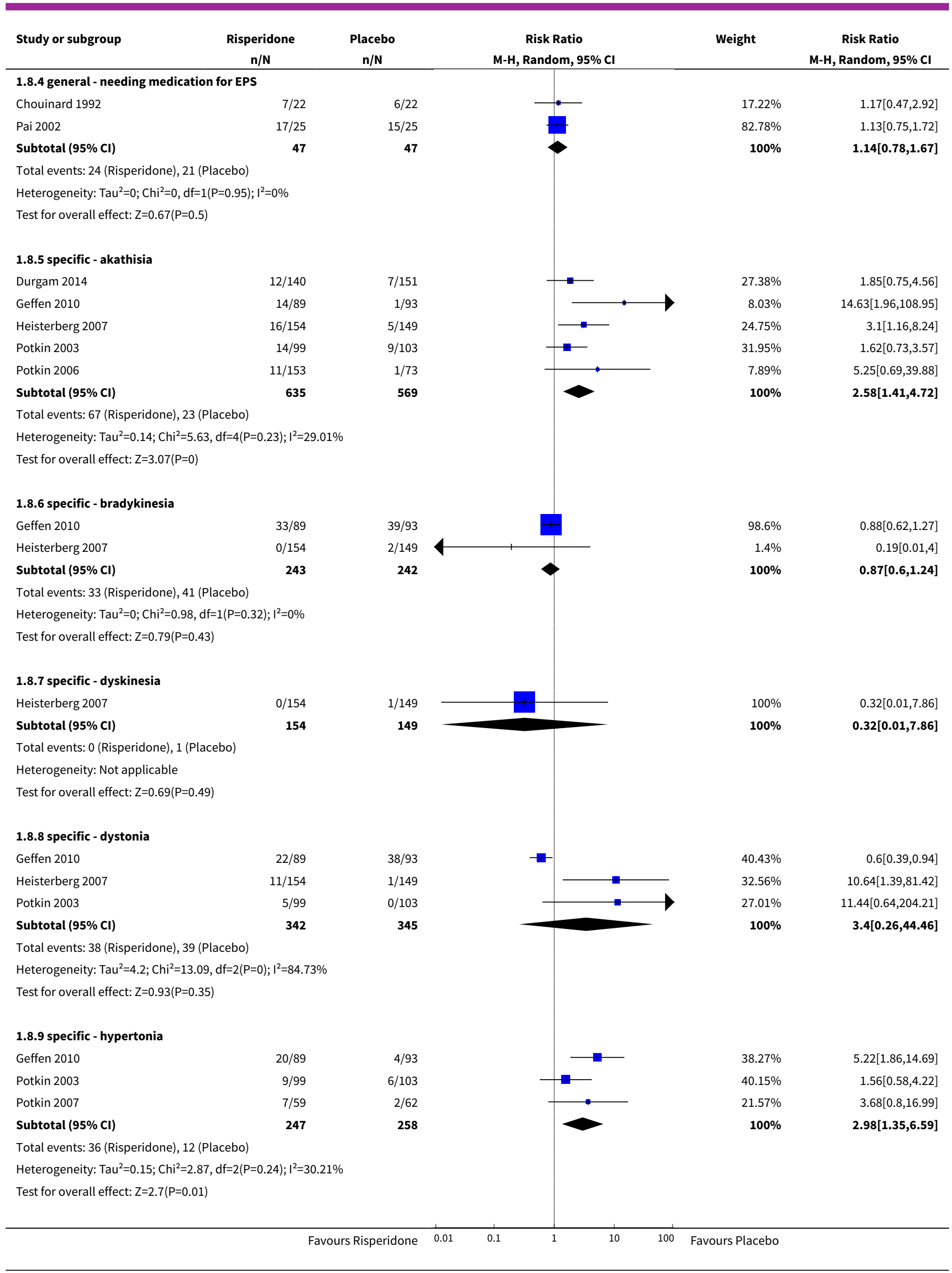

Risperidone versus placebo for schizophrenia (Review) 


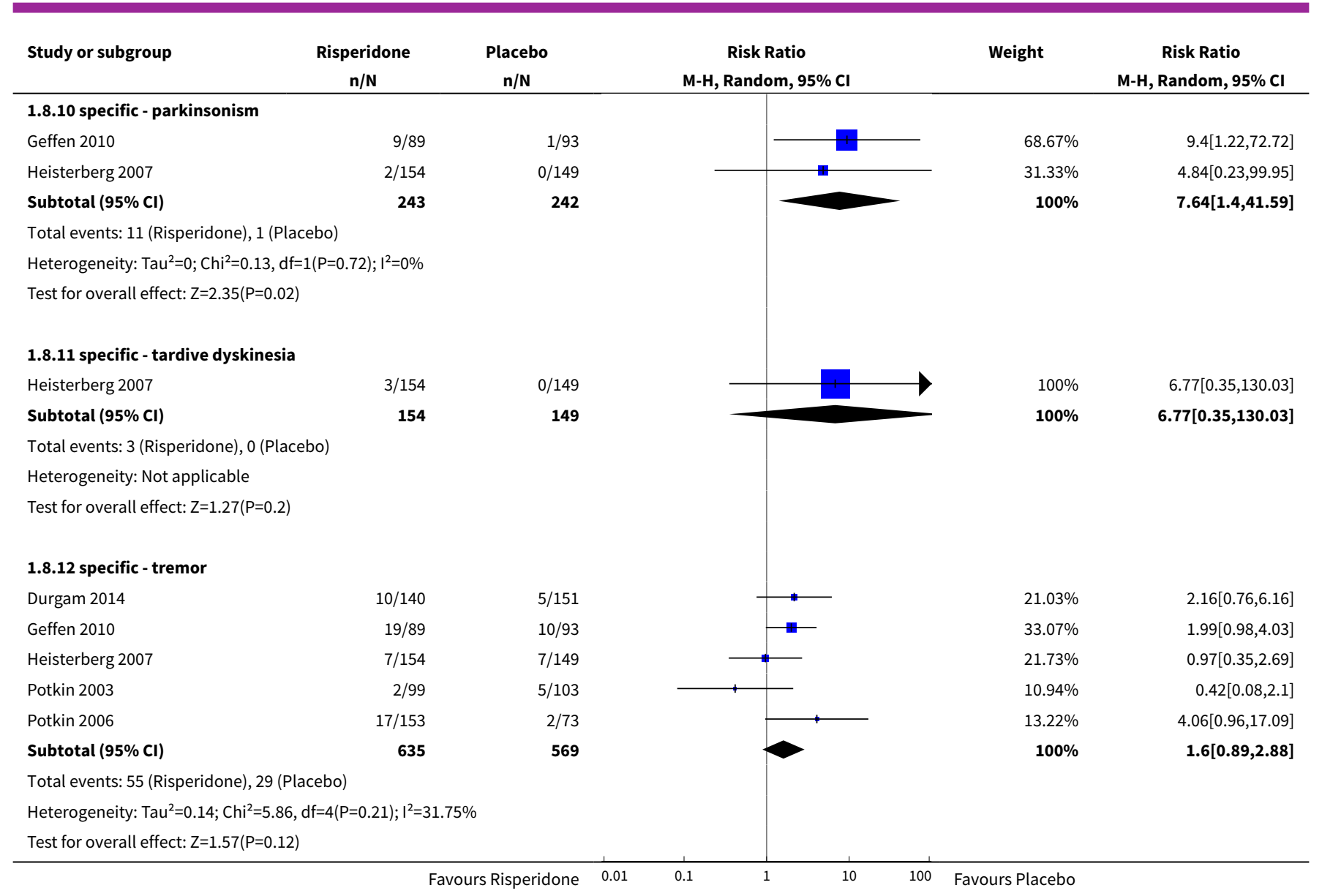

Analysis 1.9. Comparison 1 RISPERIDONE vs PLACEBO, Outcome 9 Adverse effects: 1b. extrapyramidal - AIMS average endpoint score - short term (up to 12 weeks).

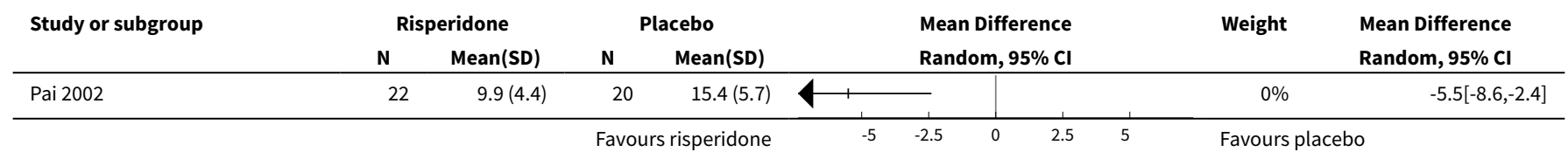

Analysis 1.10. Comparison 1 RISPERIDONE vs PLACEBO, Outcome 10 Adverse effects: 1c. extrapyramidal - skewed data (various scales) - short term (up to 12 weeks).

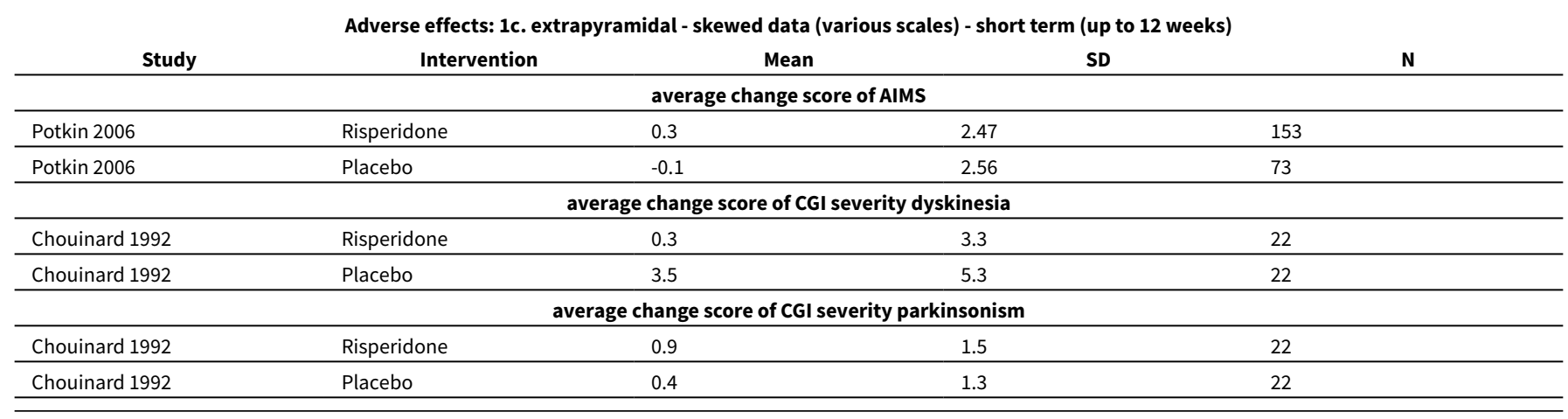




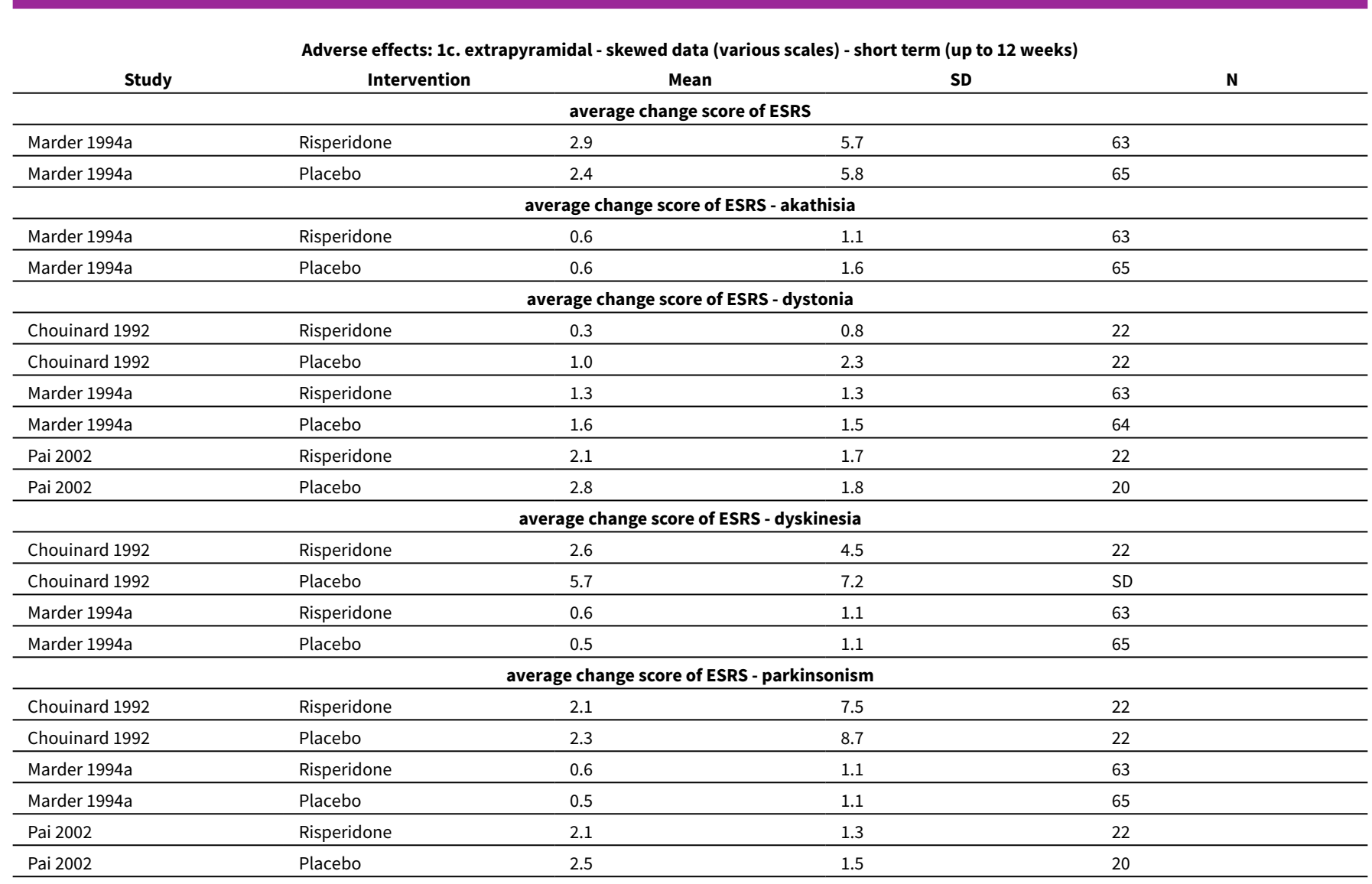

\section{Analysis 1.11. Comparison 1 RISPERIDONE vs PLACEBO, Outcome 11} Adverse effects: 2 . any adverse event - short term (up to 12 weeks).

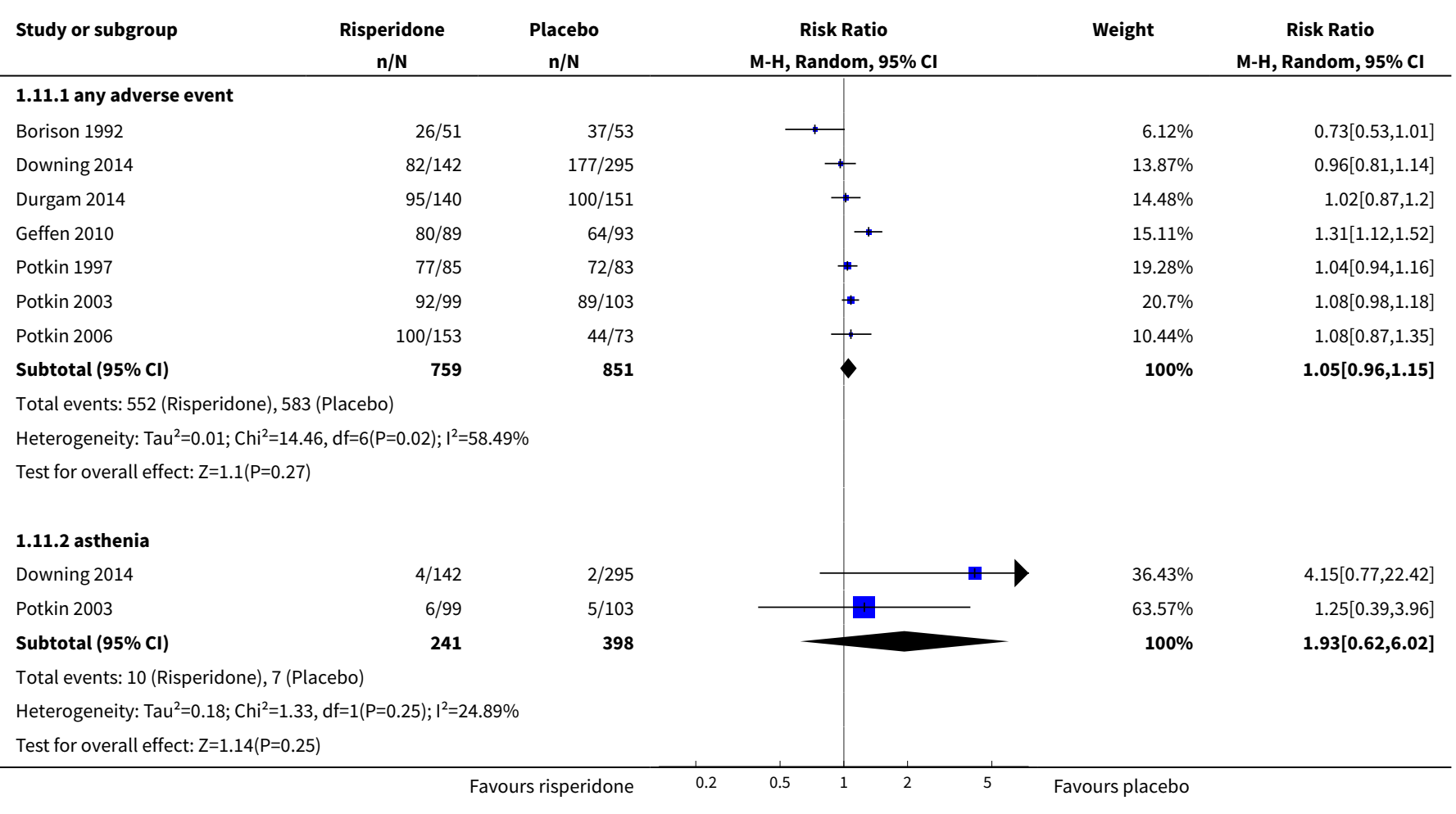




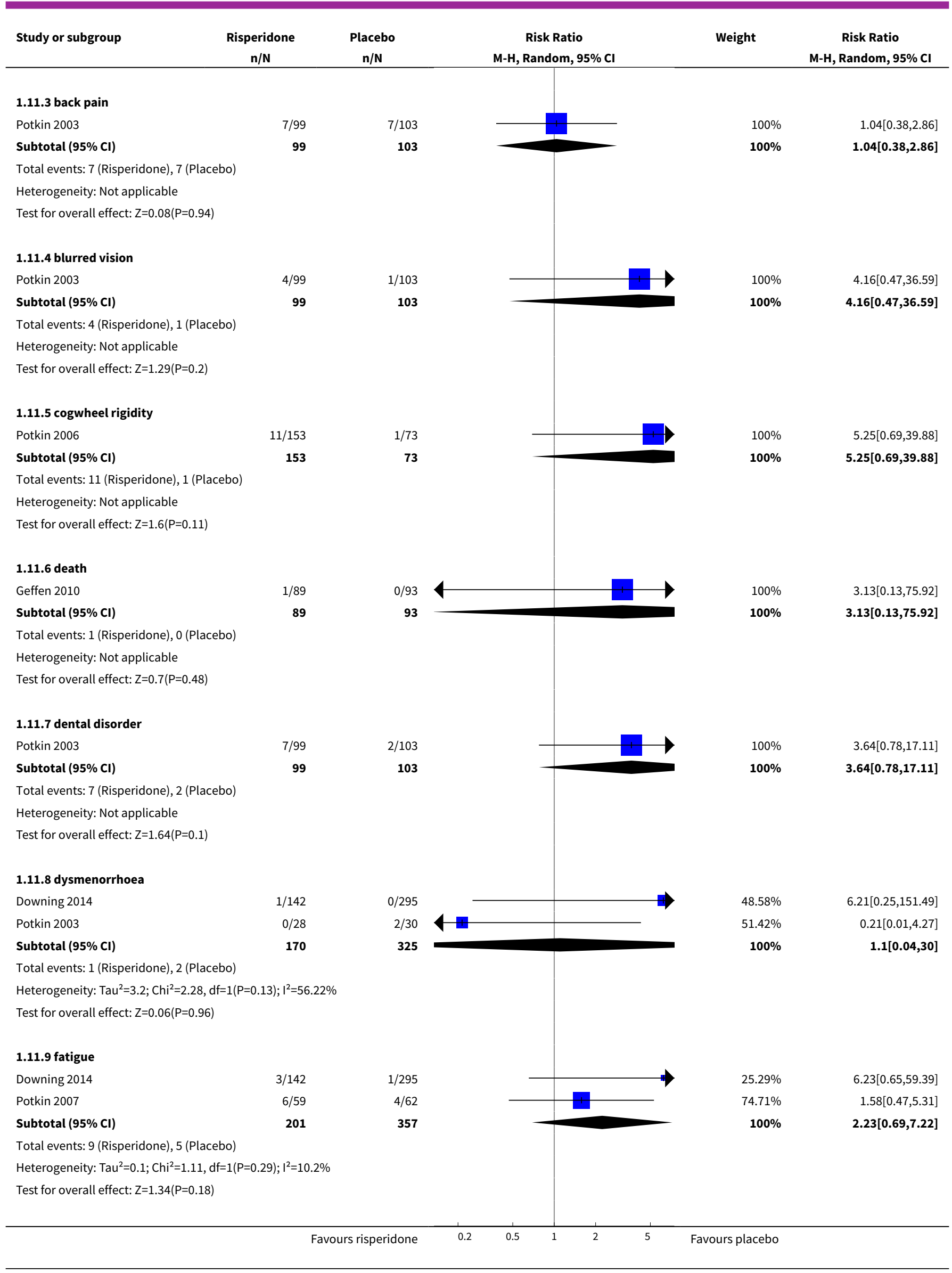

Risperidone versus placebo for schizophrenia (Review)

Copyright (c) 2016 The Cochrane Collaboration. Published by John Wiley \& Sons, Ltd. 


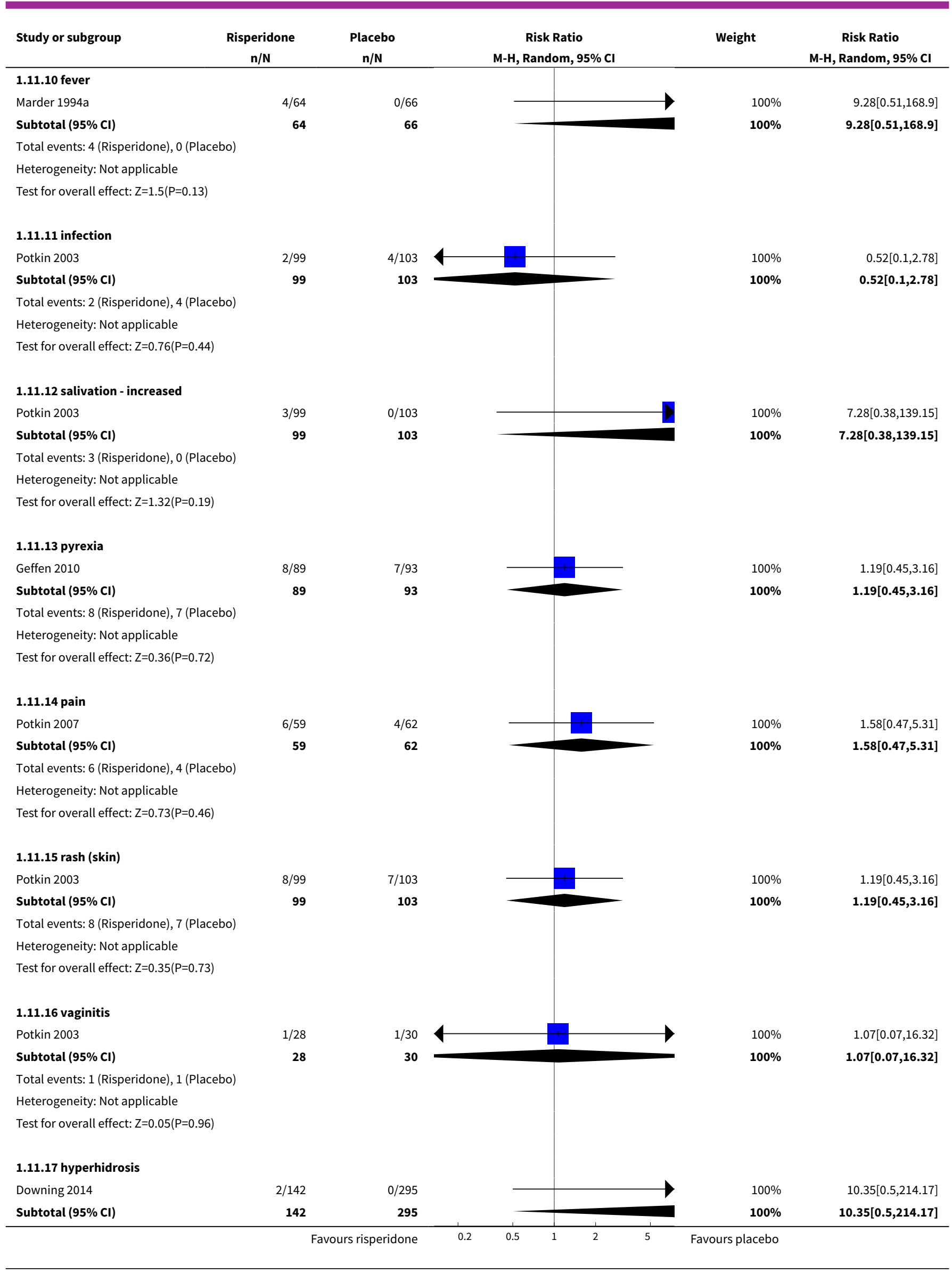

Risperidone versus placebo for schizophrenia (Review) 


\begin{tabular}{|c|c|c|c|c|c|}
\hline Study or subgroup & $\begin{array}{c}\text { Risperidone } \\
\mathrm{n} / \mathrm{N} \\
\end{array}$ & $\begin{array}{c}\text { Placebo } \\
\mathbf{n} / \mathbf{N}\end{array}$ & $\begin{array}{c}\text { Risk Ratio } \\
\text { M-H, Random, } 95 \% \mathrm{CI}\end{array}$ & Weight & \multirow[t]{2}{*}{$\begin{array}{c}\text { Risk Ratio } \\
\text { M-H, Random, } 95 \% \mathrm{Cl}\end{array}$} \\
\hline \multicolumn{5}{|c|}{ Total events: 2 (Risperidone), 0 (Placebo) } & \\
\hline \multicolumn{6}{|c|}{ Heterogeneity: Not applicable } \\
\hline \multicolumn{6}{|c|}{ Test for overall effect: $Z=1.51(P=0.13)$} \\
\hline \multicolumn{6}{|c|}{ Test for subgroup differences: $\mathrm{Chi}^{2}=16.44, \mathrm{df}=1(\mathrm{P}=0.42), \mathrm{I}^{2}=2.71 \%$} \\
\hline
\end{tabular}

Analysis 1.12. Comparison 1 RISPERIDONE vs PLACEBO, Outcome

12 Adverse effects: 3. cardiovascular - short term (up to 12 weeks).

$\begin{array}{ccccc}\text { Study or subgroup } & \text { Risperidone } & \text { Placebo } & \text { Risk Ratio } & \text { Weight } \\ \mathbf{n} / \mathrm{N} & \mathrm{n} / \mathrm{N} & \mathrm{M}-\mathrm{H}, \text { Random, } 95 \% \mathrm{Cl}\end{array}$

\subsection{1 dizziness - orthostatic}

Chouinard 1992

Subtotal $(95 \% \mathrm{Cl})$

Total events: 1 (Risperidone), 0 (Placebo)

Heterogeneity: Not applicable

Test for overall effect: $\mathrm{Z}=0.68(\mathrm{P}=0.49)$

\subsubsection{ECG abnormal}

Geffen 2010

Subtotal $(95 \% \mathrm{Cl})$

Total events: 4 (Risperidone), 0 (Placebo)

Heterogeneity: Not applicable

Test for overall effect: $Z=1.51(P=0.13)$

\subsection{3 heart rate decreased}

Geffen 2010

Subtotal $(95 \% \mathrm{CI})$

Total events: 1 (Risperidone), 2 (Placebo)

Heterogeneity: Not applicable

Test for overall effect: $Z=0.53(P=0.59)$

\subsection{4 heart rate increased}

Geffen 2010

Subtotal $(95 \% \mathrm{Cl})$

Total events: 9 (Risperidone), 11 (Placebo)

Heterogeneity: Not applicable

Test for overall effect: $Z=0.37(P=0.71)$

1.12.5 hypotension - postural

Chouinard 1992

Subtotal $(95 \% \mathrm{CI})$

$1 / 89$

89

$4 / 89$

89

$1 / 22$

22

$\mathrm{n} / \mathrm{N}$

$0 / 22$

22

\begin{tabular}{r|r}
\hline \\
\hline
\end{tabular}

(1)

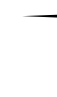

Weight

\section{$100 \%$}

$100 \%$

Risk Ratio M-H, Random, 95\% CI 


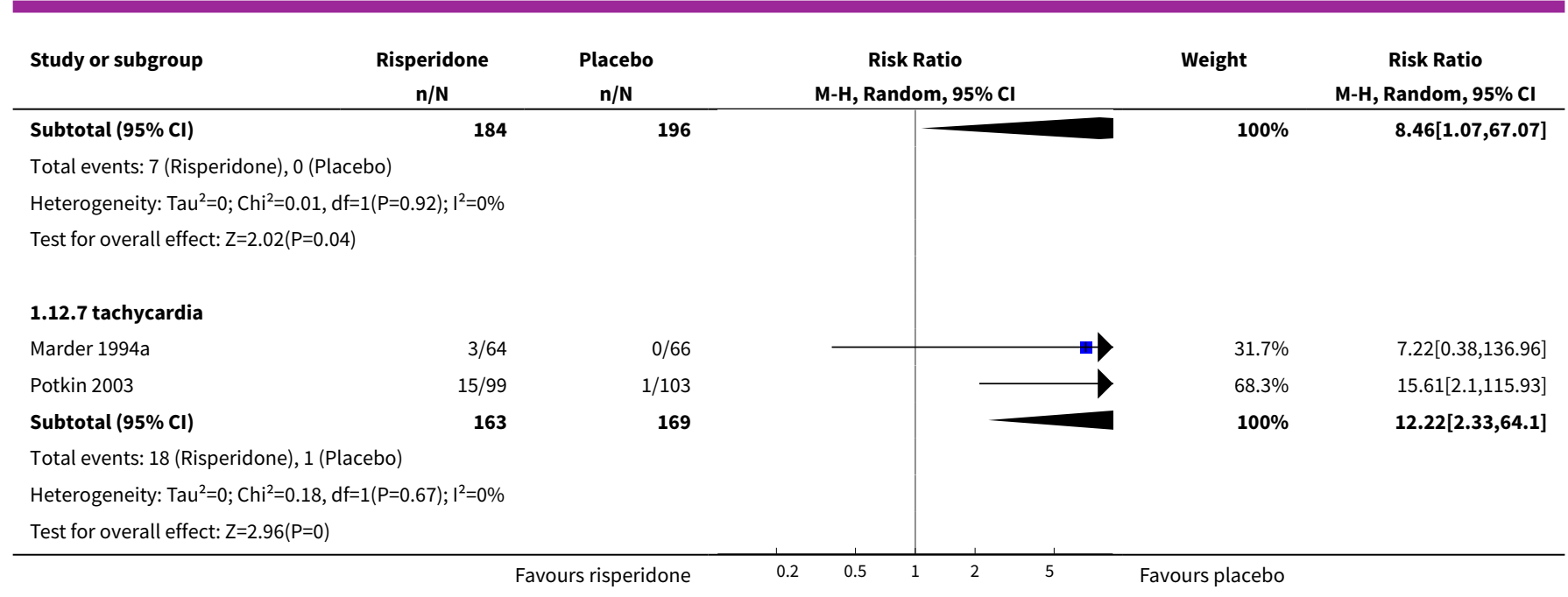

Analysis 1.13. Comparison 1 RISPERIDONE vs PLACEBO, Outcome 13 Adverse effects: 4. central nervous system - short term (up to 12 weeks).

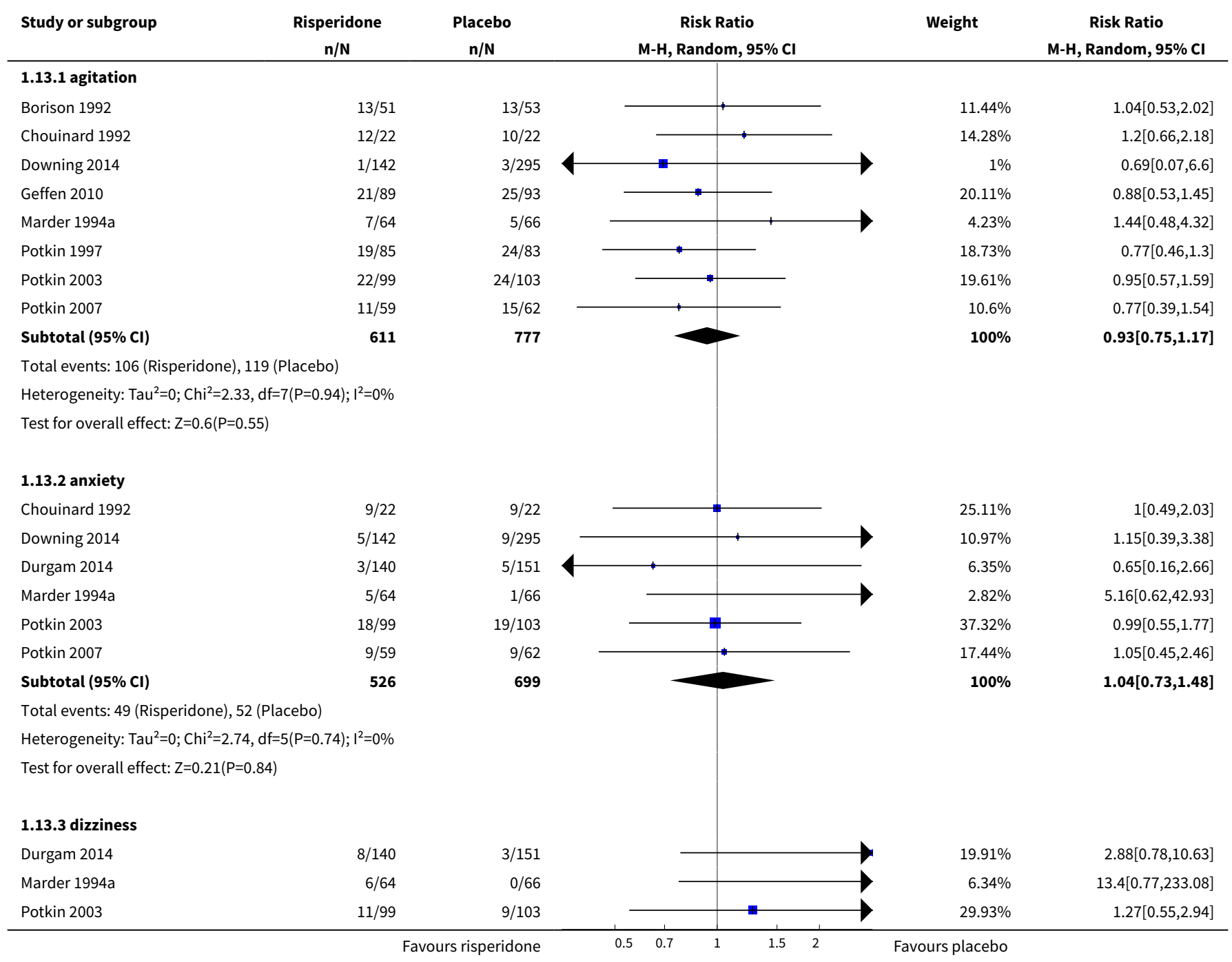




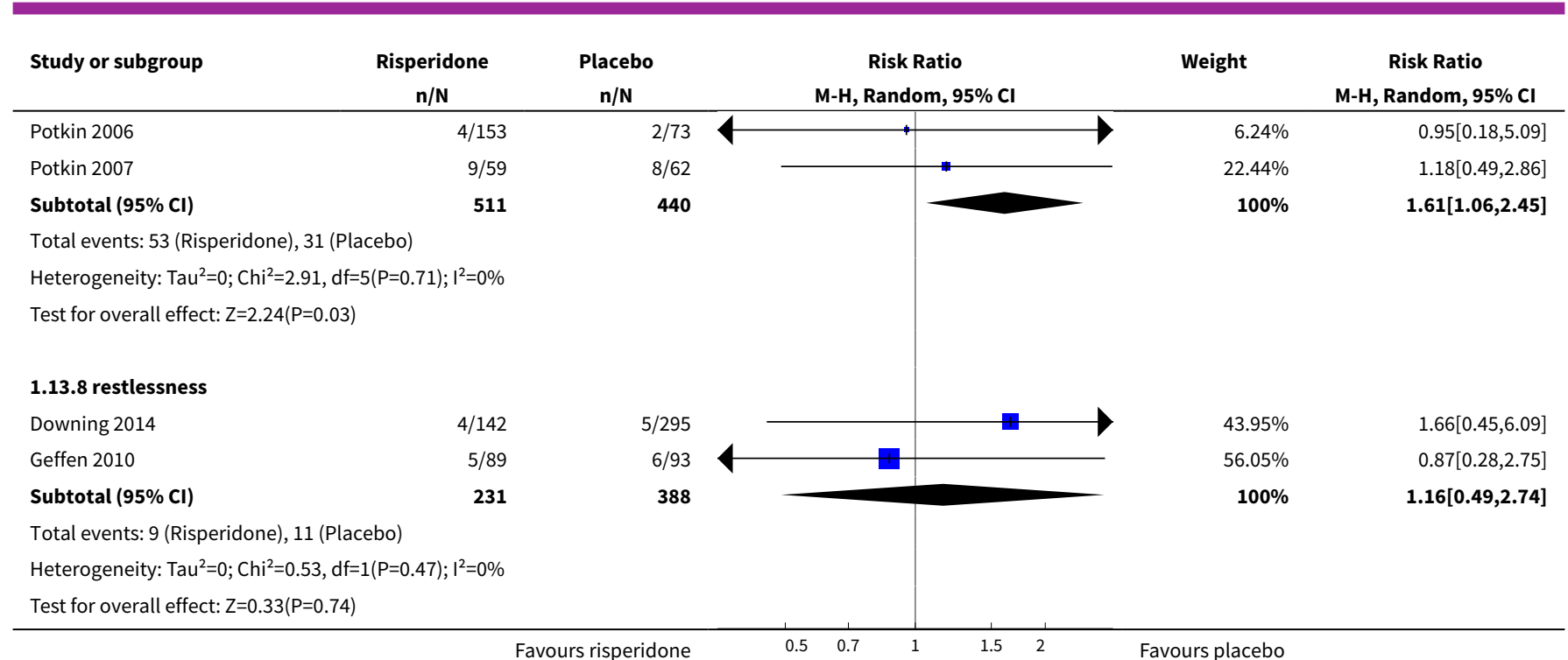

Analysis 1.14. Comparison 1 RISPERIDONE vs PLACEBO, Outcome 14 Adverse effects: 5 . endocrine - serum prolactin increase above reference range $(23 \mathrm{ng} / \mathrm{ml}$ ) - short term (up to 12 weeks).

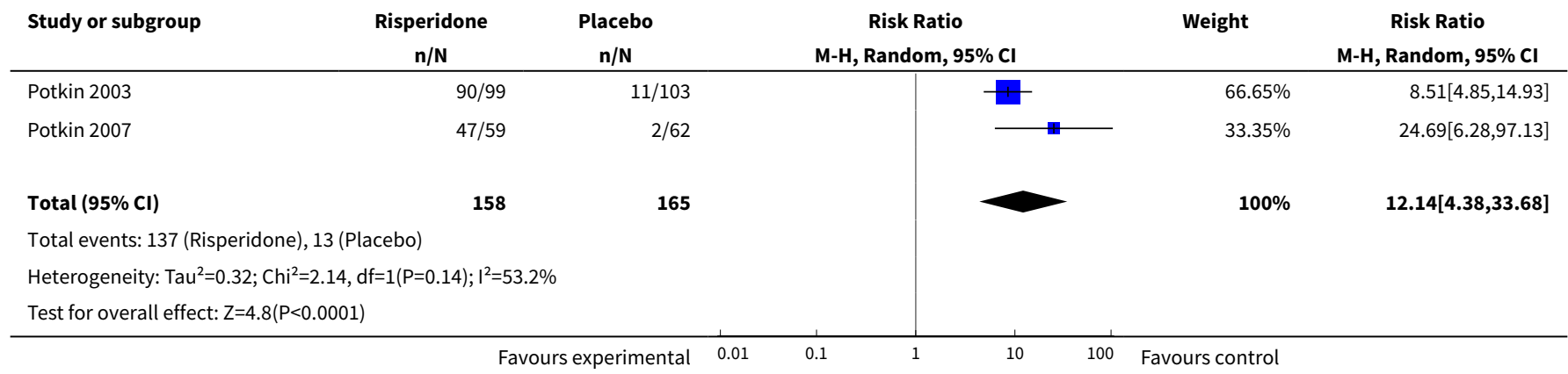

Analysis 1.15. Comparison 1 RISPERIDONE vs PLACEBO, Outcome 15 Adverse effects: 6. gastrointestinal system - short term (up to 12 weeks).

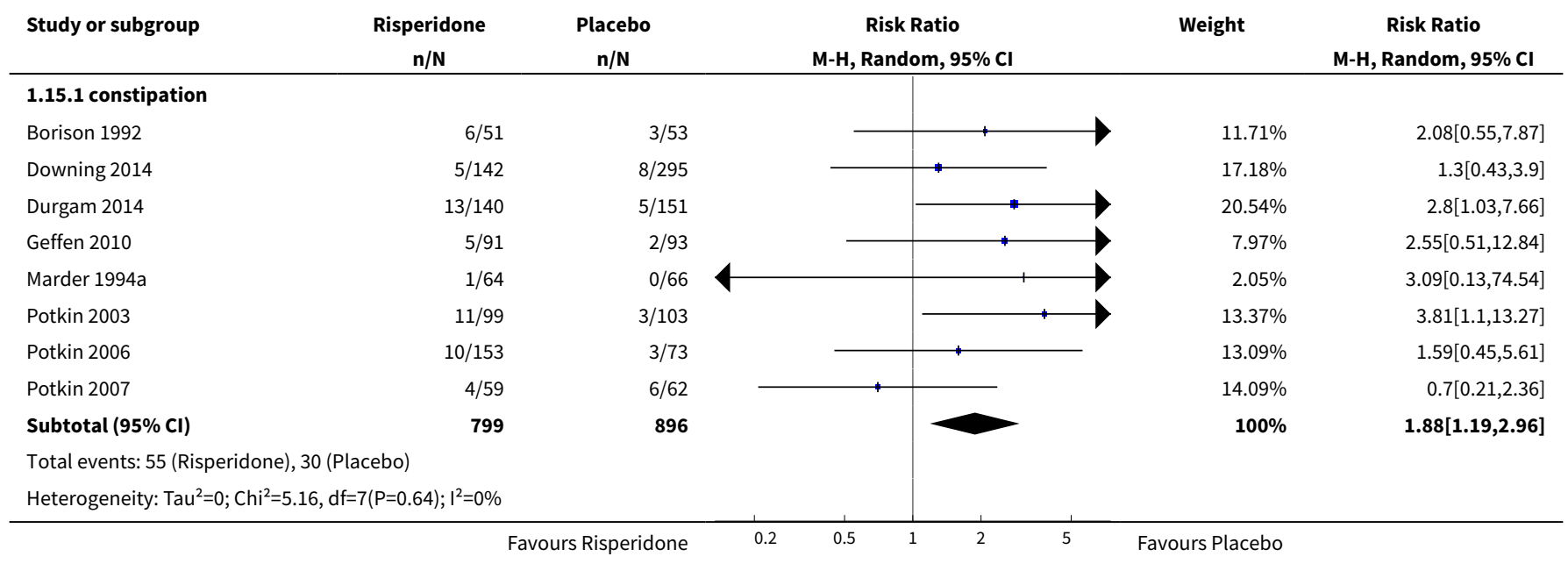




\begin{tabular}{|c|c|c|c|c|c|}
\hline Study or subgroup & $\begin{array}{c}\text { Risperidone } \\
n / N\end{array}$ & $\begin{array}{c}\text { Placebo } \\
\mathbf{n} / \mathbf{N}\end{array}$ & $\begin{array}{c}\text { Risk Ratio } \\
\text { M-H, Random, } 95 \% \mathrm{Cl}\end{array}$ & Weight & $\begin{array}{c}\text { Risk Ratio } \\
\text { M-H, Random, } 95 \% \mathrm{CI}\end{array}$ \\
\hline \multicolumn{3}{|c|}{ Test for overall effect: $Z=2.71(P=0.01)$} & & & \\
\hline \multicolumn{6}{|l|}{ 1.15.2 diarrhoea } \\
\hline Potkin 2003 & $8 / 99$ & $9 / 103$ & & $100 \%$ & $0.92[0.37,2.3]$ \\
\hline \multicolumn{6}{|c|}{ Total events: 8 (Risperidone), 9 (Placebo) } \\
\hline \multicolumn{6}{|c|}{ Heterogeneity: Not applicable } \\
\hline \multicolumn{6}{|c|}{ Test for overall effect: $Z=0.17(P=0.87)$} \\
\hline \multicolumn{6}{|l|}{ 1.15.3 dry mouth } \\
\hline Potkin 2003 & $7 / 99$ & $3 / 103$ & & $100 \%$ & $2.43[0.65,9.12]$ \\
\hline \multicolumn{6}{|c|}{ Total events: 7 (Risperidone), 3 (Placebo) } \\
\hline \multicolumn{6}{|c|}{ Heterogeneity: Not applicable } \\
\hline \multicolumn{6}{|c|}{ Test for overall effect: $Z=1.31(P=0.19)$} \\
\hline \multicolumn{6}{|l|}{ 1.15.4 dyspepsia } \\
\hline Downing 2014 & $8 / 142$ & $5 / 295$ & & $18.22 \%$ & $3.32[1.11,9.98]$ \\
\hline Marder 1994a & $6 / 64$ & $3 / 66$ & & $14.62 \%$ & $2.06[0.54,7.9]$ \\
\hline Potkin 1997 & $8 / 85$ & $9 / 83$ & & $21.75 \%$ & $0.87[0.35,2.14]$ \\
\hline Potkin 2003 & $12 / 99$ & $22 / 103$ & $\longrightarrow$ & $27.05 \%$ & $0.57[0.3,1.08]$ \\
\hline Potkin 2007 & $7 / 59$ & $5 / 62$ & * & $18.36 \%$ & $1.47[0.49,4.38]$ \\
\hline Subtotal $(95 \% \mathrm{Cl})$ & 449 & 609 & & $100 \%$ & $1.24[0.64,2.4]$ \\
\hline \multicolumn{6}{|c|}{ Total events: 41 (Risperidone), 44 (Placebo) } \\
\hline \multicolumn{6}{|c|}{ Heterogeneity: $\mathrm{Tau}^{2}=0.31 ; \mathrm{Chi}^{2}=9.21, \mathrm{df}=4(\mathrm{P}=0.06) ; \mathrm{I}^{2}=56.58 \%$} \\
\hline \multicolumn{6}{|l|}{ 1.15.5 nausea } \\
\hline Chouinard 1992 & $2 / 22$ & $1 / 22$ & & $3.82 \%$ & $2[0.2,20.49]$ \\
\hline Downing 2014 & $5 / 142$ & $14 / 295$ & & $20.62 \%$ & $0.74[0.27,2.02]$ \\
\hline Durgam 2014 & $8 / 140$ & $5 / 151$ & + & $17.29 \%$ & $1.73[0.58,5.15]$ \\
\hline Marder 1994a & $4 / 64$ & $0 / 66$ & & $2.45 \%$ & $9.28[0.51,168.9]$ \\
\hline Potkin 2003 & $12 / 99$ & $10 / 103$ & & $32.9 \%$ & $1.25[0.57,2.76]$ \\
\hline Potkin 2007 & $7 / 59$ & $8 / 62$ & $\rightarrow$ & $22.92 \%$ & $0.92[0.36,2.38]$ \\
\hline Subtotal $(95 \% \mathrm{Cl})$ & 526 & 699 & & $100 \%$ & $1.18[0.75,1.86]$ \\
\hline \multicolumn{6}{|c|}{ Total events: 38 (Risperidone), 38 (Placebo) } \\
\hline \multicolumn{6}{|c|}{ Heterogeneity: $\mathrm{Tau}^{2}=0 ; \mathrm{Chi}^{2}=3.76, \mathrm{df}=5(\mathrm{P}=0.58) ; \mathrm{I}^{2}=0 \%$} \\
\hline \multicolumn{6}{|c|}{ Test for overall effect: $\mathrm{Z}=0.72(\mathrm{P}=0.47)$} \\
\hline \multicolumn{6}{|l|}{ 1.15.6 vomiting } \\
\hline Downing 2014 & $5 / 142$ & $6 / 295$ & & $23.66 \%$ & $1.73[0.54,5.58]$ \\
\hline Durgam 2014 & $4 / 140$ & $5 / 151$ & $\longrightarrow$ & $19.44 \%$ & $0.86[0.24,3.15]$ \\
\hline Marder 1994a & $4 / 64$ & $1 / 66$ & & $7.08 \%$ & $4.13[0.47,35.92]$ \\
\hline Potkin 2003 & $8 / 99$ & $6 / 103$ & $\longrightarrow$ & $30.69 \%$ & $1.39[0.5,3.85]$ \\
\hline Potkin 2007 & $3 / 59$ & $7 / 62$ & & $19.14 \%$ & $0.45[0.12,1.66]$ \\
\hline Subtotal $(95 \% \mathrm{Cl})$ & 504 & 677 & & $100 \%$ & $1.16[0.65,2.07]$ \\
\hline \multicolumn{6}{|c|}{ Total events: 24 (Risperidone), 25 (Placebo) } \\
\hline \multicolumn{6}{|c|}{ Heterogeneity: $\mathrm{Tau}^{2}=0.01 ; \mathrm{Chi}^{2}=4.11, \mathrm{df}=4(\mathrm{P}=0.39) ; \mathrm{I}^{2}=2.66 \%$} \\
\hline Test for overall effec & & & & & \\
\hline
\end{tabular}


Analysis 1.16. Comparison 1 RISPERIDONE vs PLACEBO, Outcome 16

Adverse effects: 7 a. metabolic - weight gain - short term (up to 12 weeks).

\begin{tabular}{|c|c|c|c|c|c|}
\hline Study or subgroup & $\begin{array}{c}\text { Risperidone } \\
\mathrm{n} / \mathrm{N}\end{array}$ & $\begin{array}{c}\text { Placebo } \\
\mathrm{n} / \mathrm{N}\end{array}$ & $\begin{array}{c}\text { Risk Ratio } \\
\text { M-H, Random, } 95 \% \mathrm{Cl} \\
\end{array}$ & Weight & $\begin{array}{c}\text { Risk Ratio } \\
\text { M-H, Random, } 95 \% \mathrm{Cl} \\
\end{array}$ \\
\hline \multicolumn{6}{|l|}{ 1.16.1 any gain } \\
\hline Downing 2014 & $5 / 142$ & $2 / 295$ & + & $40.64 \%$ & $5.19[1.02,26.44]$ \\
\hline Durgam 2014 & $7 / 140$ & $1 / 151$ & $\longrightarrow$ & $24.82 \%$ & $7.55[0.94,60.59]$ \\
\hline Geffen 2010 & $3 / 89$ & $2 / 93$ & $=$ & $34.54 \%$ & $1.57[0.27,9.16]$ \\
\hline Subtotal $(95 \% \mathrm{Cl})$ & 371 & 539 & & $100 \%$ & $3.77[1.34,10.63]$ \\
\hline \multicolumn{6}{|c|}{ Total events: 15 (Risperidone), 5 (Placebo) } \\
\hline \multicolumn{6}{|c|}{ Heterogeneity: $\mathrm{Tau}^{2}=0 ; \mathrm{Chi}^{2}=1.54, \mathrm{df}=2(\mathrm{P}=0.46) ; I^{2}=0 \%$} \\
\hline \multicolumn{6}{|c|}{ Test for overall effect: $\mathrm{Z}=2.51(\mathrm{P}=0.01)$} \\
\hline \multicolumn{6}{|c|}{$1.16 .2>7 \%$ increase from baseline } \\
\hline Heisterberg 2007 & $17 / 154$ & $7 / 149$ & & $63.25 \%$ & $2.35[1,5.5]$ \\
\hline Potkin 2003 & $11 / 99$ & $2 / 103$ & $\longrightarrow$ & $23.8 \%$ & $5.72[1.3,25.17]$ \\
\hline Potkin 2007 & $8 / 47$ & $1 / 54$ & & $12.95 \%$ & $9.19[1.19,70.81]$ \\
\hline Subtotal $(95 \% \mathrm{Cl})$ & 300 & 306 & & $100 \%$ & $3.47[1.64,7.33]$ \\
\hline \multicolumn{6}{|c|}{ Total events: 36 (Risperidone), 10 (Placebo) } \\
\hline \multicolumn{6}{|c|}{ Heterogeneity: $\operatorname{Tau}^{2}=0.04 ; \mathrm{Chi}^{2}=2.17, \mathrm{df}=2(\mathrm{P}=0.34) ; \mathrm{I}^{2}=7.75 \%$} \\
\hline \multicolumn{6}{|c|}{ Test for overall effect: $Z=3.25(P=0)$} \\
\hline Test for subgroup dif & $02, \mathrm{df}=1(P=0.9), I^{2}$ & & & & \\
\hline
\end{tabular}

Analysis 1.17. Comparison 1 RISPERIDONE vs PLACEBO, Outcome 17 Adverse effects: $7 \mathrm{~b}$. metabolic - skewed data - average change value on lipid profile - short term (up to 12 weeks).

Adverse effects: 7b. metabolic - skewed data - average change value on lipid profile - short term (up to 12 weeks)

Study Intervention

Mean

SD

$\mathbf{N}$

\begin{tabular}{|c|c|c|c|c|}
\hline Study & Intervention & Mean & & $\mathbf{N}$ \\
\hline \multicolumn{5}{|c|}{ cholesterol - total } \\
\hline Durgam 2014 & Risperidone & 4.6 & 34.6 & 140 \\
\hline Durgam 2014 & Placebo & -1.3 & 30.4 & 151 \\
\hline Heisterberg 2007 & Risperidone & -2.2 & 31.4 & 154 \\
\hline Heisterberg 2007 & Placebo & -14.2 & 32.0 & 149 \\
\hline \multicolumn{5}{|c|}{ HDL } \\
\hline Durgam 2014 & Risperidone & -0.6 & 10.1 & 140 \\
\hline Durgam 2014 & Placebo & -1.1 & 9.4 & 151 \\
\hline Heisterberg 2007 & Risperidone & 2.1 & 10.3 & 154 \\
\hline Heisterberg 2007 & Placebo & -0.7 & 6.8 & 149 \\
\hline \multicolumn{5}{|c|}{ LDL } \\
\hline Durgam 2014 & Risperidone & 3.8 & 30.6 & 140 \\
\hline Durgam 2014 & Placebo & -0.1 & 25.3 & 151 \\
\hline Heisterberg 2007 & Risperidone & -2.8 & 28.8 & 154 \\
\hline Heisterberg 2007 & Placebo & -7.5 & 29.8 & 149 \\
\hline \multicolumn{5}{|c|}{ triglycerides } \\
\hline Durgam 2014 & Risperidone & 6.3 & 84.2 & 140 \\
\hline Durgam 2014 & Placebo & -3.1 & 59.9 & 151 \\
\hline Heisterberg 2007 & Risperidone & -6.7 & 136.2 & 154 \\
\hline Heisterberg 2007 & Placebo & -27.9 & 104.4 & 149 \\
\hline \multicolumn{5}{|c|}{ VLDL } \\
\hline Heisterberg 2007 & Risperidone & -1.4 & 17.7 & 154 \\
\hline Heisterberg 2007 & Placebo & -3.7 & 16.9 & 149 \\
\hline
\end{tabular}


Analysis 1.18. Comparison 1 RISPERIDONE vs PLACEBO, Outcome 18 Adverse effects: 8. musculoskeletal system - short term (up to 12 weeks).

\begin{tabular}{|c|c|c|c|c|c|}
\hline Study or subgroup & $\begin{array}{c}\text { Risperidone } \\
n / N\end{array}$ & $\begin{array}{l}\text { Placebo } \\
\mathbf{n} / \mathbf{N}\end{array}$ & $\begin{array}{c}\text { Risk Ratio } \\
\text { M-H, Random, } 95 \% \text { Cl }\end{array}$ & Weight & $\begin{array}{c}\text { Risk Ratio } \\
\text { M-H, Random, } 95 \% \text { CI }\end{array}$ \\
\hline \multicolumn{6}{|l|}{ 1.18.1 myalgia } \\
\hline Potkin 2003 & $2 / 99$ & $3 / 103$ & & $100 \%$ & $0.69[0.12,4.06]$ \\
\hline Subtotal $(95 \% \mathrm{CI})$ & 99 & 103 & & $100 \%$ & $0.69[0.12,4.06]$ \\
\hline \multicolumn{6}{|c|}{ Total events: 2 (Risperidone), 3 (Placebo) } \\
\hline \multicolumn{6}{|c|}{ Heterogeneity: $\mathrm{Tau}^{2}=0 ; \mathrm{Chi}^{2}=0, \mathrm{df}=0(\mathrm{P}<0.0001) ; \mathrm{I}^{2}=100 \%$} \\
\hline \multicolumn{6}{|c|}{ 1.18.2 Joint disorder } \\
\hline Potkin 2003 & $5 / 99$ & $2 / 103$ & & $100 \%$ & $2.6[0.52,13.1]$ \\
\hline Subtotal $(95 \% \mathrm{Cl})$ & 99 & 103 & & $100 \%$ & $2.6[0.52,13.1]$ \\
\hline \multicolumn{6}{|c|}{ Total events: 5 (Risperidone), 2 (Placebo) } \\
\hline \multicolumn{6}{|c|}{ Heterogeneity: Not applicable } \\
\hline Test for subgroup dif & $17, \mathrm{df}=1(\mathrm{P}=0.28)$ & & & & \\
\hline
\end{tabular}

Analysis 1.19. Comparison 1 RISPERIDONE vs PLACEBO, Outcome 19 Adverse effects: 9. physiology - short term (up to 12 weeks).

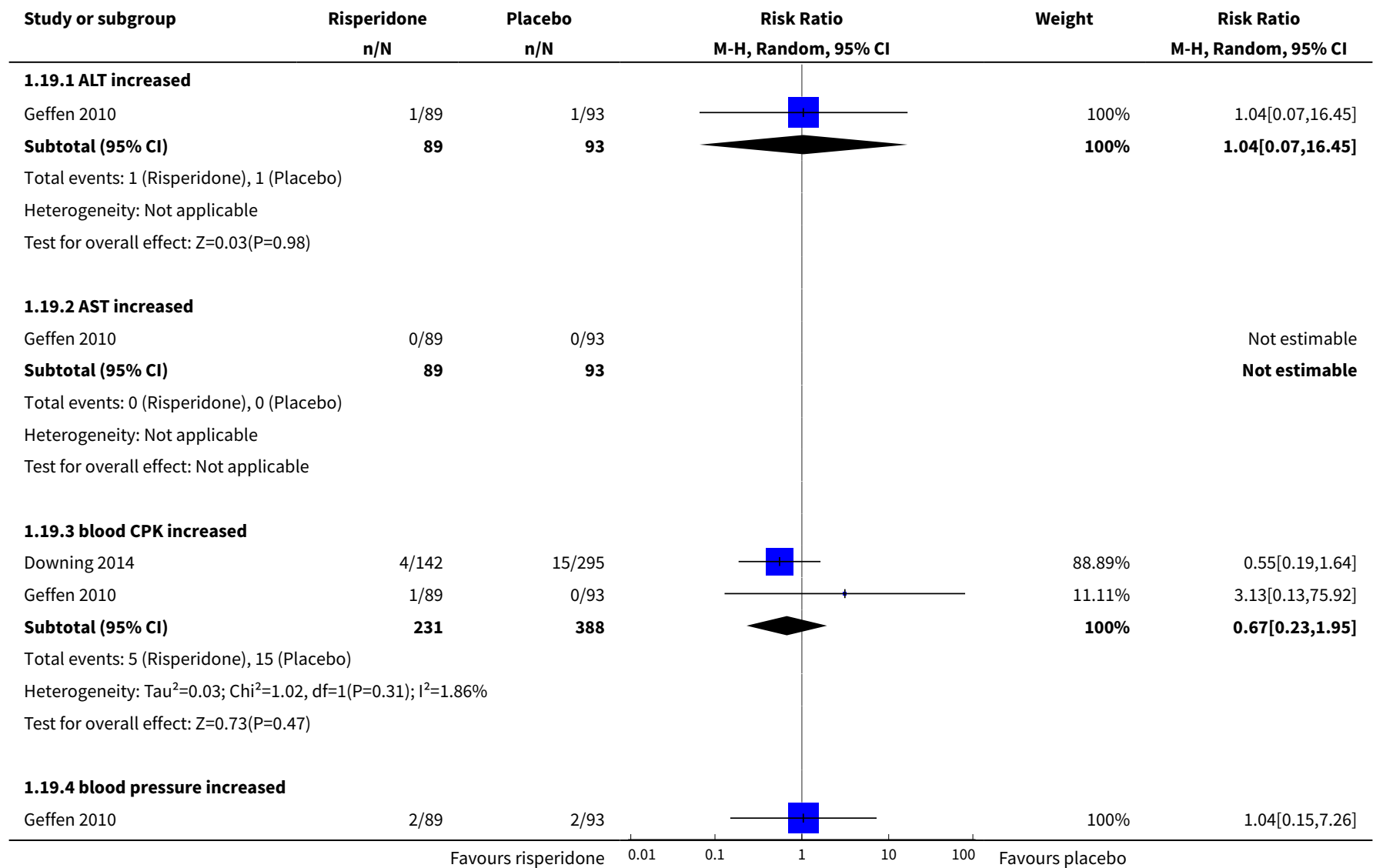




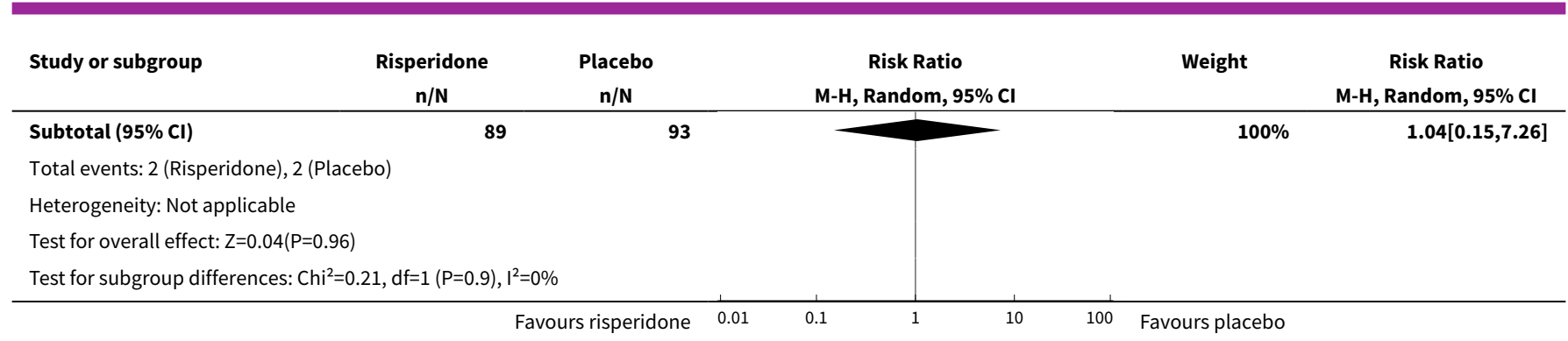

Analysis 1.20. Comparison 1 RISPERIDONE vs PLACEBO, Outcome 20 Adverse effects: 10. respiratory system - short term (up to 12 weeks).

\begin{tabular}{|c|c|c|c|c|c|}
\hline Study or subgroup & $\begin{array}{c}\text { Risperidone } \\
n / \mathbf{N}\end{array}$ & $\begin{array}{c}\text { Placebo } \\
n / N\end{array}$ & $\begin{array}{c}\text { Risk Ratio } \\
\text { M-H, Random, } 95 \% \mathrm{Cl}\end{array}$ & Weight & $\begin{array}{c}\text { Risk Ratio } \\
\text { M-H, Random, 95\% Cl }\end{array}$ \\
\hline \multicolumn{6}{|c|}{ 1.20.1 upper respiratory infection } \\
\hline Potkin 2003 & $8 / 99$ & $2 / 103$ & & $43.55 \%$ & $4.16[0.91,19.12]$ \\
\hline Potkin 2007 & $6 / 59$ & $3 / 62$ & & $56.45 \%$ & $2.1[0.55,8.02]$ \\
\hline Subtotal $(95 \% \mathrm{Cl})$ & 158 & 165 & & $100 \%$ & $2.83[1.03,7.74]$ \\
\hline \multicolumn{6}{|c|}{ Total events: 14 (Risperidone), 5 (Placebo) } \\
\hline \multicolumn{6}{|c|}{ Heterogeneity: $\mathrm{Tau}^{2}=0 ; \mathrm{Chi}^{2}=0.44, \mathrm{df}=1(\mathrm{P}=0.51) ; \mathrm{I}^{2}=0 \%$} \\
\hline \multicolumn{6}{|c|}{ Test for overall effect: $Z=2.03(P=0.04)$} \\
\hline \multicolumn{6}{|l|}{ 1.20.2 pharyngitis } \\
\hline Potkin 2003 & $2 / 99$ & $5 / 103$ & 1 & $100 \%$ & $0.42[0.08,2.1]$ \\
\hline Subtotal $(95 \% \mathrm{Cl})$ & 99 & 103 & & $100 \%$ & $0.42[0.08,2.1]$ \\
\hline \multicolumn{6}{|c|}{ Total events: 2 (Risperidone), 5 (Placebo) } \\
\hline \multicolumn{6}{|c|}{ Test for overall effect: $Z=1.06(P=0.29)$} \\
\hline \multicolumn{6}{|l|}{ 1.20.3 rhinitis } \\
\hline Borison 1992 & $9 / 51$ & $1 / 53$ & & $49.79 \%$ & $9.35[1.23,71.21]$ \\
\hline Potkin 2003 & $12 / 99$ & $1 / 103$ & & $50.21 \%$ & $12.48[1.65,94.23]$ \\
\hline Subtotal $(95 \% \mathrm{Cl})$ & 150 & 156 & & $100 \%$ & $10.81[2.58,45.29]$ \\
\hline \multicolumn{6}{|c|}{ Total events: 21 (Risperidone), 2 (Placebo) } \\
\hline \multicolumn{6}{|c|}{ Heterogeneity: $\mathrm{Tau}^{2}=0 ; \mathrm{Chi}^{2}=0.04, \mathrm{df}=1(\mathrm{P}=0.84) ; \mathrm{I}^{2}=0 \%$} \\
\hline \multicolumn{6}{|c|}{ Test for overall effect: $Z=3.26(P=0)$} \\
\hline \multicolumn{6}{|l|}{ 1.20.4 sinusitis } \\
\hline Downing 2014 & $1 / 142$ & $2 / 295$ & & $100 \%$ & $1.04[0.09,11.36]$ \\
\hline Subtotal $(95 \% \mathrm{CI})$ & 142 & 295 & & $100 \%$ & $1.04[0.09,11.36]$ \\
\hline \multicolumn{6}{|c|}{ Heterogeneity: Not applicable } \\
\hline \multicolumn{6}{|c|}{ Test for overall effect: $Z=0.03(P=0.98)$} \\
\hline Test for subgroup dif & $2, \mathrm{df}=1(\mathrm{P}=0.03)$, & & & & \\
\hline
\end{tabular}


Comparison 2. RISPERIDONE + CLOZAPINE vs PLACEBO + CLOZAPINE

\begin{tabular}{|c|c|c|c|c|}
\hline Outcome or subgroup title & No. of studies & $\begin{array}{l}\text { No. of partici- } \\
\text { pants }\end{array}$ & Statistical method & Effect size \\
\hline $\begin{array}{l}1 \text { Mental state: no clinically significant } \\
\text { response in psychotic symptoms (de- } \\
\text { fined by PANSS/BPRS<20\% decline) - } \\
\text { short term (up to } 12 \text { weeks) }\end{array}$ & 2 & 98 & $\begin{array}{l}\text { Risk Ratio (M-H, Random, } \\
95 \% \mathrm{Cl})\end{array}$ & $1.15[0.93,1.42]$ \\
\hline $\begin{array}{l}2 \text { Leaving the study early - short term } \\
\text { (up to } 12 \text { weeks) }\end{array}$ & 3 & & $\begin{array}{l}\text { Risk Ratio (M-H, Random, } \\
95 \% \mathrm{Cl})\end{array}$ & Subtotals only \\
\hline 2.1 any reason & 3 & 167 & $\begin{array}{l}\text { Risk Ratio (M-H, Random, } \\
95 \% \mathrm{Cl})\end{array}$ & $1.13[0.53,2.42]$ \\
\hline 2.2 due to adverse events & 2 & 137 & $\begin{array}{l}\text { Risk Ratio (M-H, Random, } \\
95 \% \mathrm{Cl})\end{array}$ & $4.11[0.47,36.24]$ \\
\hline 2.3 due to lack of efficacy & 1 & 69 & $\begin{array}{l}\text { Risk Ratio (M-H, Random, } \\
95 \% \mathrm{Cl})\end{array}$ & $0.55[0.11,2.78]$ \\
\hline 2.4 due to noncompliance & 1 & 69 & $\begin{array}{l}\text { Risk Ratio (M-H, Random, } \\
95 \% \mathrm{Cl})\end{array}$ & $0.36[0.02,8.61]$ \\
\hline 2.5 lost to follow-up & 1 & 69 & $\begin{array}{l}\text { Risk Ratio (M-H, Random, } \\
95 \% \mathrm{Cl})\end{array}$ & $0.36[0.02,8.61]$ \\
\hline 2.6 reported death & 1 & 68 & $\begin{array}{l}\text { Risk Ratio (M-H, Random, } \\
95 \% \mathrm{Cl})\end{array}$ & $0.0[0.0,0.0]$ \\
\hline 2.7 withdrawal of consent & 3 & 167 & $\begin{array}{l}\text { Risk Ratio (M-H, Random, } \\
95 \% \mathrm{Cl})\end{array}$ & $1.41[0.28,7.09]$ \\
\hline 2.8 administrative reasons & 1 & 69 & $\begin{array}{l}\text { Risk Ratio (M-H, Random, } \\
95 \% \mathrm{Cl})\end{array}$ & $5.44[0.27,109.34]$ \\
\hline 2.9 abnormal lab results & 1 & 69 & $\begin{array}{l}\text { Risk Ratio (M-H, Random, } \\
95 \% \mathrm{Cl})\end{array}$ & $0.36[0.02,8.61]$ \\
\hline $\begin{array}{l}3 \text { Global state: } 1 \text {. average endpoint } \\
\text { scores of CGI severity scale (high=poor) } \\
\text { - short term (up to } 12 \text { weeks) }\end{array}$ & 1 & 65 & $\begin{array}{l}\text { Mean Difference (IV, Ran- } \\
\text { dom, } 95 \% \mathrm{CI})\end{array}$ & $0.51[0.02,1.00]$ \\
\hline $\begin{array}{l}4 \text { Global state: } 2 \text {. no significant clinical } \\
\text { improvement CGI - short term (up to } 12 \\
\text { weeks) }\end{array}$ & 1 & 68 & $\begin{array}{l}\text { Risk Ratio (M-H, Random, } \\
95 \% \mathrm{Cl})\end{array}$ & $1.12[0.87,1.44]$ \\
\hline $\begin{array}{l}5 \text { Global state: } 3 \text {. general function- } \\
\text { ing - average endpoint GAF score } \\
\text { (high=good) - short term (up to } 12 \\
\text { weeks) }\end{array}$ & 1 & 30 & $\begin{array}{l}\text { Mean Difference (IV, Ran- } \\
\text { dom, 95\% CI) }\end{array}$ & $-4.5[-8.38,-0.62]$ \\
\hline $\begin{array}{l}6 \text { Mental state: } 1 \text {. average endpoint } \\
\text { scores on various scales on psychotic } \\
\text { symptoms (high=poor) - short term (up } \\
\text { to } 12 \text { weeks) }\end{array}$ & 2 & & $\begin{array}{l}\text { Mean Difference (IV, Ran- } \\
\text { dom, } 95 \% \mathrm{CI} \text { ) }\end{array}$ & Subtotals only \\
\hline
\end{tabular}




\begin{tabular}{|c|c|c|c|c|}
\hline Outcome or subgroup title & No. of studies & $\begin{array}{l}\text { No. of partici- } \\
\text { pants }\end{array}$ & Statistical method & Effect size \\
\hline 6.1 PANSS total & 2 & 95 & $\begin{array}{l}\text { Mean Difference (IV, Ran- } \\
\text { dom, } 95 \% \mathrm{CI} \text { ) }\end{array}$ & $5.56[1.59,9.53]$ \\
\hline 6.2 PANSS general pathology & 1 & 30 & $\begin{array}{l}\text { Mean Difference (IV, Ran- } \\
\text { dom, } 95 \% \mathrm{CI} \text { ) }\end{array}$ & $2.5[0.03,4.97]$ \\
\hline 6.3 PANSS delusion & 1 & 30 & $\begin{array}{l}\text { Mean Difference (IV, Ran- } \\
\text { dom, } 95 \% \mathrm{CI} \text { ) }\end{array}$ & $0.70[0.09,1.31]$ \\
\hline 6.4 PANSS negative symptom & 2 & 95 & $\begin{array}{l}\text { Mean Difference (IV, Ran- } \\
\text { dom, } 95 \% \mathrm{CI} \text { ) }\end{array}$ & $0.69[-0.68,2.05]$ \\
\hline 6.5 PANSS positive symptom & 2 & 95 & $\begin{array}{l}\text { Mean Difference (IV, Ran- } \\
\text { dom, } 95 \% \mathrm{CI} \text { ) }\end{array}$ & $2.30[0.98,3.62]$ \\
\hline $\begin{array}{l}7 \text { Mental state: } 2 \text {. average endpoint } \\
\text { scores on various scales on psychotic } \\
\text { symptoms (high=poor) - medium term } \\
\text { (up to } 26 \text { weeks) }\end{array}$ & 1 & & $\begin{array}{l}\text { Mean Difference (IV, Ran- } \\
\text { dom, } 95 \% \mathrm{Cl} \text { ) }\end{array}$ & Subtotals only \\
\hline 7.1 BPRS total & 1 & 53 & $\begin{array}{l}\text { Mean Difference (IV, Ran- } \\
\text { dom, } 95 \% \mathrm{CI} \text { ) }\end{array}$ & $-4.60[-9.88,0.68]$ \\
\hline 7.2 BPRS positive symptom & 1 & 53 & $\begin{array}{l}\text { Mean Difference (IV, Ran- } \\
\text { dom, } 95 \% \mathrm{CI} \text { ) }\end{array}$ & $-0.90[-2.81,1.01]$ \\
\hline 7.3 BPRS anxiety/depression factor & 1 & 53 & $\begin{array}{l}\text { Mean Difference (IV, Ran- } \\
\text { dom, } 95 \% \mathrm{CI} \text { ) }\end{array}$ & $-1.0[-2.80,0.80]$ \\
\hline 7.4 SANS total & 1 & 53 & $\begin{array}{l}\text { Mean Difference (IV, Ran- } \\
\text { dom, } 95 \% \mathrm{CI} \text { ) }\end{array}$ & $-3.10[-10.30,4.10]$ \\
\hline $\begin{array}{l}8 \text { Mental state: } 3 . \text { skewed data - short } \\
\text { term (up to } 12 \text { weeks) }\end{array}$ & & & Other data & No numeric data \\
\hline $\begin{array}{l}8.1 \text { average endpoint score of CDS to- } \\
\text { tal (high=poor) }\end{array}$ & & & Other data & No numeric data \\
\hline $\begin{array}{l}8.2 \text { average endpoint score on verbal } \\
\text { working memory (SD, high=good) }\end{array}$ & & & Other data & No numeric data \\
\hline $\begin{array}{l}9 \text { Adverse effects: } 1 \text { a. extrapyramidal } \\
\text { - average endpoint SAS score - short } \\
\text { term (up to } 12 \text { weeks) }\end{array}$ & 1 & & $\begin{array}{l}\text { Mean Difference (IV, Ran- } \\
\text { dom, } 95 \% \mathrm{CI} \text { ) }\end{array}$ & Subtotals only \\
\hline $\begin{array}{l}10 \text { Adverse effects: } 1 \text { b. extrapyramidal } \\
\text { - skewed data (various scales) - short } \\
\text { term (up to } 12 \text { weeks) }\end{array}$ & & & Other data & No numeric data \\
\hline 10.1 average endpoint score of AIMS & & & Other data & No numeric data \\
\hline $\begin{array}{l}10.2 \text { average change score of Barnes } \\
\text { akathisia rating scale }\end{array}$ & & & Other data & No numeric data \\
\hline 10.3 average change score of ESRS & & & Other data & No numeric data \\
\hline
\end{tabular}




\begin{tabular}{|c|c|c|c|c|}
\hline Outcome or subgroup title & No. of studies & $\begin{array}{l}\text { No. of partici- } \\
\text { pants }\end{array}$ & Statistical method & Effect size \\
\hline $\begin{array}{l}10.4 \text { average change score of ESRS - } \\
\text { dystonia }\end{array}$ & & & Other data & No numeric data \\
\hline $\begin{array}{l}10.5 \text { average change score of ESRS - } \\
\text { dyskinesia }\end{array}$ & & & Other data & No numeric data \\
\hline $\begin{array}{l}10.6 \text { average change score of ESRS - } \\
\text { parkinsonism }\end{array}$ & & & Other data & No numeric data \\
\hline $\begin{array}{l}11 \text { Adverse effects: } 1 \text { c. extrapyramidal - } \\
\text { skewed data (various scales) - medium } \\
\text { term (up to } 26 \text { weeks) }\end{array}$ & & & Other data & No numeric data \\
\hline 11.1 average endpoint score of AIMS & & & Other data & No numeric data \\
\hline 11.2 average endpoint score of SAS & & & Other data & No numeric data \\
\hline $\begin{array}{l}12 \text { Adverse effects: } 2 \text {. any adverse } \\
\text { event - short term (up to } 12 \text { weeks) }\end{array}$ & 1 & & $\begin{array}{l}\text { Risk Ratio (M-H, Random, } \\
95 \% \mathrm{Cl})\end{array}$ & Subtotals only \\
\hline 12.1 any adverse event & 1 & 64 & $\begin{array}{l}\text { Risk Ratio (M-H, Random, } \\
95 \% \mathrm{Cl})\end{array}$ & $1.14[0.83,1.58]$ \\
\hline 12.2 amenorrhoea & 1 & 64 & $\begin{array}{l}\text { Risk Ratio (M-H, Random, } \\
95 \% \mathrm{Cl})\end{array}$ & $3.0[0.13,71.00]$ \\
\hline 12.3 asthenia & 1 & 64 & $\begin{array}{l}\text { Risk Ratio (M-H, Random, } \\
95 \% \mathrm{Cl})\end{array}$ & $1.08[0.61,1.91]$ \\
\hline 12.4 depression & 1 & 64 & $\begin{array}{l}\text { Risk Ratio (M-H, Random, } \\
95 \% \mathrm{Cl} \text { ) }\end{array}$ & $1.2[0.61,2.37]$ \\
\hline 12.5 emotional indifference & 1 & 64 & $\begin{array}{l}\text { Risk Ratio (M-H, Random, } \\
95 \% \mathrm{Cl} \text { ) }\end{array}$ & $1.11[0.52,2.37]$ \\
\hline 12.6 fatigue & 1 & 64 & $\begin{array}{l}\text { Risk Ratio (M-H, Random, } \\
95 \% \mathrm{Cl} \text { ) }\end{array}$ & $1.08[0.61,1.91]$ \\
\hline 12.7 failing memory & 1 & 64 & $\begin{array}{l}\text { Risk Ratio (M-H, Random, } \\
95 \% \mathrm{Cl})\end{array}$ & $0.67[0.32,1.41]$ \\
\hline 12.8 increased duration of sleep & 1 & 64 & $\begin{array}{l}\text { Risk Ratio (M-H, Random, } \\
95 \% \mathrm{Cl} \text { ) }\end{array}$ & $1.0[0.51,1.97]$ \\
\hline 12.9 salivation - increased & 1 & 64 & $\begin{array}{l}\text { Risk Ratio (M-H, Random, } \\
95 \% \mathrm{CI})\end{array}$ & $1.25[0.81,1.94]$ \\
\hline $\begin{array}{l}13 \text { Adverse effects: } 3 \text { a. cardiovascular - } \\
\text { short term (up to } 12 \text { weeks) }\end{array}$ & 1 & & $\begin{array}{l}\text { Risk Ratio (M-H, Random, } \\
95 \% \mathrm{Cl} \text { ) }\end{array}$ & Subtotals only \\
\hline 13.1 dizziness - orthostatic & 1 & 64 & $\begin{array}{l}\text { Risk Ratio (M-H, Random, } \\
95 \% \mathrm{Cl})\end{array}$ & $1.0[0.43,2.34]$ \\
\hline 13.2 palpitation & 1 & 64 & $\begin{array}{l}\text { Risk Ratio (M-H, Random, } \\
95 \% \mathrm{Cl})\end{array}$ & $1.0[0.27,3.66]$ \\
\hline
\end{tabular}




\begin{tabular}{|c|c|c|c|c|}
\hline Outcome or subgroup title & No. of studies & $\begin{array}{l}\text { No. of partici- } \\
\text { pants }\end{array}$ & Statistical method & Effect size \\
\hline 13.3 tachycardia & 1 & 64 & $\begin{array}{l}\text { Risk Ratio (M-H, Random, } \\
95 \% \mathrm{Cl} \text { ) }\end{array}$ & $1.0[0.27,3.66]$ \\
\hline $\begin{array}{l}14 \text { Adverse effects: 3b. cardiovascu- } \\
\text { lar - QTc interval - short term (up to } 12 \\
\text { weeks) }\end{array}$ & 1 & 30 & $\begin{array}{l}\text { Mean Difference (IV, Ran- } \\
\text { dom, } 95 \% \mathrm{CI} \text { ) }\end{array}$ & $\begin{array}{l}-19.70[-42.08 \\
2.68]\end{array}$ \\
\hline $\begin{array}{l}15 \text { Adverse effects: } 4 \text {. central nervous } \\
\text { system - short term (up to } 12 \text { weeks) }\end{array}$ & 1 & & $\begin{array}{l}\text { Risk Ratio (M-H, Random, } \\
95 \% \mathrm{Cl} \text { ) }\end{array}$ & Subtotals only \\
\hline 15.1 sedation & 1 & 64 & $\begin{array}{l}\text { Risk Ratio (M-H, Random, } \\
95 \% \mathrm{Cl} \text { ) }\end{array}$ & $1.46[0.88,2.43]$ \\
\hline 15.2 somnolence & 1 & 64 & $\begin{array}{l}\text { Risk Ratio (M-H, Random, } \\
95 \% \mathrm{Cl} \text { ) }\end{array}$ & $1.0[0.51,1.97]$ \\
\hline 15.3 tension & 1 & 64 & $\begin{array}{l}\text { Risk Ratio (M-H, Random, } \\
95 \% \mathrm{Cl} \text { ) }\end{array}$ & $1.23[0.71,2.12]$ \\
\hline $\begin{array}{l}16 \text { Adverse effects: } 5 \text {. gastrointestinal } \\
\text { system - short term (up to } 12 \text { weeks) }\end{array}$ & 1 & & $\begin{array}{l}\text { Risk Ratio (M-H, Random, } \\
95 \% \mathrm{Cl})\end{array}$ & Subtotals only \\
\hline 16.1 constipation & 1 & 64 & $\begin{array}{l}\text { Risk Ratio (M-H, Random, } \\
95 \% \mathrm{Cl})\end{array}$ & $0.71[0.25,2.02]$ \\
\hline $\begin{array}{l}17 \text { Adverse effects: } 6 \text { a. haematological } \\
\text { - short term (up to } 12 \text { weeks) }\end{array}$ & 2 & & $\begin{array}{l}\text { Mean Difference (IV, Ran- } \\
\text { dom, } 95 \% \mathrm{CI} \text { ) }\end{array}$ & Subtotals only \\
\hline 17.1 neutrophil count & 1 & 57 & $\begin{array}{l}\text { Mean Difference (IV, Ran- } \\
\text { dom, } 95 \% \mathrm{CI} \text { ) }\end{array}$ & $0.37[-0.42,1.16]$ \\
\hline 17.2 prolactin level, $\mathrm{ng} / \mathrm{mL}$ & 1 & 30 & $\begin{array}{l}\text { Mean Difference (IV, Ran- } \\
\text { dom, } 95 \% \mathrm{CI} \text { ) }\end{array}$ & $\begin{array}{l}60.10[46.52 \\
73.68]\end{array}$ \\
\hline 17.3 white cell count & 1 & 61 & $\begin{array}{l}\text { Mean Difference (IV, Ran- } \\
\text { dom, } 95 \% \mathrm{CI} \text { ) }\end{array}$ & $0.66[-0.20,1.52]$ \\
\hline $\begin{array}{l}18 \text { Adverse effects: } 6 \mathrm{~b} \text {. haematological } \\
\text { - medium term (up to } 26 \text { weeks) }\end{array}$ & 1 & & $\begin{array}{l}\text { Mean Difference (IV, Ran- } \\
\text { dom, } 95 \% \mathrm{CI} \text { ) }\end{array}$ & Subtotals only \\
\hline 18.1 prolactin level $\mathrm{ng} / \mathrm{mL}$ & 1 & 44 & $\begin{array}{l}\text { Mean Difference (IV, Ran- } \\
\text { dom, } 95 \% \mathrm{CI} \text { ) }\end{array}$ & $34.1[17.63,50.57]$ \\
\hline 18.2 fasting glucose & 1 & 40 & $\begin{array}{l}\text { Mean Difference (IV, Ran- } \\
\text { dom, } 95 \% \mathrm{CI} \text { ) }\end{array}$ & $-4.60[-17.09,7.89]$ \\
\hline $\begin{array}{l}19 \text { Adverse effects: } 7 \text { a. metabolic - } \\
\text { weight gain - short term (up to } 12 \\
\text { weeks) }\end{array}$ & 1 & 64 & $\begin{array}{l}\text { Risk Ratio (M-H, Random, } \\
95 \% \mathrm{Cl})\end{array}$ & $1.0[0.40,2.52]$ \\
\hline $\begin{array}{l}20 \text { Adverse effects: } 7 \text { a. metabolic - } \\
\text { weight gain - medium term (up to } 26 \\
\text { weeks) }\end{array}$ & 1 & 48 & $\begin{array}{l}\text { Risk Ratio (M-H, Random, } \\
95 \% \mathrm{Cl} \text { ) }\end{array}$ & $0.2[0.01,3.96]$ \\
\hline
\end{tabular}




\begin{tabular}{|c|c|c|c|c|}
\hline Outcome or subgroup title & No. of studies & $\begin{array}{l}\text { No. of partici- } \\
\text { pants }\end{array}$ & Statistical method & Effect size \\
\hline $\begin{array}{l}21 \text { Adverse effects: } 7 \mathrm{~b} \text {. metabolic - av- } \\
\text { erage endpoint value on lipid profile - } \\
\text { short term (up to } 12 \text { weeks) }\end{array}$ & 1 & & $\begin{array}{l}\text { Mean Difference (IV, Ran- } \\
\text { dom, } 95 \% \mathrm{CI} \text { ) }\end{array}$ & Subtotals only \\
\hline 21.1 cholesterol - total (mg/dl) & 1 & 56 & $\begin{array}{l}\text { Mean Difference (IV, Ran- } \\
\text { dom, } 95 \% \mathrm{CI} \text { ) }\end{array}$ & $\begin{array}{l}-6.60[-29.05 \\
15.85]\end{array}$ \\
\hline 21.2 HDL cholesterol (mg/dl) & 1 & 52 & $\begin{array}{l}\text { Mean Difference (IV, Ran- } \\
\text { dom, } 95 \% \mathrm{CI} \text { ) }\end{array}$ & $0.0[-8.44,8.44]$ \\
\hline 21.3 LDL cholesterol (mg/dl) & 1 & 53 & $\begin{array}{l}\text { Mean Difference (IV, Ran- } \\
\text { dom, } 95 \% \mathrm{CI} \text { ) }\end{array}$ & $\begin{array}{l}-6.90[-26.02, \\
12.22]\end{array}$ \\
\hline 21.4 triglycerides $(\mathrm{mg} / \mathrm{dl})$ & 1 & 56 & $\begin{array}{l}\text { Mean Difference (IV, Ran- } \\
\text { dom, } 95 \% \mathrm{CI} \text { ) }\end{array}$ & $6.20[-57.57,69.97]$ \\
\hline $\begin{array}{l}22 \text { Adverse effects: } 7 c \text {. metabolic - av- } \\
\text { erage endpoint value - short term (up } \\
\text { to } 12 \text { weeks) }\end{array}$ & 2 & & $\begin{array}{l}\text { Mean Difference (IV, Ran- } \\
\text { dom, } 95 \% \mathrm{CI} \text { ) }\end{array}$ & Subtotals only \\
\hline 22.1 body mass index & 1 & 63 & $\begin{array}{l}\text { Mean Difference (IV, Ran- } \\
\text { dom, } 95 \% \mathrm{Cl} \text { ) }\end{array}$ & $1.70[-0.99,4.39]$ \\
\hline 22.2 fasting glucose $(\mathrm{mg} / \mathrm{dl})$ & 1 & 51 & $\begin{array}{l}\text { Mean Difference (IV, Ran- } \\
\text { dom, } 95 \% \mathrm{CI} \text { ) }\end{array}$ & $16.20[-3.12,35.52]$ \\
\hline 22.3 waist circumference $(\mathrm{cm})$ & 1 & 61 & $\begin{array}{l}\text { Mean Difference (IV, Ran- } \\
\text { dom, } 95 \% \mathrm{Cl} \text { ) }\end{array}$ & $5.10[-4.14,14.34]$ \\
\hline 22.4 weight gain & 2 & 94 & $\begin{array}{l}\text { Mean Difference (IV, Ran- } \\
\text { dom, } 95 \% \mathrm{CI} \text { ) }\end{array}$ & $0.34[-0.84,1.53]$ \\
\hline $\begin{array}{l}23 \text { Adverse effects: } 8 \text {. sleep - skewed } \\
\text { data - average change score (UKU) - } \\
\text { short term (up to } 12 \text { weeks) }\end{array}$ & & & Other data & No numeric data \\
\hline $\begin{array}{l}24 \text { Quality of life: average endpoint } \\
\text { score (QLS, high=good) - short term (up } \\
\text { to } 12 \text { weeks) }\end{array}$ & 1 & 30 & $\begin{array}{l}\text { Mean Difference (IV, Ran- } \\
\text { dom, } 95 \% \mathrm{CI} \text { ) }\end{array}$ & $0.80[-5.44,7.04]$ \\
\hline
\end{tabular}

\section{Analysis 2.1. Comparison 2 RISPERIDONE + CLOZAPINE vs PLACEBO + CLOZAPINE, Outcome 1 Mental state: no clinically significant response in psychotic symptoms (defined by PANSS/BPRS<20\% decline) - short term (up to 12 weeks).}

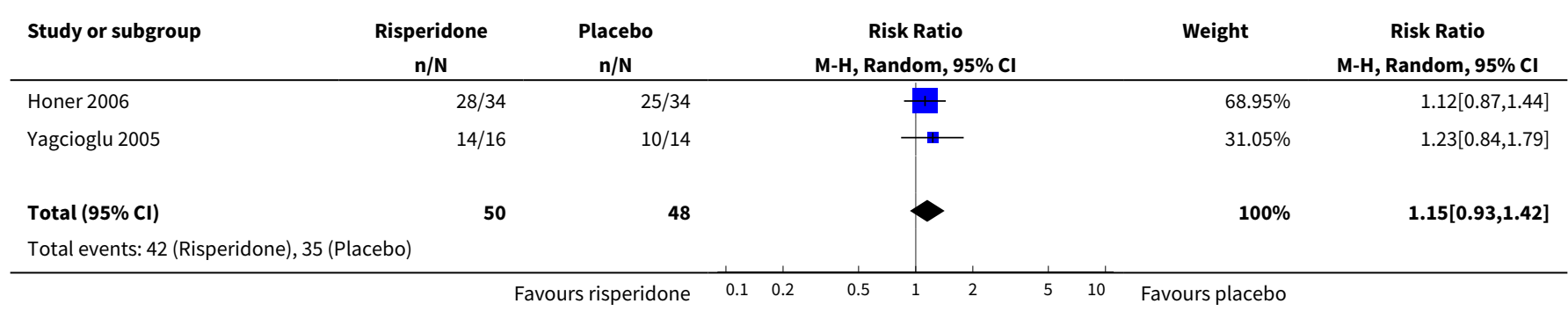




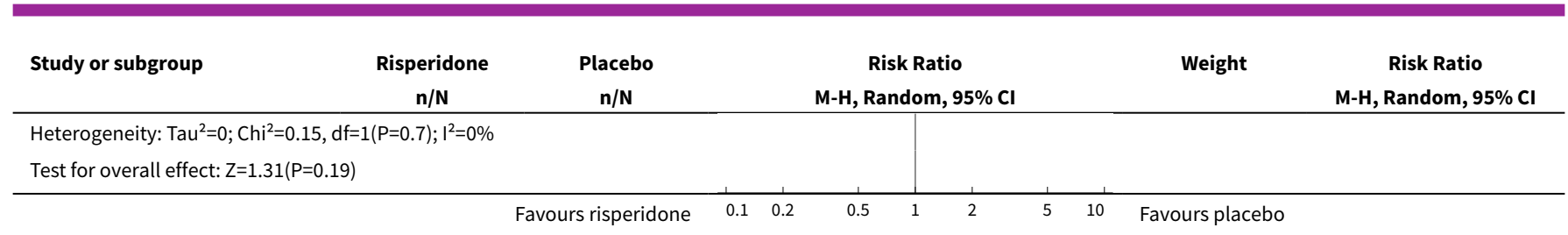

Analysis 2.2. Comparison 2 RISPERIDONE + CLOZAPINE vs PLACEBO + CLOZAPINE, Outcome 2 Leaving the study early - short term (up to 12 weeks).

\begin{tabular}{lrr} 
Study or subgroup & $\begin{array}{c}\text { Risperidone } \\
\mathbf{n} / \mathbf{N}\end{array}$ & $\begin{array}{c}\text { Placebo } \\
\mathbf{n} / \mathbf{N}\end{array}$ \\
\hline $\mathbf{2 . 2 . 1}$ any reason & & \\
Bachmann 2003 & $8 / 33$ & $8 / 36$ \\
Honer 2006 & $2 / 34$ & $2 / 34$ \\
Yagcioglu 2005 & $1 / 16$ & $0 / 14$ \\
Subtotal (95\% Cl) & $\mathbf{8 3}$ & $\mathbf{8 4}$
\end{tabular}

Total events: 11 (Risperidone), 10 (Placebo)

Heterogeneity: $\mathrm{Tau}^{2}=0 ; \mathrm{Chi}^{2}=0.31, \mathrm{df}=2(\mathrm{P}=0.86) ; \mathrm{I}^{2}=0 \%$

Test for overall effect: $Z=0.32(P=0.75)$

\subsection{2 due to adverse events}

Bachmann 2003

Honer 2006

Subtotal $(95 \% \mathrm{Cl})$

$\begin{array}{rr}2 / 33 & 0 / 36 \\ 1 / 34 & 0 / 34 \\ \mathbf{6 7} & \mathbf{7 0}\end{array}$

Total events: 3 (Risperidone), 0 (Placebo)

Heterogeneity: $\mathrm{Tau}^{2}=0 ; \mathrm{Chi}^{2}=0.07, \mathrm{df}=1(\mathrm{P}=0.79) ; \mathrm{I}^{2}=0 \%$

Test for overall effect: $Z=1.27(P=0.2)$

\subsection{3 due to lack of efficacy}

Bachmann 2003

Subtotal $(95 \% \mathrm{Cl})$

Risk Ratio

M-H, Random, 95\% Cl

Weight

Risk Ratio

Total events: 2 (Risperidone), 4 (Placebo)

Heterogeneity: Not applicable

Test for overall effect: $Z=0.73(P=0.47)$

2.2.4 due to noncompliance

Bachmann 2003

Total events: 0 (Risperidone), 1 (Placebo)

Heterogeneity: Not applicable

Test for overall effect: $\mathrm{Z}=0.63(\mathrm{P}=0.53)$

\subsection{5 lost to follow-up}

Bachmann 2003

Subtotal $(95 \% \mathrm{Cl})$

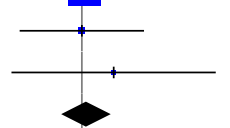

$78.16 \%$

$1.09[0.46,2.57]$

$15.94 \%$

$1[0.15,6.7]$

$5.9 \%$

$2.65[0.12,60.21]$

84

$100 \%$

$1.13[0.53,2.42]$

Total events: 0 (Risperidone), 1 (Placebo) 


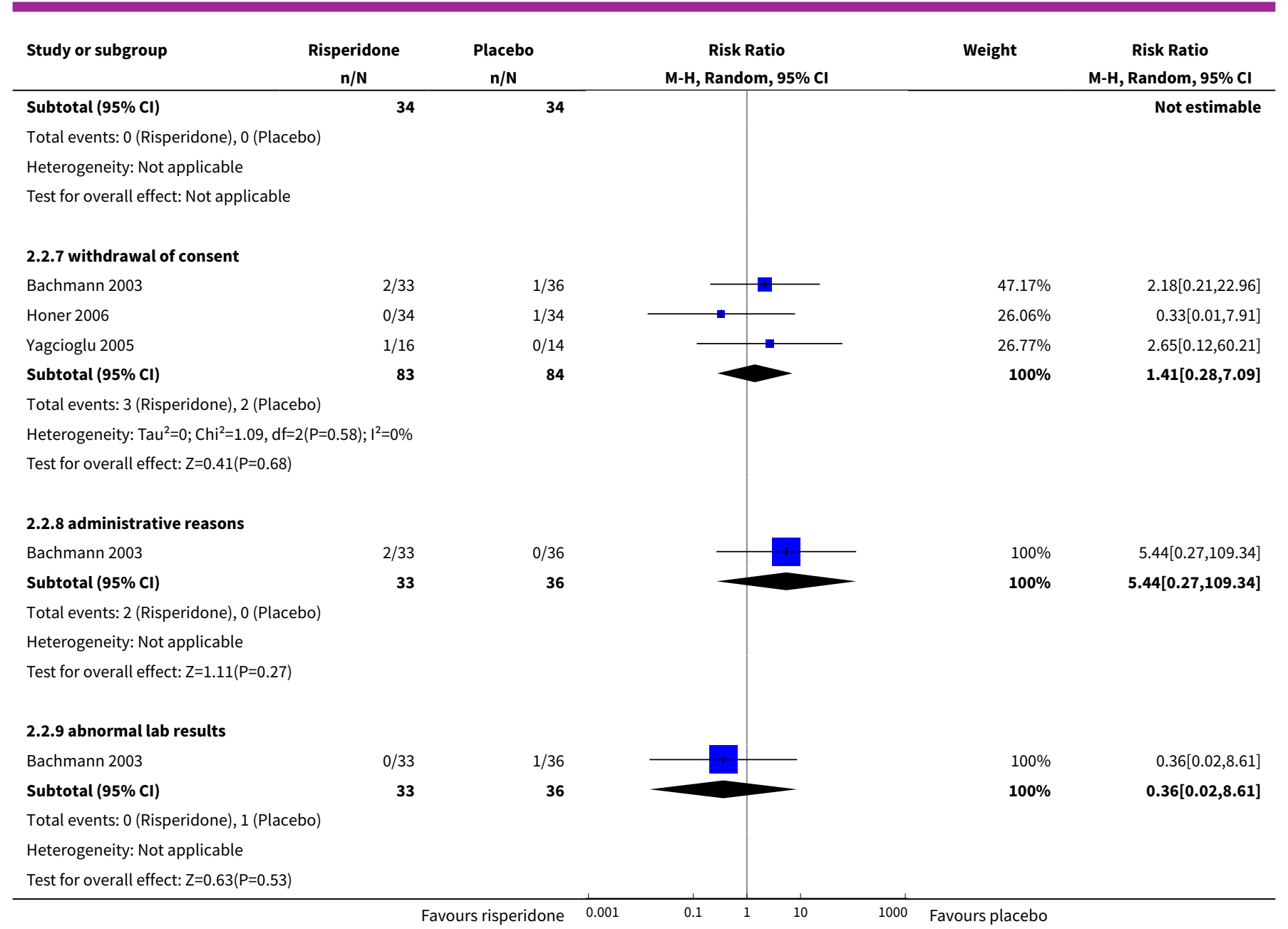

Analysis 2.3. Comparison 2 RISPERIDONE + CLOZAPINE vs PLACEBO + CLOZAPINE, Outcome 3 Global state: 1. average endpoint scores of CGI severity scale (high=poor) - short term (up to 12 weeks).

\begin{tabular}{|c|c|c|c|c|c|c|c|}
\hline \multirow[t]{2}{*}{ Study or subgroup } & \multicolumn{2}{|c|}{ Risperidone } & \multicolumn{2}{|c|}{ Placebo } & \multirow{2}{*}{$\begin{array}{l}\text { Mean Difference } \\
\text { Random, } 95 \% \mathrm{Cl}\end{array}$} & \multirow[t]{2}{*}{ Weight } & \multirow{2}{*}{$\begin{array}{l}\text { Mean Difference } \\
\text { Random, } 95 \% \mathrm{Cl}\end{array}$} \\
\hline & $\mathbf{N}$ & Mean(SD) & $\mathbf{N}$ & Mean(SD) & & & \\
\hline Honer 2006 & 32 & $5(1)$ & 33 & $4.5(1.1)$ & + & $100 \%$ & $0.51[0.02,1]$ \\
\hline Total $\star \star \star ~$ & 32 & & 33 & & $\gamma$ & $100 \%$ & $0.51[0.02,1]$ \\
\hline \multicolumn{8}{|c|}{ Heterogeneity: Not applicable } \\
\hline Test for overall effect & & & & & & & \\
\hline
\end{tabular}

Analysis 2.4. Comparison 2 RISPERIDONE + CLOZAPINE vs PLACEBO + CLOZAPINE, Outcome 4 Global state: 2 . no significant clinical improvement CGI - short term (up to 12 weeks).

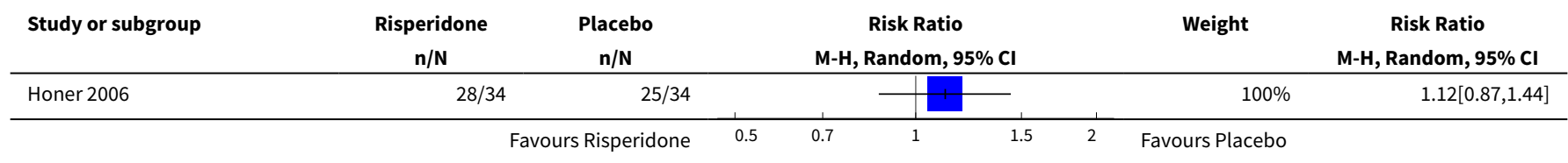




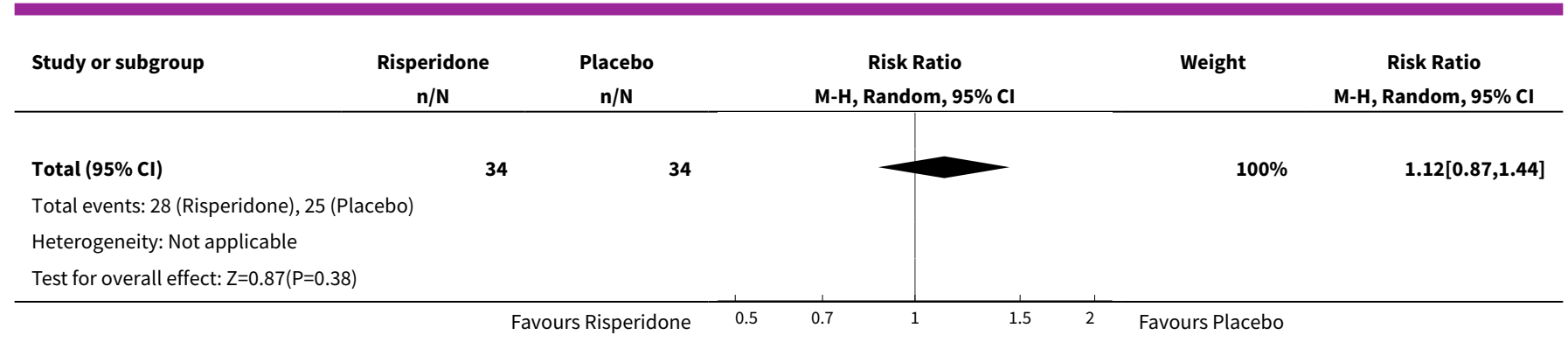

Analysis 2.5. Comparison 2 RISPERIDONE + CLOZAPINE vs PLACEBO + CLOZAPINE, Outcome 5 Global state: 3. general functioning - average endpoint GAF score (high=good) - short term (up to 12 weeks).

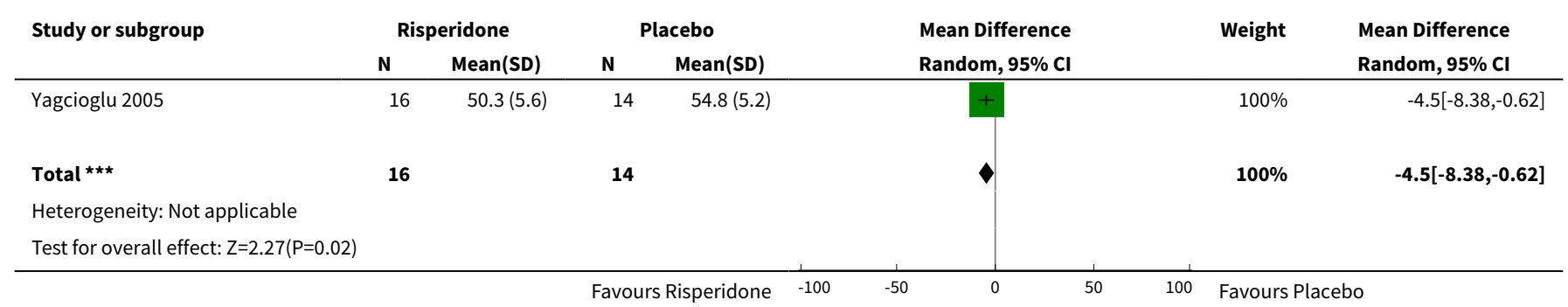

Analysis 2.6. Comparison 2 RISPERIDONE + CLOZAPINE vs PLACEBO + CLOZAPINE, Outcome 6 Mental state: 1. average endpoint scores on various scales on psychotic symptoms (high=poor) - short term (up to 12 weeks).

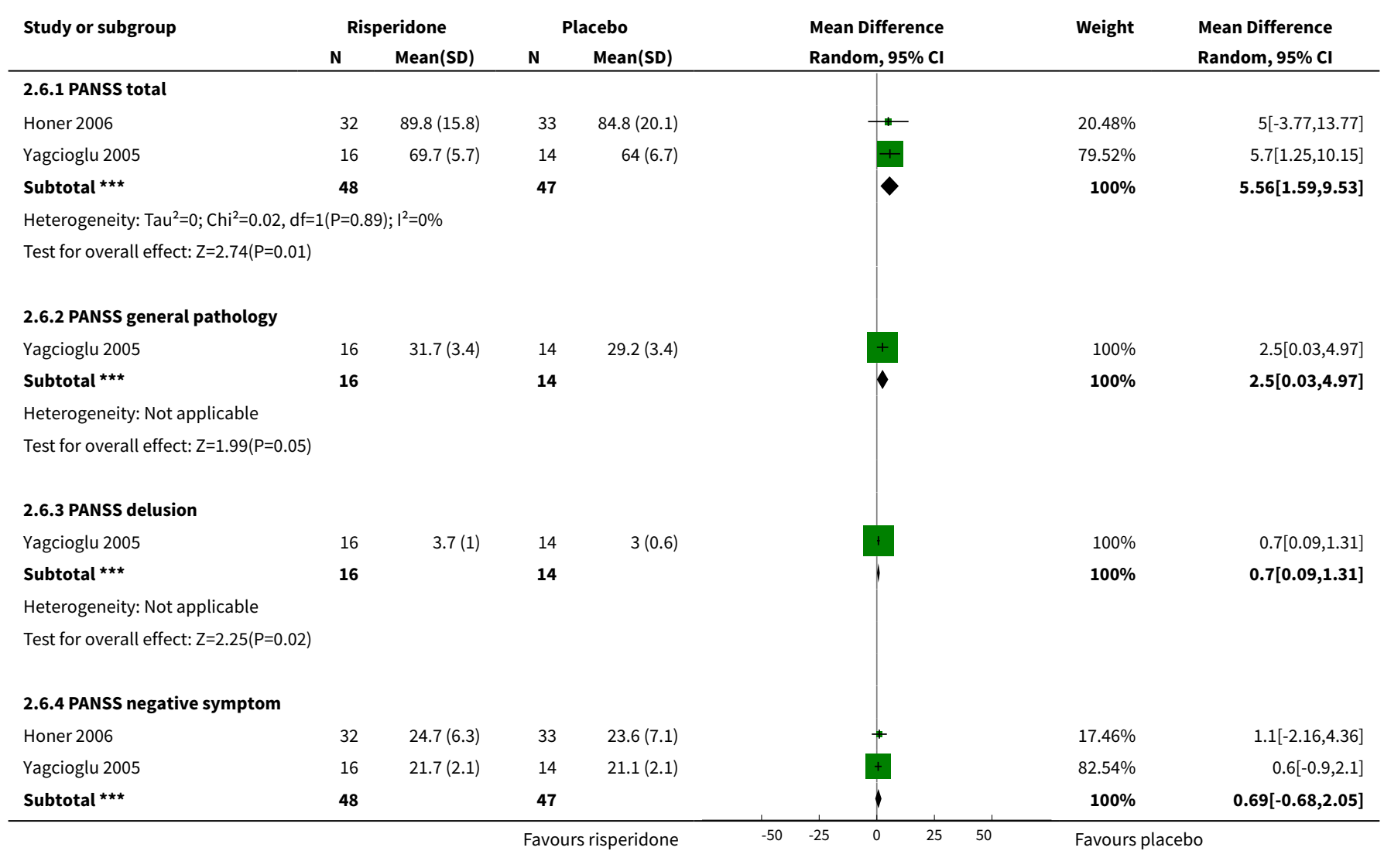




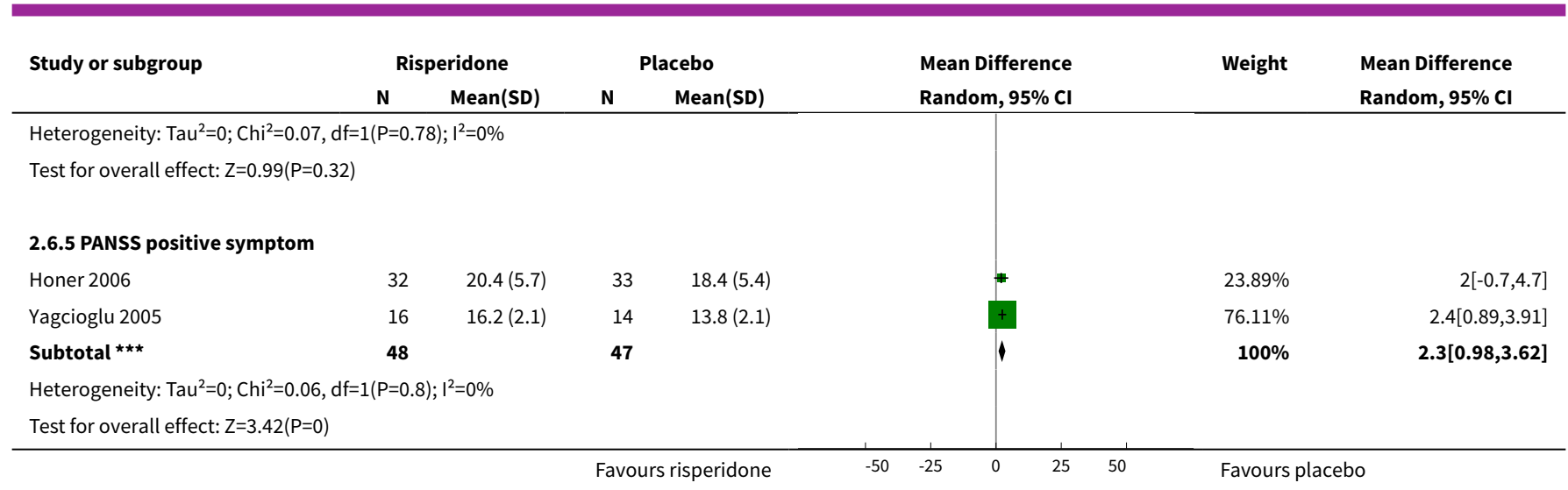

Analysis 2.7. Comparison 2 RISPERIDONE + CLOZAPINE vs PLACEBO + CLOZAPINE, Outcome 7 Mental state: 2. average endpoint scores on various scales on psychotic symptoms (high=poor) - medium term (up to 26 weeks).

\begin{tabular}{|c|c|c|c|c|c|c|c|}
\hline \multirow[t]{2}{*}{ Study or subgroup } & \multicolumn{2}{|c|}{ Risperidone } & \multicolumn{2}{|c|}{ Placebo } & \multirow{2}{*}{$\begin{array}{l}\text { Mean Difference } \\
\text { Random, } 95 \% \mathrm{Cl}\end{array}$} & \multirow[t]{2}{*}{ Weight } & \multirow{2}{*}{$\begin{array}{l}\text { Mean Difference } \\
\text { Random, } 95 \% \mathrm{Cl}\end{array}$} \\
\hline & $\mathbf{N}$ & Mean(SD) & $\mathbf{N}$ & Mean(SD) & & & \\
\hline \multicolumn{8}{|l|}{ 2.7.1 BPRS total } \\
\hline Bachmann 2003 & 25 & $36.4(9.3)$ & 28 & $41(10.3)$ & & $100 \%$ & $-4.6[-9.88,0.68]$ \\
\hline 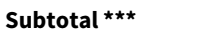 & 25 & & 28 & & & $100 \%$ & $-4.6[-9.88,0.68]$ \\
\hline \multicolumn{8}{|c|}{ Heterogeneity: Not applicable } \\
\hline \multicolumn{8}{|c|}{ Test for overall effect: $Z=1.71(P=0.09)$} \\
\hline \multicolumn{8}{|c|}{ 2.7.2 BPRS positive symptom } \\
\hline Bachmann 2003 & 25 & $13.2(3.5)$ & 28 & $14.1(3.6)$ & & $100 \%$ & $-0.9[-2.81,1.01]$ \\
\hline Subtotal $\star \star \star$ & 25 & & 28 & & & $100 \%$ & $-0.9[-2.81,1.01]$ \\
\hline \multicolumn{8}{|c|}{ Heterogeneity: Not applicable } \\
\hline \multicolumn{8}{|c|}{ Test for overall effect: $Z=0.92(P=0.36)$} \\
\hline Bachmann 2003 & 25 & $7.6(3.1)$ & 28 & $8.6(3.6)$ & & $100 \%$ & $-1[-2.8,0.8]$ \\
\hline 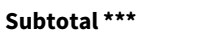 & 25 & & 28 & & & $100 \%$ & $-1[-2.8,0.8]$ \\
\hline \multicolumn{8}{|c|}{ Heterogeneity: Not applicable } \\
\hline \multicolumn{8}{|c|}{ Test for overall effect: $\mathrm{Z}=1.09(\mathrm{P}=0.28)$} \\
\hline \multicolumn{8}{|l|}{ 2.7.4 SANS total } \\
\hline Bachmann 2003 & 25 & $31.3(11.9)$ & 28 & $34.4(14.8)$ & & $100 \%$ & $-3.1[-10.3,4.1]$ \\
\hline 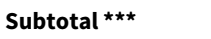 & 25 & & 28 & & & $100 \%$ & $-3.1[-10.3,4.1]$ \\
\hline \multicolumn{8}{|c|}{ Heterogeneity: Not applicable } \\
\hline \multicolumn{8}{|c|}{ Test for overall effect: $Z=0.84(P=0.4)$} \\
\hline Test for subgroup dif & $d f=1(F$ & $0.57), 1^{2}=0 \%$ & & & & & \\
\hline
\end{tabular}

Analysis 2.8. Comparison 2 RISPERIDONE + CLOZAPINE vs PLACEBO + CLOZAPINE, Outcome 8 Mental state: 3 . skewed data - short term (up to 12 weeks).

Mental state: 3 . skewed data - short term (up to 12 weeks)

Study Intervention

Mean

SD N average endpoint score of CDS total (high=poor)

\begin{tabular}{lllll}
\hline Yagcioglu 2005 & Resperidone & 1.6 & 2 & 16 \\
\hline \hline
\end{tabular}

Risperidone versus placebo for schizophrenia (Review) 


\begin{tabular}{|c|c|c|c|c|}
\hline \multicolumn{5}{|c|}{ Mental state: 3. skewed data - short term (up to 12 weeks) } \\
\hline Study & Intervention & Mean & SD & $\mathbf{N}$ \\
\hline Yagcioglu 2005 & Placebo & 1.4 & 1.9 & 14 \\
\hline \multicolumn{5}{|c|}{ average endpoint score on verbal working memory (SD, high=good) } \\
\hline Honer 2006 & Resperidone & 0.08 & 0.99 & 152 \\
\hline Honer 2006 & Placebo & 0.14 & 0.83 & 71 \\
\hline
\end{tabular}

Analysis 2.9. Comparison 2 RISPERIDONE + CLOZAPINE vs PLACEBO + CLOZAPINE, Outcome 9 Adverse effects: 1a. extrapyramidal - average endpoint SAS score - short term (up to 12 weeks).

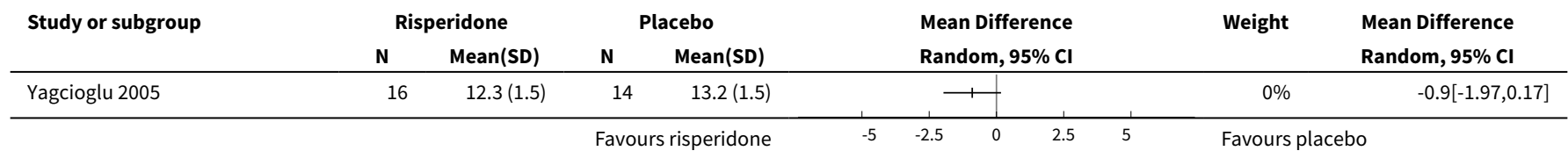

Analysis 2.10. Comparison 2 RISPERIDONE + CLOZAPINE vs PLACEBO + CLOZAPINE, Outcome 10 Adverse effects: 1b. extrapyramidal - skewed data (various scales) - short term (up to 12 weeks).

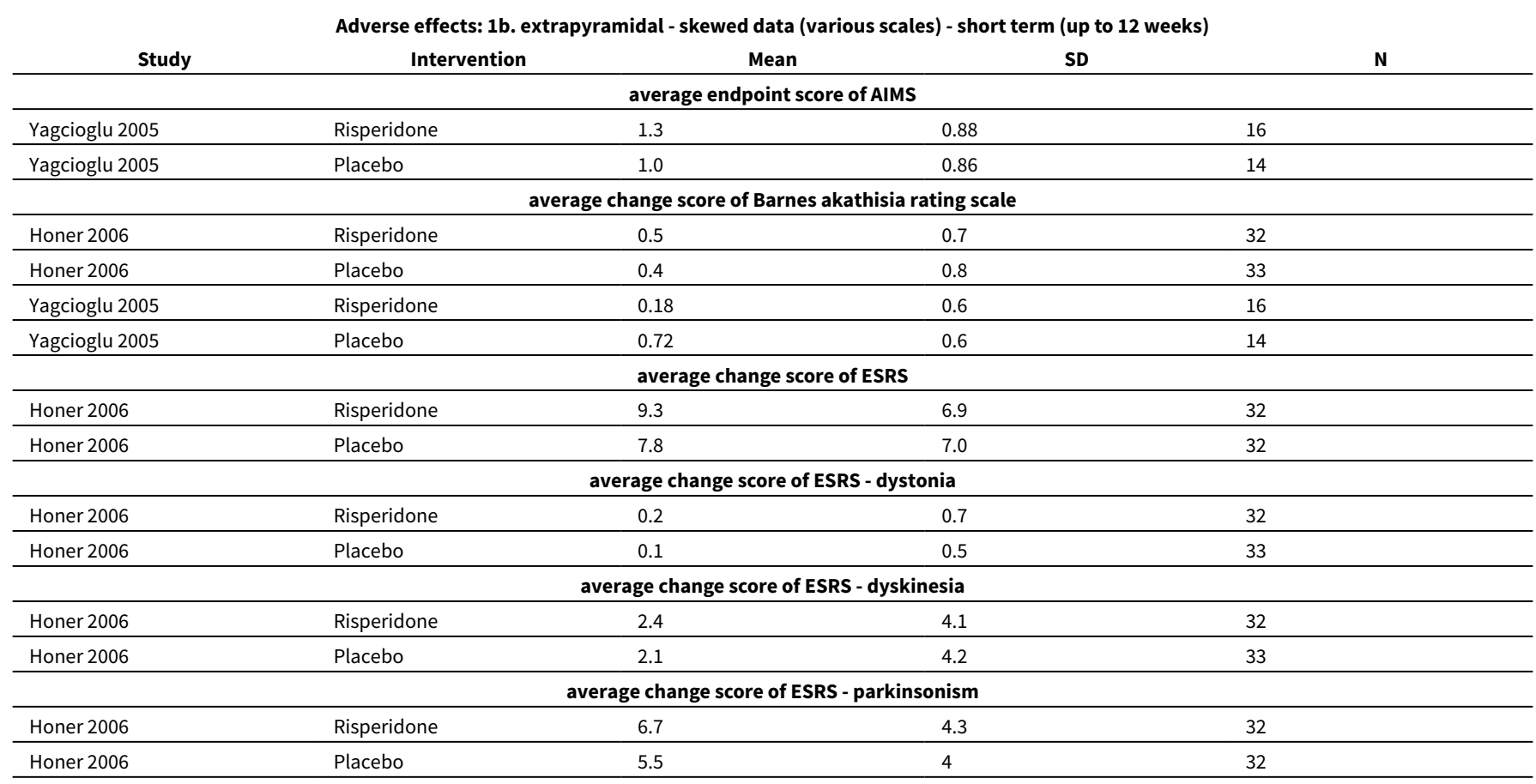

Analysis 2.11. Comparison 2 RISPERIDONE + CLOZAPINE vs PLACEBO + CLOZAPINE, Outcome 11 Adverse effects: 1c. extrapyramidal - skewed data (various scales) - medium term (up to 26 weeks).

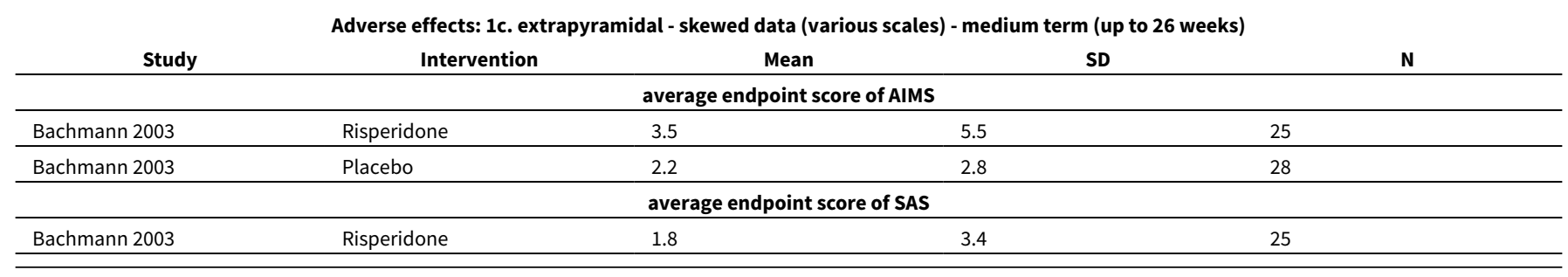


Adverse effects: 1c. extrapyramidal - skewed data (various scales) - medium term (up to 26 weeks)

\begin{tabular}{cccccc} 
Study & Intervention & Mean & SD & \\
\hline Bachmann 2003 & Placebo & 1.8 & 2.5 & \\
\hline
\end{tabular}

Analysis 2.12. Comparison 2 RISPERIDONE + CLOZAPINE vs PLACEBO + CLOZAPINE, Outcome 12 Adverse effects: 2 . any adverse event - short term (up to 12 weeks).

$\begin{array}{lr}\text { Study or subgroup } & \text { Risper } \\ \mathrm{n} /\end{array}$

Honer 2006

Subtotal $(95 \% \mathrm{Cl})$

Total events: 24 (Risperidone), 21 (Placebo)

Heterogeneity: Not applicable

Test for overall effect: $\mathrm{Z}=0.82(\mathrm{P}=0.41)$

\subsection{2 amenorrhoea}

Honer 2006

Subtotal $(95 \% \mathrm{Cl})$

Total events: 1 (Risperidone), 0 (Placebo)

Heterogeneity: Not applicable

Test for overall effect: $\mathrm{Z}=0.68(\mathrm{P}=0.5)$

\subsection{3 asthenia}

Honer 2006

Subtotal $(95 \% \mathrm{Cl})$

Total events: 14 (Risperidone), 13 (Placebo)

Heterogeneity: Not applicable

Test for overall effect: $Z=0.25(P=0.8)$

\subsection{4 depression}

Honer 2006

Subtotal $(95 \% \mathrm{CI})$

Total events: 12 (Risperidone), 10 (Placebo)

Heterogeneity: Not applicable

Test for overall effect: $Z=0.52(P=0.6)$

\subsection{5 emotional indifference}

Honer 2006

Subtotal $(95 \% \mathrm{Cl})$
$1 / 32$

32

$\mathrm{n} / \mathrm{N}$

32
Risk Ratio M-H, Random, 95\% CI

$\begin{array}{rr}24 / 32 & 21 / 32 \\ 32 & 32\end{array}$

32
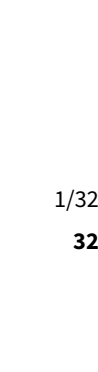

32

$13 / 32$

32

/32

32

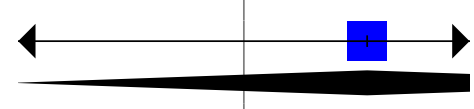

$100 \%$

$100 \%$

$3[0.13,71]$

$3[0.13,71]$

$1.14[0.83,1.58]$

$100 \%$

$1.14[0.83,1.58]$

M-H, Random, 95\% CI

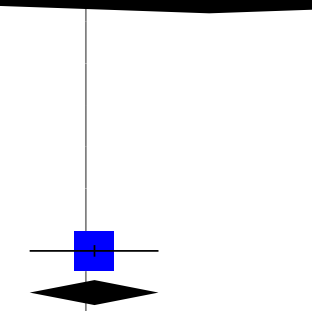

$100 \%$

$1.08[0.61,1.91]$

$100 \%$

$1.08[0.61,1.91]$
Total events: 10 (Risperidone), 9 (Placebo)

Heterogeneity: Not applicable

Test for overall effect: $\mathrm{Z}=0.27(\mathrm{P}=0.78)$

\subsection{6 fatigue}

Honer 2006

Subtotal $(95 \% \mathrm{Cl})$

32

$100 \%$

$1.2[0.61,2.37]$

$100 \%$

$1.2[0.61,2.37]$

Total events: 14 (Risperidone), 13 (Placebo)

Heterogeneity: Not applicable

Test for overall effect: $\mathrm{Z}=0.25(\mathrm{P}=0.8)$

2.12.7 failing memory 


\begin{tabular}{|c|c|c|c|c|c|}
\hline Study or subgroup & $\begin{array}{c}\text { Risperidone } \\
\mathrm{n} / \mathrm{N} \\
\end{array}$ & $\begin{array}{c}\text { Placebo } \\
\mathbf{n} / \mathbf{N}\end{array}$ & $\begin{array}{c}\text { Risk Ratio } \\
\text { M-H, Random, 95\% CI }\end{array}$ & Weight & $\begin{array}{c}\text { Risk Ratio } \\
\text { M-H, Random, } 95 \% \mathrm{Cl}\end{array}$ \\
\hline Honer 2006 & $8 / 32$ & $12 / 32$ & \begin{tabular}{l|l}
+1 & \\
\end{tabular} & $100 \%$ & $0.67[0.32,1.41]$ \\
\hline Subtotal $(95 \% \mathrm{Cl})$ & 32 & 32 & & $100 \%$ & $0.67[0.32,1.41]$ \\
\hline \multicolumn{6}{|c|}{ Total events: 8 (Risperidone), 12 (Placebo) } \\
\hline \multicolumn{6}{|c|}{ Heterogeneity: Not applicable } \\
\hline \multicolumn{6}{|c|}{ Test for overall effect: $Z=1.06(P=0.29)$} \\
\hline \multicolumn{6}{|c|}{ 2.12.8 increased duration of sleep } \\
\hline Honer 2006 & $11 / 32$ & $11 / 32$ & & $100 \%$ & $1[0.51,1.97]$ \\
\hline Subtotal $(95 \% \mathrm{Cl})$ & 32 & 32 & & $100 \%$ & $1[0.51,1.97]$ \\
\hline \multicolumn{6}{|c|}{ Total events: 11 (Risperidone), 11 (Placebo) } \\
\hline \multicolumn{6}{|c|}{ Heterogeneity: Not applicable } \\
\hline \multicolumn{6}{|c|}{ Test for overall effect: Not applicable } \\
\hline \multicolumn{6}{|c|}{ 2.12.9 salivation - increased } \\
\hline Honer 2006 & $20 / 32$ & $16 / 32$ & - & $100 \%$ & $1.25[0.81,1.94]$ \\
\hline Subtotal $(95 \% \mathrm{CI})$ & 32 & 32 & & $100 \%$ & $1.25[0.81,1.94]$ \\
\hline \multicolumn{6}{|c|}{ Total events: 20 (Risperidone), 16 (Placebo) } \\
\hline \multicolumn{6}{|c|}{ Heterogeneity: Not applicable } \\
\hline \multicolumn{6}{|c|}{ Test for overall effect: $Z=1(P=0.32)$} \\
\hline \multicolumn{6}{|c|}{ Test for subgroup differences: $\mathrm{Chi}^{2}=2.64, \mathrm{df}=1(\mathrm{P}=0.96), \mathrm{I}^{2}=0 \%$} \\
\hline
\end{tabular}

\section{Analysis 2.13. Comparison 2 RISPERIDONE + CLOZAPINE vs PLACEBO + CLOZAPINE, Outcome 13 Adverse effects: 3a. cardiovascular - short term (up to 12 weeks).}

\begin{tabular}{|c|c|c|c|c|c|}
\hline Study or subgroup & $\begin{array}{c}\text { Risperidone } \\
\mathrm{n} / \mathrm{N} \\
\end{array}$ & $\begin{array}{c}\text { Placebo } \\
\mathbf{n} / \mathbf{N}\end{array}$ & $\begin{array}{c}\text { Risk Ratio } \\
\text { M-H, Random, 95\% Cl }\end{array}$ & Weight & $\begin{array}{c}\text { Risk Ratio } \\
\text { M-H, Random, } 95 \% \text { Cl }\end{array}$ \\
\hline \multicolumn{6}{|c|}{ 2.13.1 dizziness - orthostatic } \\
\hline Honer 2006 & $8 / 32$ & $8 / 32$ & & $100 \%$ & $1[0.43,2.34]$ \\
\hline Subtotal $(95 \% \mathrm{Cl})$ & 32 & 32 & & $100 \%$ & $1[0.43,2.34]$ \\
\hline \multicolumn{6}{|c|}{ Total events: 8 (Risperidone), 8 (Placebo) } \\
\hline \multicolumn{6}{|c|}{ Heterogeneity: Not applicable } \\
\hline \multicolumn{6}{|l|}{ 2.13.2 palpitation } \\
\hline Honer 2006 & $4 / 32$ & $4 / 32$ & & $100 \%$ & $1[0.27,3.66]$ \\
\hline Subtotal $(95 \% \mathrm{CI})$ & 32 & 32 & & $100 \%$ & $1[0.27,3.66]$ \\
\hline \multicolumn{6}{|c|}{ Total events: 4 (Risperidone), 4 (Placebo) } \\
\hline \multicolumn{6}{|c|}{ Heterogeneity: Not applicable } \\
\hline \multicolumn{6}{|l|}{ 2.13.3 tachycardia } \\
\hline Honer 2006 & $4 / 32$ & $4 / 32$ & & $100 \%$ & $1[0.27,3.66]$ \\
\hline Subtotal $(95 \% \mathrm{Cl})$ & 32 & 32 & & $100 \%$ & $1[0.27,3.66]$ \\
\hline \multicolumn{6}{|c|}{ Total events: 4 (Risperidone), 4 (Placebo) } \\
\hline \multicolumn{6}{|c|}{ Heterogeneity: Not applicable } \\
\hline Test for overall effec & & & & & \\
\hline
\end{tabular}


Analysis 2.14. Comparison 2 RISPERIDONE + CLOZAPINE vs PLACEBO + CLOZAPINE, Outcome 14 Adverse effects: 3b. cardiovascular - QTc interval - short term (up to 12 weeks).

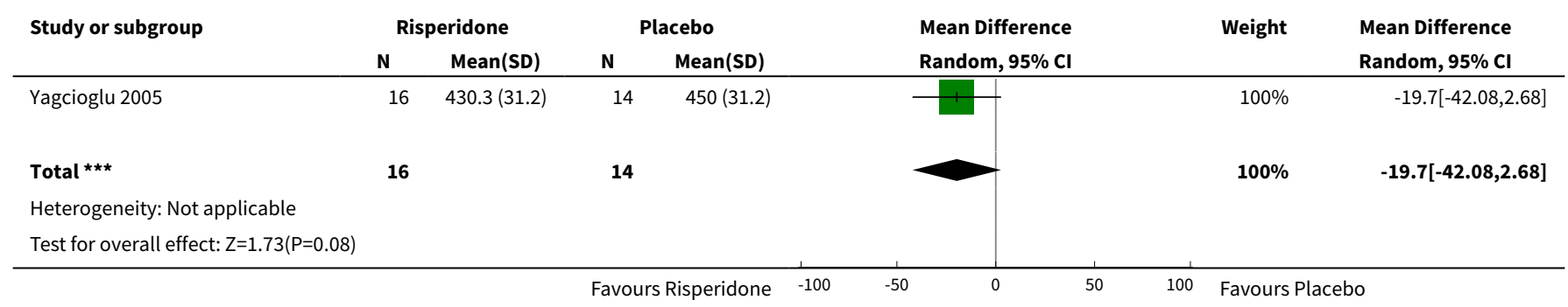

Analysis 2.15. Comparison 2 RISPERIDONE + CLOZAPINE vs PLACEBO + CLOZAPINE, Outcome 15 Adverse effects: 4. central nervous system - short term (up to 12 weeks).

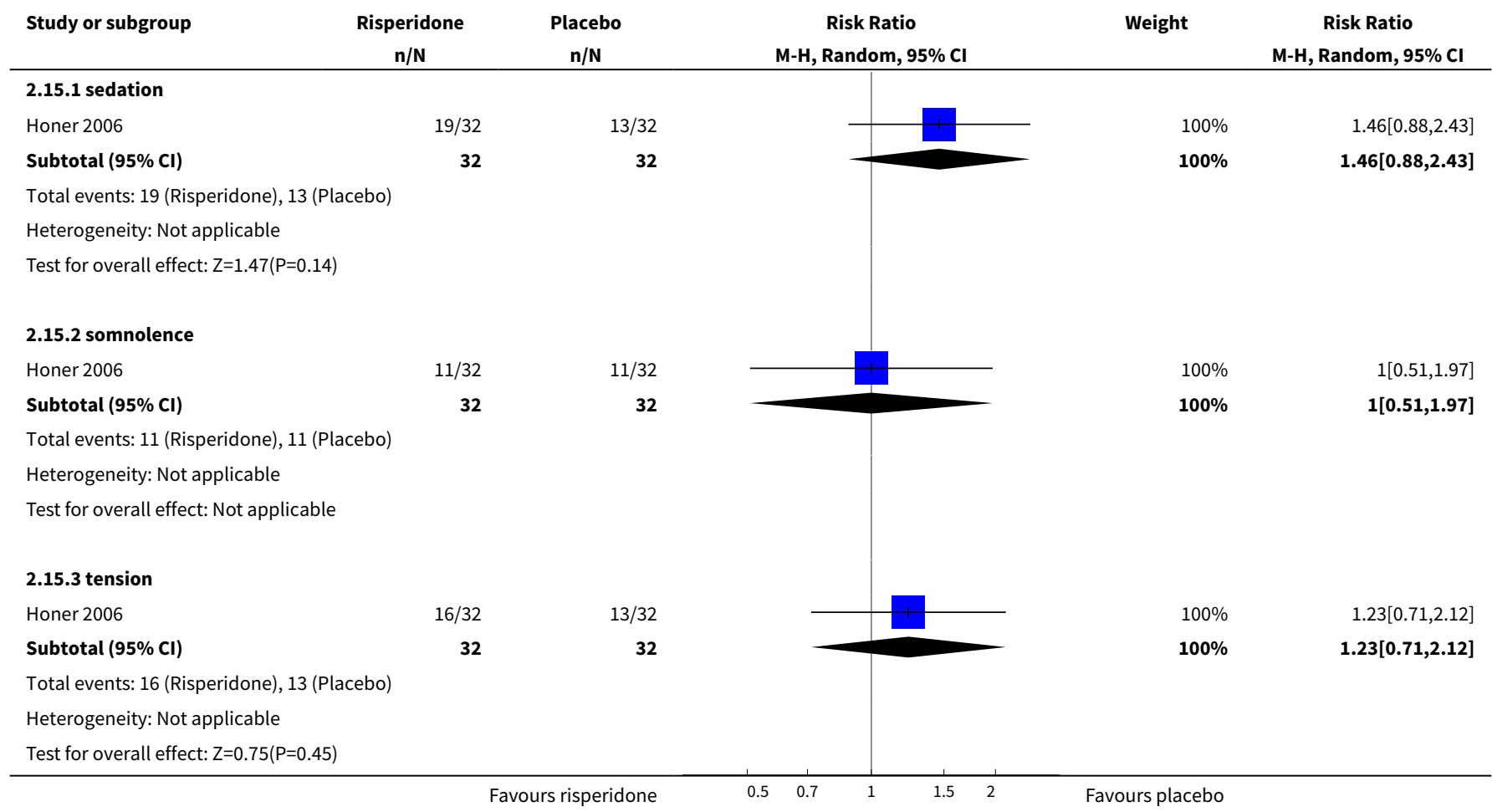

Analysis 2.16. Comparison 2 RISPERIDONE + CLOZAPINE vs PLACEBO + CLOZAPINE, Outcome 16 Adverse effects: 5 . gastrointestinal system - short term (up to 12 weeks).

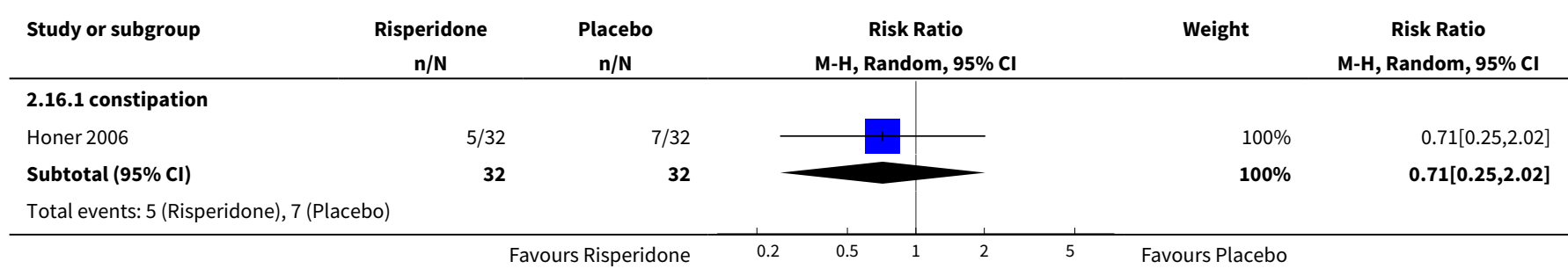




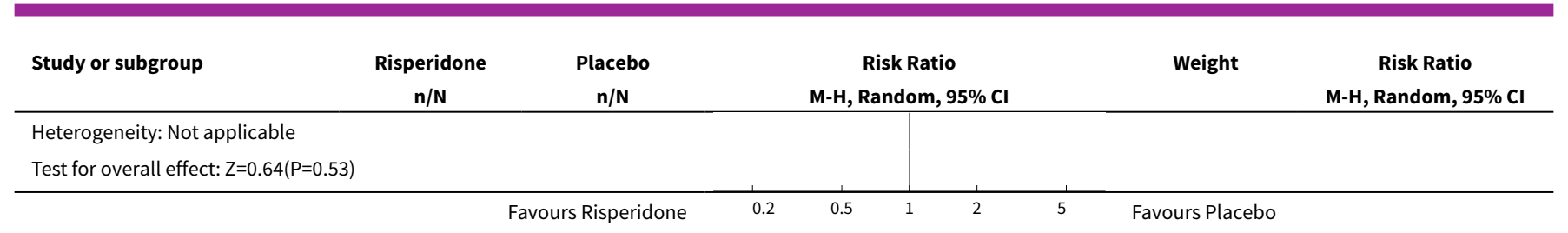

Analysis 2.17. Comparison 2 RISPERIDONE + CLOZAPINE vs PLACEBO + CLOZAPINE, Outcome 17 Adverse effects: 6a. haematological - short term (up to 12 weeks).

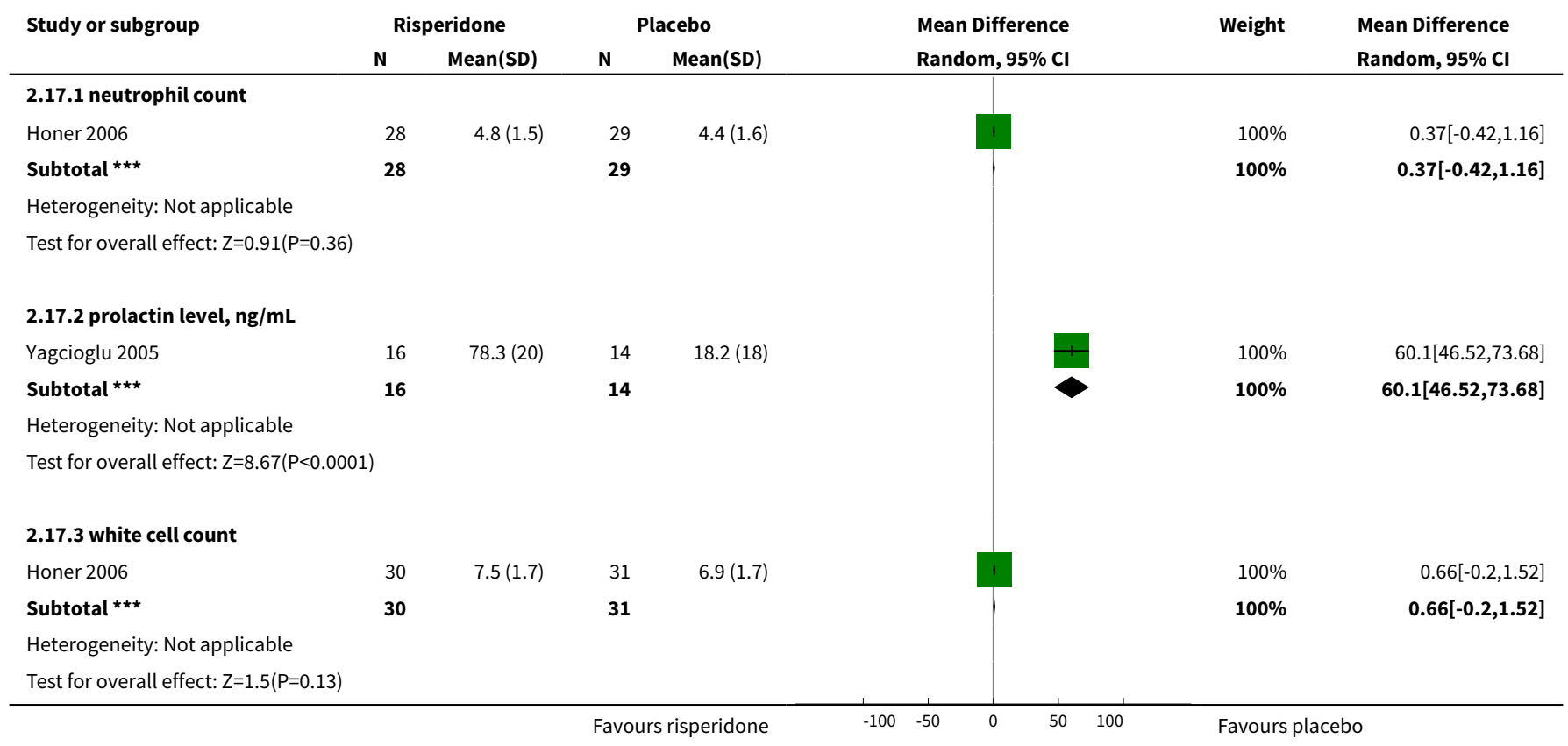

Analysis 2.18. Comparison 2 RISPERIDONE + CLOZAPINE vs PLACEBO + CLOZAPINE, Outcome 18 Adverse effects: 6 b. haematological - medium term (up to 26 weeks).

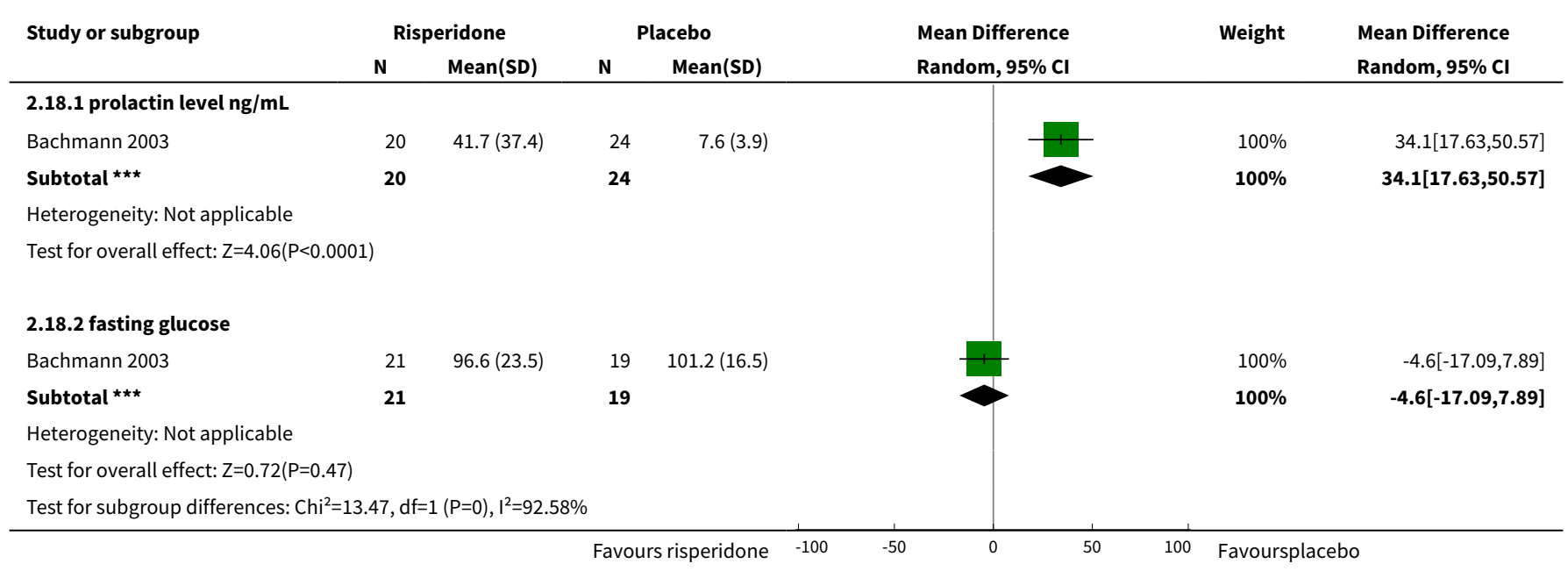


Analysis 2.19. Comparison 2 RISPERIDONE + CLOZAPINE vs PLACEBO + CLOZAPINE, Outcome 19 Adverse effects: 7a. metabolic - weight gain - short term (up to 12 weeks).

\begin{tabular}{|c|c|c|c|c|c|}
\hline Study or subgroup & $\begin{array}{c}\text { Risperidone } \\
\mathrm{n} / \mathrm{N} \\
\end{array}$ & $\begin{array}{c}\text { Placebo } \\
\text { n/N }\end{array}$ & $\begin{array}{c}\text { Risk Ratio } \\
\text { M-H, Random, } 95 \% \text { CI }\end{array}$ & Weight & $\begin{array}{c}\text { Risk Ratio } \\
\text { M-H, Random, } 95 \% \mathrm{Cl}\end{array}$ \\
\hline Honer 2006 & $7 / 32$ & $7 / 32$ & - & $100 \%$ & $1[0.4,2.52]$ \\
\hline Total $(95 \% \mathrm{CI})$ & 32 & 32 & & $100 \%$ & $1[0.4,2.52]$ \\
\hline \multicolumn{6}{|c|}{ Total events: 7 (Risperidone), 7 (Placebo) } \\
\hline \multicolumn{6}{|c|}{ Heterogeneity: Not applicable } \\
\hline Test for overall effec & & & & & \\
\hline
\end{tabular}

Analysis 2.20. Comparison 2 RISPERIDONE + CLOZAPINE vs PLACEBO + CLOZAPINE, Outcome 20 Adverse effects: 7 a. metabolic - weight gain - medium term (up to 26 weeks).

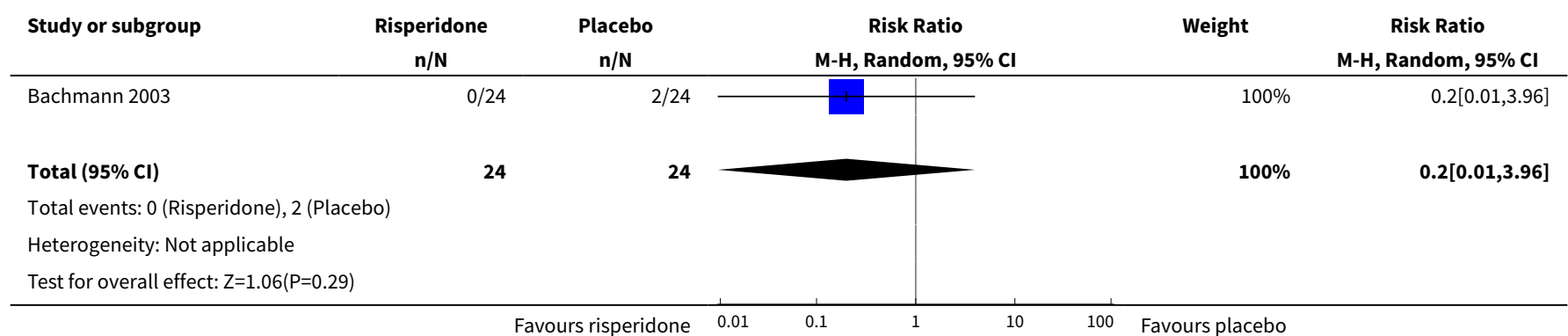

Analysis 2.21. Comparison 2 RISPERIDONE + CLOZAPINE vs PLACEBO + CLOZAPINE, Outcome 21 Adverse effects: $7 \mathrm{~b}$. metabolic - average endpoint value on lipid profile - short term (up to 12 weeks).

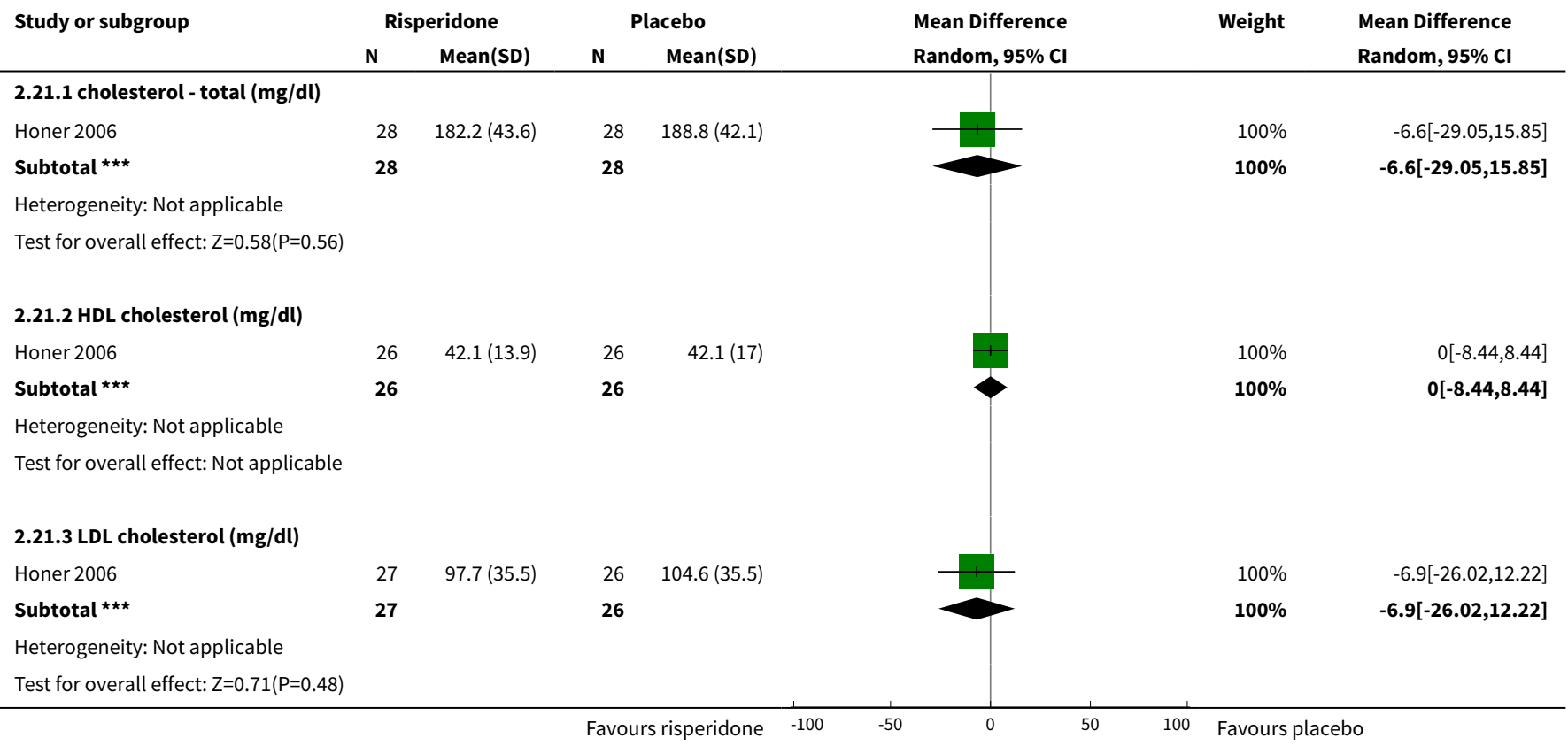




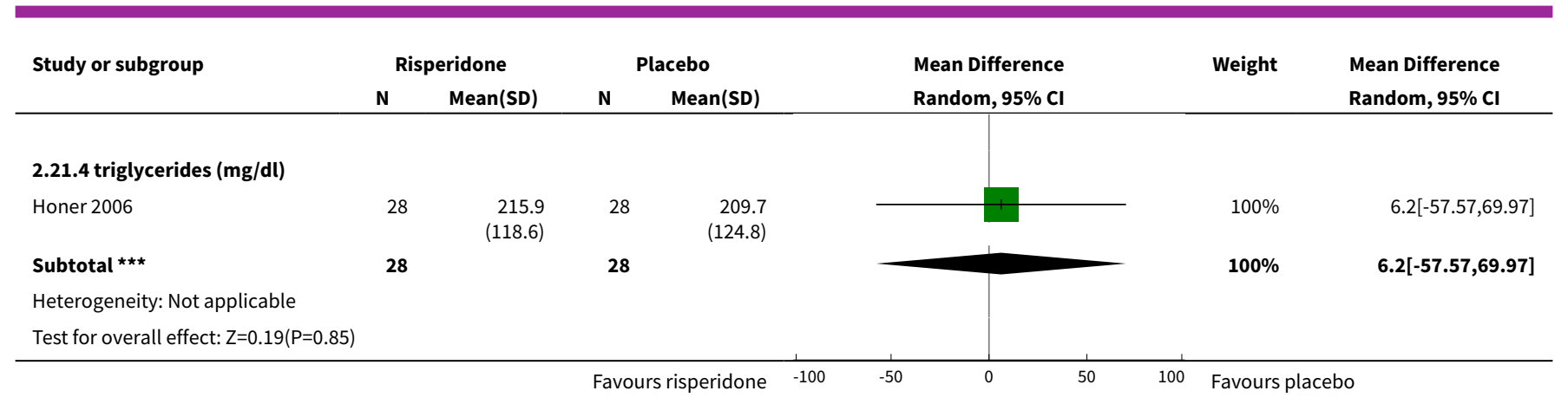

\section{Analysis 2.22. Comparison 2 RISPERIDONE + CLOZAPINE vs PLACEBO + CLOZAPINE, Outcome} 22 Adverse effects: 7c. metabolic - average endpoint value - short term (up to 12 weeks).

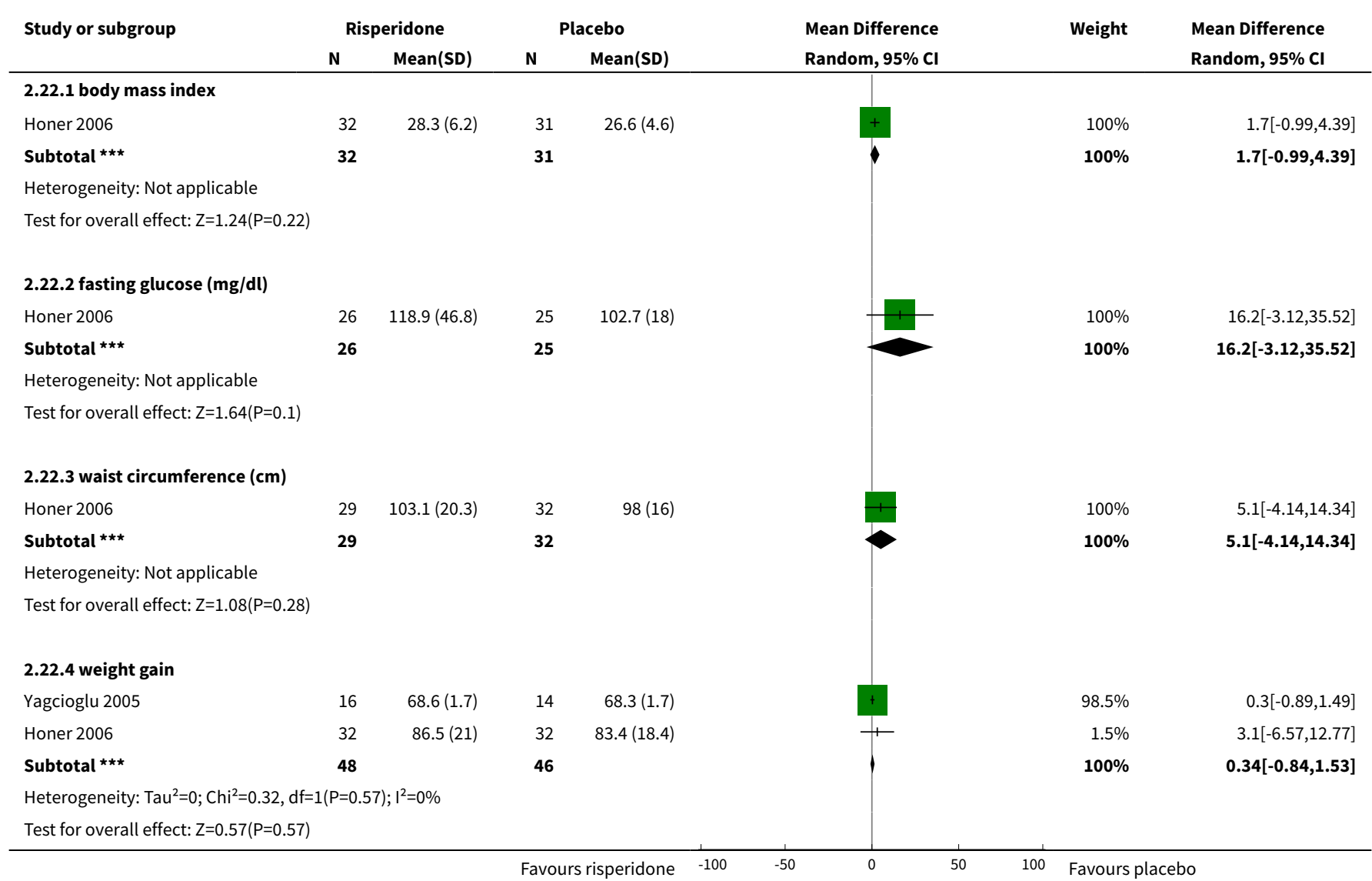

Analysis 2.23. Comparison 2 RISPERIDONE + CLOZAPINE vs PLACEBO + CLOZAPINE, Outcome 23 Adverse effects: 8. sleep - skewed data - average change score (UKU) - short term (up to 12 weeks).

\begin{tabular}{lllll}
\multicolumn{1}{c}{ Study } & \multicolumn{2}{c}{ Adverse effects: 8. sleep - skewed data - average change score (UKU) - short term (up to 12 weeks) } \\
Intervention & Mean & SD & \\
\hline Yagcioglu 2005 & Risperidone & 0.7 & 0.36 & \\
\hline Yagcioglu 2005 & Placebo & 0.2 & 0.37 & 16 \\
\hline
\end{tabular}


Analysis 2.24. Comparison 2 RISPERIDONE + CLOZAPINE vs PLACEBO + CLOZAPINE, Outcome 24 Quality of life: average endpoint score (QLS, high=good) - short term (up to 12 weeks).

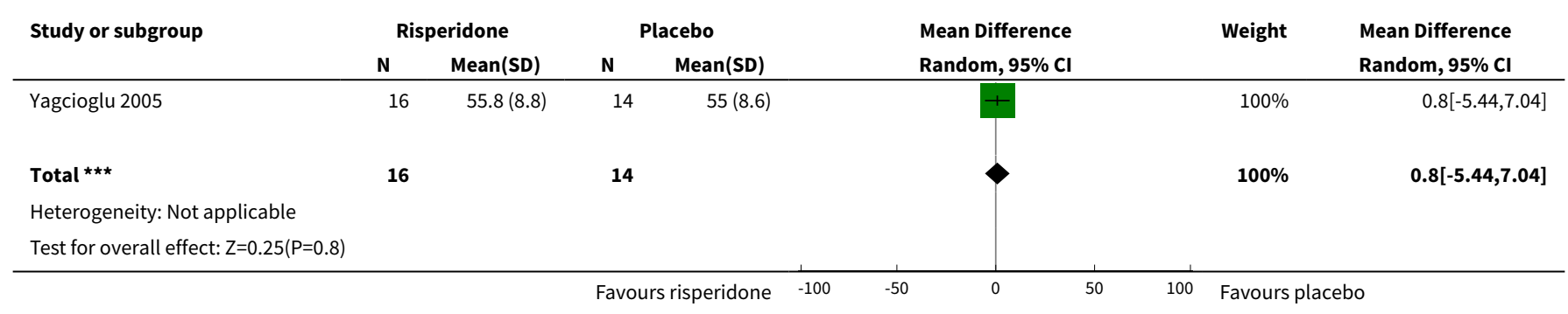

\section{Comparison 3. SENSITIVITY ANALYSIS: RISPERIDONE vS PLACEBO (based on attrition)}

\begin{tabular}{|c|c|c|c|c|}
\hline Outcome or subgroup title & No. of studies & $\begin{array}{l}\text { No. of partici- } \\
\text { pants }\end{array}$ & Statistical method & Effect size \\
\hline $\begin{array}{l}1 \text { Mental state: } 1 \text {. no clinically significant re- } \\
\text { sponse (defined by PANSS/BPRS) - short term } \\
\text { (up to } 12 \text { weeks) }\end{array}$ & 6 & & $\begin{array}{l}\text { Risk Ratio (M-H, Ran- } \\
\text { dom, } 95 \% \mathrm{Cl} \text { ) }\end{array}$ & Subtotals only \\
\hline 1.1 defined by PANSS/BPRS $<20 \%$ decline & 6 & 864 & $\begin{array}{l}\text { Risk Ratio (M-H, Ran- } \\
\text { dom, } 95 \% \mathrm{Cl} \text { ) }\end{array}$ & $0.64[0.52,0.78]$ \\
\hline $\begin{array}{l}1.2 \text { defined by PANSS/BPRS }<20 \% \text { decline } \\
\text { (without studies with }>50 \% \text { left the study ear- } \\
\text { ly) }\end{array}$ & 3 & 589 & $\begin{array}{l}\text { Risk Ratio (M-H, Ran- } \\
\text { dom, 95\% Cl) }\end{array}$ & $0.77[0.67,0.88]$ \\
\hline
\end{tabular}

Analysis 3.1. Comparison 3 SENSITIVITY ANALYSIS: RISPERIDONE vs PLACEBO (based on attrition), Outcome 1 Mental state: 1. no clinically significant response (defined by PANSS/BPRS) - short term (up to 12 weeks).

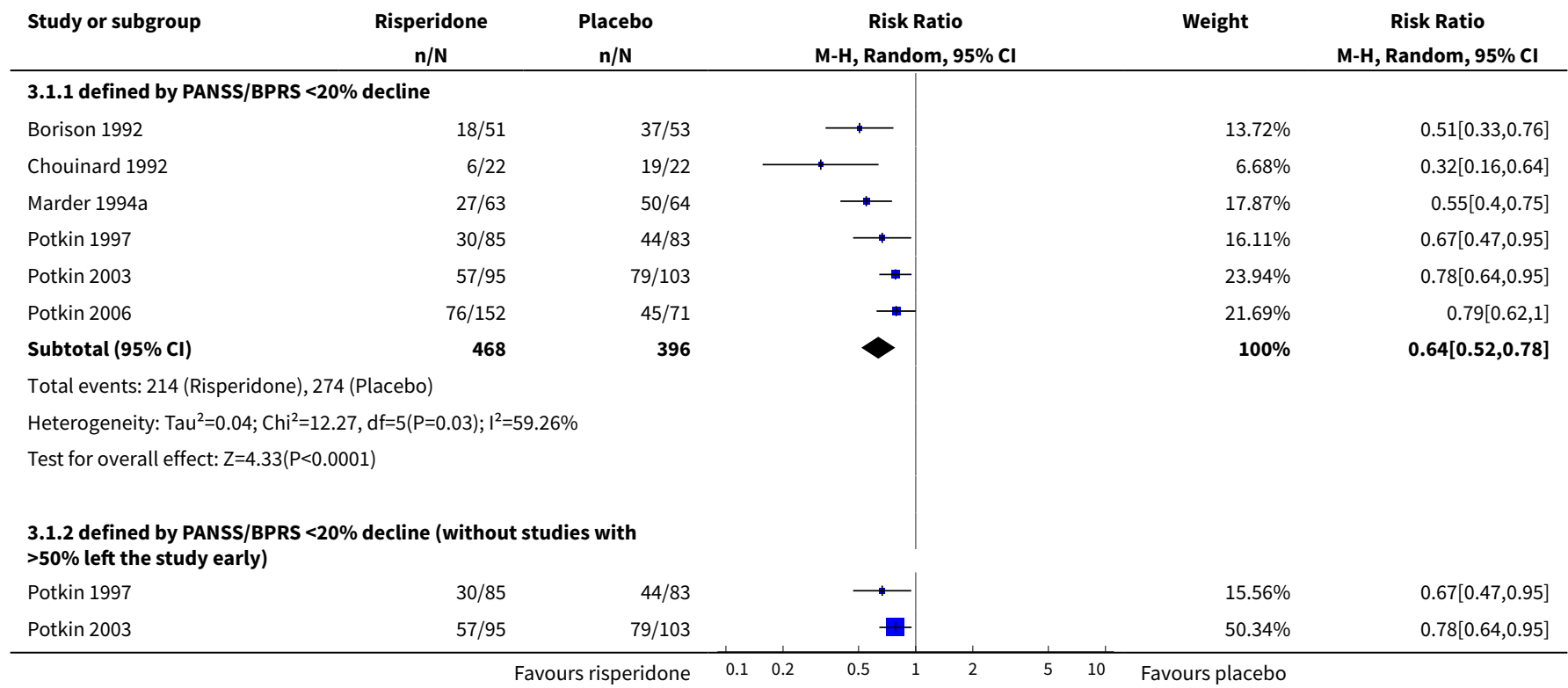




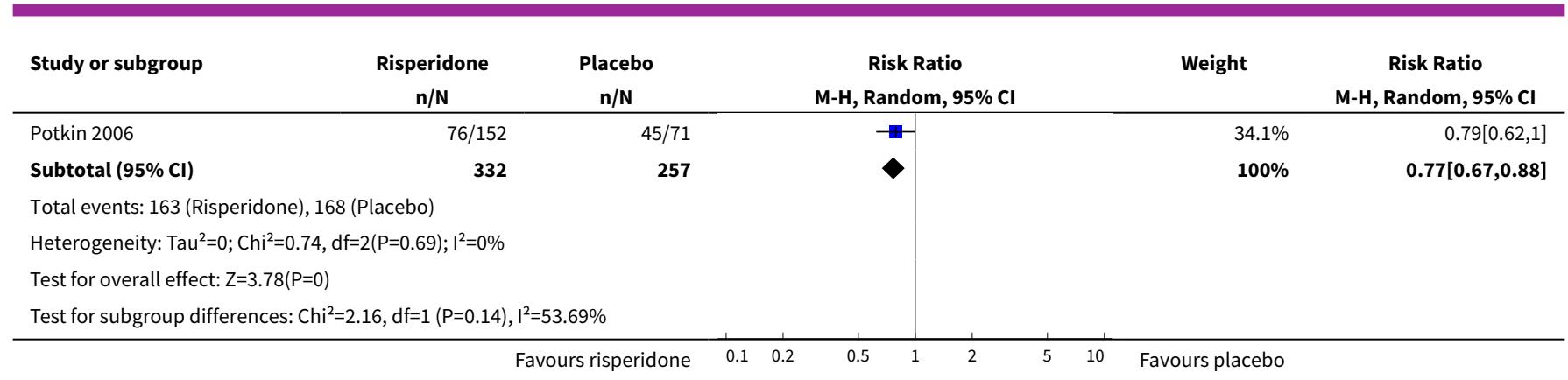

ADDITIONAL TABLES

Table 1. Risperidone reviews

\begin{tabular}{lll}
\hline Comparison & \multicolumn{1}{c}{ Reference } \\
\hline Oral risperidone & vs other atypical drugs & Gilbody 2000; Komossa 2007 \\
\cline { 2 - 3 } & vs olanzapine & Jayaram 2006 \\
\cline { 2 - 3 } & vs typical drugs & Kennedy 2000; Hunter 2003 \\
\hline Depot risperidone & Hosalli 2003 \\
\hline Risperidone dose & Li 2009 \\
\hline Risperidone for acute aggression & Ahmed 2011 \\
\hline
\end{tabular}

Table 2. Global Assessment of Functioning scale

\begin{tabular}{|c|c|}
\hline Score & Judgement \\
\hline $91-100$ & $\begin{array}{l}\text { Superior functioning in a wide range of activities, life's problems never seem to get out of hand, is } \\
\text { sought out by others because of his or her many qualities. No symptoms. }\end{array}$ \\
\hline $81-90$ & $\begin{array}{l}\text { Absent or minimal symptoms, good functioning in all areas, interested and involved in a wide } \\
\text { range of activities, socially effective, generally satisfied with life, no more than everyday problems } \\
\text { or concerns. }\end{array}$ \\
\hline $71-80$ & $\begin{array}{l}\text { If symptoms are present they are transient and expectable reactions to psychosocial stresses; no } \\
\text { more than slight impairment in social, occupational, or school functioning. }\end{array}$ \\
\hline $61-70$ & $\begin{array}{l}\text { Some mild symptoms OR some difficulty in social, occupational, or school functioning, but gener- } \\
\text { ally functioning pretty well, has some meaningful interpersonal relationships. }\end{array}$ \\
\hline $51-60$ & Moderate symptoms OR any moderate difficulty in social, occupational, or school functioning. \\
\hline $41-50$ & Serious symptoms OR any serious impairment in social, occupational, or school functioning. \\
\hline $31-40$ & $\begin{array}{l}\text { Some impairment in reality testing or communication OR major impairment in several areas, such } \\
\text { as work or school, family relations, judgement, thinking, or mood. }\end{array}$ \\
\hline
\end{tabular}


Table 2. Global Assessment of Functioning scale (Continued)
21-30
Behavior is considerably influenced by delusions or hallucinations OR serious impairment in communications or judgment OR inability to function in all areas.

\begin{tabular}{ll}
\hline $11-20$ & Some danger of hurting self or others OR occasionally fails to maintain minimal personal hygiene \\
OR gross impairment in communication.
\end{tabular}
ess impairment in communication.

Persistent danger of severely hurting self or others OR persistent inability
personal hygiene OR serious suicidal act with clear expectation of death.

$0 \quad$ Not enough information available to provide GAF.

Table 3. Reviews suggested by excluded studies

\begin{tabular}{|c|c|c|c|c|c|}
\hline $\begin{array}{l}\text { Broad cate- } \\
\text { gory of com- } \\
\text { parison }\end{array}$ & Intervention & & Control & Excluded study/studies & $\begin{array}{l}\text { Existing } \\
\text { Cochrane re- } \\
\text { views }\end{array}$ \\
\hline \multirow{7}{*}{$\begin{array}{l}\text { Augmenta- } \\
\text { tion [of] }\end{array}$} & \multirow[t]{6}{*}{ risperidone } & \multirow[t]{7}{*}{ by } & antioxidants & Zhang 2002 & \multirow[t]{7}{*}{-} \\
\hline & & & buflomedil & Zhong 2006 & \\
\hline & & & celecoxib & Riedel 2003 & \\
\hline & & & D-alanine & Tsai 2006 & \\
\hline & & & sarcosine & Tsai 2004 & \\
\hline & & & valproate & Wang 2003 & \\
\hline & clozapine & & risperidone & Mckenna 2004, Peuskens 2001a & \\
\hline \multirow{2}{*}{$\begin{array}{l}\text { Long-acting } \\
\text { preparation }\end{array}$} & \multirow{2}{*}{$\begin{array}{l}\text { depot risperi- } \\
\text { done }\end{array}$} & \multirow[t]{2}{*}{ versus } & olanzapine & Chue 2002 & \multirow[t]{2}{*}{ Hosalli 2003} \\
\hline & & & placebo & $\begin{array}{l}\text { Cada 2004, Ciliberto 2005, Lauriello } \\
2005 \text {, Nasrallah 2004a, Urioste } 2004 \text {, } \\
\text { NCT00249119 }\end{array}$ & \\
\hline \multirow{3}{*}{$\begin{array}{l}\text { Experimental } \\
\text { compound }\end{array}$} & \multirow[t]{3}{*}{ risperidone } & \multirow[t]{3}{*}{ versus } & BL-1020 & NCT01363349a & \multirow[t]{3}{*}{-} \\
\hline & & & LY2140023 & NCT01086748a & \\
\hline & & & PF-02545920 & DeMartinis 2012a, NCT01175135a & \\
\hline \multirow{4}{*}{$\begin{array}{l}\text { Versus anoth- } \\
\text { er antipsy- } \\
\text { chotic }\end{array}$} & \multirow[t]{4}{*}{ risperidone } & \multirow[t]{4}{*}{ versus } & amisulpride & $\begin{array}{l}\text { Hwang 2003, Rein 2002, Peuskens } \\
2001\end{array}$ & $\begin{array}{l}\text { Komossa 2010; } \\
\text { Komossa } 2007\end{array}$ \\
\hline & & & aripiprazole & $\begin{array}{l}\text { Dubitsky 2002, Chan 2007, Hwang } \\
\text { 2005, NCT00202007, Kane } 2005\end{array}$ & $\begin{array}{l}\text { Khanna 2014; } \\
\text { Komossa } 2007\end{array}$ \\
\hline & & & asenapine & Fleming 2007a & Komossa 2007 \\
\hline & & & cariprazine & Bose 2010b & $\begin{array}{l}\text { Protocol under- } \\
\text { way }\end{array}$ \\
\hline
\end{tabular}


Table 3. Reviews suggested by excluded studies (Continued)

\begin{tabular}{|c|c|c|c|c|c|}
\hline & & & clozapine & Bondolfi 1998, Cavazzoni 2002a & Komossa 2007 \\
\hline & & & clocapramine & Yamawaki 1996 & - \\
\hline & & & haloperidol & $\begin{array}{l}\text { Claus 1992, Friedman 2000, Lind- } \\
\text { strom 1994, Lopez 1996, Lopez-Ibor } \\
\text { 1992, NCT00253136, Peuskens 1995, } \\
\text { Rabinowitz 2001, Wirshing 1995, } \\
\text { Borison 1992a, Csernansky } 1999\end{array}$ & Hunter 2003 \\
\hline & & & molindone & McClellan 2009 & Bagnall 2007 \\
\hline & & & olanzapine & $\begin{array}{l}\text { Tollefson 1996, Edgell 2000, Tran } \\
\text { 1997, Conley 1998, Harvey 2001, } \\
\text { Brecher 1998, McClellan 2009, } \\
\text { Cavazzoni 2002a, Cooper 1997, } \\
\text { NCT00034892 }\end{array}$ & $\begin{array}{l}\text { Komossa 2007; } \\
\text { Jayaram } 2007\end{array}$ \\
\hline & & & quetiapine & Cooper 1997, NCT00034892 & $\begin{array}{l}\text { Asmal 2013; Ko- } \\
\text { mossa } 2007\end{array}$ \\
\hline & & & sertindole & Kane 2005 & $\begin{array}{l}\text { Komossa 2009; } \\
\text { Komossa } 2007\end{array}$ \\
\hline & & & $\begin{array}{l}\text { zuclopenthixol dihy- } \\
\text { drochloride }\end{array}$ & Lemmens 1994 & $\begin{array}{l}\text { Hunter 2003; } \\
\text { Kumar } 2005\end{array}$ \\
\hline Not risperi- & amisulpride & versus & placebo & Boyer 1995, Loo 1997 & Mota 2002 \\
\hline & aripiprazole & & haloperidol & Carson 2002 & $\begin{array}{l}\text { Bhattacharjee } \\
2008\end{array}$ \\
\hline & & & olanzapine & Cornblatt 2002 & Khanna 2014 \\
\hline & & & perphenazine & Gismondi 2004 & $\begin{array}{l}\text { Bhattacharjee } \\
2008\end{array}$ \\
\hline & & & placebo & Carson 2002, Casey 2003 & $\begin{array}{l}\text { Belgamwar } \\
2011\end{array}$ \\
\hline & haloperidol & & placebo & $\begin{array}{l}\text { Beasley 1996, Carson 2002, Craw- } \\
\text { ford } 1997\end{array}$ & Adams 2013 \\
\hline & olanzapine & & fluphenazine & Dossenbach 1997 & Duggan 2005 \\
\hline & & & haloperidol & $\begin{array}{l}\text { Beasley 1996, Crawford 1997, Gre- } \\
\text { gor 2000, Kinon 1998, Lieberman } \\
\text { 2005, Revicki } 1996\end{array}$ & \\
\hline & & & paliperidone & Luo 2011 & $\begin{array}{l}\text { Komossa 2007; } \\
\text { Nussbaum } 2012\end{array}$ \\
\hline & & & placebo & $\begin{array}{l}\text { Beasley 1996, Crawford 1997, Luo } \\
2011\end{array}$ & $\begin{array}{l}\text { Protocol under- } \\
\text { way }\end{array}$ \\
\hline & paliperidone & & placebo & Luo 2011 & Nussbaum 2012 \\
\hline
\end{tabular}


Table 3. Reviews suggested by excluded studies (Continued)

\begin{tabular}{|c|c|c|c|c|}
\hline $\begin{array}{l}\text { Single vs } \\
\text { polypharma- } \\
\text { cy }\end{array}$ & risperidone & versus & $\begin{array}{l}\text { amisulpride + } \\
\text { haloperidol }\end{array}$ & Peuskens 2001a \\
\hline \multirow[t]{4}{*}{$\begin{array}{l}\text { Miscella- } \\
\text { neous }\end{array}$} & $\begin{array}{l}\text { antipsychotic } \\
\text { drugs }\end{array}$ & versus & $\begin{array}{l}\text { miscellaneous } \\
\text { (risperidone, olanza- } \\
\text { pine, quetiapine) }\end{array}$ & Weickert 2003 \\
\hline & risperidone & & $\begin{array}{l}\text { valproate }+ \text { miscella- } \\
\text { neous antipsychotic } \\
\text { drugs }\end{array}$ & Citrome 2004 \\
\hline & & & $\begin{array}{l}\text { riluzole (a drug used } \\
\text { to treat amyotrophic } \\
\text { lateral sclerosis) }\end{array}$ & Rujescu 2009a \\
\hline & & & $\begin{array}{l}\text { talnetant (a } \\
\text { neurokinin } 3 \text { recep- } \\
\text { tor antagonist) }\end{array}$ & GlaxoSmithKline 2006a \\
\hline
\end{tabular}

\section{Table 4. Suggested design of study}

$\begin{array}{ll}\text { Methods } & \text { Allocation: randomised, clearly described and concealed. } \\ \text { Blinding: double, tested. }\end{array}$

Duration: 1 year or more.

Participants

Diagnosis: schizophrenia, schizotypal, schizoaffective, delusional disorder, acute psychosis, comorbid alcohol problems, and substance misuse.

$\mathrm{N}=300$.

Age: adults.

Sex: men or women.

History: perhaps once an early episode of moderate severity has subsided and after a period of stable washout of the medications used during the acute phase, living anywhere and not just in hospital.

Interventions $\quad$ 1. Risperidone: dose $4 \mathrm{mg} /$ day or above.

2. Placebo.

Outcomes Healthy days.

Mental state: improved to important degree.

Global state: improved to important degree, relapse.

Service use: in hospital.

Social functioning: employment status, relationships.

Quality of life: improved to important degree.

Economic outcomes: cost. 


\section{A P P E N D I CES}

\section{Appendix 1. Previous search}

The previous search phrases for the register via Meerkat (February 2008) were as follows:

[risperidone ${ }^{\star}$ or Risperdal ${ }^{\star}$ in title or ${ }^{*}$ risperidone* ${ }^{\star}{ }^{*}$ risperdal $^{\star}$ in abstract, index terms of REFERENCE] or [risperidone ${ }^{\star}$ in interventions of STUDY]

This register is compiled by systematic searches of major databases and their monthly updates, handsearches, and conference proceedings (see group module).

\section{Appendix 2. Previous methods}

\section{Data collection and analysis}

\section{Selection of studies}

We (RR, MJ) independently inspected all reports of identified studies. Any disagreements were resolved by consensus; where doubts remained, we acquired the full article. We independently decided whether these studies met the review criteria. We did not intend to blind the names of authors, institutions, and journal of publication. Again, we resolved any disagreements by consensus. When this was not possible, we sought further information and, in the interim, added these trials to the Studies awaiting classification list. RR and MJ independently inspected citations from the subsequent updated search (December 2007) and identified the relevant abstracts. We obtained and inspected full reports of the abstracts meeting the review criteria.

\section{Data extraction and management}

1. We (RR, MJ) independently extracted data and resolved any disagreements by discussion. When this was not possible, we sought further information from the trial authors.

\subsection{Binary data}

When summation was appropriate, with binary outcomes such as improved/not improved, we calculated the risk ratio statistic with a 95\% confidence interval and used a random-effects model. In addition, as a measure of efficiency, we estimated the number needed to treat to benefit or the number needed to treat to harm from the pooled totals.

\subsection{Continuous data}

1.2.1 Normally distributed data

Continuous data on clinical and social outcomes are often not normally distributed. To avoid the pitfall of applying parametric tests to non-parametric data, we applied the following standards to all data before inclusion: (a) standard deviations (SD) and means reported in the paper were obtained from the authors; (b) when a scale starts from the finite number 0 , the SD, when multiplied by 2 , is less than the mean (as otherwise the mean is unlikely to be an appropriate measure of the centre of the distribution) (Altman 1996); (c) if a scale started from a positive value (such as Positive and Negative Syndrome Scale, which can have values from 30 to 210), the calculation described above was modified to take the scale starting point into account. In these cases skew will be present if $2 \mathrm{SD}>(\mathrm{S}-\mathrm{S}$ min), where $\mathrm{S}$ is the mean score and $\mathrm{S}$ min is the minimum score. Endpoint scores on scales often have a finite start and endpoint, and these rules can be applied to them. When continuous data are presented on a scale that includes a possibility of negative values (such as change on a scale), it is difficult to tell whether data are non-normally distributed (skewed) or not. We presented skewed data in the 'Other data' tables rather than included in the analysis.

For change data (endpoint minus baseline), the situation is even more problematic. In the absence of individual participant data, it is impossible to know if data are skewed, though this is likely. After consulting the ALLSTAT electronic statistics mailing list, we presented the change data in order to summarise the available information. In doing this, we assumed that data was not skewed or that the analyses can cope with the unknown degree of skew. Again, without individual participant data it was impossible to test this assumption. Where both change and endpoint data were available for the same outcome category, we presented only the endpoint data. We acknowledge that by doing this, much of the published change data can be excluded, but our argument is that endpoint data is more clinically relevant and that if change data were to be presented along with endpoint data, it would give undeserved equal prominence to both. We contacted the authors of studies that only reported change for endpoint figures.

\subsubsection{Summary statistic}

For continuous outcomes, we estimated a weighted mean difference between groups. Again, this was based on the random-effects model, as this took into account any differences between studies even if there was no statistically significant heterogeneity. We did not consider continuous data presented without use of summary statistics (that is mean, SD, standard error, median, interquartile range), although we noted the existence of these data in the text. 


\section{Assessment of risk of bias in included studies}

Again working independently, review authors assessed risk of bias using the tool described in the Cochrane Handbook for Systematic Reviews of Interventions (Higgins 2008). This tool encourages consideration of how the sequence was generated, how allocation was concealed, the integrity of blinding at outcome, the completeness of outcome data, selective reporting, and other biases. We excluded studies where allocation was clearly not concealed.

We removed trials with high risk of bias (defined as at least three out of five domains categorised as 'no') from the 'included' category. When the raters disagreed, the final rating was made by consensus with the involvement of another review author. Where details of randomisation and other characteristics of trials were inadequate, we contacted authors of the studies to obtain further information. We reported nonconcurrence in quality assessment.

\section{Measures of treatment effect}

Many rating scales are available to measure outcomes in mental health trials (Marshall 2000). These scales vary in quality, and many are poorly validated. It is generally accepted that measuring instruments should have the properties of reliability (the extent to which a test effectively measures anything at all) and validity (the extent to which a test measures that which it is supposed to measure). Before publication of an instrument, most scientific journals insist that its reliability and validity be demonstrated to the satisfaction of referees. As a minimum standard, we excluded data from unpublished rating scales. In addition, the rating scale was either: (i) a self report; or (ii) completed by an independent rater or relative. If continuous data were presented from different scales rating the same outcome, we presented all data without summation and inspected the general direction of effect.

\section{Unit of analysis issues}

To facilitate comparison between trials, we intended to convert variables (such as days in hospital) that can be reported in different metrics (mean days per year, per week, or per month) to a common metric (for example mean days per month). We converted weight gain reported in pounds to kilograms where possible.

\section{Dealing with missing data}

Where possible, we analysed the data on an intention-to-treat basis and assumed that those who had not been accounted for had the less positive outcome. We did not include this rule for the outcome of 'death'. We intended to test this assumption with a sensitivity analysis. For continuous data, which was impossible to manage in this way, we presented only the 'completer' data. Wherever feasible, we converted the continuous scores to dichotomous data.

If, for a given outcome (except adverse effects), more than $50 \%$ of the total numbers randomised were not accounted for, we did not present the results, as such data are impossible to interpret with authority. If, however, more than $50 \%$ of those in one arm of a study were lost, but the total loss was less than $50 \%$, we marked such data with '*' to indicate that such result may well be prone to bias.

\section{Assessment of heterogeneity}

Firstly, we considered all the included studies within any comparison to judge clinical heterogeneity. We then visually inspected the graphs in order to investigate the possibility of statistical heterogeneity; to supplement this we used, primarily, the $\mathrm{I}^{2}$ statistic, which provides an estimate of the percentage of variability due to heterogeneity rather than due to chance alone. Where the $1^{2}$ estimate was greater than or equal to $75 \%$, we interpreted this as indicating the presence of high levels of heterogeneity (Higgins 2003). If inconsistency became high, we did not summate data, but presented it separately, and we investigated the reasons for heterogeneity.

\section{Assessment of reporting biases}

In order to investigate the likelihood of overt publication bias, we entered all data from all identified and selected trials into a funnel graph (trial effect against trial size) (Egger 1997).

\section{Data synthesis}

Where possible, we entered data in such a way that the area to the left of the line of no effect indicated a favourable outcome for risperidone. Studies increasingly employ 'cluster randomisation' (such as randomisation by clinician or practice), but analysis and pooling of clustered data pose problems. Firstly, authors often fail to account for intraclass correlation (ICC) in clustered studies, leading to a 'unit of analysis' error (Divine 1992), whereby P values are spuriously low, confidence intervals are unduly narrow, and statistical significance gets overestimated. This causes type I errors (Bland 1997, Gulliford 1999).

Where clustering was not accounted for in primary studies, we presented the data in a table with a $\left(^{\star}\right)$ symbol to indicate the presence of a probable unit of analysis error. In subsequent versions of the review, we will seek out first authors of studies to obtain ICC of their clustered data and use accepted methods to adjust for this (Gulliford 1999). Where clustering has been incorporated into the analysis of primary studies, we also presented these data as if from a non-cluster randomised study, but adjusted for the clustering effect. We have sought statistical advice and have been advised that the binary data presented in a report should be divided by a 'design effect'. This is calculated using the mean number of participants per cluster $(m)$ and the ICC Design effect $=1+(m-1)^{\star}$ ICC (Donner 2002). If the ICC was 
not reported, we assumed it to be 0.1 (Ukoumunne 1999). If cluster studies had been appropriately analysed, taking into account ICCs, and relevant data documented in the report, we synthesised these with other studies using the generic inverse variance technique.

\section{Subgroup analysis and investigation of heterogeneity}

If data were clearly heterogeneous, we checked that they had been extracted and entered correctly, and that we had made no unit of analysis errors. If the high levels of heterogeneity remained, we did not undertake a meta-analysis at this point, because if there is considerable variation in results, and particularly if there is inconsistency in the direction of effect, it may be misleading to quote an average value for the intervention effect. We prespecified no characteristics of studies that may be associated with heterogeneity except quality of trial method.

\section{Sensitivity analysis}

If studies had high attrition rates, we analysed the effect of including these studies in a sensitivity analysis, but we did not include any figures with more than $50 \%$ attrition in the analysis of efficacy. Where a trial was described as 'double-blind', but it was implied that the study was randomised, we intended to include such studies in the sensitivity analysis, but we did not come across any such studies.

\section{FEE D B A C K}

\section{Response to comments, 21 February 2013}

\section{Summary}

Hutton 2012 has highlighted the following issues regarding this review:

1. 'Fixed effect' analysis was used instead of 'random effects' analysis for the outcome of $20 \%$ change in total PANSS/BPRS scores.

2. Should not have included Marder 1994a in our analysis, as the overall attrition rate for this study was over 50\%.

3. Should not have included Borison 1992 study in our analysis, as an internal confidential report by Janssen Pharmaceuticals reports a different leaving the study early rate than that of the original published paper.

4. It is incorrect to derive standard deviation from standard error in Chouinard 1992, and data were entered wrong way round for two outcomes: endpoint Brief Psychiatric Rating Scale (BPRS) total score and Positive and Negative Syndrome Scale (PANSS) positive symptom score.

5. Honer 2006 should not have contributed to outcome 'no clinically significant improvement (CGI-S)', as they had used only PANSS scores.

\section{Reply}

Thank you for your comments.

We have now repeated the analysis for the outcome $20 \%$ change in total PANSS/BPRS score by using 'random effects' model instead of fixed effects. With the 'fixed effects' analysis RR was 0.7 favouring risperidone and with 'random effect' analysis the RR is 0.68 favouring risperidone and hence there is no change in the overall outcome.

As regards the Marder 1994a study, it has an overall attrition rate of over 50\%. However this study has three arms of risperidone and we included data from only the $6 \mathrm{mg}$ arm as this was closest to what is clinically most commonly used. This intervention arm of $6 \mathrm{mg}$ per day of risperidone had an attrition rate of 45\% (page 828, American Journal of Psychiatry, 151:6 June 1994). The attrition rate for this particular arm was less than $50 \%$ and hence this was included.

The attrition rate in Borison 1992 as reported by the original published paper is zero. This did appear too good to be true, however our attempts to contact the authors were unsuccessful and we did not have access to any other data. We would be keen to have a look at the internal confidential report by Janssen if this indeed reports a different drop out rate and would be grateful if anyone with access to this can forward the data to the authors.

For data extraction from the Chouinard 1992 study, we have used formula recommended by the Cochrane Handbook to derive Standard Deviation Higgins 2008. The authors checked Chouinard 1992 data and are assured that we have reported it accurately in our review. The paper reports the figures for the number of patients showing more than $20 \%$ improvement in BPRS/PANSS but in our review we have extrapolated the figures for ' $<20 \%$ decrease in PANSS/BPRS total score'. Although the primary publication for Honer 2006 reports only the PANSS scores, we found additional published data (International Congress of Schizophrenia Research 2005, page 487) which provides data on CGI-S scores.

\section{Contributors}

Dr Ranganath Rattehalli and Dr Mahesh Jayaram 


\section{Response to email, 3 March 2013}

\section{Summary}

Paul Hutton from the Psychosis Research Unit, Psychology Department, Greater Manchester West Mental Health Trust, UK, has sent an email to the authors of this review wherein he claims that the review authors should not have included the two clozapine augmentation studies in the review (Yagcioglu 2005 and Honer 2006), or should have analysed these separately.

\section{Reply}

We acknowledge that the two clozapine augmentation studies could have been analysed separately. We have thus now analysed our results with and without these two studies, and the results of this sensitivity analysis are as follows.

\subsection{Leaving the study early - for any reason}

With the clozapine augmentation studies the results are: $11 \mathrm{RCTs}, \mathrm{N}=1363$, RR $0.7(0.57,0.86)$, favours risperidone. Without the clozapine augmentation studies the results are: 9 RCTs, $N=1265$, RR $0.69(0.56,0.85)$, still favours risperidone. Exclusion of clozapine augmentation studies makes no difference to this outcome.

\subsection{Leaving study early - due to adverse effects}

With the clozapine augmentation studies the results are: 6 RCTs, $N=829$, RR $1.09(0.43,2.74)$, not statistically significant. Without the clozapine augmentation studies the results are: 5 RCTs, $N=761$, RR $1.03(0.38,2.81)$, still not statistically significant. Exclusion of the clozapine augmentation studies makes no difference to this outcome.

\subsection{Leaving the study early - due to withdrawal of consent}

With the clozapine augmentation studies the results are: 4 RCTs, $N=368$, RR $1.2(0.44,3.28)$, not statistically significant. Without the clozapine augmentation studies the results are: 3 RCTs, $N=300$, RR $1.39(0.48,4.00)$, still not statistically significant. Exclusion of the clozapine augmentation study makes no difference to this outcome.

\subsection{Global state - no clinically significant improvement (CGI-Severity)}

With the clozapine augmentation studies the results are: 3 RCTs, $N=397$, RR $0.8(0.55,1.15)$, not statistically significant. Without the clozapine augmentation studies the results are: 2 RCTs, $N=329$, RR $0.67(0.46,0.98)$, favours risperidone. Exclusion of the clozapine augmentation study changes the result in favour of risperidone for this outcome.

\subsection{Global state - average endpoint score (CGI-Severity)}

With the clozapine augmentation studies the results are: 4 RCTs, $N=266$, WMD $-0.29(-1.18,0.59)$, not statistically significant. Without the clozapine augmentation studies the results are: 2 RCTs, $N=171$, WMD -1.01 (-1.38, -0.64), favours risperidone. Exclusion of the clozapine augmentation study changes the result in favour of risperidone for this outcome.

\subsection{Global state - average endpoint score (GAF score)}

Akdede 2006 (clozapine augmentation study) is the only study favouring risperidone for this outcome.

\subsection{Mental state - $<20 \%$ decline on PANSS total change score}

With the clozapine augmentation studies the results are: 4 RCTs, $N=407$, RR $0.64(0.39,1.04)$, not statistically significant. Without the clozapine augmentation studies the results are: $3 \mathrm{RCTs}, \mathrm{N}=339$, RR 0.54 ( 0.40 .74$)$, favours risperidone. Exclusion of clozapine augmentation study changes the result in favour of risperidone for this outcome.

\subsection{Mental state - $<20 \%$ decrease in PANSS/BPRS total change score}

With the clozapine augmentation studies the results are: $7 \mathrm{RCTs}, \mathrm{N}=856, \mathrm{RR} 0.7(0.62,0.79)$, favours risperidone. Without the clozapine augmentation studies the results are: 6 RCTs, $N=788$, RR $0.66(0.58,0.76)$, favours risperidone. Exclusion of clozapine augmentation study makes no difference to this outcome.

\subsection{Mental state - average endpoint score (PANSS Total score)}

With the clozapine augmentation studies the results are: 4 RCTs, N = 266, WMD -7.55 $(-22.04,6.95)$, not statistically significant. Without the clozapine augmentation studies the results are: 2 RCTs, $N=171$, WMD $-20.13(-27.33, \ldots)$, favours risperidone. Exclusion of the clozapine augmentation studies changes the result in favour of risperidone for this outcome.

\subsection{Mental state - average endpoint score (PANSS General score)}

With the clozapine augmentation studies the results are: 2 RCTs, $N=74$, WMD $-5(-20.37,10)$, not statistically significant. Without the clozapine augmentation studies the results are: $1 \mathrm{RCT}, \mathrm{N}=44$, WMD $-13.2(-20.15, \ldots)$, favours risperidone. Exclusion of the clozapine augmentation study leaves only one RCT for this outcome, which is in favour of risperidone. 


\subsection{Mental state - average endpoint score (PANSS Negative symptom score)}

With the clozapine augmentation studies the results are: 4 RCTs, N = 266, WMD -0.9 $(-3.06,1.27)$, not statistically significant. Without the clozapine augmentation studies the results are: 2 RCTs, $N=171$, WMD -2.84 (-4.96, -0.73), favours risperidone. Exclusion of the two clozapine augmentation studies changes this outcome in favour of risperidone.

\subsection{Mental state - average endpoint score (PANSS Positive symptom score)}

With the clozapine augmentation studies the results are: 4 RCTs, N = 266, WMD $1.67(-2.93,6.28)$, not statistically significant. Without the clozapine augmentation studies the results are: 2 RCTs, $N=171$, WMD $1.52(-12.69,15.73)$, still not statistically significant. Exclusion of the two clozapine augmentation studies does not change this outcome.

Thus, in summary, exclusion of the two clozapine augmentation studies either makes no difference to the main outcomes or shifts the results slightly more in favour of risperidone on some of the outcomes related to mental state. These augmentation studies contribute to less than $20 \%$ of the data, and we feel that it is only fair to include them in the review, as in real life many more people with schizophrenia are going to be on a combination of antipsychotics.

\section{Contributors}

Dr Ranganath Rattehalli and Dr Mahesh Jayaram

\section{WHAT'S NEW}

\begin{tabular}{lll}
\hline Date & Event & Description \\
\hline 13 September 2016 & $\begin{array}{l}\text { New citation required but conclusions } \\
\text { have not changed }\end{array}$ & $\begin{array}{l}\text { Results of update searching added to review. Five new trials } \\
\text { added to included studies table. Data from these new trials did } \\
\text { not change overall results or conclusions of review. }\end{array}$ \\
\hline 19 October 2015 & New search has been performed & $\begin{array}{l}\text { Update search run and 25 references assessed, 2 new studies in- } \\
\text { cluded. }\end{array}$ \\
\hline 15 October 2013 & Amended & $\begin{array}{l}\text { Update search carried out 2013, 69 references assessed, 3 new } \\
\text { studies included. }\end{array}$ \\
\hline 15 March 2013 & Feedback has been incorporated & $\begin{array}{l}\text { Comments reported in Hutton 2012 regarding including trials } \\
\text { with high attrition addressed, sensitivity analysis completed and } \\
\text { added to feedback section. Overall results and conclusion of re- } \\
\text { view are unaffected. }\end{array}$ \\
\hline
\end{tabular}

\section{H IS T OR Y}

Protocol first published: Issue 1, 2008

Review first published: Issue 1, 2010

\begin{tabular}{lll}
\hline Date & Event & Description \\
\hline 3 March 2013 & Amended & See feedback section for amendments. \\
\hline 21 February 2013 & Amended & See feedback section for details. \\
\hline
\end{tabular}

\section{CONTRIBUTIONSOF AUTHORS}

RR: Initiated the review, developed the background and protocol, selected studies and extracted data, and wrote the findings of the original 2008 review, helped with 2015 update writing.

SZ: Screened search results, extracted data for the 2015 update search and wrote the report.

BL: Screened search results and extracted data for the 2015 update search. 
MJ: Helped with developing the background and protocol, cross checked data extraction, and wrote the findings of the original 2008 review, draft checking 2015 update.

JX: Screened search results, extracted data, and participated in report writing for the 2015 update.

SS: Screened and data extraction for 2013 search.

\section{DECLARATIONS OF INTEREST}

RR: none known.

SZ: none known.

BL: none known.

MJ: none known.

JX: none known.

SS: none known.

\section{SOURCES OF SUPPORT}

\section{Internal sources}

- Leeds Partnerships NHS Foundation Trust, UK.

\section{External sources}

- University of Nottingham, UK.

- Cochrane Collaboration Programme Grant 2011, UK.

Reference number: 10/4001/15

\section{DIFFERENCES BETWEEN PROTOCOL AND REVIEW}

The methods section of the protocol was updated to reflect the Cochrane Schizophrenia Group's standardised method section (see Appendix 2 for previous methods). We altered the structure of the protocol outcomes to match the structure in the data and analyses table; however, we have not changed outcomes.

\section{NOTES}

None

\section{INDEX TERMS}

\section{Medical Subject Headings (MeSH)}

Administration, Oral; Antipsychotic Agents [*administration \& dosage] [adverse effects]; Placebos [therapeutic use]; Publication Bias; Randomized Controlled Trials as Topic; Risperidone [ ${ }^{\star}$ administration \& dosage] [adverse effects]; Schizophrenia [ ${ }^{\star} d r u g$ therapy]

\section{MeSH check words}

Humans 